\title{
Dóra Chor
}

\section{Perfil de risco cardiovascular de} funcionários de banco estatal

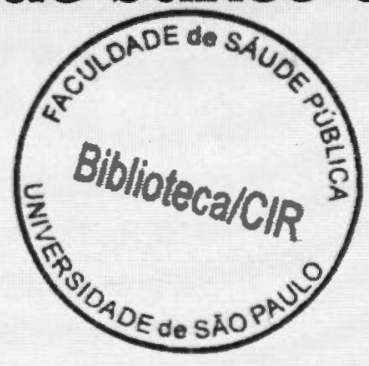

Orientador: Prof. Dr. Ruy Laurenti

Tese apresentada à Faculdade de Saúde Pública da Universidade de São Paulo para obtenção do grau de Doutora em Saúde Pública área de concentração em Epidemiologia

São Paulo

1997 
Esta tese é um dos frutos do sonho e determinação do grupo de profissionais envolvidos no "Estudo das condições de saúde dos funcionários do Banco do Brasil". $E$, por isso, dedicada a todos aqueles que trabalham com pessoas. Uma a uma, ou coletivamente. Dificil arte! Nesta ocupação, compreendemos às vezes; transformamos às vezes; mas nos sentimos fascinados com o "humano", sempre. 


\section{Agradecimentos}

Acredito que, cada vez mais, os trabalhos cientificos não são produzidos apenas em função do empenho, esforço ou dedicação de seu autor principal. São, de fato, o resultado da competência técnica, da paixão e afeto de muitos. Tive o privilégio de ter a meu lado muitos professores e amigos, ao longo deste percurso. A todos, meus agradecumentos.

Ao Prof. Ruy Laurenti, que me abriu todas as portas. Pelo muito que me ensinou do ofício de "orientar".

À Prof ${ }^{a}$ Milena P. Duchiade que me convidou a participar desta pesquisa, por tudo que compartilhamos, da vida e do trabalho, ao longo desses cinco anos.

À Pesquisadora Maria de Jesus M. da Fonseca, que muito mais que orientanda, foi companheira lúcida e serena.

À Pesquisadora Célia Regina de Andrade, pela alegria e firmeza no trabalho.

Ao Prof. Joaquim G. Valente, pela competência e solidariedade com que contribuiu para a finalização da pesquisa.

Ao Prof. Kaizô Beltrão, por todos os momentos que vivemos juntos, durante esta pesquisa.

Ao grupo de trabalho CASSI-Pesquisas Epidemiológicas: Eneida Favre, Heitor Assis Filho e Gisele Fernandes, pela materialização desta pesquisa, que sonhamos juntos.

Ao Prof. Vítor Hugo Gouvêa, pela generosidade e paciência com que me ensinou a análise de correspondência.

À Prof ${ }^{a}$ Marília Sá Carvalho, irmã de todas as horas, por me dizer a coisa certa na hora certa. Agradeço por me ensinar que, na vida e na epidemiologia, é preciso ser flexível e trabalhar com muitas "variáveis".

À Prof ${ }^{\mathrm{a}}$ Jurema P. Valente, pela viagem que fazemos juntas em muitos mundos, nos últimos quinze anos. Com seu afeto e competência, foi possível superar obstáculos e vislumbrar o $\mathbf{R}^{\mathrm{n}}$.

Ao Prof. Eduardo Massad, pela gentileza com que me recebeu e por tudo que me ensinou.

À Sra. Miriam Oliveira, pela generosidade e alegria com que me recebeu, desde o primeiro dia.

À Rosângela Machado, pela grande amizade que começou durante a pesquisa. 
Ao Prof. José de A. Lozana, pela solidariedade e competência com que ajudou a superar obstáculos aparentemente intransponíveis.

Ao Prof. Carlos Henrique Klein, pela participação no planejamento das medidas diretas. Ao Prof. Luiz Antônio B. Camacho, por tudo o que pude aprender durante a orientação conjunta de mestrandos.

A Sergio Monteiro, pela dedicação e competência com que ajudou a enriquecer a parte gráfica e a apresentação dessa tese.

À Profa. Ângela Jourdan Gadelha, pelo companheirismo e solidariedade.

Ao Prof. Luis David Castiel, pela renovada troca de conhecimentos.

Ao Prof. Evandro Coutinho, pela troca de idéias.

À Prof ${ }^{a}$ Karen Giffin, pelo companheirismo na vida e no trabalho.

Ao Prof. Jair Lício, pelas sugestões.

À Prof ${ }^{a}$ Rosane H. Griep, por acreditar nesse sonho.

Ao Prof. Odécio Sanchez, pelas sugestões.

Ao Prof. Oswaldo Gonçalves Cruz, pelo socorro no computador, nas horas dificeis.

A Sergio Magalhães, que me acolheu em sua casa e seu coração desde que a idéia do doutorado em São Paulo começou a se esboçar. Obrigado por estar sempre por perto.

À Dr ${ }^{\mathrm{a}}$ Sandra Guimarães que, amorosamente, me abriu várias portas de conhecimento.

A José Luiz dos Santos e Nilceli M. L. Vizeu, pelo abrigo e calor que recebi no Sítio da Cachoeira, sem os quais esse trabalho teria sido mais doloroso.

À Lúcia Rotemberg, por me receber tão afetuosamente em sua casa, em São Paulo.

À Rita de Cássia Shalom, secretária do Departamento de Epidemiologia da ENSP, pela solidariedade nas horas de quebrar os galhos.

A meu pai e minha mãe, Nahum Chor e Fanny Chor, pela inspiração de que estamos aqui, de passagem, para fazer o bem.

À minha irmã e sobrinhos, Teresa Chor, Jacques Márcio Wurman e André Nahum Schechter, por serem uma referência.

À Natália Chor de Souza Ribeiro, minha filha querida, pelo conforto nas horas difíceis e pela alegria compartilhada nas vitórias.

A meu parceiro, Eduardo Faerstein, por me dar a oportunidade de resgatar o melhor de mim. Obrigado pelas sugestões valiosas, mas principalmente pela linda estória de amor. 


\section{ÍNDICE}

Agradecimentos $\quad$ i

Índice $\quad$ iii

Resumo xiv

Abstract $\quad$ xvi

\section{Capítulo I - Introdução}

$\begin{array}{ll}\text { 1- Relevância do projeto } & 1\end{array}$

2- Magnitude das doenças cardiovasculares $\quad 2$

3- Fatores de risco 6

4- É possível reduzir as doenças cardiovasculares $\quad 12$

5- Pesquisa de saúde dos associados da Caixa deAssitência dos Funcionáriosdo Banco do Brasil (CASSI) 17

6- Objetivos

\section{Capítulo II - Métodos}

1- População de estudo $\quad 22$

2- Delineamento do estudo e população-alvo 23

3- Os instrumentos 23

a- O questionário e sua aplicação 23

b- Medidas diretas 24

b.1 - Medida da pressão arterial 25

b.2- Medida do peso 26

b.3- Medida da Estatura $\quad 26$

b.4- Medida da circunferência do braço 26

4- Seleção e treinamento de aplicadores e examinadores $\quad 27$

$\begin{array}{ll}\text { a- Aplicadores } & 27\end{array}$

b- Examinadores $\quad 27$

5- Delineamento amostral 28

6- Ponderação dos estimadores $\quad 30$

7- O trabalho de campo 30 
8- Digitação dos dados 31

9- Crítica e imputação dos dados 31

10- Pacotes computacionais utilizados $\quad 32$

11- Análise de dados 32

a- Validade e confiabilidade dos dados 32

b- Definição de variáveis 33

c- Testes estatísticos e intervalos de confiança 37

d- Validação das informações fornecidas sobre pressão arterial, peso e estatura $\quad 37$

$\begin{array}{ll}\text { e- Análise multivariada } & 37\end{array}$

\section{Capítulo III - Resultados}

1- Características da amostra e adesão ao estudo 44

2- Características sócio-demográficas 45

3- Prevalência dos principais fatores de risco $\quad 50$

a- Hábito de fumar $\quad 50$

b- Dieta $\quad 56$

c- Álcool $\quad 63$

d- Atividade fisica de lazer $\quad 66$

e- Pressão arterial $\quad 70$

f- Índice de massa corporal $\quad 80$

$\begin{array}{ll}\text { g- Colesterol } & 87\end{array}$

h- História familiar $\quad 89$

i- Conhecimento dos fatores de risco 90

4- Comparação entre a medida direta e as informações fornecidas sobre pressão arterial, peso e estatura

a- Índice de massa corporal $\quad 93$

b- Pressão arterial 99

5- Ocorrência simultânea de fatores de risco e efeitos 106

$\begin{array}{ll}\text { a- Fatores de risco } & 114\end{array}$

$\begin{array}{ll}\text { b- Fatores de risco, idade e sexo } & 120\end{array}$ 
c- Análise da ocorrência de hipertensão, categorias do indice de massa corporal e colesterolemia, de acordo com idade e sexo

d- Ocorrência simultânea de fatores de risco, hipertensão, sobrepeso/obesidade e hipercolesterolemia

\section{Capítulo IV - Discussão}

1- Qualidade das informações: validade de conteúdo e validade de critério $\quad 140$

a- Hábito de fumar

b- Consumo de álcool

c- Atividade física no lazer

d- Consumo alimentar

e- Índice de massa corporal

f- Colesterol 158

g- Hipertensão arterial

2- Ocorrência simultânea dos fatores de risco: o estilo de vida 165

3- Mudanças de comportamento: uma questão contemporânea

4- Para além de um diagnóstico: de como transformar nosso conhecimento em ação

5- Conclusões

\section{Referências Bibliográficas}

\section{Lista de gráficos}

Gráfico I.2.1 - Proporção de óbitos por doença isquêmica do coração segundo grupos etários. Capitais brasileiras e países selecionados

Gráfico I.2.2 - Coeficientes de mortalidade por infarto agudo do miocárdio.

Capitais brasileiras e países selecionados, sexo masculino

Gráfico III.2.1 - Distribuição etária por sexo por dependência 
Gráfico III.3.1 - Número médio de cigarros consumidos por fumantes e ex-fumantes em ambas as dependências - Homens

Gráfico III 3.2 - Número médio de cigarros consumidos por fumantes e ex-fumantes em ambas as dependências - Mulheres

Gráfico III.3.3 - Distribuição dos funcionários de acordo com tentativas de parar de fumar - ambos os sexos - ambas as dependências $\quad 56$

Gráfico III.3.4 - Escore de dieta - Direção Geral - Homens 59

Gráfico III.3.5 - Escore de dieta - Direção Geral - Mulheres 60

Gráfico III.3.6 - Escore de dieta - Cesec - Homens 60

Gráfico III.3.7 - Escore de dieta - Cesec - Mulheres 61

Gráfico III.3.8 - Escore médio por idade e por sexo 61

Gráfico III.3.9 - Impedimentos declarados para prática de atividade fisica de lazer em ambos os sexos - ambas as dependências 67

Gráfico III.3.10 - Condição de tratamento dos funcionários informados mais de uma vez de que eram hipertensos por sexo Direção Geral $\quad 76$

Gráfico III.3.11 - Condição de tratamento dos funcionários informados mais de uma vez de que eram hipertensos por sexo Cesec $\quad 76$

Gráfico III.3.12 - Distribuição do indice de massa corporal por sexo 80

Gráfico III.3.13 - Classificação do índice de massa corporal segundo sexo Direção Geral

Gráfico III.3.14 - Classificação do índice de massa corporal segundo sexo Cesec

Gráficos III.4.1 - Comparação entre índice de massa corporal medido e índice de massa corporal informado - por dependência

Gráfico III.4.2 - Distribuição dos níveis de pressão sistólica e diastólica medidos- todas as dependências- Homens

Gráfico III.4.3 - Distribuição dos níveis de pressão sistólica e diastólica medidos- todas as dependências- Mulheres

Gráfico III.5.1 - Percentagem de explicação da variância global de cada eixo Fatores de Risco

Gráfico III.5.2 - Fatores de risco - Primeiro e Segundo eixos 
Gráfico III.5.3 - Percentagem de explicação da variância global de cada eixo Fatores de risco e sexo

Gráfico III.5.4 - Fatores de risco, idade e sexo - Primeiro e Segundo eixos

Gráfico III.5.5 - Fatores de risco, idade e sexo - Primeiro e Terceiro eixos

Gráfico III.5.6 - Percentagem de explicação da variância global de cada eixo Efeitos, idade e sexo

Gráfico III.5.7 - Efeitos, idade e sexo - Primeiro e Segundo eixos

Gráfico III.5.8 - Percentagem de explicação da variância global de cada eixo Efeitos, idade e sexo

Gráfico III.5.9 - Fatores de risco e efeitos - Primeiro e Segundo eixos

\section{Lista de Tabelas}

Tabela I.3.1 - Preditores independentes da incidência e/ou mortalidade por doença coronariana

Tabela I.5.1 - Número de dependências e funcionários ativos Pesquisa de Saúde dos Associados da CASSI

Tabela II.5.1 - Número de dependências e funcionários ativos

Tabela II.6.1 - Fatores de expansão por sexo e por dependência 30

Tabela II.11.1 - Distribuição do hábito de fumar e de consumo de álcool

Tabela III.1.1 - Comparação entre população de estudo, amostra planejada e respondentes por sexo - Direção Geral

Tabela III.1.2 - Comparação entre população de estudo, amostra planejada e respondentes por sexo - Cesec

Tabela III.2.1 - Estatísticas-resumo da idade segundo sexo - Direção Geral 45

Tabela III.2.2 - Estatísticas-resumo da idade segundo sexo - Cesec 46

Tabela III.2.3 - Distribuição dos graus de escolaridade por sexo Direção Geral e Cesec 47

Tabela III.2.4 - Situação conjugal por sexo - Direção Geral e Cesec 48

Tabela III.3.1 - Hábito de fumar por sexo - Direção Geral 50

Tabela III.3.2 - Hábito de fumar por sexo - Cesec 50 
Tabela III.3.3 - Classificação de fumantes e ex-fumantes segundo número médio de cigarros consumidos por dia -por sexo Direção Geral e Cesec

Tabela III.3.4 - Distribuição do hábito e quantidade diária de cigarros consumidos por fumantes - por grupo etário e por sexo Direção Geral

Tabela III.3.5 - Distribuição do hábito e quantidade diária de cigarros consumidos por fumantes - por grupo etário e por sexo Cesec

Tabela III.3.6 - Classificação de fumantes e ex-fumantes de acordo com a quantidade diária de cigarros consumidos segundo escolaridade ambos os sexos - ambas as dependências

Tabela III.3.7 - Frequência de consumo semanal de grupos de alimentos por sexo - Direção Geral

Tabela III.3.8 - Frequência de consumo semanal de grupos de alimentos por sexo - Cesec

Tabela III.3.9 - Escore de dieta em quintis - por sexo - Direção Geral

Tabela III.3.10 - Escore de dieta em quintis - por sexo - Cesec

Tabela III.3.11 - Qualidade da dieta segundo escolaridade - ambos os sexos ambas as dependências

Tabela III.3.12 - Frequência de consumo de bebidas alcoólicas por sexo Direção Geral

Tabela III.3.13 - Frequência de consumo de bebidas alcoólicas por sexo Cesec

Tabela III.3.14 - Frequência de consumo de bebidas alcoólicas por grupo etário e sexo - ambas as dependências

Tabela III.3.15 - Distribuição da frequência de consumo de álcool segundo escolaridade - ambos os sexos - ambas as dependências

Tabela III.3.16 - Prática regular de atividades fisicas de lazer por sexo e tipo de dependência

Tabela III.3.17 - Prática regular de atividades fisicas de lazer por idade Direção Geral 
Tabela III.3.18 - Prática regular de atividades físicas de lazer por idade - Cesec 68

Tabela III.3.19 - Frequência semanal de atividades físicas de lazer por sexo Direção Geral

Tabela III.3.20 - Frequência semanal de atividades físicas de lazer por sexo Cesec

Tabela III.3.21 - Prática regular de atividades físicas segundo escolaridade por sexo - ambas as dependências

Tabela III.3.22 - Níveis informados de pressão sistólica por sexo Direção Geral

Tabela III.3.23 - Níveis informados de pressão sistólica por sexo - Cesec

Tabela III.3.24 - Níveis informados de pressão diastólica por sexo

Direção Geral

Tabela III.3.25 - Níveis informados de pressão diastólica por sexo - Cesec

Tabela III.3.26 - Informação sobre hipertensão arterial por algum profissional de saúde por sexo - Direção Geral

Tabela III.3.27 - Informação sobre hipertensão arterial por algum profissional de saúde por sexo - Cesec

Tabela III.3.28 - Comparação entre informação sobre hipertensão a partir de algum profissional de saúde e declaração de ser portador da doença - ambos os sexos - ambas as dependências

Tabela III.3.29 - Condição de tratamento entre aqueles informados sobre hipertensão arterial - Direção Geral

Tabela III.3.30 - Condição de tratamento entre aqueles informados sobre hipertensão arterial - Cesec

Tabela III.3.31 - Classificação de hipertensão por sexo - Direção Geral e Cesec 77

Tabela III.3.32 - Classificação de hipertensão por grupo etário - Direção Geral 78

Tabela III.3.33 - Classificação de hipertensão por grupo etário - Cesec 78

Tabela III.3.34 - Frequência de hipertensão arterial segundo escolaridade ambos os sexos - ambas as dependências idade menor ou igual a 40 anos 
Tabela III.3.35 - Frequência de hipertensão arterial segundo escolaridade ambos os sexos - ambas as dependências maiores de 40 anos

Tabela III.3.36 - Índice de massa corporal médio por idade - Direção Geral

Tabela III.3.37 - Índice de massa corporal médio por idade - Cesec

Tabela III.3.38 - Índice de massa corporal por idade - Direção Geral - Homens

Tabela III.3.39 - Índice de massa corporal por idade - Direção Geral - Mulheres 84

Tabela III.3.40 - Índice de massa corporal por idade - Cesec - Homens 84

Tabela III.3.41 - Índice de massa corporal por idade - Cesec - Mulheres

Tabela III.3.42 - Distribuição do índice de massa corporal acima ou abaixo do normal segundo escolaridade por sexo ambas as dependências

Tabela III.3.43 - Distribuição do índice de massa corporal acima ou abaixo do normal segundo escolaridade por grupo etário - ambos os sexos ambas as dependências

Tabela III.3.44 - Periodo de realização da última dosagem de colesterol por sexo - Idade menor ou igual a 40 anos

Tabela III.3.45 - Período de realização da última dosagem de colesterol por sexo - Maiores de 40 anos

Tabela III.3.46 -Informação sobre nível elevado de colesterol por sexo Direção Geral e Cesec

Tabela III.3.47 - Informação sobre nível elevado de colesterol segundo escolaridade - ambos os sexos - ambas as dependências

Tabela III.3.48 - Problemas de saúde diagnosticados em parentes consanguíneos ambas as dependências

Tabela III.3.49 - Respostas sobre fatores de risco que aumentam a chance de doenças do coração - ambas as dependências - Homens

Tabela III.3.49 - Respostas sobre fatores de risco que aumentam a chance de doenças do coração - ambas as dependências - Mulheres

Tabela III.4.1 - Distribuição dos funcionários examinados de acordo com a dependência 
Tabela III.4.2 - Diferenças médias entre peso medido e peso informado, e entre estatura medida e estatura informada - por sexo por dependência

Tabela III.4.3 - Médias do índice de massa corporal estimado através da medida direta e da informação dos funcionários por dependência - Homens

Tabela III.4.4 - Médias do índice de massa corporal estimado através da medida direta e da informação dos funcionários por dependência - Mulheres

Tabela III.4.5 - Coefícientes de correlação entre índice de massa corporal medido e índice de massa corporal informado por sexo por dependência

Tabelas III.4.6 - Comparação entre a classificação do índice de massa corporal segundo medida e informações do questionário por dependência

Tabela III.4.7 - Médias de pressão sistólica medida por sexo por dependência

Tabela III.4.8 - Médias de pressão diastólica medida por sexo por dependência

Tabela III.4.9 -Distribuição dos níveis de pressão arterial medida por dependência

Tabelas III.4.10 - Comparação entre a classificação de hipertensão arterial segundo medida e informação do questionário por dependência

Tabelas III.5.1 - Hábito de fumar e consumo de álcool por sexo ambas as dependências

Tabelas III.5.2 - Hábito de fumar e quintis de dieta por sexo ambas as dependências - Idade menor ou igual a 40 anos

Tabelas III.5.3 - Hábito de fumar e quintis de dieta por sexo ambas as dependências - Maiores de 40 anos

Tabelas III.5.4 - Hábito de fumar e atividade fisica semanal por sexo ambas as dependências - Idade menor ou igual a 40 anos 
Tabelas III.5.5 - Hábito de fumar e atividade física semanal por sexo ambas as dependências - Maiores de 40 anos

Tabelas III.5.6 - Atividade fisica semanal e quintis de dieta por sexo ambas as dependências - Idade menor ou igual a 40 anos

Tabelas III.5.7 - Atividade física semanal e quintis de dieta por sexo ambas as dependências - Maiores de 40 anos

Tabelas III.5.8 - Valores próprios e percentagem de explicação da variância de cada eixo - Fatores de risco

Tabelas III.5.9 - Contribuição absoluta e correlação dos principais elementos com o primeiro eixo - Fatores de risco

Tabelas III.5.10 - Características demográficas dos funcionários que apresentaram todos os fatores de risco e dos que não apresentaram nenhum fator de risco - ambas as dependências

Tabelas III.5.11 - Contribuição absoluta e correlação dos principais elementos com o segundo eixo - Fatores de risco

Tabelas III.5.12 - Valores próprios e percentagem de explicação da variância de cada eixo - Fatores de risco, idade e sexo

Tabelas III.5.13 - Contribuição absoluta e correlação dos principais elementos com o primeiro eixo - Fatores de risco, idade e sexo

Tabelas III.5.14 - Distribuição da ocorrência conjunta dos fatores de risco por sexo - ambas as dependências

Tabelas III.5.15 - Contribuição absoluta e correlação dos principais elementos com o segundo eixo - Fatores de risco, idade e sexo

Tabelas III.5.16 - Contribuição absoluta e correlação dos principais elementos com o terceiro eixo - Fatores de risco, idade e sexo

Tabelas III.5.17 - Valores próprios e percentagem de explicação da variância de cada eixo - Efeitos, idade e sexo

Tabelas III.5.18 - Contribuição absoluta e correlação dos principais elementos com o primeiro eixo - Efeitos, idade e sexo

Tabelas III.5.19 - Contribuição absoluta e correlação dos principais elementos com o segundo eixo - Efeitos, idade e sexo 
「abelas III.5.20 - Valores próprios e percentagem de explicação da variância de cada eixo - Fatores de risco e efeitos

[abelas III.5.21 - Contribuição absoluta e correlação dos principais elementos com o primeiro eixo - Fatores de risco e efeitos

[abelas III.5.22 - Contribuição absoluta e correlação dos principais elementos com o segundo eixo - Fatores de risco e efeitos

[abelas III.5.23 - Distribuição dos fatores de risco entre hipertensos e não hipertensos - ambos os sexos - ambas as dependências

Tabelas III.5.24 - Distribuição do índice de massa corporal e informação sobre hipercolesterolemia entre hipertensos e não hipertensos - ambos os sexos - ambas as dependências

Tabela IV.1.1 - Prevalências e intervalos de confiança - Todos os fatores de risco - por sexo - Direção Geral

rabela IV.1.2 - Prevalências e intervalos de confiança - Todos os fatores de risco - por sexo - Cesec

Tabela IV.1.3 - Comparação entre prevalências de sobrepeso e obesidade por sexo

[abela IV.1.4 - Comparação entre índice de massa corporal médio do grupo submetido à medida de peso e estatura e do grupo não medido por sexo - por dependência

Tabela IV.1.5- Comparação entre prevalências de hipertensão arterial por sexo

\section{Lista de Quadros}

Quadro II.3.1 - Seções do questionário geral 


\section{RESUMO}

Esta tese faz parte do "Estudo das Condições de Saúde dos Funcionários do Banco do Brasil", patrocinado pelas Caixas de Assistência e de Previdência dos Funcionários (CASSI e PREVI), tendo em vista a reformulação do conjunto da assistência à saúde oferecida aos bancários. Neste trabalho, investigamos a distribuição dos principais fatores de risco para doenças cardiovasculares, bem como a existência de padrões de hábitos e comportamentos, por meio da estimativa de prevalências e do estudo da ocorrência simultânea dos fatores de risco entre os funcionários ativos no Estado do Rio de Janeiro.

Os dados foram coletados por meio de um estudo transversal, que utilizou questionário auto-preenchido no ambiente de trabalho. A população alvo foi constituída por funcionários das carreiras administrativa (bancários) e técnica (advogados, médicos e engenheiros), de onde sorteou-se amostra aleatória simples de 1183 funcionários, lotados em dois tipos de dependências do banco: Centros de Processamento de Serviços e Comunicações (CESEC) e órgãos da Direção Geral. Além dos dados coletados por intermédio do questionário, medidas diretas de peso, estatura e pressão arterial foram também tomadas de forma direta, em uma sub-amostra dos respondentes. A distribuição dos principais fatores de risco (fumo; consumo de álcool; sedentarismo; dieta rica em gorduras saturadas, colesterol e sal; sobrepeso/obesidade; hipertensão arterial; hipercolesterolemia) foi investigada segundo sexo, idade e escolaridade. Além disso, padrões típicos de comportamento, caracterizados pela ocorrência simultânea daqueles fatores, foram identificados por meio de técnica multivariada (análise de correspondência).

A população estudada apresentou alto nível de escolaridade, já que cerca de $90 \%$ chegou a ingressar na universidade, e idade média de 38 anos. Os bancários reconhecem os principais fatores de risco para as doenças do coração. Mesmo assim, as prevalências estimadas são compatíveis com aquelas relatadas em outros grupos populacionais, chamando atenção, entre os bancários, a grande proporção de homens que apresentaram sobrepeso/obesidade e consumo de dieta rica em componentes pouco saudáveis. Padrão de aglomeração de hábitos e comportamentos mais saudáveis por um lado, e menos saudáveis por outro, foi identificado, caracterizando grupos com estilos de vida bem definidos. Diferenças importantes no perfil de risco cardiovascular foram observadas entre homens e mulheres, considerando-se hábitos e comportamentos, e também a 
prevalência de hipertensão, sobrepeso/obesidade e hipercolesterolemia. Assim, os homens constituíram o grupo de maior risco, não só pela maior prevalência da maioria dos fatores, considerados isoladamente, mas também por estarem associados à ocorrência simultânea daqueles fatores, caracterizando estilo de vida menos saudável. Além disso, escolaridade e idade também discriminaram grupos de risco.Os resultados sugerem ainda a inadequação do controle de hipertensão arterial, já que o diagnóstico dessa condição não parece determinar mudanças de comportamento, nem a adoção de tratamento específico pelo conjunto dos hipertensos (apenas $50 \%$ encontram-se em tratamento).

Aspectos relativos à validade e confiabilidade dos dados são discutidos, bem como determinantes coletivos e individuais de estilos de vida distintos e de mudanças de comportamento na população. Ações que integrem Programa de Promoção da Saúde no Ambiente de Trabalho são sugeridas, apontando importante área de atuação para profissionais de Saúde Pública no Brasil. 


\section{Abstract}

This thesis is part of the "Study on health conditions among Bank of Brazil employees", sponsored by the employees' social care and pension funds (CASSI and PREVI), which purpose was to establish a technical basis for the reformulation of health care provided to the bank employees. We investigated distribution of the main risk factors for cardiovascular disease and their simultaneous occurrence among active employees in the State of Rio de Janeiro.

Data were gathered through a cross-sectional study utilizing a self-applied questionnaire filled out at the workplace. The target population consisted of Bank of Brazil employees from both administrative careers (i.e., bank workers proper) and professional careers (attorneys, physicians, and engineers), from which we drew a simple random sample of 1183 employees, allocated at two types of bank facilities: the Services and Communication Processing Centers (CESEC) and departaments under the General Administration. Direct measurements of weight, height, and arterial blood pressure were also performed in a sub-sample of respondents. Distribution of the main risk factors was investigated by gender, age, and level of education. In addition, typical behavior patterns, characterized by the simultaneous occurrence of such factors, were identified using a multivariate technique (analysis of correspondence).

The population we studied had a high level of education, given that some $90 \%$ had at least commenced university sudies.Mean age was 38 years. The bank employees were familiar with the main risk factors for heart disease. Even so, estimated prevalences were similar to those reported for other population groups: smoking: $31,1 \%$; daily alcohol consumption: $10 \%$; sedentarism: $57,4 \%$; diet rich in saturated fats, cholesterol, and salt: 18,6\%; overweight/obesity: $34,7 \%$; high blood pressure: $18,4 \%$; and hypercholesterolemia: $24,6 \%$. We identified a pattern of clustering of healthier habits and behaviors on one side and less healthy ones on the other, thus characterizing groups with well-defined life-styles. Important differences were observed between the respective cardiovascular risk profile for men and women: men constituted a higher risk group, not only because of the higher prevalence of the majority of the factors considered separately, but also because simultaneous occurrence of factors was associated with them. In addition to gender, education and age also distinguished risk 
groups. In addition, results suggest that high blood pressure control is inadequate, since diagnosis of this condition does not appear to lead to either changes in behavior or the adoption of specific treatment by hypertensive individuals as a whole (only $50 \%$ of whom were under treatment).

We discuss aspects pertaining to data validity and reliability, as well as the collective determinants of life-style and behavior changes in population groups. We suggest measures to be included in health promotion programs at the workplace, identifying an important area for action by public heath professionals in Brazil. 
CAPÍTULO I INTRODUÇÃO 


\section{I- RELEVÂNCIA DO PROJETO}

Ao contrário do que se imagina, as doenças cardiovasculares não constituem causa de óbito importante apenas nos grupos populacionais mais idosos, no Brasil. Representam, na realidade, a causa mais freqüente em adultos jovens, tendo sido responsáveis por $33 \%$ da mortalidade entre 40 e 49 anos, em 1988 (Ministério da Saúde, 1993). Temos que nos indagar se é "natural" que uma proporção tão expressiva de homens e mulheres jovens morra por enfermidades "degenerativas", por vezes atribuídas ao envelhecimento da população.

O modelo de determinação das enfermidades cardiovasculares aceito pela maioria dos autores inclui fatores hereditários, mas evidencia a importância de hábitos e comportamentos, especialmente o fumo, dieta rica em gorduras saturadas e o sedentarismo. De acordo com este modelo, as doenças do aparelho circulatório não representam "consequências inevitáveis da vida moderna", mas do modo de vida da população, sendo assim passível de modificação (BLACKBURN \& LUEPKER, 1986). O acompanhamento dos níveis e distribuição destes fatores de risco tem sido realizado em inúmeros países desenvolvidos, contribuindo para o planejamento de programas de saúde, divulgação de informações e modificação da legislação vigente. Este acompanhamento possibilitou, por exemplo, a observação de que a prevalência dos fatores de risco vem diminuindo naqueles países, o que pode explicar, em parte, o declinio da mortalidade cardiovascular nas últimas décadas.

Experiências relacionadas a estratégias de prevenção e promoção da saúde cardiovascular na população geral e também no ambiente de trabalho, têm enfatizado o impacto de mudanças comportamentais em toda a população e não apenas entre os indivíduos de maior risco (MARMOT, 1993). Neste estudo, pretendemos estimar os níveis e identificar a distribuição dos principais fatores de risco para as enfermidades cardiovasculares, bem como sua ocorrência simultânea entre os funcionários do Banco do Brasil, ativos em dois tipos de dependência, no Estado do Rio de Janeiro. A escassez de dados nacionais relativos a estes tópicos bem como a magnitude das doenças cardiovasculares em nosso país, justificam esta investigação. Embora o estudo de uma categoria profissional não possibilite a generalização dos resultados à população em geral, o que pode ser considerado uma desvantagem, o fato de se tratar de grupo específico, que dispõe de recursos para a saúde, facilita a implantação de medidas de prevenção e controle, sugeridas a partir deste diagnóstico. Além disso, a distribuição etária da população de estudo permite que estas medidas possam ser efetivas, 
especialmente ao evitar a mortalidade ou incapacidades precoces, o que representa um aspecto particularmente interessante, do ponto de vista da Saúde Pública. Nestes tempos de racionalização de custos, nos parece bastante oportuno que parte dos recursos das Caixas de Assistência de funcionários, geralmente investidos na "cura" das enfermidades, possa ser colocado à disposição de evitá-las.

\section{2- MAGNITUDE DAS DOENÇAS CARDIOVASCULARES}

A conquista de melhores condições de vida, entre outros fatores, tornou possível a queda da mortalidade geral, especialmente através do controle das doenças infecciosas, resultando no envelhecimento da população. Neste novo quadro demográfico, as doenças crônicas, não transmissíveis, substituíram as antigas epidemias de doenças infectoparasitárias no perfil de morbi-mortalidade dos países desenvolvidos, constituindo a chamada transição epidemiológica (OMRAM, 1971). Dentre as enfermidades crônicas, as doenças cardiovasculares vêm representando, nestes países, a primeira causa de morte desde a primeira metade deste século (THOM, 1989).

As enfermidades cardiovasculares constituem o capítulo VII da $9^{a}$ Classificação Internacional de Doenças, composto por: Febre Reumática Ativa e Doença Reumática do Coração (códigos 390-398); Doença Hipertensiva (códigos 401-405); Doença Isquêmica do Coração (códigos 410-414); Doenças da Circulação Pulmonar e outras formas de Doença do Coração (códigos 415-429); Doenças Cerebrovasculares (códigos 430-438); Doenças das artérias, das arteríolas e dos capilares (códigos 440-448); Outras Doenças do Aparelho Circulatório (códigos 451-459).

A mortalidade causada pelas diferentes doenças cardiovasculares sofreu alterações importantes, nos últimos 50 anos. Aquelas de origem infecciosa, como a febre reumática, deixaram de ser causas freqüentes de óbito, enquanto as de origem aterosclerótica, entre as quais as mais freqüentes são a Doença Isquêmica do Coração (onde se inclui o Infarto Agudo do Miocárdio) e as Doenças Cerebrovasculares, tornaram-se um dos "males do século" (BLACKBURN \& LUEPKER, 1986).

$\mathrm{Na}$ maioria dos paises desenvolvidos do Ocidente, a mortalidade por doenças ateroscleróticas apresentou comportamento peculiar, com aumento progressivo durante cerca 
de trinta anos, a partir da década de 40, seguido de diminuição acentuada. Esta tendência foi particularmente importante nos Estados Unidos, cujas taxas de mortalidade masculinas por doença isquêmica decresceram cerca de 38\% entre 1970 e 1985 (BEAGLEHOLE, 1990) Três conjuntos de fatores têm sido apontados como determinantes deste declínio: mudança de hábitos e comportamentos, especialmente em relação ao fumo, dieta e exercícios físicos; novas intervenções médicas e cirúrgicas; e fatores não identificados ou pouco conhecidos, como o "ciclo natural das doenças" (GOLDMAN \& COOK, 1984). Com padrão inverso, paises do leste europeu como Hungria, Iugoslávia e Tchecoslováquia, cujas taxas de mortalidade cardiovascular eram relativamente baixas na década de 50, vêm apresentando aumento progressivo desde os anos 70 (THOM, 1989; UEMURA \& PISA, 1985).

No Brasil, as doenças do aparelho circulatório participavam com apenas $12 \%$ dos óbitos no conjunto das capitais do país em 1930; em 1980, já representavam $31 \%$ da mortalidade naquelas cidades (ESCOLA NACIONAL DE SAÚDE PÚBLICA, 1984). Como em outros países desenvolvidos, também entre nós, no Estado e Município de São Paulo, o declínio da mortalidade por doença isquêmica do coração e doenças cerebrovasculares tem sido descrito nas últimas décadas, particularmente nos grupos etários mais idosos (LAURENTI, 1981; LOLIO \& LAURENTI, 1986a; LOLIO \& LAURENTI, 1986b; LOTUFO \& LOLIO, 1993a; LOTUFO \& LOLIO, 1993b). Mesmo que esta tendência esteja ocorrendo em outras cidades, as doenças cardiovasculares foram responsáveis, em 1988, pela maior proporção de óbitos no país: $31 \%$ dos óbitos masculinos e $39 \%$ dos óbitos femininos (MINISTÉRIO DA SAÚDE, 1993).

Além de constituir a primeira causa de óbito, outras características reforçam a importância destas enfermidades entre nós já que, por exemplo, $50 \%$ dos óbitos masculinos por doença isquêmica do coração vem ocorrendo antes dos 64 anos de idade. Ainda que a composição etária da população brasileira, mais jovem, seja levada em consideração, aquela proporção é, de fato, cerca de duas vezes maior no Brasil do que nos Estados Unidos, Canadá, Cuba ou Inglaterra (CHOR, 1995a). A idade mediana de morte por Doença Isquêmica entre nós, é portanto mais precoce - 68 anos (1987) - comparada aos 73 anos na Argentina (1989), e 78 anos na Inglaterra e Estados Unidos (GRÁFICO I.2.1). 


\section{GRÁFICO I.2.1 \\ PROPORÇÃO DE ÓBITOS POR DOENÇA ISQUÊMICA DO CORAÇÃO \\ SEGUNDO GRUPOS ETÁRIOS \\ CAPITAIS BRASILEIRAS E PAÍSES SELECIONADOS}

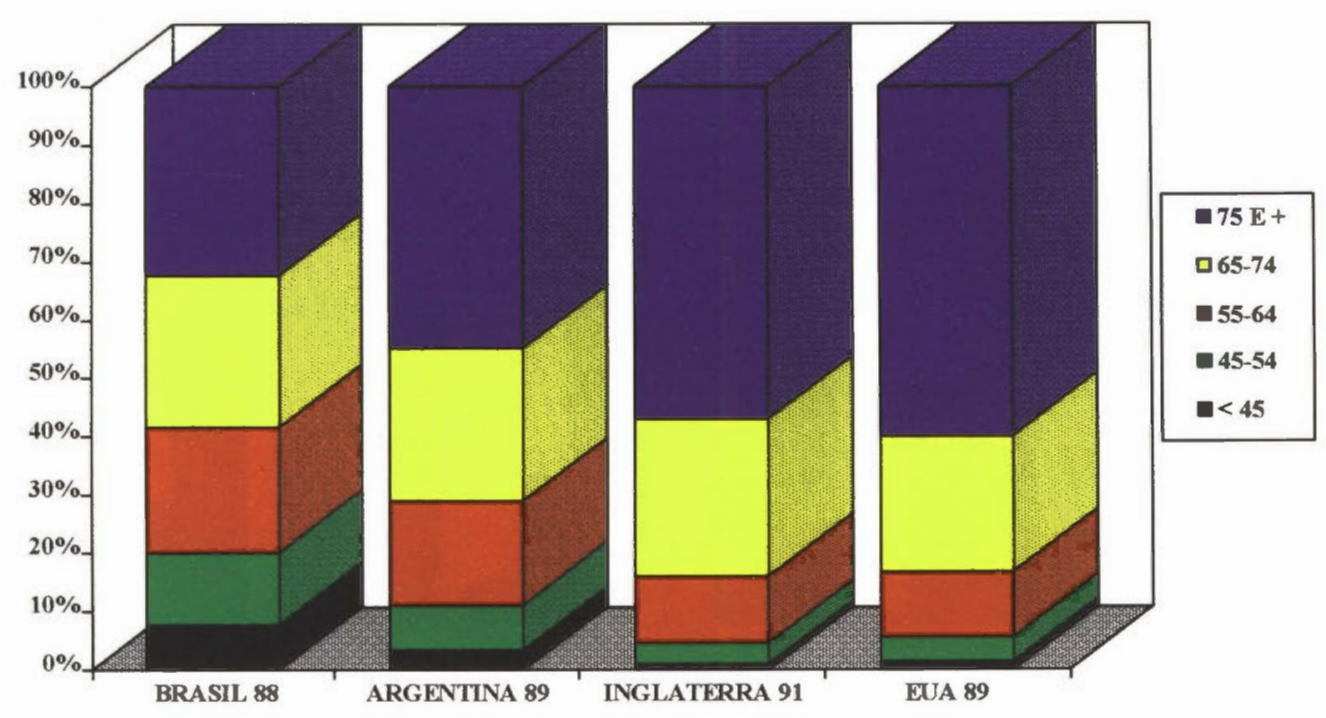

Fontes: Ministério da Saúde, 1993

World Health Statistics, 1992

Confirmando o fato de que as diferenças entre as distribuições etárias dos diversos países comparados não explicam completamente a grande proporção de óbitos precoces no Brasil, o risco de morrer também tem sido maior entre nós. Em 1988, a taxa de mortalidade masculina por infarto agudo do miocárdio, em oito capitais situadas em regiões metropolitanas, situou-se no nível dos países do leste europeu, cujos coeficientes estão entre os mais elevados do mundo (GRÁFICO I.2.2). No grupo etário mais jovem, entre 35 e 44 anos, o risco de morrer por infarto agudo do miocárdio, entre os homens, nas oito capitais brasileiras, foi cerca de três vezes maior do que o norte-americano (CHOR, 1995b). Cabe notar que a comparação ideal teria sido realizada entre taxas de mortalidade de diferentes cidades, e não entre cidades e países, já que as taxas de mortalidade tendem a ser maiores nos centros urbanos. No entanto, essa tendência não seria suficiente para explicar a magnitude da diferença entre as taxas de mortalidade das capitais brasileiras e os outros países, nem tampouco a consistência dos resultados em ambos os sexos e todas as faixas etárias. É importante acentuar portanto, que a mortalidade por doenças cardiovasculares é mais precoce nas capitais brasileiras, quando comparada a outros países. 


\section{GRÁFICO I.2.2}

COEFICIENTES DE MORTALIDADE POR INFARTO AGUDO DO MIOCÁRDIO.

CAPITAIS BRASILEIRAS E PAÍSES SELECIONADOS, SEXO MASCULINO

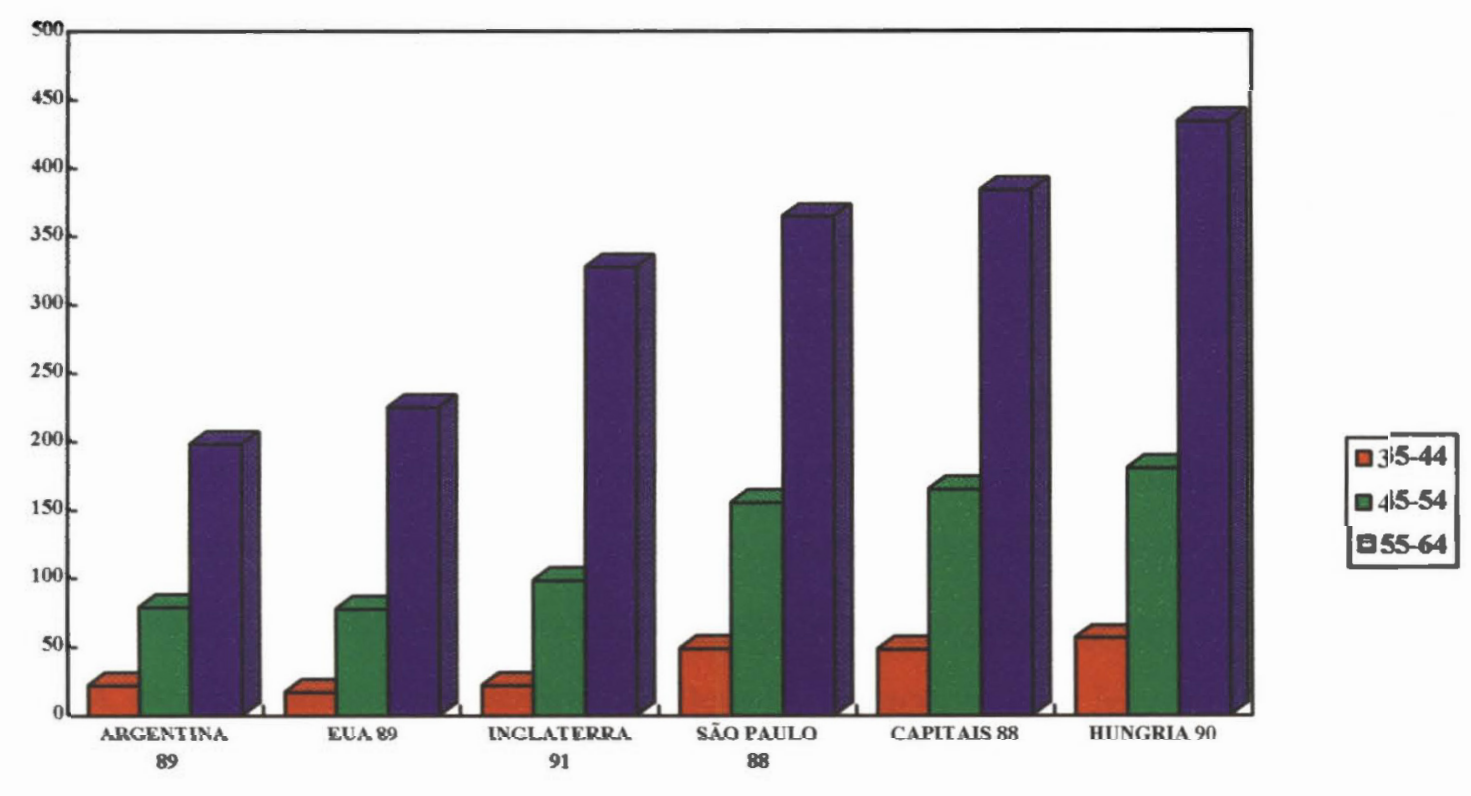

Fontes: Ministério da Saúde, 1993

World Heath Statistics, 1992

Do ponto de vista da morbidade, a hipertensão arterial merece destaque, já que sua magnitude como causa de óbito ainda é bastante subestimada no país, por serem selecionadas outras causas de óbito sempre que mencionadas na Declaração. A hipertensão vem representando a primeira causa de aposentadoria por doença e a primeira causa de licenças para tratamento no país (LESSA, 1993). De acordo com estes dados, trata-se de uma das enfermidades mais importantes em termos de Saúde Pública, especialmente em relação à população economicamente ativa. 


\section{3- FATORES DE RISCO}

Os estudos epidemiológicos das doenças cardiovasculares deram origem ao termo fator de risco. Por um lado, este conceito gerou uma busca desenfreada pela participação isolada de cada fator na determinação daquelas enfermidades. No entanto, gerou também a necessidade da elaboração de modelos multicausais, já que o envolvimento simultâneo de vários fatores de risco constituem a regra em sua determinação. Esse modelo mostrou-se bem mais complexo do que a simples estimativa do efeito de cada fator de risco isolado, ou mesmo de sua ocorrência simultânea em cada indivíduo. A distribuição dos fatores de risco na população é influenciada por características sociais, econômicas e culturais que precisam ser levadas em conta, especialmente se pretendemos alterá-la. De acordo com Marmot (1992), as doenças cardiovasculares ocorrem da relação entre condições materiais de vida (moradia, transporte); ambiente social (trabalho e vida social); nutrição e estilo de vida (fumo e atividade física). Além desse conjunto, o Autor cita ainda estudos que sugerem que o "ambiente precoce" (circunstâncias in utero ou na infância) podem ter efeito persistente nas taxas de mortalidade ao longo de toda a vida. Fortes argumentos demonstram por outro lado, que o padrão genético de cada indivíduo tem papel de menor importância: o grande declínio das taxas de mortalidade por doenças cardiovasculares em cerca de 20 anos (padrões genéticos não se alteram com essa velocidade) e as taxas de incidência em migrantes, que rapidamente tornam-se semelhantes àquelas observadas no país de adoção

O envolvimento de três fatores de risco na determinação multifatorial da doença aterosclerótica, suas complicações e manifestações clínicas -entre elas diversas doenças cardiovasculares- é reconhecido: níveis altos de colesterol sérico associados à dieta, hipertensão arterial e fumo de cigarros. Em relação à doença coronariana especificamente, apresentamos um resumo dos principais resultados de estudos que relacionam esses fatores com sua incidência e mortalidade (TABELA I.3.1). 
TABELA 1.3.1

PREDITORES INDEPENDENTES DA INCIDÊNCIA E/OU MORTALIDADE POR DOENÇA CORONARIANA

\begin{tabular}{|c|c|c|c|c|c|}
\hline Autores e Estudos & Pacientes & $\begin{array}{l}\text { Seguimento } \\
\text { (anos) }\end{array}$ & $\begin{array}{l}\text { Colesterol } \\
\text { Sérico }\end{array}$ & $\begin{array}{l}\text { Pressão } \\
\text { Arterial }\end{array}$ & $\begin{array}{c}\text { Fumo } \\
\text { Cigarros }\end{array}$ \\
\hline $\begin{array}{l}\text { De Vries et al. } \\
\text { (Zutphen Study) }\end{array}$ & 677 & 20 & + & + & SA \\
\hline $\begin{array}{l}\text { Goldbourt et al. } \\
\text { (Israel Ischemic Heart Disease } \\
\text { Study) }\end{array}$ & 10059 & 23 & + & + & + \\
\hline $\begin{array}{l}\text { Hames et al. } \\
\text { (Evans County Heart Study) }\end{array}$ & 3102 & 20 & & & \\
\hline Homens brancos & & & + & + & + \\
\hline Homens negros & & & + & + & + \\
\hline Mulheres brancas & & & + & + & NR \\
\hline Mulheres negras & & & + & + & NR \\
\hline $\begin{array}{l}\text { Kannel and Larson } \\
\text { (Frammingham Study) }\end{array}$ & & longo tempo* & & & \\
\hline Homens & & & + & + & + \\
\hline Mulheres & & & + & + & + \\
\hline $\begin{array}{l}\text { Kornitzer et al. } \\
\text { (Belgian Bank Study) }\end{array}$ & 1227 & 25 & + & + & + \\
\hline $\begin{array}{l}\text { Mennotti et al. } \\
\text { (Coortes rurais italianas) }\end{array}$ & 1712 & 25 & + & + & + \\
\hline $\begin{array}{l}\text { Pekkanen et al. } \\
\text { (Coortes finlandesas) }\end{array}$ & 1619 & 30 & + & + & + \\
\hline Stamler et al. & & & & & \\
\hline Western Eletric & 1903 & 24 & + & + & + \\
\hline Peoples Gas & 1405 & 30 & SA & + & + \\
\hline $\begin{array}{l}\text { Chicago Heart Association } \\
\text { Detection Project }\end{array}$ & & & & & \\
\hline Homens (40-59) & 8515 & 15 & + & + & + \\
\hline Mulheres (40-59) & 7082 & 15 & + & + & + \\
\hline Homens $(60-74)$ & 1490 & 15 & + & + & + \\
\hline Mulheres (60-74) & 1243 & 15 & + & + & + \\
\hline $\begin{array}{l}\text { Welin et al. } \\
\text { (Göteborg Study) }\end{array}$ & 845 & 25 & + & + & + \\
\hline
\end{tabular}

Adaptado de Kornitzer \& Goldberg, 1993

$+=$ Preditor significativo; $\mathrm{SA}=$ sem associação; $\mathrm{NR}=$ não relevante

* = Longo tempo (sem maior precisão) 
De acordo com o conhecimento científico disponivel, portanto, a associação entre cada um desses três fatores e a ocorrência de doenças cardiovasculares parece estabelecida.

A hipertensão arterial tem sido apontada como o fator de risco conhecido de maior importância para a morbidade e mortalidade precoce causadas por doenças cardiovasculares, já que está associada a taxas aumentadas de incidência e mortalidade. De fato, grandes evidências relacionam níveis elevados de pressão sistólica, diastólica ou ambas, com maior probabilidade de ocorrência de doença isquêmica do coração, doenças cerebrovasculares, aterosclerose e mortalidade geral (KEYS, 1970; Hypertension Detection and Follow-up Program Cooperative Study, 1979). A história familiar de hipertensão contribui para o risco aumentado de desenvolver a doença, mas a elevação prolongada da pressão arterial depende também de outros fatores como a relação entre a ingestão de sódio e potássio, do índice de massa corporal e do uso abusivo de álcool (INTERSALT, 1988). Além destes fatores, o stress e o fumo também causam a elevação aguda dos níveis tensionais, e no caso do primeiro, contribui para a elevação sustentada da pressão arterial.

Além da hipertensão arterial, a participação do colesterol sanguíneo e do fumo na determinação da doença isquêmica do coração foi estabelecida nos anos 60 e 70, através de estudos epidemiológicos, bioquímicos e, também por ensaios clínicos (DYER, 1981; Hypertension detection and follow-up group, 1982). Estudos epidemiológicos sugerem que somente populações com níveis elevados de colesterol sanguíneo e de ingestão de gorduras saturadas apresentam altas taxas de incidência de doença isquêmica do coração (KEYS, 1970). Esta seria uma das explicações para que paises com alta prevalência de tabagismo e baixa ingestão de gorduras animais, como Japão e China, apresentem baixa incidência de doença isquêmica, quando comparados a paises com frequência menor de tabagismo, mas ingestão maior de gorduras.

A associação estatística entre tabagismo e doença isquêmica do coração , “...é forte, consistente e independente para indivíduos que vivem em sociedades de alto risco" (onde a aterosclerose tem alta prevalência) (BLACKBURN \& LUEPKER, 1986). De acordo com estes autores, o fumo não parece ser um fator de explicação primário nas amplas diferenças populacionais encontradas entre as taxas de doença isquêmica, mas sua interação com outros fatores, principalmente hipercolesterolemia e hipertensão arterial, eleva o risco relativo daquela doença de 1,6 (fumo isolado) para 16,0 (DAWBER, 1980). O risco de morrer por doença coronariana é influenciado ainda pela precocidade do início do hábito, quantidade de 
cigarros consumidos diariamente e profundidade da tragada (FIELDING, 1986). A associação entre fumo e doenças cerebrovasculares não é tão evidente, embora mulheres fumantes e usuárias de anticoncepcionais orais apresentem maior risco para hemorragia subaracnóide e fenômenos tromboemboliticos (PETITI, 1978)

O padrão de alimentação da população é a chave em dois dos três fatores de risco apresentados anteriormente, já que além de seu papel específico, é forte determinante da prevalência de hipertensão arterial e hipercolesterolemia. Além disso, junto com o sedentarismo, é responsável pela emergência da obesidade e por niveis elevados de glicemia e uricemia, incluindo o diabetes não insulino dependente. A dieta pouco saudável tem sido definida como aquela rica em produtos animais em geral e também em produtos processados; em gordura total, gordura hidrogenada e gordura "visível"; rica em colesterol e gordura saturada; rica em açúcar processado e refinado; rica em sal; rica em álcool; rica em densidade calórica e em calorias "vazias", e na razão calorias/nutrientes essenciais; rica em calorias totais para baixo nivel de gasto energético; pobre em potássio, fibras e outros nutrientes essenciais (STAMLER, 1992)

Outros fatores vêm sendo investigados, além dos quatro já citados -dieta "rica", hipertensão, colesterol sanguíneo e fumo- que são aceitos pela maioria dos autores como os de maior importância. Entre estes, sobrepeso (proporção limitada acima do peso ideal) e obesidade (excesso de gordura) estão associados à maior mortalidade através do aumento da pressão arterial, dislipidemias, intolerância à glicose insulino-resistente, hiperuricemia e fibrinogênio elevado (BIERMAN, 1988; SORLIE, 1980). Além da associação freqüente com hiperlipidemias e hiperglicemia, que parecem mediar a relação entre obesidade e aterosclerose, flutuações de peso repetidas aceleram ainda mais a aterogênese (KANNEL, 1996). Em relação à hipertensão arterial, embora grande ênfase tenha sido dada à dieta com pouco sal, 40 a $50 \%$ dos casos podem ser atribuídos ao excesso de peso (MEISLER, 1996) Além disso, a perda de peso, mesmo que moderada, pode eliminar a necessidade de medicação em grande parcela dos casos. Em função da relação entre obesidade e inúmeros elementos que compõem o perfil de risco cardiovascular, já é possível afirmar que os níveis mais baixos de doenças do aparelho circulatório ocorrem em indivíduos que permanecem magros durante toda a vida (KANNEL, 1996). Sobrepeso e obesidade aumentam ainda o risco de doenças do aparelho músculo-esquelético, afetam negativamente a auto-imagem e interferem no relacionamento inter pessoal. Geralmente determinada pela má qualidade da 
dieta e por hábitos sedentários, a obesidade tem sido apontada como fator de risco também para doença isquêmica do coração (KANNEL, 1996).

A importância da obesidade na determinação das doenças cardiovasculares é cada vez maior, uma vez que existem evidências de que o peso corporal médio da população vem aumentando, nas últimas décadas, em diversos países desenvolvidos (BLACKBURN \& LUEPKER, 1986). Também no Brasil, resultados da Pesquisa Nacional de Saúde e Nutrição, realizada em 1989 , revelaram que $27 \%$ dos homens e $38 \%$ das mulheres acima de 18 anos apresentavam sobrepeso (COITINHO, 1991). Nos Estados Unidos, o aumento da prevalência de obesidade demonstra que estratégias populacionais voltadas para o controle de peso não têm apresentado bons resultados. Em função disso, o conceito de "peso saudável" vem evoluindo de "peso adequado à estatura" para "valores que diminuam a morbi-mortalidade" (MEISLER, 1996).

A prática regular de exercícios físicos pode levar à redução de peso, diminuição dos niveis de pressão sistólica e diastólica, e diminuição da proporção de gordura corporal (KANNEL \& SORLIE, 1979; BERLIN \& COLDITZ, 1990). O risco reduzido de doenças do coração também tem sido associado a exercícios intensos e regulares, já que individuos ativos apresentam menor taxa de incidência específica por idade, e também de mortalidade, do que individuos sedentários (SISCOVICK, 1982). Seu efeito protetor, diretamente proporcional à frequência e intensidade, parece ser mediado pelo aumento do HDL-colesterol ("high density lipoprotein"), que removem depósitos de gorduras da parede dos vasos (WOOD, 1979).

Outro campo de investigação sobre a determinação das doenças cardiovasculares se refere ao "stress", que constitui um conceito impreciso, e que por isso mesmo tem gerado ceticismo entre os pesquisadores. Parece-nos mais apropriado, de acordo com Marmot (1985), falarmos a respeito de traços específicos de personalidade e do ambiente psico-social, que contribuem para a compreensão do desenvolvimento das enfermidades. Além da imprecisão de conceitos, os estudos epidemiológicos têm que dar conta também da dificuldade de medida dos fatores ambientais que causam o "stress" (MARMOT, 1985). Ao invés do simples abandono do que é dificil conceituar e medir, vários pesquisadores têm investigado a importância dos "estressores" ambientais, o que vem contribuindo para o desenvolvimento metodológico.

A influência do ambiente psico-social também tem sido comprovada através de estudos com migrantes. Individuos que migram de sociedades com baixos níveis tensionais 
para sociedades com altos niveis, adotam estes últimos, e apresentam maior aumento da pressão arterial com a idade do que os que não migram. As explicações disponiveis para estes resultados estão relacionadas a mudanças da dieta, à tensão social e à ruptura das sociedades modernas com valores tradicionais (JOSEPH, 1983).

Em relação às características sócio-demográficas, prevalecia a idéia tradicional de que as doenças cardiovasculares ocorriam principalmente entre os grupos populacionais mais ricos, com ocupações que gerariam altos níveis de tensão emocional. Tal impressão não se confirmou através das investigações realizadas, e a maioria delas, como o Estudo de Whitehall, na Inglaterra (MARMOT, 1978), e outros nos Estados Unidos e Noruega (HOLME, 1976), encontrou pressão arterial média, prevalência de hipertensão e mortalidade por doenças cerebrovasculares de maior magnitude entre os mais pobres, com menor grau de escolaridade. Também no Brasil, a distribuição da hipertensão arterial entre os grupos populacionais segue este padrão, de acordo com estudos realizados em Porto Alegre e no Rio de Janeiro (KLEIN, 1984; ARAUJO, 1984).

A caracterização das ocupações que geram altos níveis de "stress" não é uma tarefa fácil, mas os autores têm apontado duas variáveis: demandas psicológicas e pouco poder de decisão ou de controle sobre o trabalho, que seriam englobadas no conceito de "pressão no trabalho" (“job strain”) (MARMOT, 1985; ALLBRIGHT, 1992; GARDELL, 1982). Assumese que "condições de trabalho que limitam severamente a autonomia e o uso da criatividade, entram em conflito com necessidades humanas essenciais relacionadas à capacidade de controle, estímulo à variação e auto-expressão, e que portanto são nocivas, tanto do ponto de vista biológico como social" (GARDELL, 1982). Em relação ao trabalho bancário, a expectativa que existia de que a automação diminuisse as tarefas monótonas e repetitivas não parece ter se verificado, já que estas têm sido queixas constantes entre os funcionários (SILVA FILHO, 1993). Alguns trabalhos sugerem a existência de forte associação entre pressão no trabalho e maior prevalência e/ou incidência de doença isquêmica do coração, controlando-se variáveis tradicionais como idade, raça, colesterol e fumo (KARASEK, 1981; KARASEK, 1988). Outro autor conclui que a "pressão no trabalho" pode ser um fator de risco tanto para hipertensão arterial como para alterações estruturais no coração (SCHNALL, 1990).

Considerando-se os problemas metodológicos apontados, a participação dos fatores psico-sociais na determinação das doenças cardiovasculares ainda é controversa. No entanto, 
é reconhecido que constituem uma das hipóteses explicativas para a distribuição diferenciada destas enfermidades segundo classe social e grupo étnico, e ainda para sua magnitude crescente após a modernização de sociedades rurais e tradicionais (MARMOT, 1985).

\section{4- É POSSÍVEL REDUZIR AS DOENÇAS CARDIOVASCULARES}

Os esforços de prevenção desenvolvidos atualmente apresentam maior probabilidade de adiar o aparecimento da doença isquêmica do coração e doenças cerebrovasculares, do que propriamente de evitá-las. A redução das taxas de incidência teria melhores chances de ser alcançada se uma nova geração se desenvolvesse com hábitos e ambiente mais saudáveis, desde o início da vida até a idade adulta (ROSE, 1992). Mesmo assim, o controle das causas de aterosclerose e de elevação da pressão arterial traz benefícios em termos de longevidade e melhoria da qualidade de vida, sendo portanto justificável, particularmente no caso de países como o Brasil onde como vimos, a mortalidade por enfermidades cardiovasculares atinge um grande contingente de adultos jovens.

Os tipos de estratégias de prevenção ou redução precisam ser discriminados em termos dos agravos mais freqüentes - doença coronariana e doenças cerebrovasculares- já que suas características e também os meios disponíveis de controle são diferentes. O comportamento da doença coronariana tem demonstrado que a redução expressiva do número de casos novos só tem ocorrido quando os níveis dos fatores de risco são reduzidos na grande maioria da população. Isto porque os indivíduos que apresentam níveis de risco moderados superam em número aqueles de alto risco, e também pelo efeito sinérgico entre os diversos fatores. Em função desta observação, as estratégias de controle que visaram o conjunto da população, e não apenas os grupos de alto risco, obtiveram melhores resultados. Enfoques em grupos de alto risco, embora benéficos para os indivíduos envolvidos, causaram pequeno impacto nas taxas de incidência e mortalidade (MARMOT, 1993). Enfoques de alto risco parecem ter bons resultados, por outro lado, em relação às doenças cerebrovasculares, uma vez que a maior parte dos casos ocorre entre hipertensos, cujo controle causa grande impacto na incidência daquelas enfermidades. No entanto, também nesse caso abordagens populacionais devem ser planejadas, já que a redução do consumo de sal diminuiria a prevalência geral de hipertensão e o risco de doenças cerebrovasculares entre aqueles cujos níveis tensionais situam-se na média ou pouco acima dela, e que portanto não seriam incluídos entre grupos de alto risco. $\mathrm{O}$ 
controle do hábito de fumar, do peso e do consumo de álcool melhorariam ainda mais os resultados (ROSE, 1992)

Inúmeros estudos têm demonstrado não somente que os fatores de risco podem ser modificados na população, mas tambèm que tais modificações levam à redução das taxas de doenças isquêmicas do coração e doenças cerebrovasculares (FARQUHAR, 1990; HJERMAN, 1981; KORNITZER, 1983; PUSKA, 1985). Exemplo de programa populacional de educação em saúde é o da província da Karélia do Norte, na Finlândia, que apresentava uma das maiores taxas de doença coronariana do mundo, na década de 70. Após dez anos de um programa abrangente, que incluiu a substituição de produtos tradicionalmente industrializados por outros mais saudáveis, campanhas educativas através da mídia, e envolvimento do sistema de saúde, observou-se redução da prevalência dos principais fatores de risco e também diminuição da mortalidade por doença coronariana da ordem de $24 \%$. Neste mesmo período, o declínio da mortalidade observado na área que serviu como controle foi de apenas $11 \%$ (PUSKA, 1985).

Os autores enfatizam a importância da organização das respectivas comunidades para o sucesso da estratégia, já que um dos efeitos de programas tradicionais, centrados apenas na mudança individual de hábitos e comportamentos, foi o de aprofundar desigualdades sociais. Isto porque à medida que grupos populacionais mais ricos mudaram hábitos $\mathrm{e}$ comportamentos, forte pressão passou a ser exercida sobre outros estratos sociais, no sentido de incrementarem o consumo de produtos pouco saudáveis (BEAGLEHOLE, 1990). Este padrão é repetido em escala internacional, com as indústrias de tabaco, por exemplo, concentrando-se em mercados com grande potencial de consumo, em países menos desenvolvidos.

Contando com a facilidade de atingir uma população cativa, constituída por grupos profissionais específicos, a implantação de programas de "Promoção da Saúde em Ambientes de Trabalho" ("Health Promotion in the Work-Site") ou Programas de Promoção de Saúde Ocupacional ("Occupational Health Promotion Programs") surgiu, nas últimas décadas, como estratégia de prevenção e controle dos principais agravos à saúde. Tais programas consistem de atividades custeadas ou apoiadas por empresas, que visam "promover a saúde e o bemestar dos funcionários", e sua racionalidade apoia-se no fato de existirem "fortes evidências das ciências biomédicas e de experiências passiveis de crédito" do poder das organizações de 
trabalhadores em influenciar mudanças de comportamento (GLASGOW \& TERBORG, 1988; ALDERMAN, 1993).

De acordo com Glasgow \& Terborg (1988), a criação dos Programas de Promoção da Saúde em Ambientes de Trabalho foi motivada em larga medida, pelos altíssimos custos com assistência à saúde, U\$387,4 bilhões em 1984, dos quais U\$107,2 bilhões foram pagos por empresas. Além disso, os custos da doença incluem ainda aqueles indiretos, representados pela perda de produtividade: absenteísmo, rotatividade e desempenho reduzido. Assim, do ponto de vista das empresas, que arcam ainda com os custos relativos à aposentadoria precoce e morte, as vantagens destes programas incluem, além da economia com assistência médica, também a produtividade aumentada, moral elevada dos funcionários, melhor seleção e manutenção de mão de obra qualificada, e melhor imagem corporativa. Do ponto de vista dos funcionários, as principais vantagens parecem incluir acesso facilitado ao programa, custo reduzido e oportunidade de participar com os colegas no programa, o que traz maior suporte social à mudança de comportamento.

Os programas de detecção, tratamento e seguimento de hipertensão arterial têm representado uma das áreas mais estudadas no campo da promoção de saúde ocupacional. Isto porque aquela é uma condição freqüente na população economicamente ativa: de acordo com Fielding (1984), ocorre em 15-25\% dos trabalhadores norte-americanos. Esta prevalência é ainda mais alta em empresas que contam com alta proporção de homens mais idosos, especialmente se uma grande proporção for constituída por negros. De acordo com publicação do National Heart, Lung and Blood Institute (1981), a prevalência de hipertensão em trabalhadores homens e brancos, entre 55 e 64 anos, é de $42 \%$, comparados com $59 \%$ em homens negros da mesma faixa etária. Se, por um lado, o risco de hipertensão arterial é alto na população trabalhadora, as complicações associadas, em geral, ainda não ocorreram, o que torna este grupo um alvo extremamente importante para programas de prevenção e controle. A hipertensão arterial é considerada portanto, por alguns autores, como o fator de risco com maior potencial de modificação para a doença coronariana e outras doenças cardiovasculares (GLASGOW \& TERBORG 1988).

Apesar dos inúmeros estudos realizados, não há consenso a respeito de critérios para avaliação dos programas. Isto porque existem inúmeros modelos de avaliação, os resultados são extremamente sensíveis às definições do nível de controle de pressão arterial atingido, dos critérios de custo do tratamento, do impacto sobre as complicações, efeitos sobre o 
absenteísmo e custos da doença coronariana e cerebrovasculares. Mesmo assim, os autores sugerem que, de maneira geral, os programas de detecção e controle de hipertensão arterial implantados em locais de trabalho apresentam melhores resultados do que os programas ambulatoriais, do ponto de vista de custo-efetividade, e da redução de complicações cardiovasculares (ALDERMAN, 1983; RUCHLIN, 1984). O custo anual da assistência oferecida fora do ambiente de trabalho, para tratamento e seguimento do hipertenso parece ser de U\$175 a U\$250, em média (FIELDING, 1982). Por outro lado, levantamento citado por FIELDING (1982), realizado na Companhia Ford de Motores, revelou que o custo do primeiro ano do Programa de deteç̧ão, referência, seguimento e monitoramento foi de U\$14.59 por trabalhador e de U\$37.34 por trabalhador hipertenso. No mesmo estudo, o custo anual do tratamento do funcionário, na empresa, foi de U\$96.19.

Quatro tipos diferentes de programas anti-fumo foram avaliados: intervenções com ajuda individual, aconselhamento médico, grupos que atuam através de técnicas comportamentais e procedimentos de prêmio/competição. Os programas baseados em folhetos educativos e otros materiais, para uso individual, parece produzirem baixas taxas de abandono inicial, mas bons resultados na manutenção da abstinência daqueles que conseguiram deixar o hábito. $\mathrm{O}$ aconselhamento médico parece ser pouco eficiente na mudança de hábito, embora seja possível atingir um grande número de trabalhadores através desta estratégia. Apenas cerca de $5 \%$ a $10 \%$ dos trabalhadores que recebem aconselhamento mantém a abstinência por longo período. Os programas baseados em técnicas de comportamento, que são realizados em grupo, produzem altas taxas de abandono inicial do tabagismo (30\% a 40\%), mas têm como desvantagem o pequeno número de participantes. Kledges (1986), aponta "resultados encorajadores" nos programas baseados em prêmios e competição embora não tenha utilizado grupo controle, nem confirmado seus resultados através de exames bioquímicos, o que seria necessário já que a declaração de abandono do hábito de fumar implicava, nestes casos, em recompensa financeira. Estes e outros problemas metodológicos são apontados pelos autores que, como no caso da hipertensão arterial, apontam fragilidades na avaliação dos resultados dos Programas anti-fumo.

A prática regular de exercícios físicos tem sido associada à redução do absenteísmo, sensação de melhor desempenho profissional e menor utilização de serviços de saúde (HEINZELMANN, 1970; BROWNE, 1984). Apesar disto, esta prática, realizada dentro ou fora do ambiente de trabalho, apresenta dificuldades semelhantes: participação e manutenção da atividade. Alguns estudos apontam que a proporção de trabalhadores que se engajam 
nestes programas não tem sido diferente da parcela da população em geral que pratica exercícios, entre 15\% e 40\% da população (GLASGOW \& TERBORG, 1988). Além disso, ao compararem aqueles que se engajam em programas de exercícios físicos no ambiente de trabalho com os que não se engajam, alguns autores encontraram diferenças importantes: os que participam, parecem ser mais ativos em sua rotina, ter hábitos de menor risco para a saúde, apresentar melhor desempenho profissional, menor absenteísmo e utilização menos freqüente dos serviços de saúde (BAUN, 1986). Esta menor participação de indivíduos que apresentam maior risco e também a inexistência de estudos que comparem resultados de programas implantados no ambiente de trabalho com programas externos, indicam a necessidade da busca de novas estratégias e de novas investigações.

Estudos de custo-efetividade sugerem que estratégias de controle de peso no ambiente de trabalho podem ser mais econômicas do que programas externos (BROWNELL, 1984). Tais estratégias são baseadas em técnicas de mudança de comportamento, e resultados positivos foram também alcançados através de incentivos financeiros e competições entre grupos de trabalhadores (ABRAMS \& FOLICK, 1983; BROWNELL, 1984). Embora os programas tenham apresentado bons resultados do ponto de vista da perda de peso, o retorno a antigos hábitos de alimentação e de vida sedentária ainda representa grande desafio. Autores apontam a necessidade de pesquisas adicionais a respeito dos motivos de abandono dos programas, bem como ênfase nas técnicas baseadas em grupos de trabalhadores e na discussão do tipo de alimento oferecido para lanches rápidos e refeições (GLASGOW \& TERBORG, 1988).

Além dos programas voltados para fatores de risco específicos, experiências com estratégias abrangentes, voltadas para o "bem-estar", através do controle dos fatores de risco mais importantes, são também relatadas. Os autores citam particularmente os programas implantados nas empresas Johnson \& Johnson e Controldata (BLAIR, 1986; GLASGOW \& TERBORG, 1988). Na primeira, um estudo quasi-experimental foi utilizado, no qual o programa completo foi oferecido a todos os trabalhadores de quatro filiais, enquanto em outras três, foi realizado apenas um diagnóstico de saúde. O programa completo consistia do diagnóstico das condições de saúde, e atividades de exercício físico, controle de peso, nutrição, anti-fumo, manejo de "stress", controle de hipertensão e uso de álcool. Após o primeiro ano do programa, os participantes das filiais onde o programa completo estava disponível apresentavam melhores resultados nos níveis de aptidão física, perda de peso, abandono do fumo, episódios de doença, satisfação com o trabalho e auto-estima do que as 
filiais usadas como controles. Após dois anos de duração do programa, também apresentaram melhores resultados em relação à velocidade máxima de $\mathrm{O}_{2}$, medida de capacidade cárdiorespiratória, associada a reduções de peso, proporção de gordura corporal e pressão sistólica.

Apesar da vasta literatura que fala a respeito dos Programas de Promoção da Saúde no Ambiente de Trabalho e seus bons resultados, existem também autores como Gardell (1982) que, embora reconheçam a utilidade destas estratégias em "casos individuais", salientam que a "prevenção do stress deve lidar com seus efeitos no nivel individual assim como com as possíveis causas de stress no nível coletivo ou da organização do trabalho". De acordo com esta autora, é costume transformar-se problemas no ambiente de trabalho, que dizem respeito ao conjunto de indivíduos, em problemas particulares, pressionando cada um a adaptar-se. Assim, mais importante do que programas que visam mudanças de hábitos e comportamentos, seria o reconhecimento daqueles aspectos da tecnologia e da organização do trabalho que podem constituir importantes causas de stress. Aponta a participação dos trabalhadores na decisão a respeito de métodos e equipamentos de trabalho, no uso de certos tipos de produtos e na política de recursos humanos como formas de organizar e revitalizar a vida na empresa. Não podemos deixar de lembrar que o ponto de vista desta autora está de acordo com o comportamento da maior parte das doenças que, ao longo da história, não foram prevenidas através da identificação e tratamento dos doentes, mas através da modificação dos fatores ambientais que favoreciam sua ocorrência (CASSEL, 1976).

Parece-nos de suma importância que estas diversas posições sejam reconhecidas em nosso meio, onde a implantação de programas de promoção da saúde no ambiente de trabalho já seria positiva, dada a ausência quase absoluta de atividades preventivas, mas onde recursos deveriam ser investidos também na identificação e modificação dos fatores psico-sociais relacionados à determinação das enfermidades.

\section{5- PESQUISA DE SAÚDE DOS ASSOCIADOS DA CASSI}

As atividades de pesquisa patrocinadas pela CASSI (Caixa de Assistência dos Funcionários do Banco do Brasil) e pela PREVI (Caixa de Previdência dos Funcionários do Banco do Brasil) tiveram início através do Estudo de Mortalidade dos Funcionários do Banco do Brasil. Para realizá-lo, foi reunido um grupo de funcionários do banco, com formação 
superior na área de saúde ou ciências sociais, que passaram a integrar o Grupo Técnico CASSI-Pesquisas Epidemiológicas, assessorados por um demógrafo e uma epidemiologista.

O Estudo de Mortalidade revelou que as doenças cardiovasculares representaram, entre 1977 e 1990, a primeira causa de morte nos funcionários do sexo masculino, com $38 \%$ do total de óbitos, enquanto nas funcionárias, situaram-se em terceiro lugar, representando $18 \%$ do total (GRUPO TÉCNICO CASSI-PESQUISAS EPIDEMIOLÓGICAS, 1992). Entre os homens, as mortes por doenças cardiovasculares foram causadas principalmente pelas doenças cerebrovasculares até os 29 anos, e a partir desta idade, pelo infarto agudo do miocárdio. No caso das mulheres, as doenças cerebrovasculares representaram a principal causa de morte cardiovascular. Comparada à mortalidade da população norte-americana, em 1983, observou-se excesso de óbitos devidos às doenças cerebrovasculares entre os funcionários do sexo masculino (Razão Proporcional de Mortalidade= 1,43; intervalo de confiança de 1,30 a 1,56). Tornou-se evidente portanto, através daquele estudo, que as causas cardiovasculares constituíram o grupo de maior magnitude, consumindo grande parte dos recursos de ambas as Caixas dos funcionários "através de internações em Centros de Tratamento Intensivo, exames sofisticados e cirurgias complexas". Assim, "programas com objetivo de reduzir a morbi-mortalidade por doenças cardiovasculares, provavelmente seriam aqueles de maior impacto... tanto para os bancários como para a CASSI e a PREVI" (GRUPO TÉCNICO CASSI-PESQUISAS EPIDEMIOLÓGICAS, 1992).

No caso particular da CASSI, tem havido já há alguns anos um movimento no sentido de racionalização de gastos, reorientação administrativa, programação e planejamento de ações, de modo a permitir um melhor aproveitamento dos recursos disponíveis, bem como a melhoria da qualidade dos serviços prestados. O paradoxo "recursos finitos versus demanda sem limites", que está na ordem do dia não só no Brasil mas também nos países desenvolvidos, trouxe a necessidade premente da identificação do perfil de saúde, bem como do padrão de utilização de serviços pelos funcionários, de modo a subsidiar em bases técnicas, o gerenciamento dos recursos da CASSI (PESQUISA DE SAÚDE DOS ASSOCIADOS DA CASSI, 1996).

Além disso, vive-se hoje o "dilema do terceiro pagador", no qual existe uma separação entre o indivíduo que demanda o serviço, o que presta o serviço e o que paga. Ao primeiro, interessa receber a maior quantidade e melhor qualidade de serviços; ao prestador, interessa 
maximizar o fornecimento; e ao pagador, só resta arcar com as despesas, eventualmente auditorando possiveis fraudes por parte dos outros dois.

Após a identificação dos principais agravos do ponto de vista da mortalidade e tendo em vista a necessidade de obter subsídios técnicos para a racionalização da prestação de serviços, a oportunidade do estudo das condições de saúde através da morbidade e fatores de risco tornou-se evidente. Desta forma, a Pesquisa de Saúde dos Associados da CASSI foi idealizada, com o objetivo de traçar o perfil de morbidade referida e prevalência dos fatores de risco das doenças cardiovasculares, bem como do padrão de utilização dos serviços de saúde, entre os funcionários das carreiras administrativa e técnica do Banco. A única carreira excluída foi a de apoio, constituída por contínuos, que conta apenas com cerca de 1500 funcionários em todo o país e está em extinção. Tal exclusão foi motivada principalmente pela impossibilidade de esses funcionários responderem ao questionário sem a ajuda de um entrevistador, já que seu ingresso no banco não exigia nenhum grau de escolaridade, nem ocorria através de concurso público. Desta forma, considerou-se que o pequeno número de funcionários de apoio não justificaria a mudança de estratégia de aplicação da pesquisa, do questionário auto-preenchido para entrevista, e nem a adoção de estratégia diferente para este grupo, o que dificultaria a comparação dos resultados entre os dois grupos.

Idealizada a princípio para ser aplicada em amostra de funcionários das carreiras administrativa e técnica, ativos em todo o pais, a Pesquisa de Saúde dos Associados da CASSI, foi realizada apenas no Estado do Rio de Janeiro, numa primeira fase. Os funcionários que participaram do estudo foram selecionados por um processo de amostragem probabilística, cujo tipo específico variou segundo o estrato. Estes estratos foram definidos em função dos três tipos de dependências existentes no Banco do Brasil, com características funcionais distintas. Na Direção Geral e outros órgãos estão os setores de decisão da Empresa e setores correlatos; nos Centros de Processamento de Serviços e Comunicações (CESEC), realiza-se o trabalho interno, de compensação de cheques e outros; nas Agências, o público é atendido. Nos dois primeiros estratos, uma amostra aleatória simples dos funcionários foi selecionada, enquanto as agências foram agrupadas segundo o tamanho da cidade em que estão localizadas, sendo o delineamento amostral do tipo conglomerado em dois estágios. Assim, a amostra foi dimensionada visando obter estimativas das características de interesse, de forma independente, para cada um dos estratos (Tabela I.5.1) (vide ítem II.5). 
TABELA I.5.1

NÚMERO DE DEPENDÊNCIAS E FUNCIONÁRIOS ATIVOS PESQUISA DE SAÚdE DOS ASSOCIADOS DA CASSI

\begin{tabular}{l|cc|cc}
\hline \multirow{2}{*}{ TIPO } & \multicolumn{2}{|c|}{ DEPENDÊNCIAS } & \multicolumn{2}{c}{ FUNCIONÁRIOS } \\
\cline { 2 - 5 } & POPULAÇÃO & AMOSTRA & POPULAÇÃO & AMOSTRA \\
\hline DIREÇÃO GERAL & 13 & 13 & 1174 & 599 \\
CESEC & 11 & 11 & 3283 & 671 \\
AGÊNCIA GRANDE & 74 & 10 & 5062 & 662 \\
AGÊNCIA MÉDIA & 57 & 15 & 1865 & 622 \\
AGÊNCIA PEQUENA & 10 & 10 & 121 & 121 \\
\hline TOTAL & 165 & 59 & 11505 & 2675 \\
\hline
\end{tabular}

Nesta tese, apenas os dois primeiros estratos -Direção Geral e Cesec- foram incluídos, tendo em vista os objetivos expostos a seguir. 


\section{6- OBJETIVOS}

\section{GERAL}

Estimar a prevalência e descrever a distribuição dos principais fatores de risco para doenças cardiovasculares em amostra de funcionários ativos na Direção Geral e Centros de Processamento de Serviços e Comunicações (CESEC) do Banco do Brasil, no Estado do Rio de Janeiro.

\section{ESPECÍFICOS}

1. Estimar a prevalência de comportamentos associados ao maior risco de ocorrência das doenças cardiovasculares como hábito de fumar; frequência de consumo de bebidas alcoólicas; dieta rica em colesterol, gorduras saturadas e sal; sedentarismo. e história familiar por sexo e idade na população-alvo.

2. Estimar a prevalência de outros fatores de risco como sobrepeso/obesidade; hipertensão arterial e hipercolesterolemia por sexo e idade na população-alvo.

3. Identificar padrões de ocorrência simultânea dos fatores de risco para doenças cardiovasculares.

1. Identificar características demográficas e sócio-econômicas de sub-grupos da população classificados de acordo com a ocorrência dos fatores de risco.

;. Identificar o nível de conhecimento da população a respeito dos principais fatores de risco para as doenças cardiovasculares.

Sugerir o planejamento de ações de assistência e controle das doenças cardiovasculares, bem como de promoção da saúde no ambiente de trabalho. 
CAPÍtulo II MÉtodos 


\section{1- POPULAÇÃO DE ESTUDO}

O Banco do Brasil foi criado em 1808 para desempenhar o papel de instrumento do governo para a execução da política econômico-financeira. $O$ histórico da empresa pode ser resumido em três períodos (SILVA FILHO, 1993):

1808-1930 - Criação da empresa e esforços no sentido de seu estabelecimento. A estrutura de poder e padrões de relação de trabalho são definidos nesse período.

1930-1964 - Grandes mudanças na história do País e conquistas de direitos dos funcionários.

1964-1995 - Transformações macro-econômicas e políticas que afetam a atuação da empresa. Profundas alterações nas relações de trabalho.

A imagem que o Banco possui como bom empregador transformou o processo de seleção e recrutamento num dos aspectos mais marcantes da política de recursos humanos. $\mathrm{O}$ ingresso no Banco do Brasil só é possível através de concurso público, que é considerado difícil e é também bastante disputado, fazendo com que os aprovados apresentem bom nível de qualificação. Muitos dos funcionários desistiram de outras aspirações profissionais em troca da estabilidade e bons salários que caracterizavam a tradição da empresa.

A partir da década de 70 , os bancos começaram a desenvolver todas as atividades típicas do setor financeiro, o que exigiu a centralização do processo administrativo com ênfase na padronização de rotinas e atividades. As tarefas, antes realizadas manualmente, passam a ser automatizadas. De acordo com Silva Filho (1993), “O bancário tradicional, detentor de conhecimentos de contabilidade e outros tantos, torna-se minoritário nas agências, onde aparece um novo e numeroso contingente de trabalhadores de quem são exigidos menores conhecimentos".

O Projeto Novo Rosto do Banco do Brasil, de 1990, foi o marco da mudança de comportamento no Banco. Este preconizava grande redução do quadro de funcionários e implementou definitivamente princípios de competitividade e produtividade: "Vamos ter que desenvolver nossa capacidade de correr atrás da captação. Vamos ter que melhorar nosso atendimento. Vamos transformar a agência em balcão de venda de produtos, tradicionais ou não" (Silva Filho, 1993). 
É neste contexto que as condições de saúde dos funcionários do Banco foram avaliadas: grandes transformações nas relações de trabalho e principalmente nas expectativas dos funcionários em relação a seu futuro profissional. O período da coleta de dados antecedeu o Programa de Demissão Voluntária do Banco, do qual já se ouvia falar com frequência em várias dependências

\section{2- DELINEAMENTO DO ESTUDO E POPULAÇÃO-ALVO}

Trata-se de estudo seccional, cuja população-alvo foi constituída pelos funcionários em atividade nos Centros de Processamento e Serviços de Comunicações (CESEC) e órgãos da Direção Geral, no Estado do Rio de Janeiro, no ano de 1994. As carreiras administrativa e técnica foram incluídas, sendo a primeira composta pelos "bancários" propriamente dito ou seja, pelas atividades-fim da empresa, cujo ingresso ocorre exclusivamente através de concurso público. A carreira técnica é integrada por profissionais de nível superior que exercem suas funções específicas como engenheiros, médicos e advogados. A carreira de apoio, constituída por contínuos, foi portanto a única excluída (ver ítem I.5).

\section{3- OS INSTRUMENTOS}

\section{a- O Questionário e sua aplicação}

O questionário foi testado através de estudo piloto, em 114 funcionários da agência e do CESEC São Cristovão, cerca de um ano e meio antes do início do trabalho de campo, em abril de 1993. Com base nos problemas então detectados, chegou-se ao formato final do instrumento. As principais modificações realizadas no questionário estiveram relacionadas a seu formato, já que esta foi a queixa principal dos respondentes. Assim, reformulamos completamente a disposição das perguntas, distribuindo-as de forma a tornar a leitura e o preenchimento mais agradáveis. Além disso, questões relativas ao consumo alimentar, qualidade de vida e trabalho foram também reformuladas.

Os dados foram coletados através de questionário preenchido pelo próprio funcionário, com a ajuda de aplicadores treinados. Antes de responder ao questionário, um 
"Termo de Consentimento para Participação em Pesquisa Científica" (Anexo 1) foi apresentado ao funcionário, onde se esclarecia que sua participação não era obrigatória, e que no caso de participar, sua identificação através de nome e matrícula também era voluntária.

Dois questionários separados foram aplicados: o primeiro, para ser respondido pelo conjunto dos funcionários, de ambos os sexos; o segundo, contendo questões relativas à saúde feminina, a serem respondidas apenas pelas mulheres.

As seções do questionário geral abrangem os seguintes temas:

\section{QUADRO II.3.1 \\ SEÇÕES DO QUESTIONÁRIO GERAL}

\begin{tabular}{|l|l|}
\hline SEÇÃO 1 & SOCIO- DEMOGRÁFICA \\
SEÇÃO 2 & USO DOS SERVIÇOS DE SAÚDE \\
SEÇÃO 3 & FATORES DE RISCO \\
SEÇÃOO 4 & PROBLEMAS DE SAÚDE \\
SEÇÃO 5 & QUALIDADE DE VIDA \\
SEÇÃO 6 & PERFIL FUNCIONAL \\
SEÇÃOO 7 & PERFIL ECONÔMICO \\
SEÇÃO 8 & DEPENDENTES E BENEFICIÁRIOS \\
SEÇÃOO 9 & INFORMAÇÕES FINAIS \\
\hline
\end{tabular}

O "questionário da mulher" abrangeu questões relativas à história ginecológica, uso de métodos contraceptivos e prevenção do câncer ginecológico.

\section{b-Medidas Diretas}

Embora, no teste piloto, praticamente todos os respondentes tenham declarado que conheciam suas medidas de pressão arterial, peso e estatura, e tenham registrado seus valores (o que era esperado, já que o exame periódico legalmente obrigatório, vinha sendo realizado anualmente), procedemos à validação destas informações. Esta verificação foi realizada através de duas medidas de pressão arterial, e uma medida de peso e estatura, durante o preenchimento do questionário, em uma sub-amostra dos respondentes. Esta sub-amostra foi escolhida entre os funcionários sorteados para participar do estudo, em dependências selecionadas de forma intencional. Assim, não realizamos novo sorteio para a escolha dos funcionários submetidos às medidas diretas, que foram obtidas em quatro dependências Agência Centro, Cesec Centro, Direção Geral e Agência Ilha do Governador- onde o número 
de respondentes e as condições necessárias para a tomada das medidas foram consideradas adequadas. Nessas dependências, buscamos realizar as medidas na maior quantidade possível de respondentes, em igual número de mulheres e homens, e também em menores e maiores de 40 anos de idade. As medidas objetivas foram registradas em formulário próprio (Mapa da Pressão Arterial - Anexo 2).

\section{b.1-Medida da Pressão Arterial}

Os níveis de pressão arterial sistólica e diastólica foram determinados com o auxílio de estetoscópios e esfingmomanômetros de coluna de mercúrio, com manguito apropriado para medidas em adultos (de 26 por $12 \mathrm{~cm}$ ), construídos pela coordenação do Estudo Multicêntrico de Hipertensão Arterial no Brasil, já utilizados em outras pesquisas epidemiológicas no país (KLEIN, 1985; KLEIN, 1992). Os esfigmomanômetros originais eram de procedência nacional, da marca Ofitec, e foram modificados na oficina de reparos do CEMEq (INAMPS), no Rio de Janeiro. Tais modificações tiveram como objetivo reduzir a possibilidade de erros do observador, tais como "previsão" dos níveis tensionais baseados na idade, sexo e peso do examinado; aproximação para medidas tidas como normais; preferência por determinados niveis tensionais; variações na velocidade de inflação e desinflação do manguito (KLEIN, 1992).

As alterações do esfigmomanômetro consistiram na substituição da válvula por outra que obstrui a saída de ar do manguito ao ser abandonada pela mão do examinador, e na aceleração constante de desinflação do manguito. A velocidade média de desinflação entre 200 e $100 \mathrm{mmHg} / \mathrm{s}$ é de $2,7 \mathrm{mmHg} / \mathrm{s}$, e entre 100 e $30 \mathrm{mmHg}$ é de $1,3 \mathrm{mmHg} / \mathrm{s}$. Além disso, a escala de leitura foi substituída por uma placa de acrílico de cor azul escuro, com os números correspondentes à graduação vazados sobre um filme de raio- $X$, colado na parte posterior da placa. Em um ambiente com iluminação normal, a visualização dos números só é possível quando é acionado um sistema de iluminação, através da pressão de um botão. Para acioná-lo é preciso soltar uma das mãos da válvula do manguito, interrompendo assim a desinflação. A escala graduada permite fazer leituras com discriminações mínimas de 2 $\mathrm{mmHg}$.

O examinador sentou-se em posição oblíqua à do indivíduo observado, diante de seu braço esquerdo. $\mathrm{O}$ antebraço esquerdo do observado foi totalmente apoiado sobre uma mesa, semi-fletido, na altura do coração. O braço estava tão despido quanto possível, de forma a 
permitir que a margem inferior do manguito ficasse cerca de $3 \mathrm{~cm}$ acima da prega do cotovelo. O examinador palpou a artéria umeral na região antecubital, colocando ai o cabeçote do estetoscópio. $\mathrm{O}$ manguito foi inflado até que a coluna de mercúrio atingisse a marca de $200 \mathrm{mmHg}$. Se, neste ponto, os sons de Korotkow ainda fossem audíveis, o manguito era inflado até a pressão máxima do aparelho, $260 \mathrm{mmHg}$. A partir daí, começavase a desinflação do manguito, pela abertura da válvula.

O valor da sistólica correspondeu ao segundo batimento regular, com um intervalo aproximado de até um segundo desde o primeiro, e o valor da diastólica correspondeu à fase $\mathrm{V}$ dos sons de Korotkow (ponto em que desaparecem os sons). Os registros foram feitos em milímetros, aproximando-se para o valor mais próximo indicado pela escala graduada, o que significa que os valores registrados têm dígitos terminais pares $(0,2,4,6$ e 8$)$.

\section{b.2-Medida do Peso}

O peso dos examinados foi identificado através de balanças portáteis, microeletrônicas, da marca Filizola, cedidas pela Unidade de Atendimento Germano Sinval Faria da Escola Ncional de Saúde Pública/FIOCRUZ. A balança foi colocada em local rígido e plano, e o indivíduo foi pesado sem sapatos, sem agasalhos e com bolsos vazios. A medida foi registrada em quilos, com precisão de $100 \mathrm{~g}$.

\section{b.3-Medida da Estatura}

A estatura dos indivíduos foi determinada através de antropômetros da marca Stanley, de procedência francesa, cedidos também pela Unidade de Atendimento Germano Sinval Faria da Escola Ncional de Saúde Pública/FIOCRUZ. Estes instrumentos foram fixados à parede, de acordo com as especificações de uso, informadas durante o treinamento dos examinadores, descrito a seguir. A precisão foi da ordem de 1 centímetro.

\section{b.4- Medida da Circunferência do Braço}

Com a finalidade de avaliar as vantagens do ajuste das medidas de pressão arterial segundo a circunferência do braço, essa medida foi realizada, já que dispúnhamos apenas de um tamanho de manguito. Para isso, utilizamos fita métrica comum, cortada ao meio, com 
comprimento de $75 \mathrm{~cm}$. Mediu-se a distância média entre o acrômio e o olecrânio, e neste ponto, a leitura da circunferência foi realizada, e registrada em centímetros.

\section{4- SELEÇÃO E TREINAMENTO DE APLICADORES E EXAMINADORES}

\section{a-Aplicadores}

A aplicação do questionário foi realizada por quatro bancários que faziam parte do Grupo de Trabalho CASSI-Pesquisas Epidemiológicas, por qutro bancários que constituiam o Grupo de Trabalho CASSI-Terceira Idade, e por cinco alunos do Curso de Especialização em Saúde Pública da Escola Nacional de Saúde Pública. O treinamento, coordenado pelos assessores da pesquisa, foi realizado durante oito horas, nas quais o "Manual do Aplicador" foi lido, já que continha objetivos e metodologia da pesquisa; informações sobre o questionário; termo de compromisso com o sigilo das informações e tarefas do aplicador. Estas tarefas consistiam em entregar o Termo de Consentimento para Participação em Pesquisa ao funcionário, solicitar sua leitura, e fornecer o questionário, no caso do funcionário concordar em participar. Além disso, deveria também estar disponível durante o preenchimento, para o esclarecimento de dúvidas a respeito das perguntas.

A segunda parte do treinamento consistiu no preenchimento do questionário pelos aplicadores que receberam, por escrito, nome, idade, dependência em que trabalhava, história de doenças e outras características fictícias, para que pudessem respondê-lo como se fossem quaisquer funcionários. Ao final do treinamento, solicitou-se a assinatura de um Termo de Sigilo do Aplicador, onde concordavam em não divulgar as informações, não fornecer cópias, e não manusear em público os questionários (Anexo 3).

\section{b- Examinadores}

O grupo de examinadores foi constituído por três médicos e uma enfermeira para a medida da pressão arterial e circunferência do braço, e duas pesquisadoras da Escola Nacional de Saúde Pública (uma estatística e uma assistente-social) para a medida de peso e altura.

O treinamento, coordenado pela autora deste trabalho, consistiu na aplicação de sessões de adestramento e simulação adequadas a cada tipo de medida. Para a pressão arterial, 
iniciamos com a exibição de um vídeo, elaborado pelo Núcleo de Tecnologia de Ensino da Universidade Federal do Rio de Janeiro, no qual o esfigmomanômetro utilizado é apresentado, e uma série de 10 leituras deve ser realizada por cada treinando. Os resultados são então comparados a um gabarito (duração de uma hora). Após esta sessão, foram distribuídas aos examinadores fitas para gravador com o treinamento idealizado por Geoffrey Rose, que simula sons de Korotkow. A técnica consiste em utilizar cronômetros para medir os intervalos de tempo decorridos entre um som, que marca o início da desinflação, e os pontos correspondentes à sistólica e à diastólica. A fita contem duas séries de 12 gravações, uma de treinamento e a outra de teste. Os resultados obtidos pelos treinandos na série de treinamento são comparados a um gabarito padrão. Já o gabarito da série de teste só é conhecido pelo instrutor, para que este possa avaliar, por meio das médias das diferenças, se o treinando pode realizar as medidas adequadamente.

$\mathrm{O}$ treinamento das medidas de peso, altura e circunferência do braço foi realizado através de um sistema de padronização (HABICHT, 1974). Este consiste na execução de duas medidas de cada sujeito observado, com intervalo mínimo de 15 minutos. Ao realizar a segunda medida, o treinando não tem acesso ao registro da primeira, e ambas são comparadas às medidas de um instrutor, que servem como padrão. As diferenças entre a primeira e a segunda medida de cada treinando, avaliam a "precisão" ou confiabilidade, enquanto as diferenças em relação às medidas do instrutor avaliam a "exatidão" ou validade.

\section{5- DELINEAMENTO AMOSTRAL}

O plano amostral adotado levou em consideração o fato de que se desejava obter estimativas das características de interesse para cada um dos tipos de dependência -Direção Geral e Cesec's- constituindo-se dessa forma duas amostras independentes.

A precisão teórica, desejada das estimativas, foi estabelecida na ordem de $4 \%$, com nível de confiança de $95 \%$. Tendo-se em conta o desconhecimento da variabilidade das principais características populacionais a serem investigadas, e ainda que se desejava proceder à estimação de proporções, na maioria dos casos, o dimensionamento da amostra foi realizado considerando-se a situação mais desfavorável, em que a prevalência de "sucessos" e "não sucessos" é igual a 50\%. O tamanho da amostra foi então calculado, para cada estrato, 
considerando-se o estimador proporção, que é aquele que se deseja obter, na maioria das vezes (LEVY \& LEMESHOW, 1989):

$$
\begin{aligned}
& \mathrm{n}=\frac{z^{2} p(1-p)}{d^{2}}=600 \\
& \text { onde } \mathrm{z}=1,96 \\
& \mathrm{p}=\text { prevalência de sucessos } \\
& \mathrm{d}=0,04=\text { precisão da estimativa }
\end{aligned}
$$

\section{CESEC}

Existem 11 Cesec's no Estado do Rio de Janeiro, dos quais uma amostra sistemática dos 3283 funcionários, ordenados por sexo, foi selecionada. Assim, os 662 funcionários sorteados equivalem a fração amostral de $20 \%$ (Quadro II.5.1 e Anexo 4).

\section{Órgãos da Direção Geral}

Nos 13 órgãos restantes, de Direção Geral e outros, dimensionou-se também uma amostra sistemática de 600 funcionários, dentre os 1162 ativos, também ordenados por sexo (fração amostral de 50\%) (Tabela II.5.1 e Anexo 4).

TABELA II.5.1

NÚMERO DE DEPENDÊNCIAS E FUNCIONÁRIOS ATIVOS

\begin{tabular}{l|cc|cc}
\hline \multirow{2}{*}{ TIPO } & \multicolumn{2}{|c|}{ DEPENDÊNCIAS } & \multicolumn{2}{c}{ FUNCIONÁRIOS } \\
\cline { 2 - 5 } & POPULAÇÃO & AMOSTRA & POPULAÇÁO & AMOSTRA \\
\hline DIREÇÃO GERAL & 13 & 13 & 1174 & 599 \\
CESEC & 11 & 11 & 3283 & 671 \\
\hline TOTAL & 24 & 24 & 4457 & 1270 \\
\hline
\end{tabular}




\section{6- PONDERAÇÃO DOS ESTIMADORES}

Em função das diferentes frações amostrais em cada tipo de dependência, os estimadores foram corrigidos por fator de expansão (inverso da fração amostral) sempre que os resultados referentes aos dois estratos -Direção Geral e Cesec- foram adicionados (Tabela II. 6.1). O fator de expansão foi utilizado através do comando "WEIGHT" do Software SPSS for Windows (NORUSIS, 1992).

TABELA II.6.1

FATORES DE EXPANSÃO POR SEXO E DEPENDÊNCIA

\begin{tabular}{l|cc|cc}
\hline \multirow{2}{*}{ VARIÁ VEIS } & \multicolumn{4}{c}{ DEPENDÊNCIAS } \\
\cline { 2 - 5 } & \multicolumn{3}{|c|}{ CESEC } & \multicolumn{2}{c}{ DIREÇÃO GERAL } \\
& HOMEM & MULHER & HOMEM & MULHER \\
\hline POPULAÇÃO ALVO & 1948 & 1335 & 726 & 448 \\
RESPONDENTES & 358 & 289 & 331 & 205 \\
FATOR DE EXPANSÃO & 5,441 & 4,619 & 2,193 & 2,185 \\
\hline
\end{tabular}

\section{7- O TRABALHO DE CAMPO}

Com o objetivo de facilitar a adesão ao estudo, divulgou-se a pesquisa através da distribuição de cartazes e veiculação de seus objetivos nos meios de comunicação internos do Banco (BB-mail).

A coleta de dados foi realizada entre 15 de agosto e 11 de novembro de 1994. Este período foi considerado adequado por estar fora do calendário de férias de fim de ano ou carnaval. Além disso, embora as negociações do dissídio coletivo ocorram nesta época do ano, não houve greve ou qualquer paralisação das atividades normais durante a coleta de dados.

Cada questionário foi identificado por uma etiqueta numerada sequencialmente. Os quatro primeiros dígitos referiam-se ao código da dependência e os outros três, ao número de ordem do indivíduo sorteado na amostra. Para cada questionário foram confeccionadas três etiquetas: uma para o caderno principal, outra para o questionário da mulher, e a terceira para 
lacrar o envelope onde eram colocados os questionários. Cada respondente fechou seu próprio envelope após o preenchimento para evitar o manuseio dos questionários por pessoas alheias à pesquisa, e também para que os funcionários depositassem maior confiança na privacidade e sigilo das informações.

\section{8- DIGITAÇÃO DOS DADOS}

A etapa seguinte consistiu na preparação dos questionários para digitação, o que foi realizado através da marcação das respostas escolhidas pelos respondentes com círculos de caneta vermelha. Tal procedimento foi necessário uma vez que a composição gráfica dos questionários foi desenhada priorizando-se o conforto visual do respondente como prioridade, e não a do digitador.

A digitação foi executada por firma contratada pelo Banco do Brasil, sob supervisão dos bancários integrantes do Grupo de Trabalho CASSI-Pesquisas Epidemiológicas. O programa de entrada de dados, em DBASE, foi simples, e cada linha correspondeu a uma pergunta, ou alternativa múltipla dentro da pergunta. Para maior segurança, realizou-se dupla digitação.

\section{9- CRÍTICA E IMPUTAÇÃO DE DADOS}

A primeira fase da crítica consistiu na comparação entre os dados digitados de forma dupla. O primeiro programa de crítica tratou de identificar discordâncias entre as duas rodadas de digitação, procedendo-se à correção, após consulta ao questionário. Este processo foi repetido pelo menos cinco vezes, num processo de "limpeza", em que cada rodada continha cada vez menos questionários a serem checados manualmente.

Em seguida procedeu-se à avaliação da consistência interna das respostas. Verificavase, por exemplo, se um indivíduo digitado como sendo homem apresentava respostas relativas a partos ou outros tópicos específicos das mulheres. Esta verificação, que relacionou blocos distintos do questionário, também demandou o retorno ao questionário original. A identificação de "outliers" (valores aberrantes) também foi realizada nesta fase, através de estatísticas sumárias, sendo corrigidos sempre que necessário, após consulta ao questionário. 
Todos os procedimentos de crítica foram realizados por seis profissionais, envolvidos na pesquisa ao longo de seis meses

Somente omissões nos campos de identificação (idade, escolaridade e situação conjugal) foram imputados pelo método "hotdeck" (usando-se como controle: lotação, data de admissão ao banco, sexo e demais variáveis demográficas disponíveis). Não houve nenhuma omissão de informação de sexo, enquanto apenas 76 questionários necessitaram de imputação em algum campo de identificação.

\section{0- PACOTES COMPUTACIONAIS UTILIZADOS}

A entrada de dados foi realizada através do programa dBASE IV (MANUAL DE REFERENNCIA, 1988). Crítica e imputação dos dados foram realizadas através do dBASE e EPIINFO (DEAN, 1990), enquanto a análise de dados foi realizada através do SPSS for Windows - Statistical Package for Social Sciences, versão 6.1.2 (NORUSIS, 1992).

\section{1- ANÁLISE DOS DADOS}

\section{a-Validade e Confiabilidade dos Dados}

A adequação do instrumento utilizado (questionário auto-respondido) ao que se desejava medir foi avaliada através da discussão de sua validade e confiabilidade. Validade se refere às diferenças sistemáticas encontradas entre as informações obtidas em resposta às perguntas formuladas e: 1-o significado completo do conceito que as perguntas pretendem expressar (validade de conteúdo); 2-as medidas consideradas "verdadeiras" ou padrão ouro (validade de critério); 3-teorias ou hipóteses sobre a relação das informações obtidas com outros conceitos (validade de constructo) (ADAY,1991). Dentre estes três tipos, a validade de conteúdo foi avaliada através da comparação com outros estudos a respeito das variáveis incluídas e as respectivas dimensões medidas. A validade de critério das informações sobre peso, estatura e pressão arterial foi estudada através da comparação com a medida direta dessas varáveis em uma subamostra de funcionários. 
Confiabilidade se refere à estabilidade de medidas repetidas do mesmo conceito. A confiabilidade do escore, elaborado para o estudo do consumo alimentar, foi avaliada através do Teste Alpha de Cronbach (ADAY, 1991)

\section{b- Definição de Variáveis}

Para efeito de classificação da população de estudo nas diversas categorias das variáveis principais, serão adotadas as seguintes definições:

Informado sobre Hipertensão: indivíduo que tenha respondido à pergunta $\mathrm{n}^{\circ}$ 68: "Algum médico ou outro profissional de saúde já lhe informou que você era hipertenso ou tinha pressão alta?" com uma das duas opções: "sim; mais de uma vez; em dias diferentes" ou "sim, apenas uma vez"; ou indivíduo que declarou ser portador ou ter sido portador de hipertensão arterial (pergunta $\mathrm{n}^{\circ}$ 97); ou indivíduo que declarou estar em tratamento específico para controle de hipertensão arterial (pergunta $n^{\circ} 70$ )

Hipertenso segundo medida direta: O critério de classificação de hipertensão adotado no sub-grupo onde as medidas foram realizadas foi aquele recomendado pela Organização Mundial de Saúde (WHO, 1978): indivíduos cujas pressão sistólica e diastólica sejam iguais ou superiores a 160 ou $95 \mathrm{mmHg}$, respectivamente, durante a segunda medida de pressão ou que tenham declarado estar sob tratamento específico, independente dos resultados obtidos à medida da pressão arterial.

\section{Hábito de Fumar}

- Não fumante: indivíduo que nunca fumou cigarros ou que não chegou a fumar pelo menos cinco carteiras de cigarro, ao longo da vida.

- Fumante: indivíduo que fumou, ao longo da vida, pelo menos cinco carteiras de cigarro e fuma atualmente.

- Fumante leve: indivíduo que admitiu fumar, em média, até 20 cigarros por dia.

- Grande fumante: individuo que admitiu fumar, em média, mais de 20 cigarros por dia. 
- Ex-fumante: individuo que parou de fumar há pelo menos um ano.

Índice de Massa Corporal (IMC) (peso em $\mathrm{kg} /$ estatura $^{2}$ em metros)

- Baixo peso: IMC menor do que $20 \mathrm{~kg} / \mathrm{m}^{2}$

- Normal: IMC igual ou maior do que $20 \mathrm{~kg} / \mathrm{m}^{2}$ e menor ou igual a $24,9 \mathrm{~kg} / \mathrm{m}^{2}$

- Sobrepeso: IMC igual ou maior do que $25 \mathrm{~kg} / \mathrm{m}^{2}$ e menor ou igual a $30 \mathrm{~kg} / \mathrm{m}^{2}$

- Obeso: IMC maior do que $30 \mathrm{~kg} / \mathrm{m}^{2}$

- Sobrepeso e Obeso segundo medida direta: igual ao adotado para a informação contida no questionário.

Atividade Física Regular: praticar atividades fisicas específicas para melhorar a saúde, condicionamento físico ou para fins estéticos pelo menos duas vezes por semana, durante 20 minutos cada vez.

Aqueles que declararam praticar atividades fisicas regularmente foram ainda classificados de acordo com a frequência semanal:

- Pouco Frequiente: praticam entre 2 e 4 vezes por semana

- Moderada: praticam 5 ou 6 vezes por semana

- Muito Freqüente: praticam 7 vezes por semana

\section{Dieta}

As respostas às questões relativas à frequência de consumo de grupos de alimentos (pergunta $n^{\circ} 46$ ) foram resumidas através de um escore, elaborado para possibilitar o agrupamento do indivíduos com hábitos semelhantes, classificando-os de acordo com critérios de risco da dieta (FONSECA, 1996). 
Elaboração do escore:

O consumo de cada grupo de alimentos foi tratado como variável ordinal e recebeu os valores a seguir: zero pontos, quando o individuo informou que não consumia; um ponto, para consumo menor que uma vez por semana; dois pontos, para consumo de uma a três vezes por semana e, finalmente, três pontos, para consumo de quatro ou mais vezes por semana.

$\mathrm{O}$ total de pontos foi obtido somando-se a freqüência de cada indivíduo, nos onze grupos de alimentos considerados de risco para doenças cardiovasculares. Deste total, subtraiu-se o valor da freqüência de verduras, legumes e frutas, pois não são considerados de risco. A freqüência de consumo de verduras, legumes e frutas foi tratada, também, como variável ordinal, tendo recebido valores de zero a três, segundo a freqüência semanal mencionada. O total de pontos assim obtido foi "ponderado" pelo máximo de pontos que cada funcionário poderia ter obtido, de acordo com o consumo máximo (quatro ou mais vezes) dos itens preenchidos. $\mathrm{O}$ escore preliminar foi então obtido através da divisão dos pontos que o indivíduo obteve pelo total possivel no seu caso. Assim, um funcionário que tivesse respondido aos doze itens (onze itens de risco e um item referente a verduras, legumes e frutas) poderia obter um máximo de trinta e três pontos, que resultaria de três pontos (consumo máximo semanal) vezes onze itens, menos os pontos referentes a verduras, legumes e frutas, neste caso, zero, que corresponderia à ausência de consumo. Se, por exemplo, esse mesmo funcionário tivesse obtido 20 pontos em seu consumo alimentar, seu escore preliminar teria sido 20/33. No caso de outro funcionário que tivesse preenchido apenas sete itens, seu total seria calculado tomando-se 21 como denominador. Sendo assim, quanto maior o escore obtido maior o consumo de alimentos de risco.

O escore final, denominado simplesmente escore alimentar, resultou da multiplicação do escore preliminar por 100 .

Escore Alimentar $=\frac{\text { Total de pontos obtidos }}{\text { Maximo de pontos possíveis }} \times 100$ 
Além de ser analisado como variável contínua, o consumo alimentar foi também categorizado, através de pontos de corte estabelecidos segundo os quintis do escore. Os indivíduos situados no primeiro quintil, que apresentavam os menores valores do escore alimentar, são aqueles que apresentavam a dieta mais saudável, enquanto no quinto quintil situam-se aqueles que referiram consumir maior quantidade de gordura saturada, colesterol e sal.

\section{Informado sobre níveis de colesterol sanguíneo:}

- Nunca mediu: aqueles que marcaram esta opção na pergunta $\mathrm{n}^{\circ} 50$

- Informado: aqueles que responderam "sim" à pergunta "Algum médico ou outro profissional de saúde já lhe disse que seus níveis de colesterol no sangue estavam elevados?"

- Não informado: aqueles que responderem "não" à mesma pergunta.

\section{Consumo de bebidas alcoólicas (Pergunta ${ }^{\circ} 60$ )}

- Não bebe: indivíduos que responderam "parei de beber" ou "nunca tomei bebida alcoólica".

- Bebe ocasionalmente: indivíduos que responderam "pelo menos uma vez por mês" ou "menos de uma vez por mês".

- Bebe semanalmente: individuos que responderam "pelo menos uma vez por semana".

- Bebe diariamente: individuos que responderam "diariamente ou quase todo dia".

\section{Conhecimento sobre fatores de risco para doenças cardiovasculares}

- Conhece: indivíduo que respondeu positivamente pelo menos aos seguintes itens: fumar cigarros, hipertensão arterial, estar muito acima do peso, dieta com muita gordura animal, história familiar de doenças do coração e colesterol alto. 


\section{c- Testes Estatisticos e Intervalos de Confiança}

As prevalências e respectivos erros amostrais foram estimados segundo sexo, idade e dependência do banco. As médias de variáveis continuas foram testadas através do teste tstudent, enquanto diferenças entre proporções foram testadas através do teste $\chi^{2}$.

Os intervalos de confiança para proporções foram estimados através da fórmula abaixo, específica para homens e mulheres, quando as prevalências foram estimadas por sexo, ou para o conjunto dos respondentes (LEVY \& LEMESHOW, 1989).

$$
\begin{aligned}
& \text { Intervalo de Confiança }(95 \%)=\mathrm{p}_{\mathrm{y}} \pm \mathrm{z}_{1-\alpha / 2}\left(\frac{N-n}{N}\right)^{1 / 2} \times\left(\frac{p(1-p)}{n-1}\right)^{1 / 2} \\
& \qquad \begin{aligned}
\text { onde: } & \mathrm{N}=\text { população alvo } \\
\mathrm{n} & =\text { respondentes } \\
\mathrm{p} & =\text { proporção estimada } \\
\mathrm{z} & =1,96 \\
\mathrm{p} & =\text { prevalência de sucessos }
\end{aligned}
\end{aligned}
$$

\section{d-Validação das informações fornecidas sobre Pressão Arterial, Peso e}

\section{Estatura:}

A comparação entre as classificações obtidas através da informação do funcionário contida no questionário e da medida direta foi realizada através do coeficiente Kappa (FLEISS, 1981) no caso da hipertensão arterial, e do coeficiente de correlação de Pearson no caso do Indice de Massa Corporal.

\section{e-Análise Multivariada}

Com o objetivo de identificar relações entre os quatro fatores de risco -fumo, consumo de álcool, dieta e sedentarismo- bem como entre eles e a ocorrência de "efeitos" como sobrepeso/obesidade, hipertensão arterial e hipercolesterolemia, utilizamos a Análise de Correspondência Múltipla ou Análise de Homogeneidade. Os softwares utilizados foram uma simplificação do SPAD (Système Portable pour l'Ánlyse des Donnés) (Lebart \& Fénelon, 1973) e também o Módulo "Categories" do Software SPSS for Windows, versão 6.1, que 
apresenta melhor resolução gráfica. Os gráficos obtidos foram ainda aperfeiçoados através do Software Coreldraw, versão 5.0 Photopaint.

As características importantes de um grupo populacional que se pretende apreender através de grandes bancos de dados, como no caso dessa investigação, raramente conseguem ser descritas somente através de estatísticas-resumo e gráficos que apresentam cada variável isoladamente. Essa forma de apresentação dos dados pode ser totalmente insuficiente para revelar padrões importantes de distribuição das variáveis naquele grupo (GREENACRE, 1984). Assim por exemplo, as prevalências isoladas de consumo diário de bebidas alcoólicas e de dieta pouco saudável podem ser baixas em determinada população, mas é possível que justamente os indivíduos que apresentam a primeira característica, sejam aqueles que exibem também a segunda. Para identificar todos os padrões desse tipo, um número excessivamente grande de tabelas $\mathrm{n} \times \mathrm{n}$ seriam necessárias, e todas as possiveis relações entre variáveis teriam que ser levantadas a priori. Técnicas exploratórias, como a Análise de Correspondência Múltipla, permitem que novos padrões sejam revelados, mesmo que não tivessem sido suspeitados anteriormente. A idéia central é agrupar perfis semelhantes de variáveis, de forma a permitir uma visão global dos dados.

Sem pretender uma discussão extensa da técnica utilizada, pretendemos apresentar os tópicos fundamentais cuja compreensão permitiu sua aplicação.

A Análise de Correspondência é especialmente indicada para descrever matrizes com grande volume de dados discretos e positivos, permitindo a visualização gráfica das relações mais importantes de um grande conjunto de variáveis. Tais relações podem ser identificadas através da distância entre as diversas categorias de cada variável, representadas por pontos no gráfico (GREENACRE, 1984; GOUVÊA, 1993).

Cada linha e cada coluna de uma matriz de dados tem um "perfil" ou seja, uma distribuição proporcional aos totais de linhas e colunas. Por exemplo, vejamos uma tabela com apenas duas variáveis: 
TABELA II.11.1

DISTRIBUIÇÃO DO HÁBITO DE FUMAR E DE CONSUMO DE ÁLCOOL

\begin{tabular}{l|c|c|c}
\hline \multirow{2}{*}{ CONSUMO DE ÁLCOOL } & \multicolumn{3}{|c}{ HÁBITO DE FUMAR } \\
\cline { 2 - 4 } DIÁRIO & SIM (PC)* & NÃO (PC)* & TOTAL \\
(PL)** & $24(0,12)$ & $19(0,061)$ & $43(0,084)$ \\
SEMANAL & $(0,56)$ & $(0,44)$ & $(1,00)$ \\
(PL)** & $82(0,41)$ & $88(0,28)$ & $170(0,33)$ \\
\hline OCASIONAL & $(0,48)$ & $(0,52)$ & $(1,00)$ \\
(PL)** & $84(0,42)$ & $160(0,51)$ & $244(0,48)$ \\
\hline NÃO CONSOME & $(0,34)$ & $(0,66)$ & $(1,00)$ \\
(PL)** & $10(0,05)$ & $44(0,14)$ & $54(0,11)$ \\
\hline TOTAL & $(0,19)$ & $(0,82)$ & $(1,00)$ \\
\hline
\end{tabular}

* PC - Perfil de Coluna

** PL - Perfil de Linha

Adaptado de CARVALHO, 1990

Os valores entre parênteses ao lado do número absoluto representam o "perfil" de cada coluna, e os valores abaixo do número, o perfil de cada linha. Cada categoria de cada variável é descrita em função de seu perfil de linha e coluna. Na tabela acima pode-se ler: $12 \%$ dos fumantes consomem álcool diariamente (perfil de coluna), enquanto $56 \%$ daqueles que consomem álcool diariamente são fumantes (perfil de linha).

A representação usual separaria as informações, apresentando por exemplo, as proporções de consumo de álcool entre fumantes e não fumantes, através de gráfícos de barras, e outro gráfico com a distribuição do hábito de fumar em cada categoria de consumo de álcool. A Análise de Correspondência Múltipla, por outro lado, possibilita a visualização simultânea de todas as categorias apresentadas na tabela, evidenciando quais categorias têm maior e menor probabilidade de ocorrerem ao mesmo tempo. Essa representação gráfica 
assume ainda maior importância se imaginarmos o cruzamento de grande número de variáveis, cuja apresentação não seria exequivel através dos métodos usuais

A tradução geométrica da matriz numérica é realizada considerando-se cada categoria de cada variável como um ponto no espaço, sendo a representação de toda a matriz uma "nuvem" de pontos. As distâncias entre os pontos representam as relações entre as variáveis que se deseja analisar e, portanto, é essencial compreender o modelo utilizado para a determinação destas distâncias (GREENACRE, 1981).

A distância entre duas categorias é calculada a partir de seu perfil de coluna "ponderado" por ou levando em consideração o "peso" de cada linha isto é, o quanto o total daquela linha representa sobre o total da matriz. Utilizando ainda a tabela acima, a distância entre as categorias "SIM" e "NÃO" (colunas) da variável HÁBITO DE FUMAR é calculada da seguinte forma (adaptado de CARVALHO, 1990):

1. calcula-se a frequência do "SIM" de cada categoria de consumo de álcool em relação ao total de "SIM", procedendo da mesma forma com o "NÃO" (perfil de coluna): 24/200 = 0,12 para o SIM e $19 / 311=0,061$ para o NÃO entre os consumidores diários. Este procedimento é repetido até que todas as frequências de cada categoria de consumo de álcool tenham sido calculadas em relação ao total de cada coluna.

2. Para cada categoria de consumo de álcool, calcula-se o quadrado da diferença entre os perfis de coluna do SIM e do NÃO: $(0,12-0,061)^{2} ;(0,41-0,28)^{2} ;(0,42-0,51)^{2} ;(0,05-0,14)^{2}$.

3. Cada um dos valores calculados acima é dividido pela frequência total de cada linha: 0,084 para consumidores diários; 0,33 para semanais; 0,48 para ocasionais; 0,11 para os que nunca consomem álcool.

4. Somam-se os valores obtidos em cada linha (para cada categoria de consumo de álcool), calculando-se então o quadrado da distância entre as duas categorias "SIM" e "NÃO".

Estas operações são repetidas também em outro sentido isto é, para as linhas, "ponderadas" pelo perfil de coluna. Por exemplo, a distância entre "consumo diário de álcool" e "consumo semanal de álcool" é calculada da forma descrita acima, levando-se em 
consideração o "peso" da respectiva coluna: 0,39. Cada categoria tem portanto sua localização no espaço também determinada por seu perfil de linha e pelo "peso" de cada coluna no total da matriz. Há então uma perfeita correspondência entre linhas e colunas. sendo a frequência relativa ou perfil de linha o "ponderador" das colunas e vice-versa. A distância calculada dessa forma é chamada "Distância do Qui-Quadrado".

De acordo com os procedimentos descritos, cada categoria tem sua distância calculada em relação a todas as demais, configurando uma "nuvem de pontos" em um espaço multidimensional. Esta nuvem de pontos pode então ser projetada em planos, representados por pares de eixos, e aqueles que preservam da melhor maneira possível as relações (distâncias) entre os pontos são selecionados. Os auto-vetores da matriz de dados fornecem a solução matemática para esta situação.

O diagnóstico que avalia a qualidade de cada eixo auxilia a interpretação da Análise de Correspondência Múltipla, e é por isso apresentado nos resultados. Os elementos que constituem esse diagnóstico são o Valor Próprio ou Auto-Valor e a Percentagem de Explicação da Variância Global da Matriz. O Valor Próprio é uma medida da capacidade de cada eixo de representar a "nuvem de pontos". Quanto maior o seu valor, melhor a representação da distribuição dos pontos no espaço e, consequentemente, das relações que existem entre as variáveis. Além disso, cada eixo selecionado representa uma percentagem da variância global da matriz, obtida através da proporção que o valor próprio de cada eixo representa em relação à soma dos valores próprios. De forma semelhante ao valor próprio, quanto maior a percentagem de explicação, melhor a qualidade da representação da "nuvem de pontos" através daquele eixo.

Como os eixos são selecionados de forma a preservar as relações entre as categorias, cada uma delas contribui de forma diferente para a definição de cada eixo. Esta contribuição é chamada Contribuição Absoluta, e quanto maior o seu valor, maior a contribuição daquela categoria na definição do eixo. Significa a parte da variância global explicada por cada categoria de cada variável. Sendo assim, ela depende do "peso" da categoria $\left(\mathrm{p}_{\mathrm{i}}\right)$ no total da matriz, já que (GOUVÊA, 1993):

$$
\begin{aligned}
& \text { Variância }=\sum_{i=1}^{n}(x-\mu) p_{j} \quad \text { onde } x=\text { valor de cada casela } \\
& \mathrm{j}=\mathrm{n}^{\mathrm{o}} \text { de colunas } \\
& \mathrm{i}=\mathrm{n}^{\mathrm{o}} \text { de linhas }
\end{aligned}
$$


Categorias com valores altos de contribuição absoluta para determinado eixo apresentam forte correlação com aquele eixo e também forte correlação entre si.

Além da Contribuição Absoluta, a Correlação entre cada categoria e cada eixo constitui também parte do diagnóstico da participação de cada ponto, auxiliando na interpretação dos resultados. Seu valor não depende do "peso" da categoria, mas do ângulo (e seu cosseno quadrado) definido pelo vetor de cada ponto com cada eixo. Quanto maior o cosseno quadrado, maior a correlação entre o vetor e o eixo (GREENACRE, 1981).

Comparando-se os elementos importantes na determinação da Contribuição Absoluta e da Correlação, é possível perceber que elementos de pequena contribuição absoluta na definição de determinado eixo, por seu "peso" baixo, podem apresentar alta correlação como o mesmo eixo.

A última questão relevante para compreensão da técnica utilizada é a escolha do critério que determinará o número de eixos a serem analisados, já que o número máximo depende do número de linhas e colunas de cada tabela. De fato, não há uma regra fixa para essa decisão, mas alguns critérios são descritos (GOUVÊA, 1993):

1. A percentagem de explicação da variância global dos primeiros eixos é alta, e somente esses são analisados.

2. Há uma queda brusca na percentagem de explicação da variância global a partir de determinado eixo, e a análise engloba os fatores anteriores ao da queda.

3. Se as variáveis não tivessem nenhuma relação entre si, cada um dos eixos explicaria igual proporção da variância, representada por $100 / \mathrm{n}^{\circ}$ de fatores. O resultado dessa divisão indicaria o valor mínimo da percentagem de explicação a partir do qual os eixos deveriam ser analisados.

4. As correlações entre categorias de variáveis e o eixo são baixas, sugerindo a exclusão daquele eixo.

No caso de nossa matriz de dados (esparsa, com grande número de valores pequenos ou nulos) não é de se esperar que a percentagem de explicação da variância global dos primeiros fatores seja elevada, o que exclui o primeiro critério. De acordo com o terceiro critério, um grande número de fatores teria que ser analisado apesar das baixas correlações 
entre os elementos e cada eixo (quarto critério). Assim, utilizamos o segundo e o quarto critério para determinar o número de eixos a serem analisados em cada situação. 
CAPÍtULO III RESULTADOS 


\section{1- CARACTERÍSTICAS DA AMOSTRA E ADESÃO AO ESTUDO}

Considerando-se o número de homens e mulheres, o perfil dos funcionários que efetivamente responderam ao questionário foi muito semelhante ao da população de estudo, em ambas as dependências. Na Direção Geral, a razão homem/mulher foi de 1,6 na população de estudo e também os respondentes (Tabela III.1.1entre). No outro tipo de dependência - Cesec's- essa razão foi de 1,5 na população de estudo e 1,2 entre os respondentes (Tabela III.1.2).

A adesão ao estudo foi elevada, já que $89,5 \%$ da amostra planejada para a Direção Geral e 96,4\% dentre os sorteados nos Cesec's concordaram em participar (ver detalhes da amostra no Anexo 4). Os motivos para não participação variaram segundo a dependência. Nos Cesec's, houve apenas 19 recusas (2,8\% da amostra). Os outros funcionários que não participaram estavam ausentes por férias, licença, ou por estarem prestando serviço fora do local de trabalho no dia do preenchimento do questionário. A proporção de recusas foi maior na Direção Geral -39 funcionários (6,5\% da amostra)-, mas ainda assim pode ser considerada baixa. Além dos funcionários que se recusaram a participar da pesquisa, as outras ausências foram motivadas por razões semelhantes aquelas descritas para os Cesec's.

TABELA III.1.1

COMPARAÇÃO ENTRE POPULAÇÃO DE ESTUdO, AMOSTRA

PLANEJADA E RESPONDENTES POR SEXO DIREÇÃO GERAL

\begin{tabular}{l|cccccc}
\hline & \multicolumn{2}{|c}{ POPULAÇA DE } & \multicolumn{2}{c}{ AMOSTRA } & \multicolumn{2}{c}{ RESPONDENTES } \\
& \multicolumn{2}{|c}{ ESTUDO } & \multicolumn{2}{c}{ PLANEJADA } & & \\
SEXO & $\mathrm{N}$ & $\%$ & $\mathrm{n}$ & $\%$ & $\mathrm{n}$ & $\%$ \\
\hline HOMENS & 726 & 61,8 & 378 & 63,1 & 331 & 61,8 \\
MULHERES & 448 & 38,2 & 221 & 36,9 & 205 & 38,3 \\
\hline TOTAL & 1174 & 100,0 & 599 & 100,0 & 536 & 100,0 \\
\hline
\end{tabular}


TABELA III.1.2

COMPARAÇÃo ENTRE POPULAÇÃO dE ESTUdO, AMOSTRA

PLANEJADA E RESPONDENTES POR SEXO

CESEC

\begin{tabular}{l|cccccc}
\hline & \multicolumn{2}{|c}{ POPULAÇÃO DE } & \multicolumn{2}{c}{ AMOSTRA } & \multicolumn{2}{c}{ RESPONDENTES } \\
SEXO & ESTUDO & \multicolumn{2}{c}{ PLANEJADA } & & \\
\hline HOMENS & $\mathrm{N}$ & $\%$ & $\mathrm{n}$ & $\%$ & $\mathrm{n}$ & $\%$ \\
MULHERES & 1948 & 59,34 & 379 & 56,48 & 358 & 55,33 \\
TOTAL & 1335 & 40,66 & 292 & 43,52 & 289 & 44,67 \\
\hline
\end{tabular}

\section{2- CARACTERÍSTICAS SÓCIO-DEMOGRÁFICAS}

A distribuição etária foi bastante semelhante entre homens e mulheres, na Direção Geral, e assim, as respectivas idades médias não apresentaram diferença estatisticamente significativa ( $p=0,614)$ - Tabela III.2.1 e Gráfico III.2.1. Por outro lado, a idade média das mulheres dos Cesec's foi maior do que a dos homens $(p<0,001)$, além de apresentarem valor mais alto também no primeiro quartil (Tabela III.2.2 e Gráfico III.2.1).

TABELA III.2.1

ESTATÍSTICAS-RESUMO DA IDADE SEGUNDO SEXO DIREÇÃO GERAL

\begin{tabular}{l|cc}
\hline \multirow{2}{*}{ ESTATÍSTICAS } & \multicolumn{2}{|c}{ SEXO } \\
\cline { 2 - 3 } & HOMENS & MULHERES \\
\hline MÉDIA (EP*) & $38,7(0,366)$ & $38,9(0,343)$ \\
MEDIANA & 39,2 & 39,1 \\
lo QUARTL & 34,1 & 36,4 \\
3o QUARTIL & 42,6 & 42,1 \\
MÍNIMA & 22,6 & 22,3 \\
MÁXIMA & 56,9 & 53,5 \\
\hline
\end{tabular}

* $\mathrm{EP}=$ Erro padrão da média

$t=0,5 p=0,614$ (Diferença entre médias segundo sexo) 
TABELA III.2.2

ESTATÍSITICAS-RESUMO DA IDADE SEGUNDO SEXO

CESEC

\begin{tabular}{l|cc}
\hline \multirow{2}{*}{ ESTATISTICAS } & \multicolumn{2}{|c}{ SEXO } \\
\cline { 2 - 3 } & HOMENS & MULHERES \\
\hline MÉDIA (EP*) & $36.91(0,384)$ & $39,10(0,281)$ \\
MEDIANA & 38,13 & 39,40 \\
10 QUARTIL & 31,84 & 36,71 \\
3o QUARTIL & 41,82 & 42,14 \\
MÍNIMA & 22,38 & 23,81 \\
MÁXIMA & 59,15 & 59,19 \\
\hline
\end{tabular}

* EP= Erro padrão da média

$t=4,6 p<0,001$ (Diferença entre médias segundo sexo)
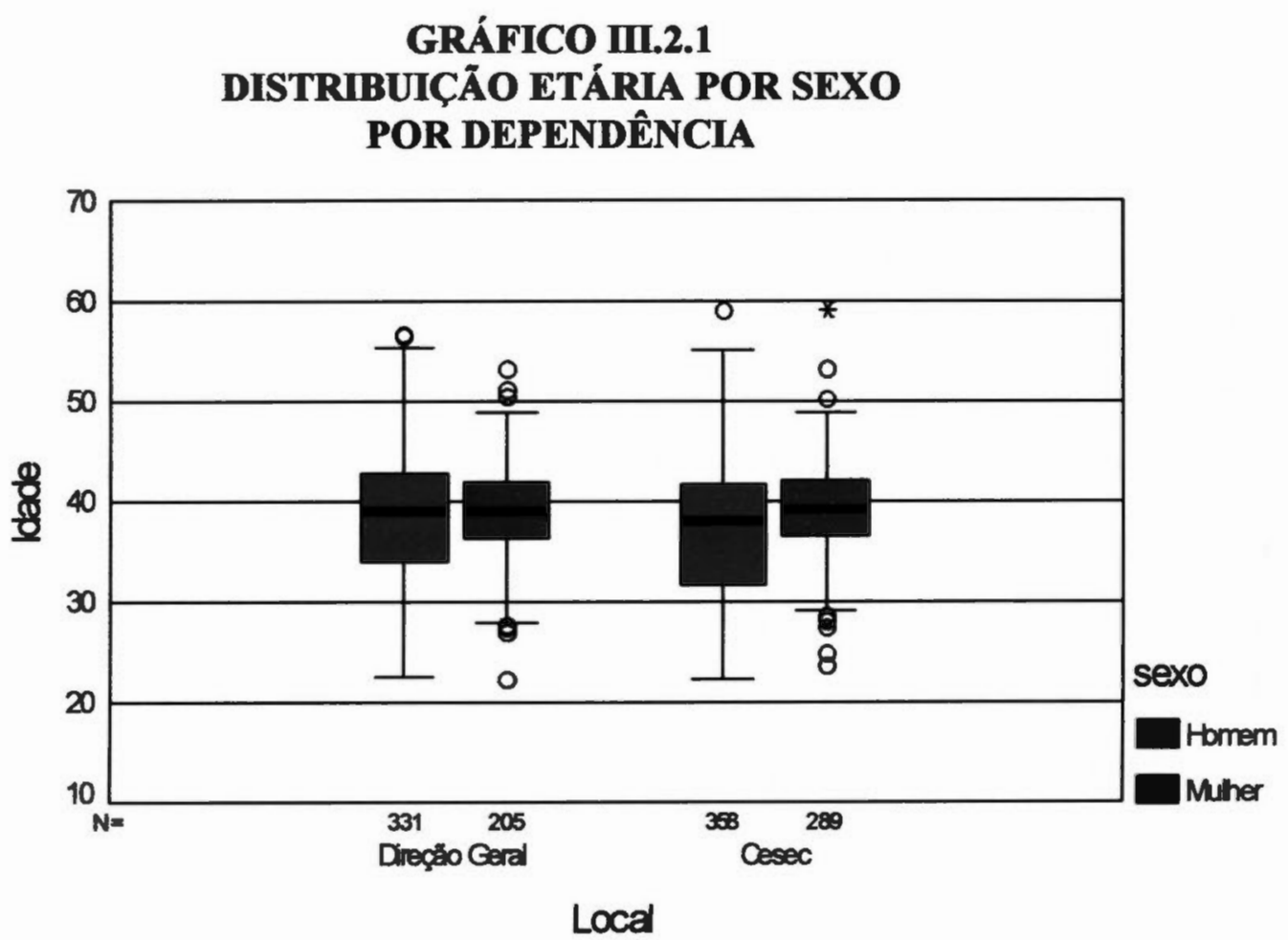

Em relação à escolaridade, as mulheres apresentaram nível mais elevado em ambas as dependências: 78,5\% (IC 95\%: 74,3-82,7) têm curso superior completo, comparado a 64,7\% (IC 95\%: 60,9-68,5) dos homens, na Direção Geral, enquanto 66,8\% (IC 95\%: 62,0-71,6) das mulheres e 47,2\% (IC 95\%: 42,5-51,9) dos homens estão nessa categoria, nos Cesec's (Tabela III.2.3) 
TABELA III.2.3

DISTRIBUIÇÃO DOS GRAUS DE ESCOLARIDADE POR SEXO

DIREÇÃO GERAL E CESEC

\begin{tabular}{|c|c|c|c|c|c|c|}
\hline \multirow[b]{2}{*}{ SEXO } & \multicolumn{6}{|c|}{ ESCOLARIDADE } \\
\hline & $\begin{array}{c}\text { SECUNDARIO } \\
\text { INCOMPLETO } \\
\% \\
\end{array}$ & $\begin{array}{c}\text { SECUNDARIO } \\
\text { COMPLETO } \\
\% \\
\end{array}$ & \multicolumn{2}{|c|}{$\begin{array}{cc}\text { SUPERIOR } & \text { SUPERIOR } \\
\text { INCOMPLETO } & \text { COMPLETO* } \\
\% & \%\end{array}$} & \multicolumn{2}{|c|}{$\overline{\text { TOTAL }}$} \\
\hline $\begin{array}{l}\text { DIREÇĀO } \\
\text { GERAL }\end{array}$ & & & & & & \\
\hline HOMENS & 1,2 & 5,1 & 29,0 & 64,7 & 331 & 100,1 \\
\hline MULHERES & - & 2,9 & 18,5 & 78,5 & 205 & 100,1 \\
\hline TOTAL & 0,7 & 4,3 & 25,0 & 70,0 & 536 & 100,1 \\
\hline $\begin{array}{l}\text { CESEC } \\
\text { HOMENS }\end{array}$ & 2,2 & 12,0 & 38,5 & 47,2 & 358 & $100,($ \\
\hline MULHERES & 1,0 & 11,8 & 20,4 & 66,8 & 289 & $100, \mathrm{C}$ \\
\hline TOTAL & 1,7 & 11,9 & 30,4 & 56,0 & 647 & $100, \mathrm{C}$ \\
\hline
\end{tabular}

Direção Geral $\chi^{2}=12,95 p=0,005$

$\operatorname{Cesec} \chi^{2}=29,57 p<0,001$

* Com ou sem pós-graduação

A maior parte dos funcionários de ambos os sexos e dependências estava unida, através de casamento ou união consensual. Cabe notar que cerca de $20 \%$ das mulheres encontrava-se separada ou viúva, proporção duas vezes maior do que a dos homens. $\mathrm{Na}$ Direção Geral, a proporção de divorciadas e viúvas é duas vezes maior do que a mesma parcela de homens, enquanto nos Cesec's, esta proporção é também significativamente maior: $17,6 \%$ (IC $95 \%$ : $\pm 3,9$ ) para o sexo feminino e $10,1 \%$ (IC $95 \%: \pm 2,82$ ) para o masculino -Tabela III.2.4. 
TABELA III.2.4

SITUAÇÃo CONJUGAL POR SEXO

DIREÇÃO GERAL E CESEC

\begin{tabular}{|c|c|c|c|c|c|}
\hline \multirow[b]{3}{*}{ SEXO } & \multicolumn{5}{|c|}{ SITUAÇĀO CONJUGAL } \\
\hline & \multirow{2}{*}{$\begin{array}{c}\text { SOLTEIRO } \\
\%\end{array}$} & \multirow{2}{*}{$\begin{array}{c}\text { CASADO } \\
\%\end{array}$} & \multirow{2}{*}{$\begin{array}{c}\text { SEPARADO } \\
\text { OU VIÚVO } \\
\%\end{array}$} & \multicolumn{2}{|c|}{ TOTAL } \\
\hline & & & & $\mathbf{n}$ & $\%$ \\
\hline DIREÇĀO GERAL & & & & & \\
\hline HOMENS & 13,6 & 76,7 & 9,7 & 331 & 100,0 \\
\hline MULHERES & 20,0 & 61,0 & 19,0 & 205 & 100,0 \\
\hline CESEC & & & & & \\
\hline HOMENS & 29,6 & 60,3 & 10,1 & 358 & 100,0 \\
\hline MULHERES & 19,7 & 62,6 & 17,6 & 289 & 100,0 \\
\hline
\end{tabular}

Direção Geral $\chi^{2}=16,05 p=0,000$

$\operatorname{Cesec} \chi^{2}=13,19 p=0,001$

Não houve diferença significativa entre as médias salariais de homens e mulheres, em ambas as dependências. Na Direção Geral, esta medida foi de R\$1432,70 e $R \$ 1511,32$, respectivamente $(t=0,51 ; p=0,607)$, enquanto nos Cesec's foi de $R \$ 1340,71$ para os homens e $R \$ 1292,44$ para as mulheres $(t=0,35 ; p=0,729)$. No entanto, a renda per capita (renda familiar $/ \mathrm{n}^{\circ}$ de dependentes) foi maior entre as mulheres, em ambas as dependências. Na Direção Geral, variou entre R\$94,80 e R\$5000,00, com média de $R \$ 657,42( \pm 62,30)$ entre os homens e R\$792,21 $( \pm 77,07)$ entre as mulheres. Nos Cesec's, variou entre $R \$ 80,60$ e $\mathbf{R} \$ 4000,00$, com média de $\mathbf{R} \$ 586,49( \pm 50,27)$ para os homens e $R \$ 657,08( \pm 62,01)$ para as mulheres (Gráfico III.2.2). 
GRÁFICO III.2.2

RENDA PER CAPITA POR SEXO

POR DEPENDÊNCIA

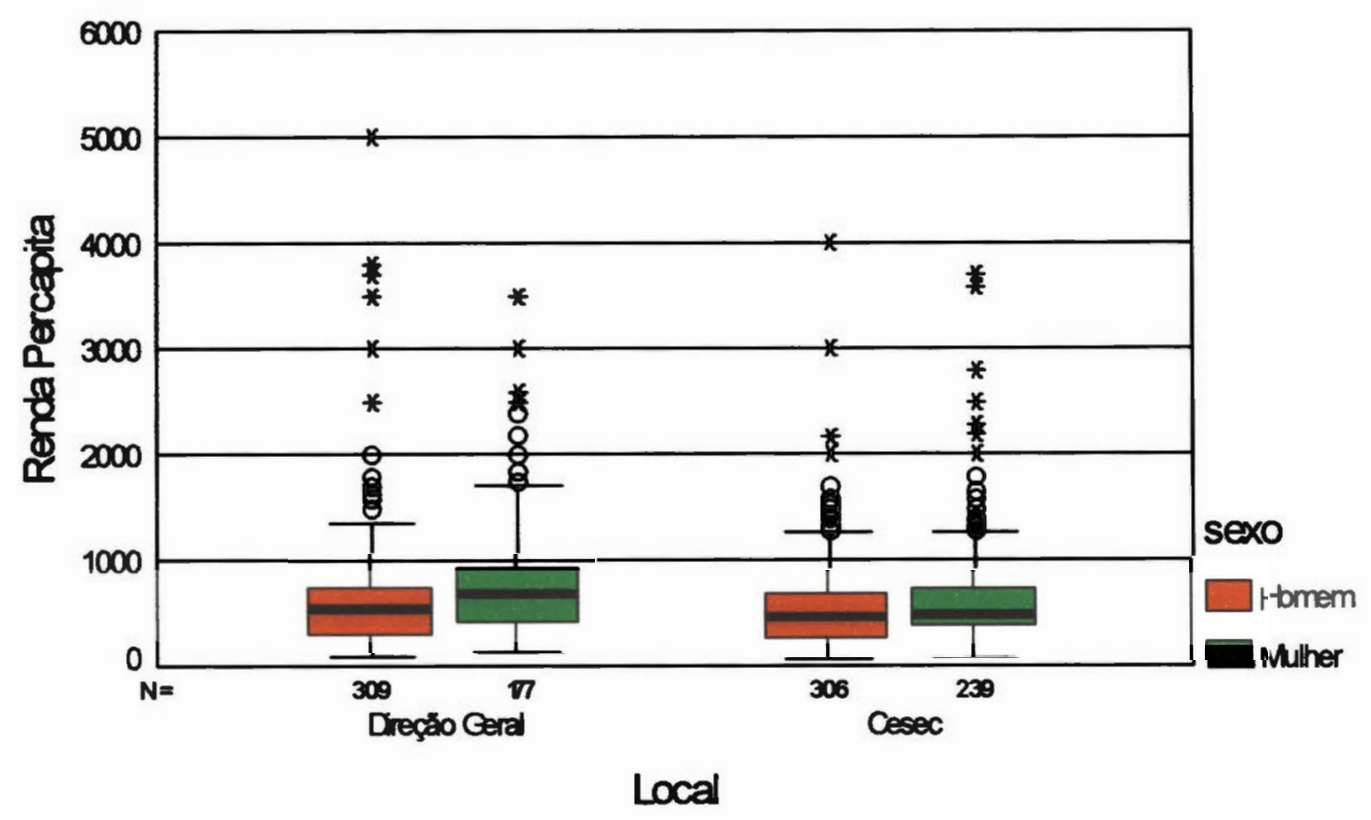




\section{3- PREVALENCIA DOS PRINCIPAIS FATORES DE RISCO}

Nessa seção, as principais características de cada um dos fatores de risco serão descritas. As estimativas de prevalência são apresentadas com os respectivos intervalos de confiança de $95 \%$.

\section{a- HABBITO DE FUMAR}

A prevalência estimada do hábito de fumar foi de $30,9 \%$ (IC $95 \%: 27,7-34,1$ ) na Direção Geral e 31,0\% (IC 95\%: 27,8-34,2) nos Cesec's (Tabelas III.3.1 e III.3.2). A chance de ser fumante comparada a de não fúmar não foi diferente entre homens e mulheres tanto na Direção Geral (OR=1,27; IC 95\%: 0,84-1,91) como nos Cesec's (OR=1,20; IC 95\%: 0,841,72). A prevalência de ex-fumantes também foi semelhante nos dois tipos de dependência, $21,2 \%$ e $20,8 \%$ respectivamente, enquanto a maior parte dos funcionários de ambos os sexos nunca fumou.

TABELA III.3.1

HÁBITO DE FUMAR POR SEXO DIREÇÃO GERAL

\begin{tabular}{|c|c|c|c|c|c|c|c|c|}
\hline \multirow[b]{3}{*}{ SEXO } & \multicolumn{6}{|c|}{ HÁBTTO DE FUMAR } & & \\
\hline & \multicolumn{2}{|c|}{ FUMANTE } & \multicolumn{2}{|c|}{ EX-FUMANTE } & \multicolumn{2}{|c|}{ NUNCA FUMOU } & \multicolumn{2}{|c|}{ TOTAL } \\
\hline & $\mathbf{n}$ & $\%$ & $\mathbf{n}$ & $\%$ & $\mathbf{n}$ & $\%$ & $\mathbf{n}$ & $\%$ \\
\hline HOMENS & 107 & $\overline{32,6}$ & 69 & 21,0 & 152 & 46,3 & 328 & $\overline{100,0}$ \\
\hline MULHERES & 56 & 28,0 & 43 & 21,5 & 101 & 50,5 & 200 & 100,0 \\
\hline TOTAL & 163 & 30,9 & 112 & 21,2 & 253 & 47,9 & 528 & 100,0 \\
\hline
\end{tabular}

$\chi^{2}=1,32 p=0,517$

TABELA III.3.2

HÁBITO DE FUMAR POR SEXO

CESEC

\begin{tabular}{l|cccccc|cc}
\hline & \multicolumn{7}{|c|}{ HÁBTTO DE FUMAR } \\
\cline { 2 - 10 } SEXO & FUMANTE & EX-FUMANTE & \multicolumn{2}{c}{ NUNCA } & \multicolumn{2}{c}{ TOTAL } \\
\hline HOMENS & $\mathbf{n}$ & $\%$ & $\mathrm{n}$ & $\%$ & $\mathrm{n}$ & $\%$ & $\mathrm{n}$ & $\%$ \\
MULHERES & 117 & 32,8 & 72 & 20,2 & 168 & 47,1 & 357 & 100,0 \\
\hline TOTAL & 200 & 28,8 & 62 & 21,5 & 143 & 49,7 & 288 & 100,0 \\
\hline
\end{tabular}

$\chi^{2}=1,17 \mathrm{p}=0,558$ 
Embora a prevalência do hábito de fumar tenha sido semelhante em homens e mulheres, cses se diferenciaram pela quantidade de cigarros consumidos, em média, por dia (Pergunta n55: "Quantos cigarros, em média, voce fuma ou fumava por dia?") (Gráficos III.3.1 e III.3.2). Os homens, fumantes e ex-fumantes da Direçăo Geral, informaram fumar, em média, 20,9 cigarros por dia, enquanto essa medida foi de 17,4 para as mulheres $(p=0,039)$. Resultado semelhante foi observado nos Cesec's, onde os homens também consumiram maior quantidade diária de cigarros, $19,6 \mathrm{em}$ média, e as mulheres, 16,7 cigarros $(p=0,046)$.

\section{GRÁrICO III.3.1 \\ NÚMITRO MÚDIO DE CIGARROS CONSUMIDOS \\ POR FUMANTES E EX-FUMANTES - AMRAS AS DEPENDÔNCCIAS \\ HOMINSS}

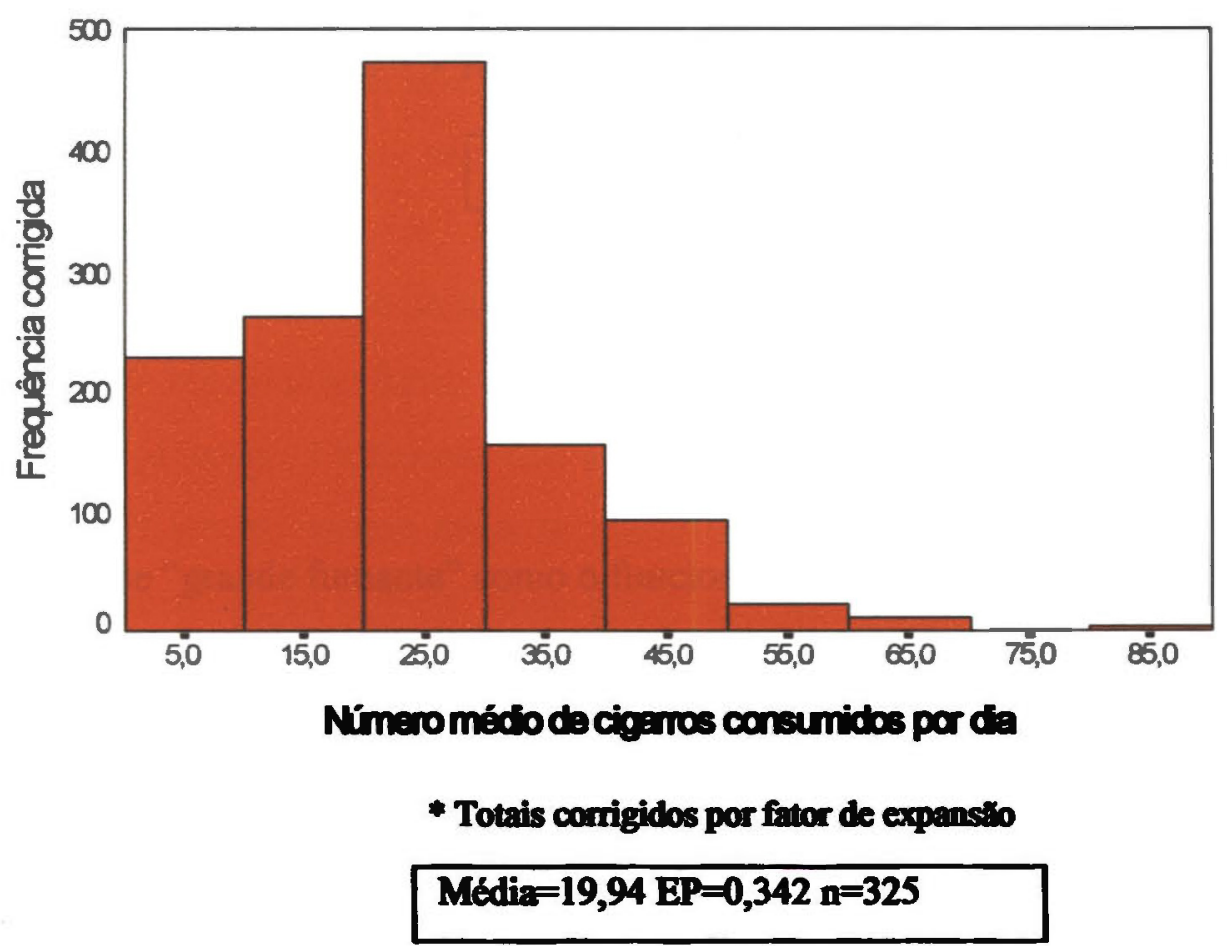




\section{GRÁFICO III.3.2 \\ NÚMERO MÉDIO DE CIGARROS CONSUMIDOS \\ POR FUMANTES E EX-FUMANTES - AMBAS AS DEPENDÊNCIAS \\ MULHERES}

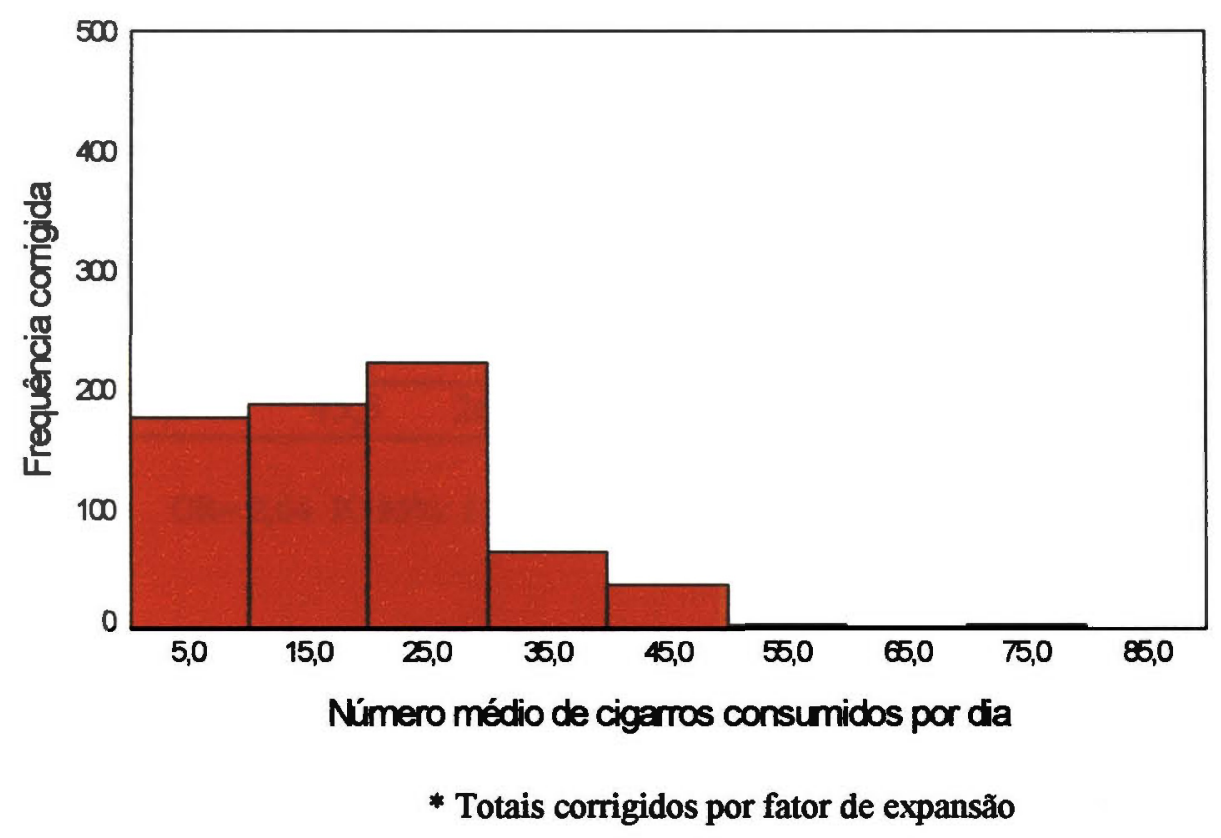

Média $=16,86 \mathrm{EP}=0,428 \mathrm{n}=299$

Definindo-se "grande fumante" como o funcionário que referiu consumir 20 cigarros ou mais diariamente, os fumantes e ex-fumantes do sexo masculino, da Direção Geral, tiveram chance 2,64 vezes maior de estar nesta categoria, do que de estar na categoria "fumante leve". Assim, $63,2 \%$ dos homens e $39,4 \%$ das mulheres foram classificados como grandes fumantes (Tabela III.3.3). Nos Cesec's, embora a prevalência de grandes fumantes também tenha sido maior entre os homens $-53,3 \%$ contra $42,4 \%$ - a medida de associação não foi significativa (Tabela III.3.3). 
TABELA III.3.3

\section{CLASSIFICAC̄̃̃O DE FUMANTES E EX-FUMANTES SEGUNDO NÚMERO MÉDIO DE CIGARROS CONSUMIDOS POR DIA \\ POR SEXO \\ DIREÇÃO GERAL E CESEC}

\begin{tabular}{l|cccc|cccc}
\hline & \multicolumn{8}{|c}{ TIPO DE FUMANTE } \\
\cline { 2 - 10 } SEXO & \multicolumn{7}{|c}{ DIREÇÃO GERAL } & \multicolumn{4}{c}{ CESEC } \\
GRANDE & LEVE & TOTAL & GRANDE & LEVE & \multicolumn{2}{c}{ TOTAL } \\
HOMENS & $\%$ & $\%$ & $\mathrm{n}$ & $\%$ & $\%$ & $\%$ & $\mathrm{n}$ & $\%$ \\
MULHERES & 39,2 & 36,8 & 171 & 100,0 & 53,3 & 46,7 & 180 & 100,0 \\
\hline TOTAL & 54,7 & 60,6 & 94 & 100,0 & 42,4 & 57,6 & 132 & 100,0 \\
\hline
\end{tabular}

$\mathrm{OR}=2,64$ IC $95 \%: 1,57-4,43$

OR= 1,55 IC $95 \%: 0,98-2,44$

Considerando-se apenas os fumantes e excluindo-se os ex-fumantes, a frequência e intensidade do hábito de fumar variaram de forma importante com a idade, sendo a tendência linear estatisticamente significativa em ambos os sexos nos Cesec's e entre os homens da Direção Geral (Tabelas III.3.4 e III.3.5). Enquanto a maioria dos funcionários mais jovens nunca fumou, cerca de $60 \%$ dos homens de 45 anos ou mais na Direção Geral, e $75 \%$ nos Cesec's, já estiveram expostos ao fumo. Entre as mulheres desse grupo etário, cerca da metade fuma atualmente ou já fumou. Cabe notar que a prevalência de grandes fumantes é menor entre os funcionários mais jovens, exceto entre as mulheres dos Cesec's, onde essa prevalência é semelhante em todos os grupos etários. Além disso, embora a proporção de grandes fumantes seja maior entre os homens, na maioria das faixas etárias e em ambas as dependências, há dois grupos em que as prevalências se equivalem. Assim, 10,2\% das mulheres entre 20 e 34 anos, dos Cesec's, são grandes fumantes, comparadas a 9,2\% dos homens. Entre as mulheres mais velhas da Direção Geral, 22,2\% (IC 95\%: 7,6-36,8) são grandes fumantes comparadas a 16,7\% (IC 95\%: 8,8-24,6) dos homens (Tabela III.3.5). Esses resultados sugerem que quando consideramos apenas os funcionários que fumam atualmente, a diferença de intensidade do hábito de fumar entre homens e mulheres parece menos importante do que ao analisarmos fumantes e ex-fumantes em conjunto, conforme apresentado na Tabela III.3.3. 
TABELA III.3.4

DISTRIBUIÇÃO DO HÁBITO E DA QUANTIDADE DIÁRIA DE CIGARROS CONSUMIDOS POR FUMANTES POR GRUPO ETÁRIO

POR SEXO - DIREÇÃO GERAL

\begin{tabular}{|c|c|c|c|c|c|c|}
\hline \multirow[b]{3}{*}{ IDADE } & \multicolumn{4}{|c|}{ FUMO } & \multirow{2}{*}{\multicolumn{2}{|c|}{ TOTAL }} \\
\hline & GRANDE* & LEVE* & $\begin{array}{c}\text { EX- } \\
\text { FUMANTE }\end{array}$ & $\begin{array}{l}\text { NUNCA } \\
\text { FUMOU }\end{array}$ & & \\
\hline & $\%$ & $\%$ & $\%$ & $\%$ & $\mathrm{n}$ & $\%$ \\
\hline \multicolumn{7}{|c|}{ HOMENS } \\
\hline $20-34$ & 9,1 & 13,6 & 10,2 & 67,0 & 88 & 100,0 \\
\hline $35-39$ & 29,8 & 7,4 & 20,2 & 42,6 & 94 & 100,0 \\
\hline $40-44$ & 24,2 & 8,4 & 30,5 & 36,8 & 95 & 100,0 \\
\hline $45 e+$ & 16,7 & 20,8 & 25,0 & 37,5 & 48 & 100,0 \\
\hline TOTAL & 20,6 & 11,4 & 21,2 & 46,8 & 325 & 100,0 \\
\hline \multicolumn{7}{|c|}{ MULHERES } \\
\hline $20-34$ & 3,0 & 21,2 & $\overline{0}$ & 75,8 & 33 & 100,0 \\
\hline $35-39$ & 11,7 & 11,7 & 27,7 & 48,9 & 94 & 100,0 \\
\hline $40-44$ & 15,4 & 15,4 & 28,8 & 40,4 & 52 & 100,0 \\
\hline $45 e+$ & 22,2 & 16,7 & 11,1 & 50,0 & 18 & 100,0 \\
\hline TOTAL & 12,2 & 14,7 & 21,8 & 51,3 & 197 & 100,0 \\
\hline
\end{tabular}

Tendência Linear $\chi^{2}=11,51 \mathrm{p}<0,001$ (HOMEM)

Tendência Linear $\chi^{2}=1,20 \mathrm{p}=0,27379$ (MULHER)

* 14 funcionários não informaram sobre tabagismo ou quantidade de cigarros

TABELA III.3.5

DISTRIBUIÇÃO DO HÁBITO E DA QUANTIDADE DIÁRIA DE CIGARROS CONSUMIDOS POR FUMANTES POR GRUPO ETÁRIO.

POR SEXO - CESEC

\begin{tabular}{|c|c|c|c|c|c|c|}
\hline \multirow[b]{3}{*}{ IDADE } & \multicolumn{6}{|c|}{ FUMO } \\
\hline & \multirow{2}{*}{$\begin{array}{c}\text { GRANDE } \\
* \\
\% \\
\end{array}$} & \multirow{2}{*}{$\begin{array}{c}\text { LEVE* } \\
\%\end{array}$} & \multirow{2}{*}{$\begin{array}{c}\text { EX- } \\
\text { FUMANTE } \\
\%\end{array}$} & \multirow{2}{*}{$\begin{array}{c}\text { NUNCA } \\
\text { FUMOU } \\
\%\end{array}$} & \multicolumn{2}{|c|}{ TOTAL } \\
\hline & & & & & $\mathrm{n}$ & $\%$ \\
\hline \multicolumn{7}{|c|}{ HOMENS } \\
\hline $20-34$ & 9,2 & 13,8 & 8,5 & 68,5 & 130 & 100,0 \\
\hline $35-39$ & 22,5 & 14,6 & 20,2 & 42,7 & 89 & 100,0 \\
\hline $40-44$ & 21,2 & 14,1 & 31,3 & 33,3 & 99 & 100,0 \\
\hline $45 \mathrm{e}+$ & 28,1 & 9,4 & 37,5 & 25,0 & 32 & 100,0 \\
\hline TOTAL & 17,7 & 13,7 & 20,6 & 48,0 & 350 & 100,0 \\
\hline \multicolumn{7}{|c|}{ MULHERES } \\
\hline $20-34$ & 10,2 & 6,1 & 18,4 & 65,3 & 49 & 100,0 \\
\hline $35-39$ & 15,5 & 16,5 & 24,3 & 43,7 & 103 & 100,0 \\
\hline $40-44$ & 12,6 & 15,5 & 21,4 & 50,5 & 103 & 100,0 \\
\hline $45 \mathrm{e}+$ & 12,0 & 8,0 & 24,0 & 56,0 & 25 & 100,0 \\
\hline TOTAL & 13,2 & 13,6 & 22,1 & 51,1 & 280 & 100,0 \\
\hline
\end{tabular}

Tendência Linear $\chi^{2}=13,90 \mathrm{p}<0,001$ (HOMEM)

Tendência Linear $\chi^{2}=5,57 \mathrm{p}=0,01828$ (MULHER)

** 17 funcionários não informaram sobre tabagismo ou quantidade de cigarros 
A quantidade diária de cigarros consumidos por fumantes e ex-fumantes variou com a escolaridade, embora o número de funcionários com segundo grau incompleto seja pequeno. Mesmo assim, é possível observar tendência crescente da proporção de grandes fumantes a medida que o grau de escolaridade diminui (Tabela III.3.6): 87,2\% (IC 95\%: 70,0-100,0) daqueles que têm segundo grau incompleto são grandes fumantes, enquanto 47,3\% (IC 95\%: $43,9-50,7)$ dos funcionários com curso superior completo estão nessa categoria.

TABELA III.3.6

CLASSIFICAÇÃO DE FUMANTES E EX-FUMANTES DE ACORDO COM A QUANTIDADE DIÁRIA DE CIGARROS CONSUMIDOS SEGUNDO ESCOLARIDADE AMBOS OS SEXOS AMBAS AS DEPENDÊNCIAS

\begin{tabular}{l|cccc}
\hline & \multicolumn{4}{|c}{ TIPO DE FUMANTE } \\
\cline { 2 - 5 } ESCOLARIDADE & GRANDE & LEVE & \multicolumn{2}{c}{ TOTAL } \\
\hline$<2^{\circ}$ GRAU & $\%$ & $\%$ & $\mathrm{n}$ & $\%$ \\
$2^{\circ}$ GRAU COMPLETO & 87,2 & 12,8 & 9 & 100,0 \\
SUPERIOR INCOMPLETO & 60,4 & 39,6 & 47 & 100,0 \\
SUPERIOR COMPLETO & 51,6 & 48,4 & 177 & 100,0 \\
\hline
\end{tabular}

$\mathrm{n}=577$

Proporçōes corrigidas por fator de expansão

A maioria dos funcionários que fumam já tentou abandonar o hábito, sendo que cerca de $50 \%$ foi bem sucedido nessa tentativa, enquanto $20,2 \%$ nunca tentou parar de fumar (Gráfico III.3.3). Considerando-se ambas as dependências, os motivos declarados com maior frequência para parar de fumar foram "Porque o fumo faz mal à saúde" $(72,4 \%)$, "Pressões familiares"(13,9\%) e "Por ordem médica"( $8,5 \%)$. 


\section{GRÁFICO III.3.3 \\ DISTRIBUIÇÃO DOS FUNCIONÁRIOS DE ACORDO COM \\ TENTATIVAS DE PARAR DE FUMAR \\ AMBOS OS SEXOS \\ AMBAS AS DEPENDÊNCIAS}
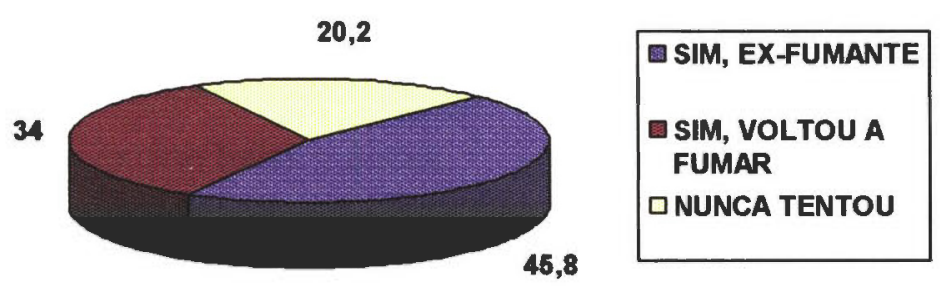

*Proporções corrigidas por fator de expansão

Em relação à existência de políticas de restrição ao fumo no ambiente de trabalho, 94,8\% dos funcionários da Direção Geral declararam que o fumo é permitido no ambiente de trabalho. Nos Cesec's, essa proporção foi de $88,2 \%$, sugerindo que os programas de combate ao fumo implantados no Banco não vem atingindo bons resultados.

\section{b- DIETA}

Grande parcela da população apresenta hábitos alimentares saudáveis. Assim, por exemplo 57,0\% (IC 95\%: 53,9-60,1) dos funcionários da Direção Geral alimenta-se com comida caseira na principal refeição diária. Essa proporção foi ainda maior nos Cesec's: 67,1\% (IC 95\%: 63,8-70,4). Por outro lado, 90,1\% (IC 95\%: 88,2-92,0) dos funcionários da Direção Geral e 90,6\% (IC 95\%: 88,6-92,6) nos Cesec's utilizam óleo vegetal para fritura de alimentos, enquanto $18,8 \%$ e $18,9 \%$ respectivamente, utilizam gordura animal (banha de porco ou manteiga) com a mesma finalidade. $O$ hábito de acrescentar sal, sempre ou quase sempre, aos alimentos já preparados, foi declarado por apenas 17,4\% (IC 95\%: 15,0-19,8) na Direção Geral e $16,9 \%$ (IC 95\%: 14,3-19,5) nos Cesec's.

A análise da frequência semanal de consumo dos grupos de alimentos confirma a alta prevalência de hábitos dietéticos saudáveis nessa população (Tabelas III.3.7 e III.3.8). Em 
ambos os tipos de dependências, a maior parcela de funcionários consome pouco ou não consome alimentos ricos em gordura saturada, sal e/ou colesterol como carnes salgadas, produtos industrializados, embutidos, carne de porco e ovos. Por outro lado, o consumo de verduras, legumes e frutas é muito frequente para a maioria da população, especialmente a feminina. As exceções a esse padrão ocorreram nas frituras,carne de vaca, refrigerantes (principalmente entre homens), balas ou doces, açúcar e manteiga, cujo consumo é frequente. Os homens declararam maior consumo da maioria dos alimentos com alto teor de gordura saturada, colesterol ou sal $(p<0,05)$, exceto balas e doces.

TABELA III.3.7

FREQUÊNCIA DE CONSUMO SEMANAL DE GRUPOS DE ALIMENTOS POR SEXO

DIREÇÃO GERAL

\begin{tabular}{|c|c|c|c|c|c|c|}
\hline Alimento & Sexo & $\overline{\mathbf{n}}$ & $\begin{array}{c}\text { Não } \\
\text { consome }\end{array}$ & $\begin{array}{c}\text { Menor } \\
\text { que } 1 \text { vez }\end{array}$ & $\begin{array}{c}\text { De } 1 \text { a } 3 \\
\text { Vezes }\end{array}$ & $\begin{array}{l}4 \text { ou }+ \\
\text { vezes }\end{array}$ \\
\hline \multirow[t]{2}{*}{ Carnes salgadas* } & Mas & 321 & 12,1 & 69,5 & 14,3 & 4,0 \\
\hline & Fem & 202 & 17,8 & 72,8 & 7,9 & 1,5 \\
\hline \multirow{2}{*}{$\begin{array}{l}\text { Produtos } \\
\text { industrializados }^{+}\end{array}$} & Mas & 322 & 18,0 & 45,7 & 26,4 & 9,9 \\
\hline & Fem & 202 & 17,3 & 53,5 & 21,3 & 7,9 \\
\hline \multirow[t]{2}{*}{ Embutidos $^{+}$} & Mas & 327 & 8,3 & 54,4 & 33,3 & 4,0 \\
\hline & Fem & 203 & 14,3 & 56,2 & 26,6 & 3,0 \\
\hline \multirow{2}{*}{ Frituras* } & Mas & 326 & 4,0 & 27,9 & 45,7 & 22,4 \\
\hline & Fem & 203 & 5,4 & 37,9 & 46,8 & 9,9 \\
\hline \multirow[t]{2}{*}{$\overline{\text { Manteiga }}^{+}$} & Mas & 325 & 21,8 & 18,8 & 21,2 & 38,2 \\
\hline & Fem & 202 & 22,3 & 12,4 & 17,8 & 47,5 \\
\hline \multirow[t]{2}{*}{ Carne de porco* } & Mas & 321 & 28,7 & 63,6 & 7,8 & - \\
\hline & Fem & 195 & 37,4 & 59,5 & 3,1 & - \\
\hline \multirow[t]{2}{*}{ Carne de vaca* } & Mas & 328 & 2,1 & 9,8 & 46,0 & 42,1 \\
\hline & Fem & 204 & 5,4 & 16,2 & 43,1 & 35,3 \\
\hline \multirow{2}{*}{ Refrigerantes* } & Mas & 326 & 22,7 & 24,5 & 27,3 & 25,5 \\
\hline & Fem & 203 & 30,5 & 38,4 & 21,2 & 9,9 \\
\hline \multirow[t]{2}{*}{ Balas, doces * } & Mas & 326 & 15,0 & 36,8 & 31,3 & 16,9 \\
\hline & Fem & 202 & 5,9 & 45,0 & 28,7 & 20,3 \\
\hline \multirow[t]{2}{*}{ Açúcar, mel* } & Mas & 326 & 16,3 & 13,2 & 16,9 & 53,7 \\
\hline & Fem & 204 & 29,4 & 10,8 & 11,8 & 48,0 \\
\hline \multirow[t]{2}{*}{$\overline{\text { Ovos* }}$} & Mas & 328 & 8,5 & 46,0 & 38,1 & 7,3 \\
\hline & Fem & 205 & 6,3 & 49,3 & 42,4 & 2,0 \\
\hline \multirow[t]{2}{*}{ Verduras* } & Mas & 330 & 0,6 & 8,5 & 32,4 & 58,5 \\
\hline & Fem & 204 & - & 7,8 & 16,7 & 75,5 \\
\hline
\end{tabular}

* Existe diferença significativa entre homens e mulheres com $\mathrm{p}<0,05$

+ Não foi detectada diferença significativa entre homens e mulheres 
TABELA III.3.8

FREQUÊNCIA DE CONSUMO SEMANAL DE GRUPOS DE ALIMENTOS POR

SEXO

CESEC

\begin{tabular}{|c|c|c|c|c|c|c|}
\hline Alimento & Sexo & $\overline{\mathbf{n}}$ & $\begin{array}{c}\text { Não } \\
\text { consome }\end{array}$ & $\begin{array}{c}\text { Menor } \\
\text { que } 1 \text { vez }\end{array}$ & $\begin{array}{l}\text { De } 1 \text { a } 3 \\
\text { Vezes }\end{array}$ & $\begin{array}{l}4 \text { ou }+ \\
\text { vezes }\end{array}$ \\
\hline Carnes salgadas* & $\begin{array}{l}\text { Mas } \\
\text { Fem }\end{array}$ & $\begin{array}{l}355 \\
281\end{array}$ & $\begin{array}{l}15,5 \\
18,5\end{array}$ & $\begin{array}{l}63,7 \\
71,2\end{array}$ & $\begin{array}{r}74,9 \\
7,8\end{array}$ & $\begin{array}{l}5,9 \\
2,5\end{array}$ \\
\hline $\begin{array}{l}\text { Produtos } \\
\text { industrializados }{ }^{+}\end{array}$ & $\begin{array}{l}\text { Mas } \\
\text { Fem }\end{array}$ & $\begin{array}{l}351 \\
280\end{array}$ & $\begin{array}{l}17,1 \\
14,9\end{array}$ & $\begin{array}{l}45,6 \\
53,6\end{array}$ & $\begin{array}{l}29,1 \\
21,8\end{array}$ & $\begin{array}{r}8,3 \\
10,0\end{array}$ \\
\hline Embutidos $^{+}$ & $\begin{array}{l}\text { Mas } \\
\text { Fem }\end{array}$ & $\begin{array}{l}356 \\
285\end{array}$ & $\begin{array}{l}10,7 \\
12,3\end{array}$ & $\begin{array}{l}49,2 \\
54,4\end{array}$ & $\begin{array}{l}34,8 \\
30,2\end{array}$ & $\begin{array}{l}5,3 \\
3,2\end{array}$ \\
\hline Frituras* & \begin{tabular}{|l} 
Mas \\
Fem
\end{tabular} & $\begin{array}{l}356 \\
286\end{array}$ & $\begin{array}{l}4,2 \\
6,3\end{array}$ & $\begin{array}{l}23,0 \\
36,4\end{array}$ & $\begin{array}{l}51,1 \\
46,2\end{array}$ & $\begin{array}{l}21,6 \\
11,2\end{array}$ \\
\hline Manteiga $^{+}$ & \begin{tabular}{|l} 
Mas \\
Fem
\end{tabular} & $\begin{array}{l}354 \\
286\end{array}$ & $\begin{array}{l}21,5 \\
21,7\end{array}$ & $\begin{array}{l}19,5 \\
19,6\end{array}$ & $\begin{array}{l}21,8 \\
15,7\end{array}$ & $\begin{array}{l}37,3 \\
43,0\end{array}$ \\
\hline Carne de porco* & $\begin{array}{l}\text { Mas } \\
\text { Fem }\end{array}$ & $\begin{array}{l}352 \\
282\end{array}$ & $\begin{array}{l}29,0 \\
44,0\end{array}$ & $\begin{array}{l}59,4 \\
51,8\end{array}$ & $\begin{array}{r}11,1 \\
3,9\end{array}$ & $\begin{array}{l}0,6 \\
0,4\end{array}$ \\
\hline Carne de vaca* & $\begin{array}{l}\text { Mas } \\
\text { Fem }\end{array}$ & $\begin{array}{l}355 \\
286\end{array}$ & $\begin{array}{l}4,2 \\
6,6\end{array}$ & $\begin{array}{r}9,0 \\
15,4\end{array}$ & $\begin{array}{l}42,8 \\
37,8\end{array}$ & $\begin{array}{l}43,9 \\
40,2\end{array}$ \\
\hline Refrigerantes* & $\begin{array}{l}\text { Mas } \\
\text { Fem }\end{array}$ & $\begin{array}{l}355 \\
285\end{array}$ & $\begin{array}{l}19,2 \\
30,2\end{array}$ & $\begin{array}{l}28,2 \\
37,5\end{array}$ & $\begin{array}{l}27,3 \\
18,9\end{array}$ & $\begin{array}{l}25,4 \\
13,3\end{array}$ \\
\hline Balas, doces & $\begin{array}{l}\text { Mas } \\
\text { Fem }\end{array}$ & $\begin{array}{l}353 \\
288\end{array}$ & $\begin{array}{r}12,2 \\
7,3\end{array}$ & $\begin{array}{l}40,8 \\
42,4\end{array}$ & $\begin{array}{l}31,2 \\
34,7\end{array}$ & $\begin{array}{l}15,9 \\
15,6\end{array}$ \\
\hline Açúcar, mel* & $\begin{array}{l}\text { Mas } \\
\text { Fem }\end{array}$ & $\begin{array}{l}356 \\
284\end{array}$ & $\begin{array}{l}17,7 \\
28,9\end{array}$ & $\begin{array}{l}13,8 \\
10,2\end{array}$ & $\begin{array}{r}12,1 \\
9,2\end{array}$ & $\begin{array}{l}56,5 \\
51,8\end{array}$ \\
\hline Ovos $^{+}$ & \begin{tabular}{|l} 
Mas \\
Fem
\end{tabular} & $\begin{array}{l}353 \\
286\end{array}$ & $\begin{array}{l}7,4 \\
4,9\end{array}$ & $\begin{array}{l}44,5 \\
52,8\end{array}$ & $\begin{array}{l}41,1 \\
38,5\end{array}$ & $\begin{array}{l}7,1 \\
3,8\end{array}$ \\
\hline Verduras* & $\begin{array}{l}\text { Mas } \\
\text { Fem }\end{array}$ & $\begin{array}{l}356 \\
288\end{array}$ & $\begin{array}{c}0,6 \\
-\end{array}$ & $\begin{array}{l}9,0 \\
4,2\end{array}$ & $\begin{array}{l}32,3 \\
16,0\end{array}$ & $\begin{array}{l}58,1 \\
79,9\end{array}$ \\
\hline
\end{tabular}

* Existe diferença significativa entre homens e mulheres com $p<0,05$

+ Não foi detectada diferença significativa entre homens e mulheres

De acordo com os procedimento descritos na metodologia do estudo, um escore foi construído com base nos doze grupos de alimentos listados na tabela anterior, buscando-se resumir, em apenas uma medida, as informações contidas na pergunta $n^{\circ} 46$ (Anexo 8).

A validade e confiabilidade do escore foram avaliadas através de três procedimentos (Rowland, 1991): observação dos coeficientes de correlação entre os ítens que compuseram o escore; observação dos coeficientes de correlação entre cada ítem e o escore; e estimativa do Coeficiente Alpha de Cronbach (Anexo 5). Nenhum dos grupos de alimentos apresentou zorrelação próxima de zero ou de um com muitos outros ítens, o que indicaria sua exclusão. 
Nenhum dos itens apresentou correlação menor do que 0,20 com o escore, o que também indicaria sua exclusão. Assim, todos os grupos alimentares foram mantidos no escore. A consistência interna do escore foi avaliada através do Coeficiente Alpha de Cronbach, estimado em 0,73, o que representa boa confiabilidade (Rowland, 1991).

Conforme descrito na metodologia, quanto maior o valor do escore, maior o consumo de alimentos de risco. O escore médio dos homens da Direção Geral -53,16- foi maior do que o escore médio das mulheres da mesma dependência $-48,11-(p<0,001)$ - Gráficos III.3.4 e III.3.5. Os homens dos Cesec's também apresentaram maior consumo de alimentos pouco saudáveis, com escore médio de 53,74 , maior do que o das mulheres $-48,16-(p<0,001)$ Gráficos III.3.6 e III..3.7.

\section{GRÁFICO III.3.4 \\ ESCORE DE DIETA \\ DIREÇÃO GERAL-HOMENS}

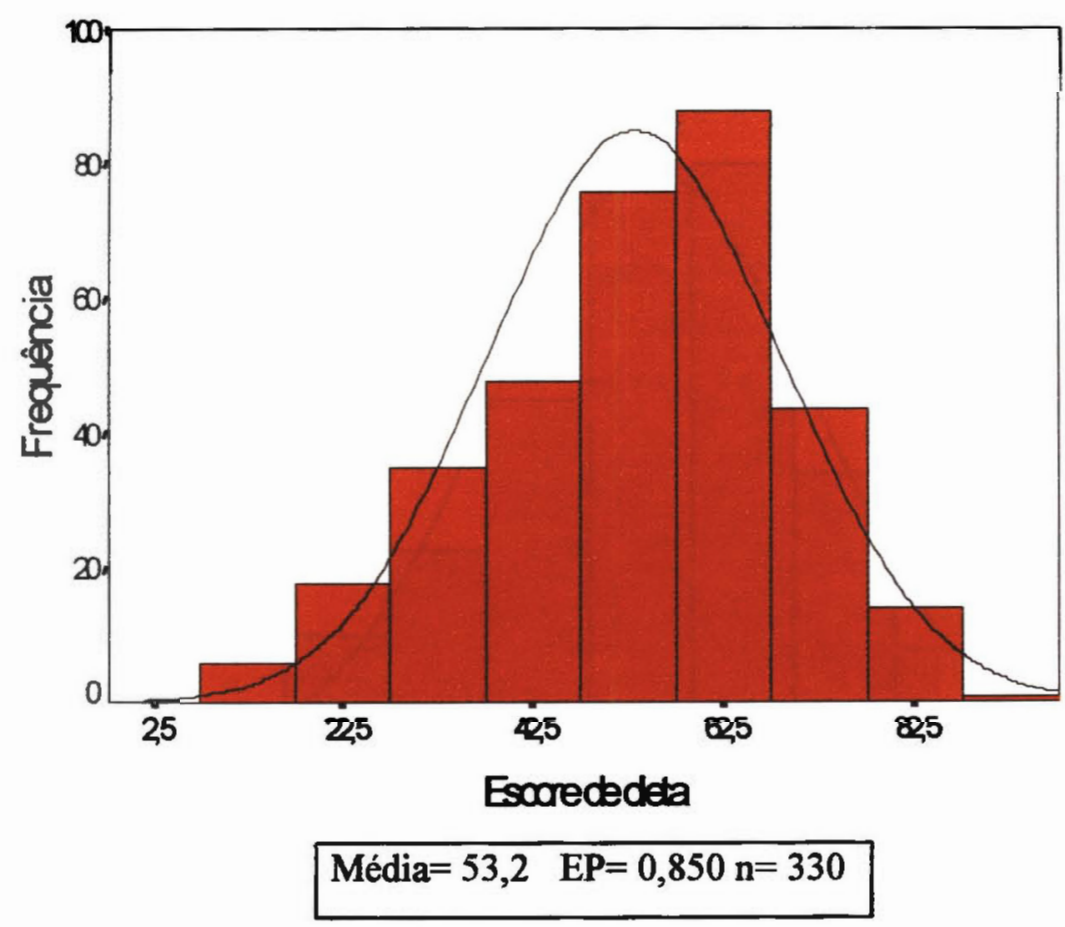



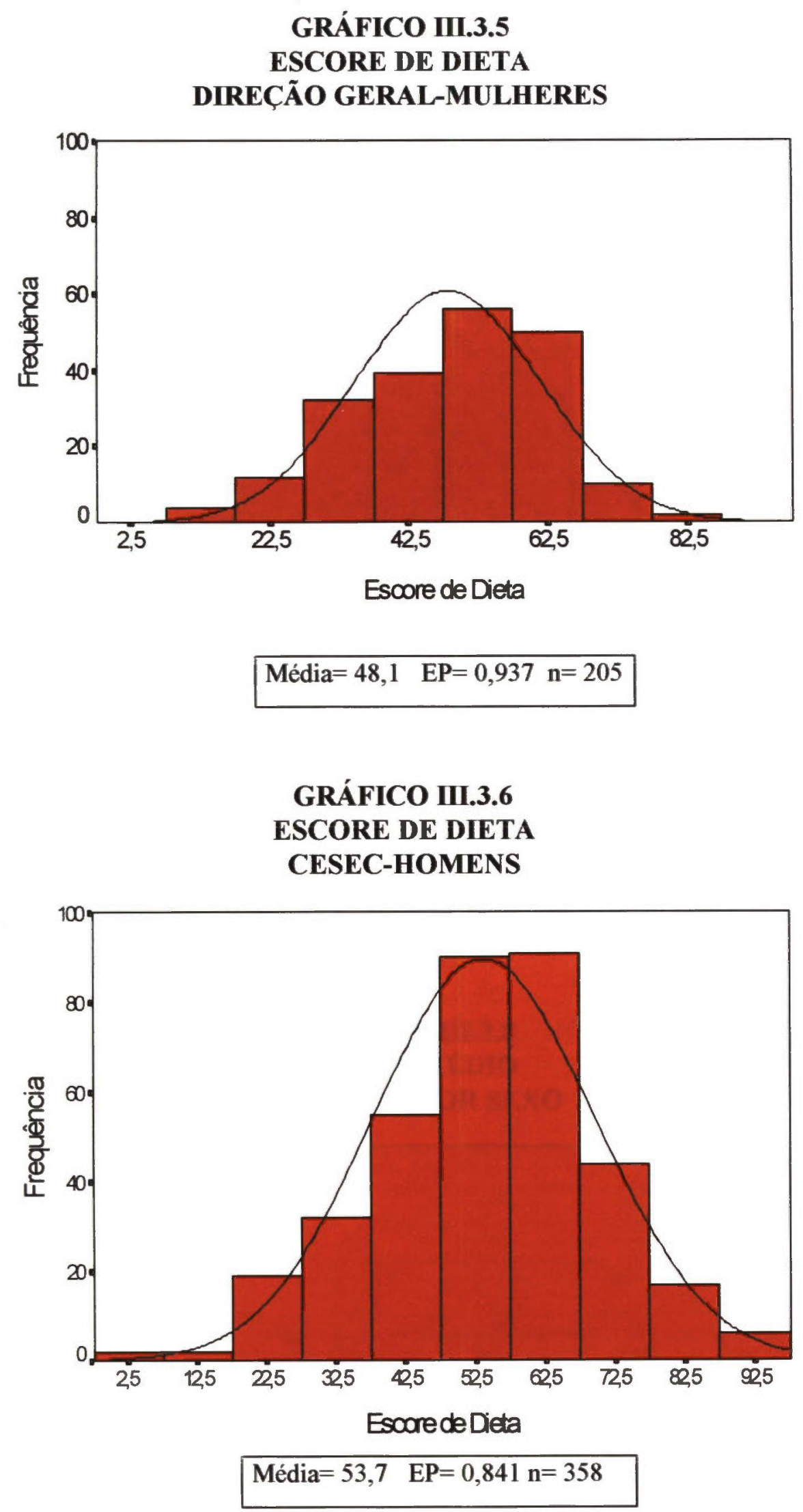
GRÁFICO III.3.7

ESCORE DE DIETA

CESEC-MULHERES

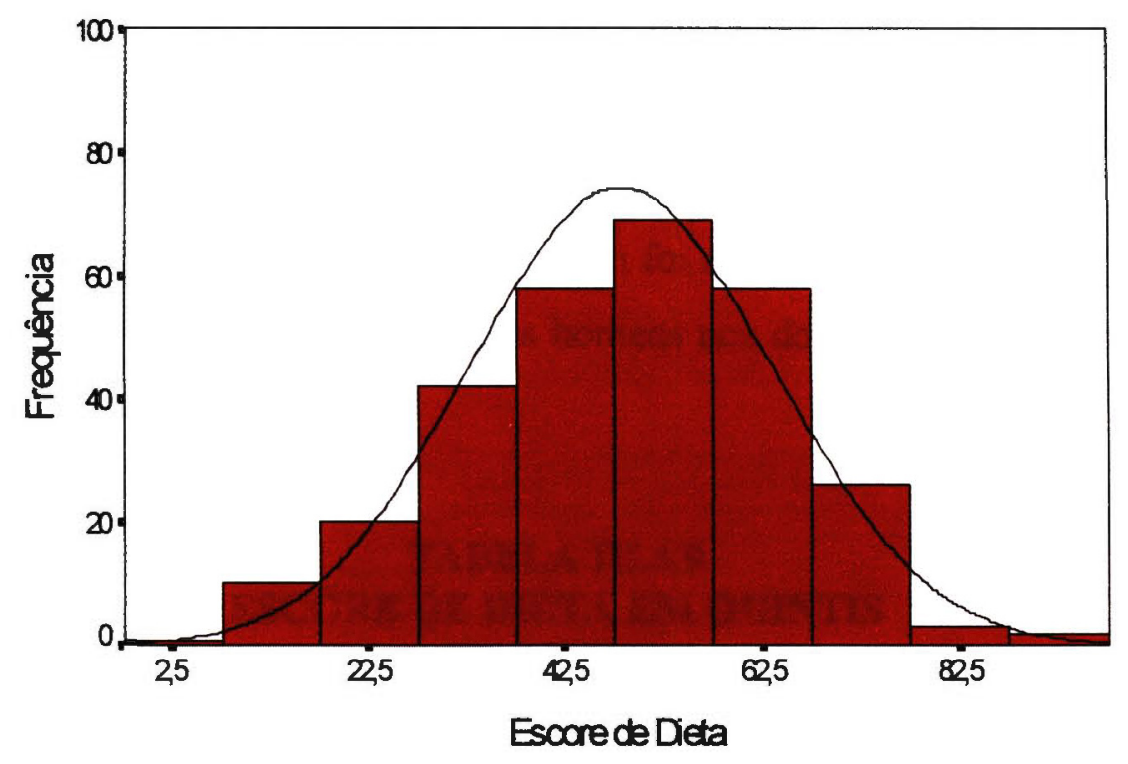

Média $=48,2 \quad \mathrm{EP}=0,910 \mathrm{n}=289$

A distribuição dos escores em função da idade revelou que os funcionários mais jovens apresentaram maior consumo de alimentos de risco quando comparados aos mais velhos (Gráfico III.3.8). Esse comportamento foi particularmente importante entre os homens de $20 \mathrm{a}$ 29 anos, cujo escore médio - 60,6 (IC 95\%: 59,2-62,0)- situou-se bem acima dos mais velhos 46,7 (IC 95\%: 44,6-48,8)-.
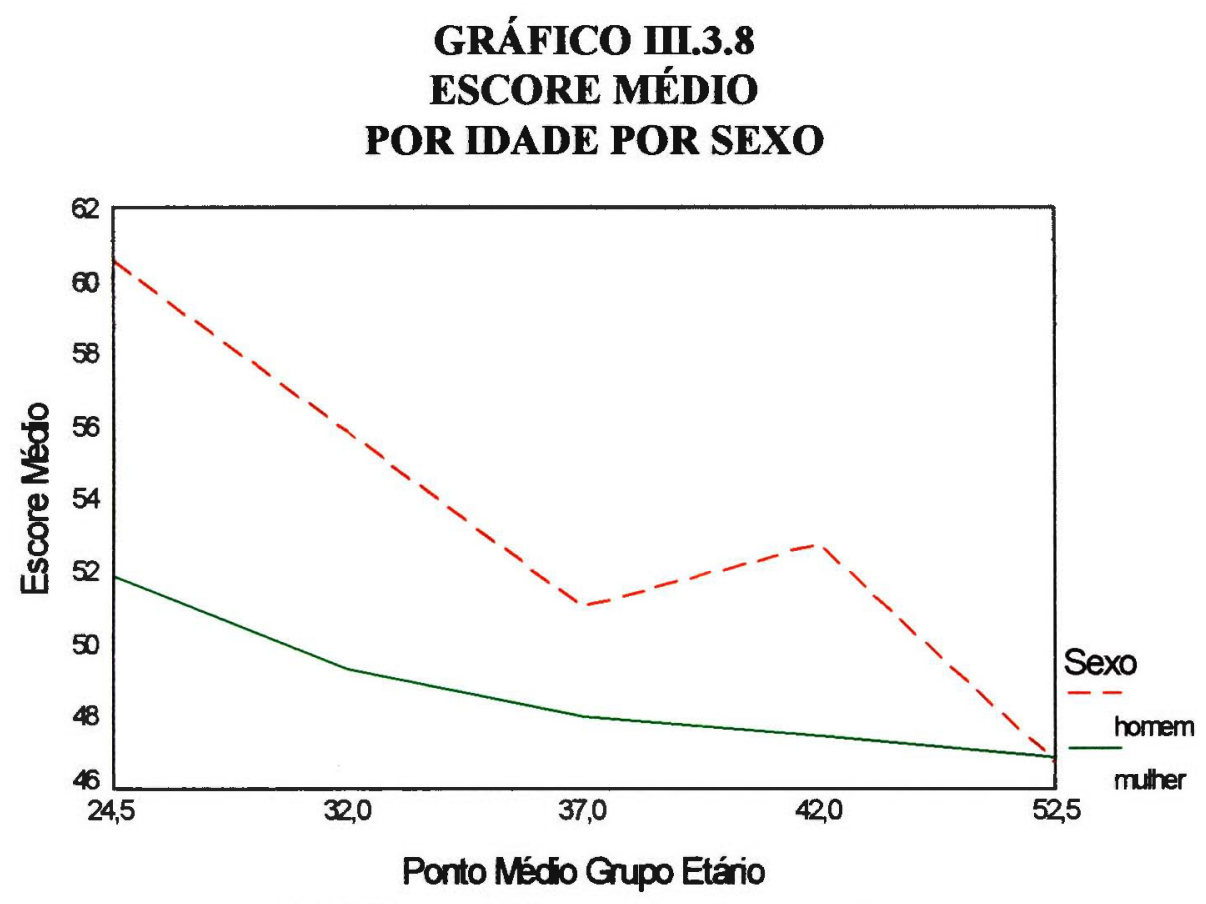

* Médias corrigidas por fator de expansão 
A distribuição do escore foi categorizada de acordo com cinco quintis, observando-se diferença estatisticamente significativa entre as proporções de homens e mulheres alocadas em cada um, na Direção Geral (Tabelas III.3.9 e III.3.10). Nessa dependência, 45,4\% (IC 95\%: $41,4-49,4)$ dos homens situaram-se no quarto e quinto quintis -os de maior consumo de alimentos de risco- enquanto apenas $31,2 \%$ (IC 95\%: 26,5-35,9) das mulheres foram incluídas nessas categorias. A distribuição do escore também foi diferente entre homens e mulheres nos Cesec's, com 44,4\% (IC 95\%: $39,7-49,1$ ) dos homens nos dois últimos quintis, contra $31,8 \%$ (IC 95\%: 27,0-36,6) das mulheres.

TABELA III.3.9

ESCORE DE DIETA EM QUINTIS

POR SEXO

DIREÇÃO GERAL

\begin{tabular}{|c|c|c|c|c|c|c|c|}
\hline \multirow[b]{3}{*}{ SEXO } & \multicolumn{5}{|c|}{ QUINTIS DA ESCALA } & & \\
\hline & $1^{\circ}$ & $2^{\circ}$ & $3^{\circ}$ & $4^{\circ}$ & $5^{\circ}$ & \multicolumn{2}{|c|}{ TOTAL } \\
\hline & $\%$ & $\%$ & $\%$ & $\%$ & $\%$ & $\mathbf{n}$ & $\%$ \\
\hline HOMENS & 21,2 & 18,5 & 14,8 & 21,5 & 23,9 & 330 & 100,0 \\
\hline MULHERES & 27,3 & 27,3 & 14,1 & 23,9 & 7,3 & 205 & 100,0 \\
\hline TOTAL & 23,6 & 21,9 & 14,6 & 22,4 & 17,6 & 535 & 100,0 \\
\hline
\end{tabular}

$\chi^{2}=26,76 p<0,001$

TABELA III.3.10

ESCORE DE DIETA EM QUINTIS

POR SEXO

CESEC

\begin{tabular}{|c|c|c|c|c|c|c|c|}
\hline \multirow[b]{3}{*}{ SEXO } & \multicolumn{5}{|c|}{ QUINTIS DO ESCORE } & & \\
\hline & $1^{\circ}$ & $2^{\circ}$ & $3^{\circ}$ & $4^{\circ}$ & $5^{\circ}$ & \multicolumn{2}{|c|}{ TOTAL } \\
\hline & $\%$ & $\%$ & $\%$ & $\%$ & $\%$ & $\mathbf{N}$ & $\%$ \\
\hline HOMENS & 19,6 & 20,1 & 15,9 & 21,2 & 23,2 & 358 & 100,0 \\
\hline MULHERES & 30,1 & 23,5 & 14,5 & 19,0 & 12,8 & 289 & 100,0 \\
\hline TOTAL & 24,3 & 21,6 & 15,3 & 20,2 & 18,5 & 647 & 100,0 \\
\hline
\end{tabular}

$\chi^{2}=18,07 p=0,00119$

A qualidade da dieta (quintis do escore) foi melhor entre os funcionários com maior nível de escolaridade já que 48,3\% (IC 95\%: 45,2-51,4) daqueles com curso superior completo ou incompleto foram classificados nos quintis mais saudáveis (primeiro e segundo), enquanto 
38,6\% (IC 95\%: 30,9-46,3) dos funcionários que não chegaram a ingressar na universidade foram incluídos nessa categoria. (Tabela III.3.11).

TABELA III.3.11

QUALIDADE DA DIETA SEGUNDO ESCOLARIDADE

AMBOS OS SEXOS

AMBAS AS DEPENDÊNCIAS

\begin{tabular}{|c|c|c|c|c|c|}
\hline \multirow{2}{*}{ ESCOLARIDADE } & \multicolumn{3}{|c|}{ QUINTIS DO ESCORE DE DIETA } & & TOTAL \\
\hline & $\begin{array}{c}\text { PRIMEIRO } \\
\text { E SEGUNDO** }\end{array}$ & $\begin{array}{c}\text { TERCEIRO } \\
\end{array}$ & $\begin{array}{l}\text { QUARTO } \\
\text { E QUINTO }\end{array}$ & $\mathrm{TO}$ & $\overline{\mathrm{AL}}$ \\
\hline < SUPERIOR* & 38,6 & 16,8 & 44,6 & 114 & 100,0 \\
\hline $\begin{array}{l}\text { SUPERIOR } \\
\text { INCOMPLETO }\end{array}$ & 42,0 & 17,3 & 40,7 & 331 & 100,0 \\
\hline $\begin{array}{l}\text { SUPERIOR } \\
\text { COMPLETO }\end{array}$ & 48,3 & 13,7 & 37,9 & 737 & 100,0 \\
\hline
\end{tabular}

$\mathrm{n}=1182$

Proporções corrigidas por fator de expansão

* $2^{\circ}$ grau incompleto ou completo

** Quintis correspondentes a dietas mais saudáveis

\section{$c-A L C O O L$}

$\mathrm{O}$ consumo de bebida alcoólica foi mais frequente entre os homens, em ambos os tipos de dependência: 60,0\% na Direção Geral e 54,2\% nos Cesec's costumam beber diariamente ou semanalmente, em comparação a $28,4 \%$ e $25,9 \%$ das mulheres, respectivamente (Tabelas III.3.12 e III.3.13). Na Direção Geral, apresentaram 7,05 vezes mais chance de beber diariamente comparado a não beber, do que as mulheres (OR=7,05 IC 95\%: 2,47-20,14). Nos Cesec's, a associação entre frequência de consumo de álcool e sexo foi ainda maior: os homens tiveram 9,07 vezes mais chance de beber diariamente do que as mulheres (OR=9,07 IC 95\%: 3,79-21,71). A maior parte das mulheres consome bebidas alcoólicas ocasionalmente, e apenas 7,4\% na Direção Geral e 13,8\% nos Cesec's declararam não beber nunca. 
TABELA III.3.12

FREQUÊNCIA DE CONSUMO DE BEBIDAS ALCOÓLICAS POR SEXO DIREÇÃO GERAL

\begin{tabular}{|c|c|c|c|c|c|c|}
\hline \multirow[b]{3}{*}{ SEXO } & \multicolumn{4}{|c|}{ FREQUÊNCIA DE CONSUMO } & \multirow{2}{*}{\multicolumn{2}{|c|}{ TOTAL }} \\
\hline & \multirow{2}{*}{$\begin{array}{c}\text { DIARIO } \\
\%\end{array}$} & \multirow{2}{*}{$\begin{array}{c}\text { SEMANAL } \\
\%\end{array}$} & \multirow{2}{*}{$\begin{array}{c}\text { OCASIONAL* } \\
\%\end{array}$} & \multirow{2}{*}{$\begin{array}{c}\text { NUNCA } \\
\%\end{array}$} & & \\
\hline & & & & & $\mathbf{n}$ & $\%$ \\
\hline HOMENS & 17,0 & 43,3 & 34,5 & 5,2 & 330 & 100,0 \\
\hline MULHERES & 3,4 & 25,0 & 64,2 & 7,4 & 204 & 100,0 \\
\hline TOTAL & 11,8 & 36,3 & 45,9 & 6,0 & 534 & 100,0 \\
\hline
\end{tabular}

$\chi^{2}=56,45 p<0,001$

*Pelo menos uma vez por mês

\section{TABELA III.3.13 \\ FREQUÊNCIA DE CONSUMO DE BEBIDAS ALCOÓLICAS POR SEXO CESEC'S}

\begin{tabular}{l|cccc|cc}
\hline \multirow{2}{*}{ SEXO } & \multicolumn{7}{|c}{ FREQUENCIA DE CONSUMO } \\
\cline { 2 - 7 } & DIARIO & SEMANAL & OCASIONAL* & NUNCA & \multicolumn{2}{c}{ TOTAL } \\
\hline HOMENS & $\%$ & $\%$ & $\%$ & $\%$ & $n$ & $\%$ \\
MULHERES & 13,7 & 40,5 & 39,1 & 6,7 & 358 & 100,0 \\
\hline TOTAL & 3,1 & 22,8 & 60,2 & 13,8 & 289 & 100,0 \\
\hline
\end{tabular}

$\chi^{2}=58,14 p<0,001$

*Pelo menos uma vez por mês

Considerando-se os diferentes grupos etários, a frequência de consumo não variou de forma importante, exceto entre os homens mais jovens, cujo consumo diário foi menos frequente: $9,4 \%$ (IC 95\%: 6,1-12,7), comparado a 15,2\% (IC 95\%: 10,7-19,7) do grupo entre 35 e 39 anos. Comparando-se homens e mulheres, a diferença de consumo manteve-se em todos os grupos etários: os homens declararam consumir álcool predominantemente com frequência semanal ou diária, enquanto entre as mulheres, a frequência foi principalmente ocasional (Tabela III.3.14). 
TABELA III.3.15

DISTRIBUIÇÃO dA FREQUÊNCIA DE CONSUMO dE ÁlCOOL

SEGUNDO ESCOLARIDADE

AMBOS OS SEXOS

AMBAS AS DEPENDÊNCIAS

\begin{tabular}{l|ccc|cc}
\hline & \multicolumn{5}{|c}{ FREQUENCIA DE CONSUMO } \\
\cline { 2 - 6 } & $\begin{array}{l}\text { DIARIO OU } \\
\text { ESCOLARIDADE }\end{array}$ & OCASIONAL & NUNCA & TOTAL \\
& $\%$ & $\%$ & $\%$ & $\mathrm{n}$ & $\%$ \\
\hline $2^{\circ}$ GRAU & 57,6 & 34,8 & 7,6 & 15 & 100,0 \\
$2^{\circ}$ GRAU COMPLETO & 44,9 & 43,1 & 12,1 & 99 & 100,0 \\
SUPERIOR & 51,1 & 41,7 & 7,2 & 331 & 100,0 \\
NCOMPLETO & & & & & \\
SUPERIOR COMPLETO & 40,2 & 51,0 & 8,8 & 736 & 100,0 \\
\hline
\end{tabular}

$n=1181$

Proporçoes corrigidas por fator de expansão

* Ocasional= pelo menos uma vez por mês

\section{d-ATIVIDADE FISICA DE LAZER}

Mais da metade dos funcionários de ambos os sexos e ambas as dependências não pratica atividades fisicas de lazer com regularidade (duas vezes ou mais por semana, durante pelo menos vinte minutos cada vez) - Tabela III.3.16. Não houve diferença significativa entre as proporções de homens e mulheres que declararam esse hábito. Assim, na Direção Geral 45,6\% (IC 95\%: 41,0-50,2) dos homens praticam em comparação a 40,5\% (IC 95\%: 45,5-35,5) das mulheres. Nos Cesec's, prevalências semelhantes foram observadas: 43,6\% (IC 95\%: 39,647,6) dos homens e 40,1 (IC 95\%: 35,1-45,1) das mulheres praticam atividades fisicas de lazer.

TABELA III.3.16

PRÁTICA REGULAR DE ATIVIDADES FÍSICAS DE LAZER POR SEXO E TIPO DE DEPENDÊNCIA

\begin{tabular}{|c|c|c|c|c|c|c|c|c|}
\hline \multirow[b]{4}{*}{ SEXO } & \multicolumn{8}{|c|}{ PRÁTICA DE ATIVIDADES FISICAS } \\
\hline & \multicolumn{4}{|c|}{ DIREÇĀO GERAL } & \multicolumn{4}{|c|}{ CESEC } \\
\hline & \multirow{2}{*}{$\begin{array}{c}\text { NÃOO } \\
\%\end{array}$} & \multirow{2}{*}{$\begin{array}{c}\text { SIM } \\
\%\end{array}$} & \multicolumn{2}{|c|}{ TOTAL } & \multirow{2}{*}{$\begin{array}{c}\text { NÁO } \\
\%\end{array}$} & \multirow{2}{*}{$\begin{array}{c}\text { SIM } \\
\%\end{array}$} & \multicolumn{2}{|c|}{ TOTAL } \\
\hline & & & $\mathbf{n}$ & $\%$ & & & $\mathbf{n}$ & $\%$ \\
\hline HOMEM & 54,4 & 45,6 & 331 & 100,0 & 56,4 & 43,6 & 358 & 100,0 \\
\hline MULHER & 59,5 & 40,5 & 205 & 100,0 & 59,9 & 40,1 & 289 & 100,0 \\
\hline TOTAL & 56,3 & 43,7 & $\overline{536}$ & 100,0 & 58,0 & 42,0 & 647 & 100,0 \\
\hline
\end{tabular}


Diferentes impedimentos foram apontados para não praticar exercícios físicos regularmente, sendo a "Rotina de atividades pessoais" o mais frequente (Gráfico III.3.9).

\section{GRÁFICO III.3.9 \\ IMPEDIMENTOS DECLARADOS PARA A \\ PRÁTICA DE ATIVIDADE FÍSICA DE LAZER \\ EM AMBOS OS SEXOS \\ AMBAS AS DEPENDÊNCIAS}

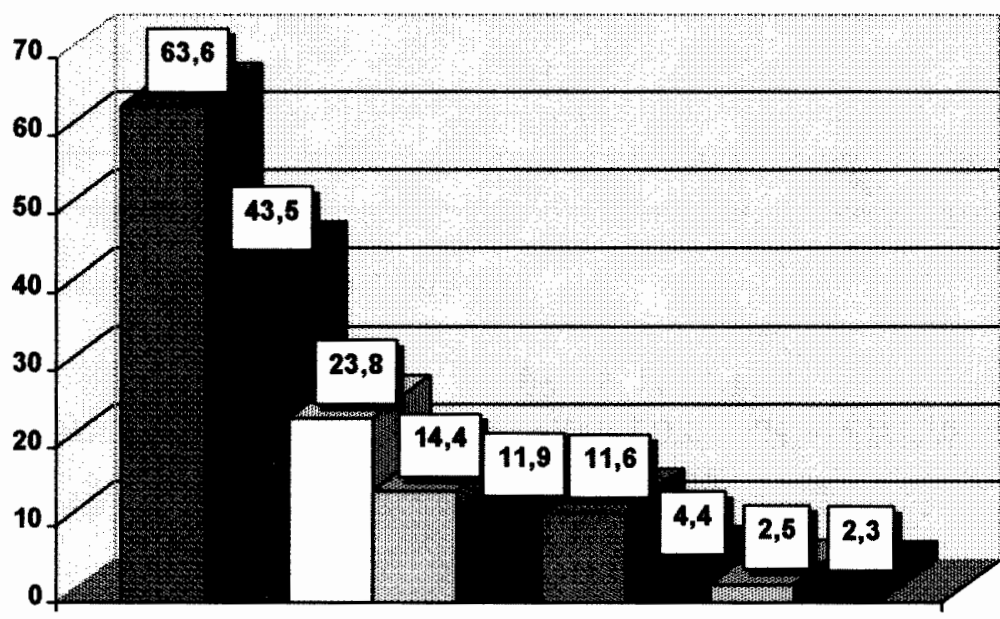

ROTINA DE ATIVIDADES PESSOAS - NÄO GOSTA

口 HORÁRIO DE TRABALHO

DFALTA DE OPÇÖES PERTO

- FALTA DE ÂNIMO

- IMPEDIMENTO FÍSICO

- OUTRO FATOR

G DIFICULDADE FINANCEIRA

- NÃo VÉ NECESSIDADE

* Proporções corrigidas com base na expansão de totais

A prevalência da prática de exercícios físicos de acordo com a idade apresentou padrão diferente na Direção Geral e no Cesec (Tabelas III.3.17 e III.3.18). Na primeira, não se identificaram diferenças importantes entre os grupos etários. Nos Cesec's, embora não se tenha encontrado diferença significativa entre as proporções, é possível identificar tendência à diminuição da prática de exercícios com o aumento da idade. Assim, enquanto 51,8\% (IC 95\%: 41,1-62,5) dos mais jovens declararam esse hábito, apenas 35,6\% (IC 95\%: 23,3-47,9) dos maiores de 45 anos o fizeram. 
TABELA III.3.17

PRÁTICA REGULAR DE ATIVIDADES FÍSICAS DE LAZER

POR IDADE

DIREÇÃO GERAL

\begin{tabular}{l|cccc}
\hline \multirow{2}{*}{ IDADE } & \multicolumn{4}{|c}{ PRATICA ATIVIDADE FISICA } \\
\cline { 2 - 5 } & NÃO & SIM & TOTAL \\
\hline $20-29$ & $\%$ & $\%$ & 58 & $\%$ \\
$30-34$ & 55,2 & 44,8 & 68 & 100,0 \\
$35-39$ & 55,9 & 44,1 & 190 & 100,0 \\
$40-44$ & 57,4 & 42,6 & 151 & 100,0 \\
45 e + & 58,3 & 41,7 & 69 & 100,0 \\
\hline TOTAL & 50,7 & 49,3 & 536 & 100,0 \\
\hline
\end{tabular}

Tendência Linear : $\chi^{2}=0,06 p=0,81069$

\section{TABELA III.3.18 \\ PRÁTICA REGULAR DE ATIVIDADES FÍSICAS DE LAZER POR IDADE \\ CESEC}

\begin{tabular}{l|cccc}
\hline \multirow{2}{*}{ IDADE } & \multicolumn{4}{|c}{ PRÁTICA ATIVIDADE FISICA } \\
\cline { 2 - 5 } & NÃO & SIM & TOTAL & $\%$ \\
\hline $20-29$ & $\%$ & $\%$ & $\mathbf{n}$ & 100,0 \\
$30-34$ & 48,2 & 51,8 & 100 & 100,0 \\
$35-39$ & 54,0 & 46,0 & 197 & 100,0 \\
$40-44$ & 56,3 & 43,7 & 206 & 100,0 \\
45 e + & 63,6 & 36,4 & 59 & 100,0 \\
\hline TOTAL & 64,4 & 35,6 & 647 & 100,0 \\
\hline
\end{tabular}

Tendência Linear : $\chi^{2}=7,36 \mathrm{p}=0,00667$

Um dos resultados positivos encontrado nesse estudo refere-se à alta frequência de atividades físicas dos funcionários que declararam esse hábito. Na Direção Geral, dentre os 151 homens que praticam atividades físicas regulares, $50,3 \%$ o fazem pelo menos cinco vezes por semana, durante 20 minutos ou mais de cada vez (tabela III.3.19). Entre as mulheres, $43,2 \%$ das que praticam, também o fazem pelo menos cinco vezes por semana. Nos Cesec's, o mesmo padrão foi observado (Tabela III.3.20). 
TABELA III.3.19

FREQUÊNCIA SEMANAL DE ATIVIDADES FÍSICAS DE LAZER

POR SEXO

DIREÇÃO GERAL

\begin{tabular}{|c|c|c|c|c|c|c|}
\hline \multirow[b]{3}{*}{ SEXO } & \multicolumn{6}{|c|}{ FREQÜÊNCIA } \\
\hline & \multirow{2}{*}{$\begin{array}{c}7 \text { VEZES } \\
\%\end{array}$} & \multirow{2}{*}{$\begin{array}{c}50 U 6 \\
\text { VEZES } \\
\%\end{array}$} & \multicolumn{2}{|c|}{2 A 4 VEZES NÃO FAZ } & \multicolumn{2}{|c|}{ TOTAL } \\
\hline & & & $\%$ & $\%$ & $\mathbf{n}$ & $\%$ \\
\hline HOMENS & 10,6 & 12,4 & 22,7 & 54,4 & 331 & 100,0 \\
\hline MULHERES & 7,9 & 9,4 & 22,7 & 60,1 & 203 & 100,0 \\
\hline TOTAL & 9,6 & 11,2 & 22,7 & 56,6 & 534 & 100,0 \\
\hline
\end{tabular}

$\chi^{2}=2,70856 \mathrm{p}=0,43877$

TABELA III.3.20

FREQUÊNCIA SEMANAL DE ATIVIDADES FÍSICAS DE LAZER POR SEXO

CESEC

\begin{tabular}{|c|c|c|c|c|c|c|}
\hline \multirow[b]{3}{*}{ SEXO } & \multicolumn{6}{|c|}{ FREQUEENCIA } \\
\hline & 7 VEZES & $\begin{array}{l}5 \text { OU } 6 \\
\text { VEZES }\end{array}$ & 2 A 4 VEZES & NÁO FAZ & TO & $\overline{\mathrm{AL}}$ \\
\hline & $\%$ & $\%$ & $\%$ & $\%$ & $\mathbf{n}$ & $\%$ \\
\hline HOMENS & 13,0 & $\overline{8,8}$ & 21,2 & 57,1 & 354 & 100,0 \\
\hline MULHERES & 8,7 & 13,2 & 17,8 & 60,3 & 287 & 100,0 \\
\hline TOTAL & 11,1 & 10,8 & 19,7 & 58,5 & 641 & 100,0 \\
\hline
\end{tabular}

$\chi^{2}=6,80675 p=0,07832$

A prática de atividades físicas não variou de forma importante de acordo com a escolaridade: 50\% (IC 95\%: 42,1-57,9) dos funcionários que não ingressaram na universidade praticam, comparados a 41,9\% (IC 95\%: 38,8-45,0) daqueles que têm curso superior completo. Cabe ressaltar que os funcionários que não apresentam curso superior são mais jovens, o que pode explicar, em parte, as prevalências estimadas (Tabela III.3.21). 
TABELA III.3.21

PRÁTICA REGULAR DE ATIVIDADES FÍSICAS*

SEGUNDO ESCOLARIDADE

AMBOS OS SEXOS

AMBAS AS DEPENDÊNCIAS

\begin{tabular}{l|cccc}
\hline \multirow{2}{*}{ ESCOLARIDADE } & \multicolumn{3}{|c}{ PRÁTICA DE ATIVIDADES FISICAS } \\
\cline { 2 - 5 } & SIM & NÃO & \multicolumn{2}{c}{ TOTAL } \\
\hline < SUPERIOR** & $\%$ & $\%$ & n & $\%$ \\
SUPERIOR INCOMPLETO & 50,0 & 50,0 & 115 & 100,0 \\
SUPERIOR COMPLETO & 41,0 & 59,0 & 331 & 100,0 \\
\end{tabular}

$\mathrm{n}=1183$

Proporções corrigidas por fator de expansão

* Mínimo de duas vezes por semana, durante pelo menos vinte minutos de cada vez

* * $2^{\circ}$ grau incompleto ou completo

\section{e-PRESSÃO ARTERIAL}

Uma vez que a medida de pressão arterial faz parte da rotina do exame de saúde realizado anualmente em todos os funcionários, $92,6 \%( \pm 1,3)$ deles informou que a última medida foi tomada no último ano antes do preenchimento do questionário, e outros $7,1 \%$ $( \pm 1,3)$, entre um e dois anos antes.

Em primeiro lugar, chama a atenção a maior proporção de homens que não souberam informar seus níveis de pressão arterial habitual -25,2\% (IC 95\%: 21,7-28,7) na DG e 31,1\% (IC 95\%: 26,8-35,4) nos Cesec's- quando comparada à mesma proporção de mulheres, em ambos os tipos de dependência: 13,8\% (IC 95\%: 10,3-17,3) e 12,5\% (IC 95\%: 9,1-15,9), respectivamente (Tabelas III.3.22 e III.3.23).

Maior proporção de homens também informou ter níveis habituais mais altos ( $\geq 140 \mathrm{mmHg}$ ) de pressão sistólica: 10,0\% (IC 95\%: 7,6-12,4-), comparados a apenas 1,5\% (IC 95\%: 0,3-2,7) das mulheres, na Direção Geral. Nos Cesec's, a diferença foi menor mas ainda importante, já que 9,0\% (IC 95\%: 6,3-11,7) dos homens e 4,2\% (IC 95\%: 2,1-6,3) das mulheres foram incluídos nessa categoria. Em relação aos níveis informados de pressão diastólica, o mesmo comportamento foi observado, com maior prevalência de níveis elevados $(\geq 90 \mathrm{mmHg}$ ) entre os homens (Tabelas III.3.24 e III.3.25). 
TABELA III.3.22

NÍVEIS INFORMADOS DE PRESSÃO SISTÓLICA

POR SEXO

DIREÇÃO GERAL

\begin{tabular}{|c|c|c|c|c|c|c|c|c|}
\hline \multirow[b]{3}{*}{ SEXO } & \multicolumn{6}{|c|}{ PRESSĀO SISTÓLICA } & & \\
\hline & \multicolumn{2}{|c|}{$<140 \mathrm{mmHg}$} & \multicolumn{2}{|c|}{$\geq 140 \mathrm{mmHg}$} & \multicolumn{2}{|c|}{$\begin{array}{l}\text { NÃO SABE } \\
\text { INFORMAR }\end{array}$} & \multicolumn{2}{|c|}{ TOTAL } \\
\hline & $\mathbf{n}$ & $\%$ & $\mathbf{n}$ & $\%$ & $\mathrm{n}$ & $\%$ & $\mathrm{n}$ & $\%$ \\
\hline HOMENS & 214 & 64,8 & $\overline{33}$ & 10,0 & $\overline{83}$ & 25,2 & 330 & 100,0 \\
\hline MULHERES & 172 & 84,7 & 3 & 1,5 & 28 & 13,8 & 203 & 100,0 \\
\hline TOTAL & 386 & 72,4 & $\overline{36}$ & 6,8 & 111 & 20,8 & 533 & 100,0 \\
\hline
\end{tabular}

$\chi^{2}=28,16 p<0,001$

TABELA III.3.23

NIVEIS INFORMADOS DE PRESSÃO SISTÓLICA

POR SEXO

CESEC

\begin{tabular}{|c|c|c|c|c|c|c|c|c|}
\hline \multirow[b]{3}{*}{ SEXO } & \multicolumn{6}{|c|}{ PRESSÃO SISTÓLICA } & & \\
\hline & \multicolumn{2}{|c|}{$<140 \mathrm{mmHg}$} & \multicolumn{2}{|c|}{$\geq 140 \mathrm{mmHg}$} & \multicolumn{2}{|c|}{$\begin{array}{l}\text { NĀO SABE } \\
\text { INFORMAR }\end{array}$} & \multicolumn{2}{|c|}{ TOTAL } \\
\hline & $\mathbf{n}$ & $\%$ & $\mathbf{n}$ & $\%$ & $\mathbf{n}$ & $\%$ & $\mathbf{n}$ & $\%$ \\
\hline HOMENS & 214 & 59,9 & 32 & 9,0 & 111 & $\overline{31,1}$ & 357 & 100,0 \\
\hline MULHERES & 240 & 83,3 & 12 & 4,2 & 36 & 12,5 & 288 & 100,0 \\
\hline TOTAL & 454 & 70,4 & 44 & 6,8 & 147 & $\overline{22,8}$ & 645 & 100,0 \\
\hline
\end{tabular}

$\chi^{2}=41,94 p<0,001$

TABELA III.3.24

NÍVEIS INFORMADOS DE PRESSÃO DIASTÓLICA

POR SEXO

DIREÇÃO GERAL

\begin{tabular}{|c|c|c|c|c|c|c|c|c|}
\hline \multirow[b]{3}{*}{ SEXO } & \multicolumn{8}{|c|}{ PRESSĀO DIASTÓLICA } \\
\hline & \multicolumn{2}{|c|}{$<90 \mathrm{mmHg}$} & \multicolumn{2}{|c|}{$\geq 90 \mathrm{mmHg}$} & \multicolumn{2}{|c|}{$\begin{array}{l}\text { NÁO SABE } \\
\text { INFORMAR }\end{array}$} & \multicolumn{2}{|c|}{ TOTAL } \\
\hline & $\mathbf{n}$ & $\%$ & n & $\%$ & n & $\%$ & $\mathbf{n}$ & $\%$ \\
\hline HOMENS & 208 & $\overline{63,0}$ & 39 & $\overline{11,8}$ & 83 & 25,2 & 330 & 100,0 \\
\hline MULHERES & 168 & 82,8 & 7 & 3,4 & 28 & 13,8 & 203 & 100,0 \\
\hline TOTAL & 376 & 70,5 & $\overline{46}$ & 8,6 & 111 & 20,8 & 533 & $\overline{100,0}$ \\
\hline
\end{tabular}

$\chi^{2}=24,92 p<0,001$ 
TABELA III.3.25

NÍVEIS INFORMADOS DE PRESSÃO DIASTÓLICA

POR SEXO

CESEC

\begin{tabular}{l|cccccc|cc}
\hline & \multicolumn{7}{|c|}{ PRESSÁO DIASTÓLICA } \\
\cline { 2 - 9 } SEXO & $<90 \mathrm{mmHg}$ & $\geq 90 \mathrm{mmHg}$ & \multicolumn{2}{c|}{ NÁO SABE } & \multicolumn{2}{c}{ TOTAL } \\
\hline HOMENS & $\mathrm{n}$ & $\%$ & $\mathrm{n}$ & $\%$ & $\mathrm{n}$ & $\%$ & $\mathrm{n}$ & $\%$ \\
MULHERES & 200 & 56,0 & 46 & 12,9 & 111 & 31,1 & 330 & 100,0 \\
TOTAL & 234 & 81,3 & 18 & 6,3 & 36 & 12,5 & 203 & 100,0 \\
\hline
\end{tabular}

$\chi^{2}=46,33 p<0,001$

Dentre os homens da Direção Geral, 20,1\% (IC 95\%: 16,9-23,3) já foram informados pelo menos uma vez por um profissional de saúde, de que "eram hipertensos ou tinham pressão alta" (pergunta $n^{\circ}$ 68) (Tabela III.3.26). Na mesma dependência, 10,0\% (IC 95\%: 7,0-13,0) das mulheres já tiveram esse tipo de informação. Também nos Cesec's maior proporção de homens $-23,1 \%$ (IC 95\%: 19,2-27,0)- do que de mulheres -13,9\% (IC 95\%: 10,4-17,4) - já foram informados sobre hipertensão (Tabela III.3.27).

TABELA III.3.26

INFORMAC̄̃̃O SOBRE HIPERTENSÃO ARTERIAL POR ALGUM PROFISSIONAL DE SAÚDE

POR SEXO

DIREÇÃO GERAL

\begin{tabular}{|c|c|c|c|c|c|c|c|c|}
\hline \multirow[b]{3}{*}{ SEXO } & \multicolumn{8}{|c|}{ INFORMAÇĀO SOBRE HIPERTENSĀO } \\
\hline & \multicolumn{2}{|c|}{$\begin{array}{l}\text { APENAS } \\
\text { UMA VEZ }\end{array}$} & \multicolumn{2}{|c|}{$\begin{array}{l}\text { MAIS DE } \\
\text { UMA VEZ }\end{array}$} & \multicolumn{2}{|c|}{ NUNCA } & \multicolumn{2}{|c|}{ TOTAL } \\
\hline & $\mathbf{n}$ & $\%$ & $\mathrm{n}$ & $\%$ & $\mathbf{n}$ & $\%$ & $\mathbf{n}$ & $\%$ \\
\hline HOMENS & 25 & 7,6 & 41 & 12,5 & 261 & 79,8 & 327 & 100,0 \\
\hline MULHERES & 6 & 3,0 & 14 & 7,0 & 181 & 90,0 & 201 & 100,0 \\
\hline TOTAL & 31 & 5,9 & 55 & 10,4 & 442 & 83,7 & 528 & 100,0 \\
\hline
\end{tabular}

$\chi^{2}=9,87 \mathrm{p}=0,007$

Obs: $3(1,5 \%)$ mulheres referiram hipertensão apenas durante a gestação 
TABELA III.3.27

INFORMAÇÃO SOBRE HIPERTENSÃO ARTERIAL

POR ALGUM PROFISSIONAL DE SAÚDE

POR SEXO

CESEC

\begin{tabular}{|c|c|c|c|c|c|c|c|c|}
\hline \multirow[b]{3}{*}{ SEXO } & \multicolumn{8}{|c|}{ INFORMAÇĀO SOBRE HIPERTENSĀO } \\
\hline & \multicolumn{2}{|c|}{$\begin{array}{l}\text { APENAS } \\
\text { UMA VEZ }\end{array}$} & \multicolumn{2}{|c|}{$\begin{array}{l}\text { MAIS DE } \\
\text { UMA VEZ }\end{array}$} & \multicolumn{2}{|c|}{ NUNCA } & \multicolumn{2}{|c|}{ TOTAL } \\
\hline & $\mathrm{n}$ & $\%$ & $\mathrm{n}$ & $\%$ & $\mathbf{n}$ & $\%$ & $\mathrm{n}$ & $\%$ \\
\hline HOMENS & $\overline{28}$ & 7,9 & 54 & 15,2 & 274 & 77,0 & 356 & 100,0 \\
\hline MULHERES & 16 & 5,7 & 23 & 8,2 & 241 & 86,1 & 280 & 100,0 \\
\hline TOTAL & 44 & 6,9 & 23 & 8,2 & 241 & 86,1 & 636 & 100,0 \\
\hline
\end{tabular}

$\chi^{2}=8,91 \mathrm{p}=0,012$

Obs: $7(2,4 \%)$ mulheres referiram hipertensão apenas durante a gestação

Apresentamos em seguida a comparação entre os resultados obtidos com duas questões que buscam estimar a prevalência conhecida de hipertensão (Tabela III.3.28). Assim, as respostas à pergunta $n^{\circ} 68$ (Anexo 8), apresentadas acima, foram comparadas aos resultados da pergunta $n^{\circ} 97$ (Anexo 8), onde se solicita que o funcionário assinale as condições relacionadas ao aparelho cardiovascular que "já teve ou tem atualmente". A pergunta $n^{\circ} 97$ busca portanto a auto-classificação do funcionário em hipertenso ou não hipertenso.

Os resultados variaram segundo a dependência. Na Direção Geral, 61,3\% dos 31 funcionários informados sobre hipertensão por um profissional de saúde apenas uma vez, se classificaram como hipertensos. Nos Cesec's, apenas 38,1\% dos 42 funcionários informados apenas uma vez de que tinham pressão alta, classificaram-se dessa forma. De acordo com o esperado, a concordância entre as duas perguntas foi maior entre aqueles que foram informados sobre hipertensão mais de uma vez, em dias diferentes. Dentre esses, 89,1\% na Direção Geral e $85,7 \%$ nos Cesec's se classificaram como hipertensos. Dentre as sete funcionárias dos Cesec's que foram informadas apenas durante a gestação, quatro se classificaram como hipertensas. Além disso, dentre aqueles que nunca foram informados sobre hipertensão por um profissional de saúde, $3(0,7 \%)$ funcionários da Direção Geral e $4(0,8 \%)$ dos Cesec's se classificaram como hipertensos. 
TABELA III.3.28

COMPARAÇÃO ENTRE INFORMAÇÃO SOBRE HIPERTENSÃO

A PARTIR DE ALGUM PROFISSIONAL DE SAÚdE

E DECLARAÇÃO DE SER PORTADOR DA DOENÇA

AMBOS OS SEXOS

AMBAS AS DEPENDÊNCLAS

\begin{tabular}{|c|c|c|c|c|c|c|c|c|}
\hline \multirow{4}{*}{$\begin{array}{l}\text { INFORMAÇÃO } \\
\text { SOBRE } \\
\text { HIPERTENSÃO }\end{array}$} & \multicolumn{8}{|c|}{ DECLAROU SER HIPERTENSO } \\
\hline & \multicolumn{4}{|c|}{ DIREÇÃO GERAL } & \multicolumn{4}{|c|}{ CESEC } \\
\hline & \multirow{2}{*}{$\begin{array}{c}\text { NÁO } \\
\%\end{array}$} & \multirow{2}{*}{$\begin{array}{c}\text { SIM } \\
\%\end{array}$} & \multicolumn{2}{|c|}{ TOTAL } & \multirow{2}{*}{$\begin{array}{c}\text { NAOO } \\
\%\end{array}$} & \multirow{2}{*}{$\begin{array}{c}\text { SIM } \\
\%\end{array}$} & \multicolumn{2}{|c|}{ TOTAL } \\
\hline & & & $\mathbf{n}$ & $\%$ & & & $\mathbf{n}$ & $\%$ \\
\hline APENAS UMA VEZ & 38,7 & 61,3 & $\overline{31}$ & 100,0 & 61,9 & 38,1 & $\overline{42}$ & 100,0 \\
\hline MA VEZ & 10,9 & 89,1 & 55 & 100,0 & 14,3 & 85,7 & 77 & 100,0 \\
\hline $\begin{array}{l}\text { S DURANTE } \\
\text { DEZ }\end{array}$ & 100,0 & 0 & 33 & 100,0 & 42,9 & 57,1 & 7 & 100,0 \\
\hline NUNCA & 99,3 & 0,7 & 441 & 100,0 & 99,2 & 0,8 & 501 & 100,0 \\
\hline TOTAL & 86,5 & 13,5 & 530 & 100,0 & 86,1 & 13,9 & $\overline{627}$ & 100,0 \\
\hline
\end{tabular}

A proporção de funcionários em tratamento para controle de hipertensão arterial é pequena tanto entre os funcionários que se declararam hipertensos à pergunta $n^{\circ} 97-51,5 \%$ na DG e 56,3\% nos Cesec's- quanto entre os informados sobre hipertensão por um profissional de saúde (pergunta $n^{\circ} 68$ ). Considerando-se essa pergunta, dentre os funcionários informados mais de uma vez sobre hipertensão, 58,5\% declararam estar em tratamento, mas $15,1 \%$ nunca se trataram e $26,4 \%$ não se tratam mais, na Direção Geral (Tabela III.3.29). De acordo com o esperado, a proporção de funcionários em tratamento é ainda menor entre aqueles que foram informados apenas uma vez. O mesmo padrão foi observado nos Cesec's, onde $26,0 \%$ (IC 95\%: 23,0-29,0) dos funcionários informados mais de uma vez sobre hipertensão não se tratam mais, e 20,5\% (IC 95\%: 17,7-23,3) nunca se trataram (Tabela III.3.30).

Considerando-se ambas as dependências, é interessante notar que os motivos de interrupção do tratamento para controle de hipertensão mais frequentes foram "Porque fiquei curado" $(-45,3 \%-)$ e "Porque não sentia nada" $(-29,8 \%-)$. Nenhum funcionário assinalou "Falta de resultados do tratamento"ou o"Preço dos medicamentos"; 5,8\% apontaram "Tratamento demorado", e apenas 2,9\% referiram ter parado porque os "Medicamentos faziam mal". Cerca de um terço dos funcionários apontaram "outros motivos" para a interrupção do tratamento. 
TABELA III.3.29

CONDIÇÃO DE TRATAMENTO ENTRE AQUELES INFORMADOS SOBRE HIPERTENSÃO ARTERIAL

DIREÇÃO GERAL

\begin{tabular}{|c|c|c|c|c|c|c|c|c|}
\hline \multirow{4}{*}{$\begin{array}{l}\text { INFORMAÇÃO } \\
\text { SOBRE } \\
\text { HIPERTENSÃO }\end{array}$} & \multicolumn{8}{|c|}{ CONDIÇĀO DE TRATAMENTO } \\
\hline & \multirow{2}{*}{\multicolumn{2}{|c|}{$\begin{array}{l}\text { TRATOU NO } \\
\text { PASSADO }\end{array}$}} & \multirow{2}{*}{\multicolumn{2}{|c|}{$\begin{array}{c}\text { ESTA EM } \\
\text { TRATAMENTO }\end{array}$}} & \multirow{2}{*}{\multicolumn{2}{|c|}{$\begin{array}{l}\text { NUNCA } \\
\text { TRATOU }\end{array}$}} & \multirow{2}{*}{\multicolumn{2}{|c|}{ TOTAL }} \\
\hline & & & & & & & & \\
\hline & $\mathbf{n}$ & $\%$ & $\mathbf{n}$ & $\%$ & $\mathbf{n}$ & $\%$ & $\mathrm{n}$ & $\%$ \\
\hline APENAS UMA VEZ & 7 & 28,0 & 5 & 20,0 & 13 & 52,0 & 25 & 100,0 \\
\hline MAIS DE UMA VEZ & 14 & 26,4 & 31 & 58,5 & 8 & 15,1 & 53 & 100,0 \\
\hline TOTAL & 21 & 26,9 & $\overline{31}$ & 58,5 & 8 & 15,1 & 78 & 100,0 \\
\hline
\end{tabular}

$\chi^{2}=14,06 p=0,0009$

TABELA III.3.30

CONDIÇÃO DE TRATAMENTO ENTRE AQUELES INFORMADOS SOBRE HIPERTENSÃO ARTERIAL

CESEC

\begin{tabular}{|c|c|c|c|c|c|c|c|c|}
\hline \multirow{3}{*}{$\begin{array}{l}\text { INFORMAÇÃO } \\
\text { SOBRE } \\
\text { HIPERTENSÃO }\end{array}$} & \multicolumn{8}{|c|}{ CONDIÇÁO DE TRATAMENTO } \\
\hline & \multicolumn{2}{|c|}{$\begin{array}{l}\text { TRATOUNO } \\
\text { PASSADO }\end{array}$} & \multicolumn{2}{|c|}{$\begin{array}{c}\text { ESTA EM } \\
\text { TRATAMENTO }\end{array}$} & \multicolumn{2}{|c|}{$\begin{array}{l}\text { NUNCA } \\
\text { TRATOU }\end{array}$} & \multicolumn{2}{|c|}{ TOTAL } \\
\hline & n & $\%$ & n & $\%$ & $\mathrm{n}$ & $\%$ & $\mathbf{n}$ & $\%$ \\
\hline APENAS UMA VEZ & 9 & 24,3 & 10 & 27,0 & 18 & 48,6 & 37 & 100,0 \\
\hline MAIS DE UMA VEZ & 19 & 26,0 & 39 & 53,4 & 15 & 20,5 & 73 & 100,0 \\
\hline TOTAL & 28 & 25,5 & 39 & 53,4 & 15 & 20,5 & 110 & 100,0 \\
\hline
\end{tabular}

$\chi^{2}=10,33 p=0,006$

Considerando-se homens e mulheres informados mais de uma vez sobre hipertensão arterial, maior proporção do sexo feminino encontrava-se em tratamento, em ambas as dependências: 61,5\% (IC 95\%: 56,6-66,4) em comparação a 55,5\% (IC 95\%: 51,5-59,5) dos homens, na Direção Geral e 57,1\% (IC 95\%: 52,0-62,2) contra 51,9\% (IC 95\%: 47,2-56,6) nos Cesec's (Gráficos III.3.10 e III.3.11). 
GRÁFICO III.3.10

CONDIÇÃO DE TRATAMENTO DOS FUNCIONÁRIOS INFORMADOS MAIS DE

UMA VEZ DE QUE ERAM HIPERTENSOS

POR SEXO

DIREÇ̃̃O GERAL

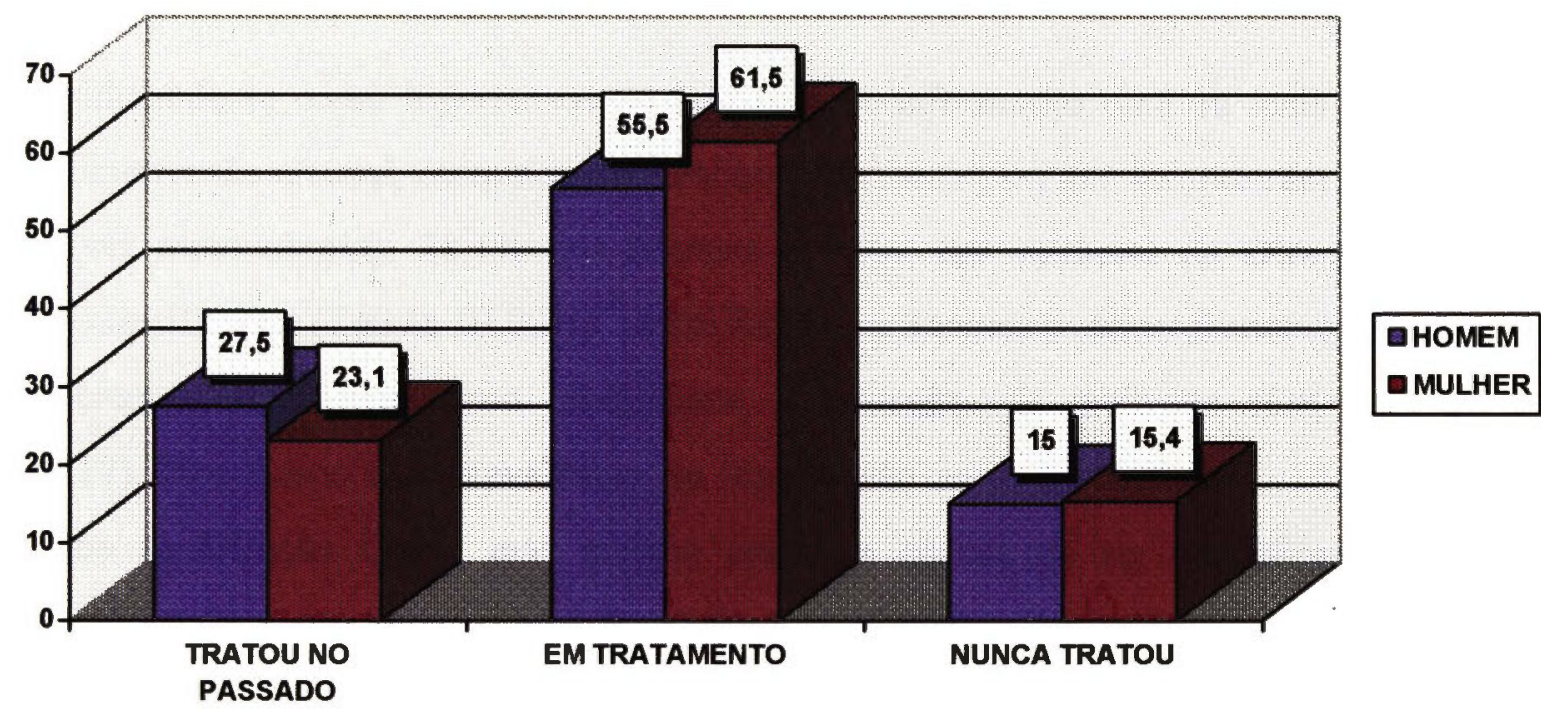

GRÁFICO III.3.11

CONDIÇÃO DE TRATAMENTO DOS FUNCIONÁRIOS INFORMADOS MAIS DE UMA VEZ DE QUE ERAM HIPERTENSOS POR SEXO

CESEC

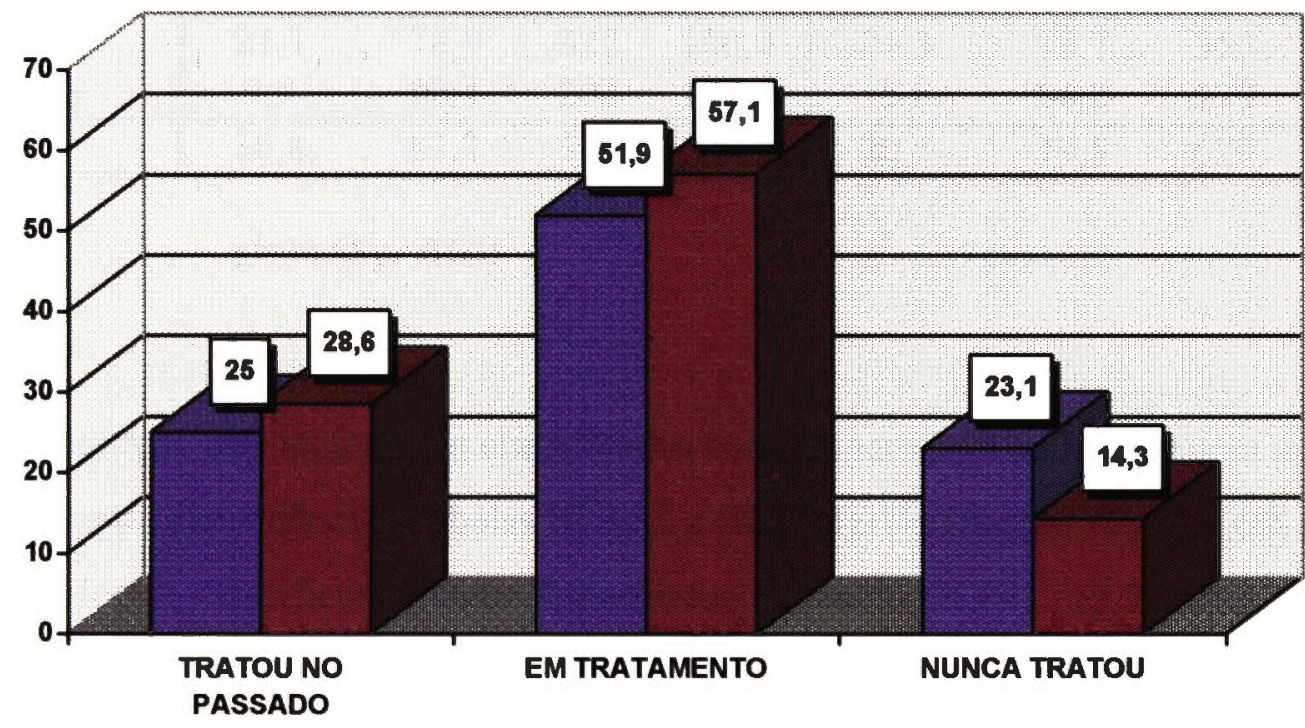

D HOMEM a MULHER 
Dentre os funcionários da Direção Geral e dos Cesec's que estão em tratamento para controle de hipertensão arterial, a maior parte utiliza medicamentos $-80,6 \%-; 70,9 \%$ fazem restrição de sal; $45,7 \%$ controlam o peso; $33,45 \%$ praticam exercícios físicos, e 7,9\% utilizam outros meios.

Considerando-se como hipertensos os funcionários informados uma ou mais vezes de que tinham hipertensão arterial, ou que se declararam hipertensos, ou que informaram estar sob tratamento (ver metodologia), $21,1 \%$ dos homens e $9,9 \%$ das mulheres da Direção Geral foram assim classificados (Tabela III.3.31). Dessa forma, os homens tiveram chance 2,45 vezes maior de serem classificados como hipertensos, comparados às mulheres $(O R=2,45$ IC 95\%:1,44-4,17). Nos Cesec's, a prevalência de hipertensão entre as mulheres $-15,8 \%$ - foi maior do que na Direção Geral, mas mesmo assim, a chance de ser classificado como hipertenso também foi maior entre os homens: (OR=1,71 IC 95\%: 1,14-2,57)- Tabela III.3.31.

TABELA III.3.31

CLASSIFICAÇÃO DE HIPERTENSÃO POR SEXO DIREÇÃO GERAL E CESEC

\begin{tabular}{|c|c|c|c|c|c|c|c|c|}
\hline \multirow[b]{4}{*}{ SEXO } & \multicolumn{8}{|c|}{ HIPERTENSÃO } \\
\hline & \multicolumn{4}{|c|}{ DIREÇĀO GERAL } & \multicolumn{4}{|c|}{ CESEC } \\
\hline & \multirow{2}{*}{$\begin{array}{c}\text { SIM } \\
\%\end{array}$} & \multirow{2}{*}{$\begin{array}{c}\text { NÁO } \\
\%\end{array}$} & \multicolumn{2}{|c|}{ TOTAL } & \multirow{2}{*}{$\begin{array}{c}\text { SIM } \\
\%\end{array}$} & \multirow{2}{*}{$\begin{array}{c}\text { NÃO } \\
\%\end{array}$} & \multicolumn{2}{|c|}{ TOTAL } \\
\hline & & & $\mathrm{N}$ & $\%$ & & & $\mathbf{N}$ & $\%$ \\
\hline HOMENS & 21,1 & 78,9 & 327 & 100,0 & 24,3 & 75,7 & 350 & 100,0 \\
\hline MULHERES & 9,9 & 90,1 & 203 & 100,0 & 15,8 & 84,2 & 279 & 100,0 \\
\hline TOTAL & 16,8 & 83,2 & 530 & 100,0 & 20,5 & 79,5 & 629 & 100,0 \\
\hline
\end{tabular}

A proporção de funcionários classificados como hipertensos aumentou com a idade, em ambos os tipos de dependência (Tabelas III.3.32 e III.3.33). Na Direção Geral, 8,6\% $( \pm 2,4)$ dos mais jovens foram classificados como hipertensos enquanto $25,0 \%( \pm 3,7)$ dos mais velhos foram incluídos nessa categoria. Nos Cesec's, as prevalências variaram entre $13,4 \%( \pm 2,6)$ nos mais jovens e $33,9 \%( \pm 3,7)$ do grupo com 45 anos ou mais. 
TABELA III.3.32

CLASSIFICAÇÃO DE HIPERTENSÃO POR GRUPO ETÁRIO DIREÇÃO GERAL

\begin{tabular}{l|cc|cc}
\hline \multirow{2}{*}{ IDADE } & \multicolumn{3}{|c|}{ HIPERTENSÃO } & \multicolumn{2}{c}{ TOTAL } \\
\cline { 2 - 6 } & HIPERTENSO & NÃO HIPERTENSO & n & $\%$ \\
\hline $20-29$ & $\%$ & $\%$ & 58 & 100,0 \\
$30-34$ & 8,6 & 91,4 & 67 & 100,0 \\
$35-39$ & 14,9 & 85,1 & 187 & 100,0 \\
$40-44$ & 14,4 & 85,6 & 150 & 100,0 \\
$45 \mathrm{e}+$ & 20,0 & 80,0 & 68 & 100,0 \\
\hline TOTAL & 25,0 & 75,0 & 530 & 100,0 \\
\hline
\end{tabular}

Tendência Linear: $\chi^{2}=7,27 \mathrm{p}=0,00702$

TABELA III.3.33

CLASSIFICAÇÃo dE HIPERTENSÃo POR GRUPO ETÁRIO CESEC

\begin{tabular}{l|cc|cc}
\hline \multirow{2}{*}{ IDADE } & \multicolumn{3}{|c}{ HIPERTENSÃO } \\
\cline { 2 - 6 } & HIPERTENSO & NÃO HIPERTENSO & \multicolumn{2}{c}{ TOTAL } \\
\hline $20-29$ & $\%$ & $\%$ & 82 & $\%$ \\
$30-34$ & 13,4 & 86,6 & 97 & 100,0 \\
$35-39$ & 16,5 & 83,5 & 192 & 100,0 \\
$40-44$ & 16,1 & 83,9 & 199 & 100,0 \\
45 e + & 25,6 & 74,4 & 59 & 100,0 \\
\hline TOTAL & 33,9 & 66,1 & 629 & 100,0 \\
\hline
\end{tabular}

Tendência Linear: $\chi^{2}=12,34 p<0,001$

Em relação à distribuição da hipertensão segundo escolaridade, nos funcionários até 40 anos de idade, aqueles que ingressaram na universidade apresentaram maior prevalência, quando comparados àqueles que não ingressaram. Assim, apenas 9,1\% (IC 95\%: 2,9-15,3) daqueles com menor escolaridade foram classificados como hipertensos em comparação a 17,6\% (IC 95\%: 13,1-22,1) daqueles que não concluíram curso superior, e 15,1\% (IC 95\%: 12,2-18,0) daqueles que o concluíram (Tabela III.3.34). Entre os funcionários com mais de 40 
anos, por outro lado, a prevalência de hipertensão foi semelhante nos diversos estratos de escolaridade (Tabela III.3.35).

TABELA III.3.34

FREQUÊNCIA DE HIPERTENSÃO ARTERIAL

SEGUNDO ESCOLARIDADE

AMBOS OS SEXOS

AMBAS AS DEPENDÊNCIAS

IDADE MENOR OU IGUAL A 40 ANOS

\begin{tabular}{l|cc|c}
\hline \multirow{2}{*}{ ESCOLARIDADE } & \multicolumn{3}{|c}{ HIPERTENSĀO } \\
\cline { 2 - 4 } & SIM & NÄO & TOTAL \\
\hline S SUPERIOR* & $\%$ & $\%$ & n \\
SUPERIOR INCOMPLETO & 9,1 & 90,9 & 62 \\
SUPERIOR COMPLETO & 17,6 & 82,4 & 204 \\
\hline
\end{tabular}

$\mathrm{n}=683$

Proporçoes corrigidas por fator de expansão

* $2^{\circ}$ grau incompleto ou completo

TABELA III.3.35

FREQUÊNCIA DE HIPERTENSÃO ARTERIAL

SEGUNDO ESCOLARIDADE

AMBOS OS SEXOS

AMBAS AS DEPENDÊNCIAS

MAIORES DE 40 ANOS

\begin{tabular}{l|cc|c}
\hline \multirow{2}{*}{ ESCOLARIDADE } & \multicolumn{3}{|c}{ PRATICA DE ATIVIDADES FISICAS } \\
\cline { 2 - 4 } & SIM & NÁO & TOTAL \\
$\%$ & 26,2 & 73,8 & 50 \\
\hline < SUPERIOR* & 25,1 & 74,9 & 120 \\
SUPERIOR & & & \\
INCOMPLETO & 26,8 & 73,2 & 306 \\
SUPERIOR COMPLETO & \multicolumn{3}{|c}{} \\
\hline
\end{tabular}

$\mathrm{N}=476$

Proporções corrigidas por fator de expansão

* $2^{\circ}$ grau incompleto ou completo 


\section{F-ÍNDICE DE MASSA CORPORAL}

Dentre os fatores de risco estudados, o Índice de Massa Corporal (IMC) foi um dos que apresentou maiores diferenças entre os sexos. Considerando-se a média do IMC, os valores dos homens foram maiores do que os valores das mulheres em ambas as dependências). Na Direção Geral, o IMC médio foi de $24,95 \mathrm{~kg} / \mathrm{m}^{2}$ entre os homens, e $22,27 \mathrm{~kg} / \mathrm{m}^{2}$ entre as mulheres $(p<0,001)$. Nos Cesec's, o IMC médio foi de $25,03 \mathrm{~kg} / \mathrm{m}^{2}$ contra $23,28 \mathrm{~kg} / \mathrm{m}^{2}$ no sexo masculino e feminino, respectivamente $(p<0,001)$ (Gráfico III.3.12).
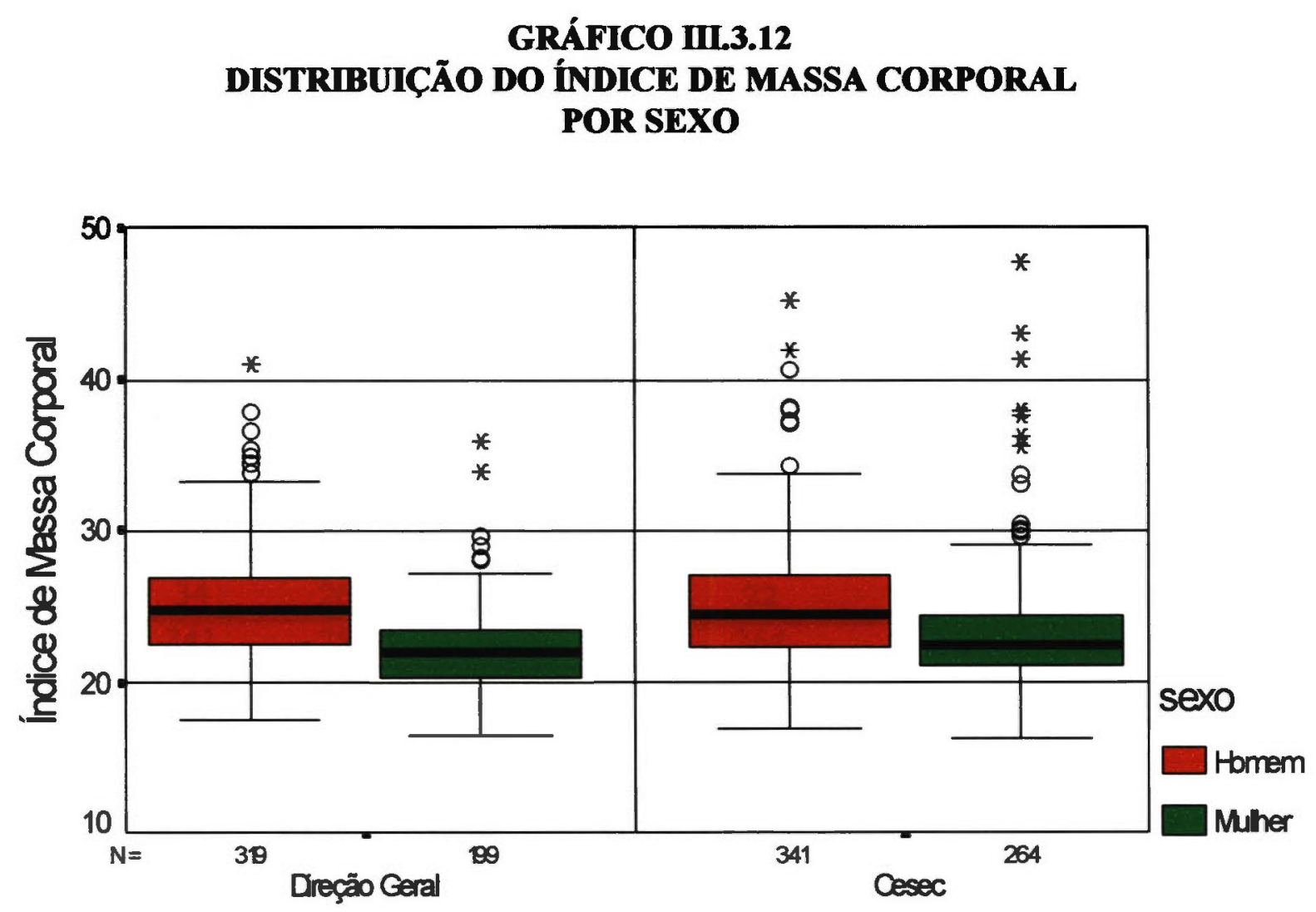

Local 
O IMC médio do sexo masculino também foi maior do que o feminino em todos os grupos etários na Direção Geral, enquanto nos Cesec's, as diferenças foram significativas em todas as faixas etárias, exceto no grupo de 45 anos ou mais (Tabelas III.3.36 e III.3.37).

\section{TABELA III.3.36 \\ ÍNDICE DE MASSA CORPORAL MÉDIO POR IDADE - DIREÇÃO GERAL}

\begin{tabular}{c|ccc|ccc}
\hline & \multicolumn{6}{|c}{ SEXO } \\
\cline { 2 - 7 } DOADE & $\mathbf{n}$ & Média & EP média & n & Média & EP média \\
\hline $20-29$ & 43 & 23,82 & 0,442 & 15 & 21,38 & 0,983 \\
$30-34$ & 45 & 24,70 & 0,550 & 17 & 22,04 & 0,413 \\
$35-39$ & 91 & 24,99 & 0,337 & 93 & 22,21 & 0,287 \\
$40-44$ & 91 & 25,13 & 0,358 & 54 & 22,37 & 0,397 \\
45 e + & 49 & 25,76 & 0,557 & 20 & 23,09 & 0,470 \\
\hline TOTAL & 319 & 24,95 & 0,192 & 199 & 22,27 & 0,196 \\
\hline
\end{tabular}

TABELA III.3.37

ÍNDICE DE MASSA CORPORAL MÉDIO POR IDADE - CESEC

\begin{tabular}{l|ccc|ccc}
\hline & \multicolumn{6}{|c}{ SEXO } \\
\cline { 2 - 7 } IDADE & $\mathrm{n}$ & MÓDIA & EP média & $\mathrm{n}$ & MÉDIA & EP média \\
\hline $20-29$ & 62 & 23,64 & 0,405 & 13 & 22,01 & 0,612 \\
$30-34$ & 61 & 25,00 & 0,535 & 33 & 22,36 & 0,756 \\
$35-39$ & 87 & 24,90 & 0,385 & 102 & 22,93 & 0,286 \\
$40-44$ & 97 & 25,53 & 0,358 & 94 & 23,75 & 0,423 \\
45 e + & 34 & 26,54 & 0,908 & 22 & 24,99 & 1,313 \\
\hline TOTAL & 341 & 25,03 & 0,210 & 264 & 23,28 & 0,240 \\
\hline
\end{tabular}

Ao categorizarmos o IMC em quatro grupos (vide metodologia), os resultados confirmaram a situação desfavorável do sexo masculino já que $39,5 \%$ dos homens na Direção Geral e 36,4\% nos Cesec's apresentaram sobrepeso. Essas prevalências podem ser comparadas com as femininas, que foram bem inferiores: $12,6 \%$ e $16,7 \%$, respectivamente (Gráficos III.3.13 e III.3.14). Assim, a chance masculina de estar com o IMC acima do normal (sobrepeso + obesidade em relação a baixo peso + peso normal) foi 5,38 vezes maior $(\mathrm{OR}=5,38$ IC 95\%: 3,38-8,55) na Direção Geral. Nos Cesec's, onde a proporção de mulheres com sobrepeso e obesidade foi maior do que na Direção Geral, a diferença entre os sexos foi menor. Mesmo assim, nessa dependência, a chance masculina de estar com o IMC acima do normal foi $2,96$ vezes maior do que a feminina (OR=2,96; IC 95\%: $2,05-4,26)$. 


\section{GRÁFICO III.3.13}

CLASSIFICAÇÃO DO ÍNDICE DE MASSA CORPORAL

SEGUNDO SEXO

DIREÇÃO GERAL

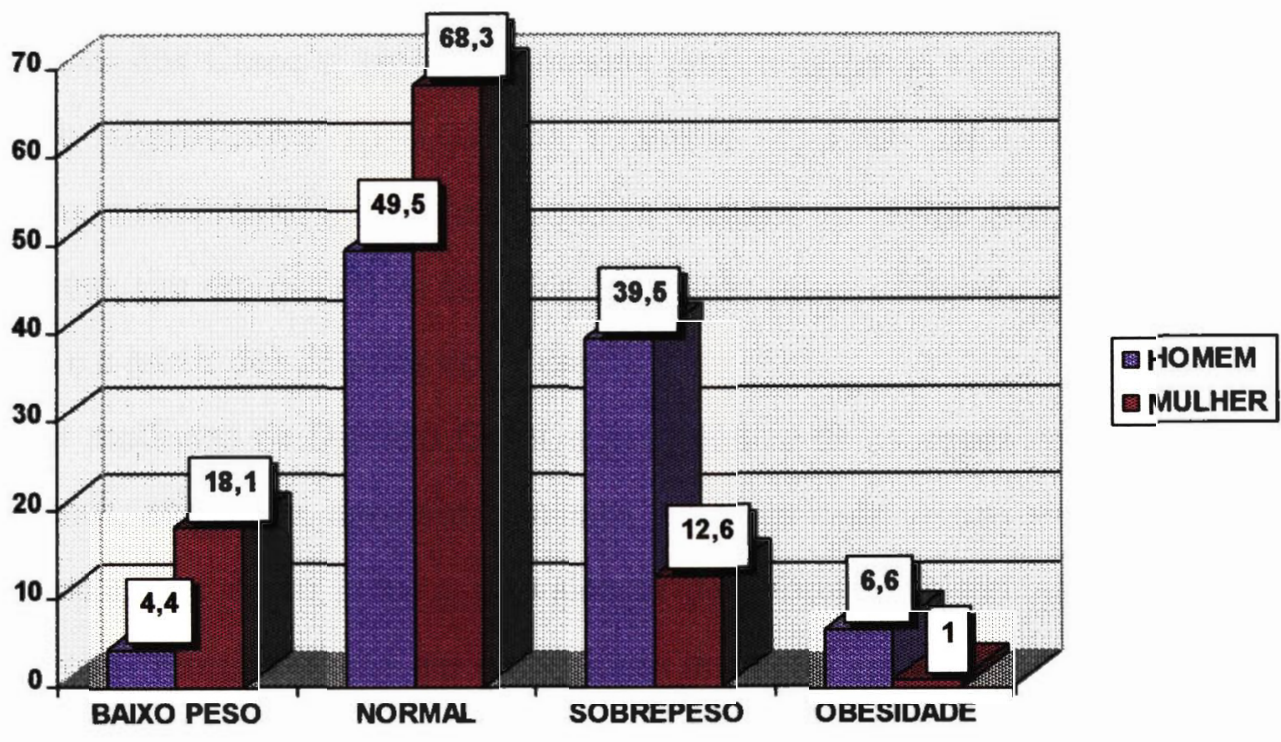

$\chi^{2}=70,57 \mathrm{p}<0,001$

$\mathrm{n}=319$ (HOMENS)

$\mathrm{n}=199$ (MULHERES)

\section{GRÁFICO III.3.14 \\ CLASSIFICAÇÃO DO ÍNDICE DE MASSA CORPORAL \\ SEGUNDO SEXO \\ CESEC}

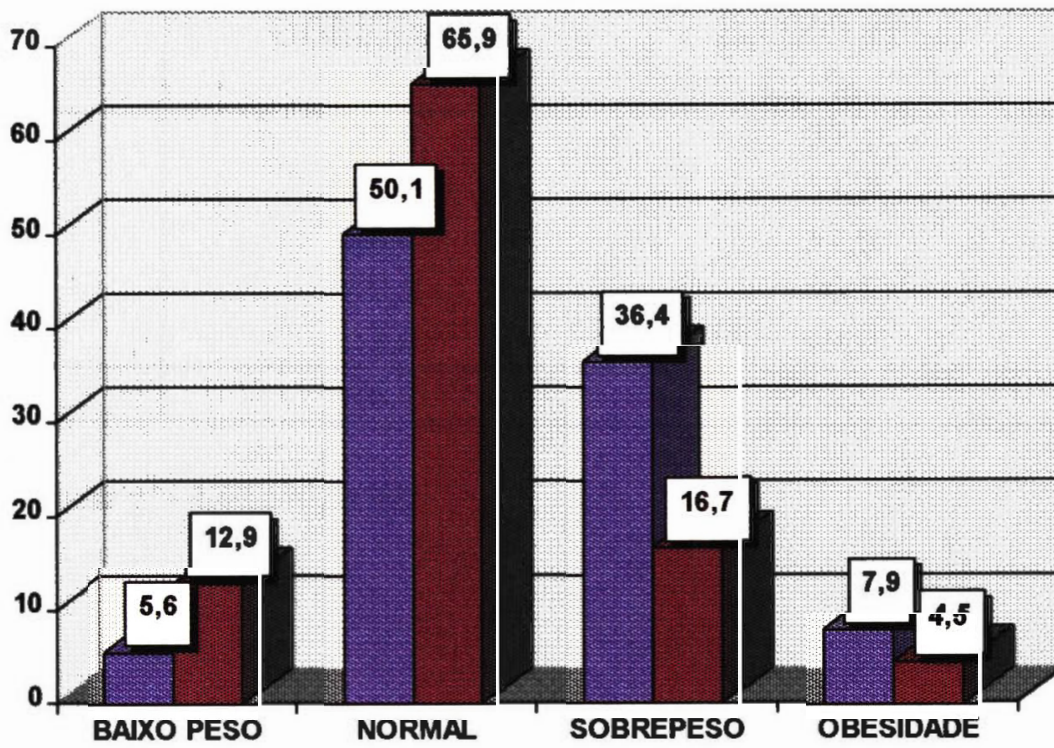

$$
\begin{aligned}
& \chi^{2}=38,97 \mathrm{p}<0,001 \\
& \mathrm{n}=341 \text { (HOMENS) } \\
& \mathrm{n}=264 \text { (MULHERES) }
\end{aligned}
$$


Comparando-se as duas categorias acima do IMC normal (sobrepeso e obesidade) com baixo peso e IMC normal, observa-se que a prevalência de sobrepeso e obesidade aumentam com a idade, em homens e mulheres da Direção Geral, e também entre os homens dos Cesec's. Entre as mulheres dos Cesec's, embora a mesma tendência tenha sido observada, esta não foi estatisticamente significativa $(p=0,05536)$ (Tabelas III.3.38, III.3.39, III.3.40, III.3.41). Enquanto, aproximadamente, um em cada quatro homens apresenta IMC acima do normal no grupo mais jovem, um em cada dois homens é incluído nessa categoria a partir dos 30 anos na Direção Geral, e a partir dos 35 anos nos Cesec's.

Entre as mulheres da Direção Geral, a prevalência de sobrepeso/obesidade aumentou a partir dos 35 anos, atingindo, aproximadamente, uma em cada quatro mulheres acima dos 45 anos. Nos Cesec's, por outro lado, a prevalência de sobrepeso/obesidade já é mais alta nos grupos mais jovens, atingindo uma em cada quatro mulheres entre 40 e 44 anos, e cerca de um terço do grupo mais velho.

\section{TABELA III.3.38 \\ ÍNDICE DE MASSA CORPORAL POR IDADE DIREÇÃO GERAL - HOMENS}

\begin{tabular}{l|cc|cc}
\hline & \multicolumn{3}{|c|}{ INDICE DE MASSA CORPORAL } & \multicolumn{2}{c}{ TOTAL } \\
\cline { 2 - 6 } IDADE & $\begin{array}{c}\text { SOBREPESO e } \\
\text { OBESIDADE }\end{array}$ & $\begin{array}{c}\text { NORMAL e } \\
\text { BAIXO PESO }\end{array}$ & & \\
\hline $20-29$ & $\%$ & $\%$ & 43 & 100,0 \\
$30-34$ & 27,9 & 72,1 & 45 & 100,0 \\
$35-39$ & 46,7 & 53,3 & 91 & 100,0 \\
$40-44$ & 48,4 & 51,6 & 91 & 100,0 \\
45 e + & 49,5 & 50,5 & 49 & 100,0 \\
\hline TOTAL & 51,0 & 49,0 & 319 & 100,0 \\
\hline
\end{tabular}

Tendência linear $\chi^{2}=4,40 p=0,03586$ 
TABELA III.3.39

ÍNDICE DE MASSA CORPORAL POR IDADE

DIREÇÃO GERAL

MULHERES

\begin{tabular}{l|cc|cc}
\hline \multirow{2}{*}{ IDADE } & \multicolumn{3}{|c|}{ INDICE DE MASSA CORPORAL } & \multicolumn{2}{c}{ TOTAL } \\
\cline { 2 - 6 } & $\begin{array}{c}\text { SOBREPESO e } \\
\text { OBESIDADE }\end{array}$ & $\begin{array}{c}\text { NORMAL e } \\
\text { BAIXO PESO }\end{array}$ & & \\
\hline $20-29$ & $\%$ & $\%$ & 15 & 100,0 \\
$30-34$ & 6,7 & 93,3 & 17 & 100,0 \\
$35-39$ & 5,9 & 94,1 & 93 & 100,0 \\
$40-44$ & 11,8 & 88,2 & 54 & 100,0 \\
45 e + & 16,7 & 83,3 & 20 & 100,0 \\
\hline TOTAL & 25,0 & 75,0 & 199 & 100,0 \\
\hline
\end{tabular}

Tendência linear $\chi^{2}=4,26 p=0,03903$

TABELA II.3.40

ÍNDICE DE MASSA CORPORAL POR IDADE

CESEC

HOMENS

\begin{tabular}{l|cccc}
\hline \multirow{2}{*}{ IDADE } & \multicolumn{4}{|c}{ INDICE DE MASSA CORPORAL } \\
\cline { 2 - 6 } & $\begin{array}{c}\text { SOBREPESO e } \\
\text { OBESIDADE }\end{array}$ & $\begin{array}{c}\text { NORMAL } \\
\text { BAIXO PESO }\end{array}$ & TOTAL \\
\hline $20-29$ & $\%$ & $\%$ & n & $\%$ \\
$30-34$ & 25,8 & 74,2 & 62 & 100,0 \\
$35-39$ & 42,6 & 57,4 & 61 & 100,0 \\
$40-44$ & 47,1 & 52,9 & 87 & 100,0 \\
45 e + & 50,5 & 49,5 & 97 & 100,0 \\
\hline TOTAL & 55,9 & 44,1 & 34 & 100,0 \\
\hline
\end{tabular}

Tendência linear $\chi^{2}=12,31 \mathrm{p}=0,00107$ 


\section{TABELA III.3.41 \\ ÍNDICE DE MASSA CORPORAL POR IDADE \\ CESEC \\ MULHERES}

\begin{tabular}{l|cc|cc}
\hline \multirow{2}{*}{ IDADE } & \multicolumn{3}{|c|}{ INDICE DE MASSA CORPORAL } & \multicolumn{2}{c}{ TOTAL } \\
\cline { 2 - 6 } & $\begin{array}{c}\text { SOBREPESO e } \\
\text { OBESIDADE }\end{array}$ & $\begin{array}{c}\text { NORMAL } \\
\text { BAIXO PESO }\end{array}$ & & \\
\hline $20-29$ & $\%$ & $\%$ & 13 & 100,0 \\
$30-34$ & 15,4 & 84,6 & 33 & 100,0 \\
$35-39$ & 15,2 & 84,8 & 102 & 100,0 \\
$40-44$ & 17,6 & 82,4 & 94 & 100,0 \\
45 e + & 25,5 & 74,5 & 22 & 100,0 \\
\hline TOTAL & 31,8 & 68,2 & 264 & 100,0 \\
\hline
\end{tabular}

Tendência linear $\chi^{2}=3,67 \mathrm{p}=0,05536$

A distribuição do IMC segundo escolaridade apresentou tendência semelhante entre homens e mulheres, e também em maiores e menores de 40 anos de idade: aqueles com maior nivel de escolaridade apresentaram maior prevalência de sobrepeso ou obesidade. Entre os homens (Tabela III.3.44), 35,5\% (IC 95\%: 25,8-45,2) dos funcionários que não ingressaram na universidade apresentaram IMC acima do normal, enquanto essa proporção foi de $49,7 \%$ (IC 95\%: 45,3-54,1) entre os que completaram curso superior. Entre as mulheres (Tabela III.3.42), a diferença foi ainda maior já que 21,7\% (IC 95\%: 14,5-28,9) e 19,8\% (IC 95\%: 16,1-23,5) das funcionárias com curso superior incompleto e completo apresentaram IMC acima do normal, comparadas a apenas 7,3\% (IC 95\%: 0-14,7) das funcionárias que não ingressaram na universidade. 


\section{TABELA III.3.42}

\section{DISTRIBUIÇÃO DO IMC ACIMA OU ABAIXO DO NORMAL SEGUNDO ESCOLARIDADE \\ AMBAS AS DEPENDÊNCIAS POR SEXO}

\begin{tabular}{l|cc|cc}
\hline & \multicolumn{4}{|c}{ INDICE DE MASSA CORPORAL } \\
\cline { 2 - 6 } ESCOLARIDADE & $\begin{array}{c}\text { SOBREPESO e } \\
\text { OBESIDADE }\end{array}$ & $\begin{array}{c}\text { NORMAL } \\
\text { BAIXO PESO }\end{array}$ & \multicolumn{2}{c}{ TOTAL } \\
\hline HOMENS & $\%$ & $\%$ & $\mathrm{n}$ & $\%$ \\
\hline < SUPERIOR* & 35,5 & 64,5 & 69 & 100,0 \\
SUPERIOR INCOMPLETO & 40,5 & 59,5 & 220 & 100,0 \\
SUPERIOR COMPLETO & 49,7 & 50,3 & 371 & 100,0 \\
\hline MULHERES & & & & \\
\hline < SUPERIOR* & 7,3 & 92,7 & 36 & 100,0 \\
SUPERIOR INCOMPLETO & 21,7 & 78,3 & 93 & 100,0 \\
SUPERIOR COMPLETO & 19,8 & 80,2 & 334 & 100,0 \\
\hline
\end{tabular}

$\mathrm{n}=660$ (Homens)

463 (Mulheres)

Proporçoses corrigidas por fator de expansão

* $2^{\circ}$ grau incompleto ou completo

Uma vez que os funcionários que não apresentam curso superior são mais velhos do que aqueles que apresentam, analisamos também a associação entre IMC e escolaridade segundo grupos etários (Tabela III.3.43). Tendência semelhante àquela apontada na análise por sexo foi encontrada: a prevalência de sobrepeso ou obesidade também é maior entre os funcionários com maior nível de escolaridade, tanto entre os mais jovens quanto entre os mais velhos, embora as diferenças tenham sido estatisticamente significativas apenas entre os maiores de 40 anos de idade. Assim, nesse grupo, 29,2\% (IC 95\%: 17,8-40,6) dos funcionários com menor nível de escolaridade apresentaram IMC acima do normal, comparados a 42,2\% (IC 95\%: 34,4-50,0) e 41,9\% (IC 95\%: 37,1-46,7) daqueles com curso superior incompleto e completo, respectivamente. 
TABELA III.3.43

DISTRIBUIÇÃO DO IMC ACIMA OU ABAIXO DO NORMAL

SEGUNDO ESCOLARIDADE

POR GRUPO ETÁRIO

AMBOS OS SEXOS

AMBAS AS DEPENDÊNCIAS

\begin{tabular}{l|cc|cc}
\hline & \multicolumn{4}{|c}{ INDICE DE MASSA CORPORAL } \\
\cline { 2 - 6 } ESCOLARIDADE & $\begin{array}{c}\text { SOBREPESO e } \\
\text { OBESIDADE }\end{array}$ & $\begin{array}{c}\text { NORMAL e } \\
\text { BAIXO PESO }\end{array}$ & \multicolumn{2}{c}{ TOTAL } \\
\hline S40 ANOS & $\%$ & $\%$ & $\mathrm{n}$ & $\%$ \\
\hline < SUPERIOR* & 24,4 & 75,6 & 59 & 100,0 \\
SUPERIOR INCOMPLETO & 31,6 & 68,4 & 198 & 100,0 \\
SUPERIOR COMPLETO & 31,3 & 68,8 & 405 & 100,0 \\
\hline >40 ANOS & & & & \\
\hline <SUPERIOR* & 29,2 & 70,8 & 46 & 100,0 \\
SUPERIOR INCOMPLETO & 42,2 & 57,8 & 115 & 100,0 \\
SUPERIOR COMPLETO & 41,9 & 58,1 & 300 & 100,0 \\
\hline
\end{tabular}

$n=662(\leq 40$ anos $)$

461 (>40 anos)

Proporçoes corrigidas por fator de expansão

* $2^{\circ}$ grau incompleto ou completo

\section{g-COLESTEROL}

Cerca de um terço dos homens com menos de 40 anos de idade mediu o colesterol no último ano, enquanto $44,6 \%$ das mulheres do mesmo grupo etário mediram também nesse periodo. No entanto, quase a metade dos homens mais jovens nunca realizou dosagem do colesterol sanguíneo -47,1\% (IC 95\%: 42,3-51,9)- em comparação a 28,9\% (IC 95\%: 23,734,1) das mulheres (Tabela III.3.44).

TABELA III.3.44

PERÍODO DE REALIZAÇÃO DA ÚLTIMA DOSAGEM DE COLESTEROL POR SEXO

IDADE MENOR OU IGUAL A 40 ANOS

\begin{tabular}{l|ccc|cc}
\hline & \multicolumn{3}{|c|}{ EPOCA DO EXAME } \\
\cline { 2 - 7 } SEXO & MENOS DE & MAIS DE UM & NUNCA & \multicolumn{2}{c}{ TOTAL } \\
& UM ANO & ANO & MEDIU & & \\
\hline HOMENS & $\%$ & $\%$ & $\%$ & n & $\%$ \\
MULHERES & 30,9 & 21,9 & 47,1 & 376 & 100,0 \\
\hline TOTAL & 44,6 & 26,6 & 28,9 & 266 & 100,0 \\
\hline
\end{tabular}

Proporções corrigidas por fator de expansão 
No grupo de 40 anos ou mais, $71,7 \%$ dos homens e $77,0 \%$ das mulheres dosaram o colesterol sanguíneo no último ano, e menos de $10 \%$ dos funcionários nunca realizou esse exame (Tabela III.3.45).

TABELA III.3.45

PERÍdo dE REALIZAÇÃo dA ÚlTIMA DOSAGEM DE COLESTEROL - POR SEXO

MAIORES DE 40 ANOS

\begin{tabular}{l|ccc|cc}
\hline & \multicolumn{4}{|c}{ EPOCA DO EXAME } \\
\cline { 2 - 7 } SEXO & MENOS DE & MAIS DE UM & NUNCA MEDIU & \multicolumn{2}{c}{ TOTAL } \\
& UM ANO & ANO & & & \\
\hline HOMENS & $\%$ & $\%$ & $\%$ & n & $\%$ \\
MULHERES & 71,7 & 20,5 & 7,9 & 271 & 100,0 \\
\hline TOTAL & 77,0 & 18,1 & 4,9 & 202 & 100,0 \\
\hline
\end{tabular}

Proporções corrigidas por fator de expansão

A associação entre informação sobre níveis elevados de colesterol e sexo apresentou padrão semelhante em ambas as dependências, já que maior proporção de homens do que de mulheres já foi informado que seus níveis estavam elevados. Na Direção Geral, a chance foi 1,5 vezes maior para os homens de obter esse resultado, embora a medida de associação inclua marginalmente a unidade (ver OR na tabela III.3.46). Nos Cesec's, no entanto, a chance masculina de ter sido informado sobre níveis elevados de colesterol foi 1,77 vezes maior, e o intervalo de confiança do OR não inclua a unidade.

\section{TABELA III.3.46 \\ INFORMAÇÃO SOBRE NÍVEL ELEVADO DE COLESTEROL POR SEXO \\ DIREÇÃO GERAL E CESEC}

\begin{tabular}{|c|c|c|c|c|c|c|c|c|}
\hline \multirow[b]{4}{*}{ SEXO } & \multicolumn{8}{|c|}{ COLESTEROL ELEVADO } \\
\hline & \multicolumn{4}{|c|}{ DIREÇĀO GERAL } & \multicolumn{4}{|c|}{ CESEC } \\
\hline & \multirow{2}{*}{$\begin{array}{c}\text { SIM } \\
\%\end{array}$} & \multirow{2}{*}{$\begin{array}{c}\text { NÁO } \\
\%\end{array}$} & \multicolumn{2}{|c|}{ TOTAL } & \multirow{2}{*}{$\begin{array}{c}\text { SIM } \\
\%\end{array}$} & \multirow{2}{*}{$\begin{array}{c}\text { NÃO } \\
\%\end{array}$} & \multicolumn{2}{|c|}{ TOTAL } \\
\hline & & & $\mathbf{n}$ & $\%$ & & & $\mathrm{n}$ & $\%$ \\
\hline HOMENS & 28,9 & 71,1 & 242 & 100,0 & 28,7 & 71,3 & 244 & 100,0 \\
\hline MULHERES & 21,3 & 78,7 & 164 & 100,0 & 18,5 & 81,5 & 238 & 100,0 \\
\hline TOTAL & 25,9 & $\overline{74,1}$ & 406 & 100,0 & 23,7 & 76,3 & 482 & 100,0 \\
\hline
\end{tabular}


A distribuição da informação sobre nível elevado de colesterol não variou segundo o nivel de escolaridade dos funcionários, sugerindo igual acesso de todos aos serviços de saúde e ao exame de saúde periódico, realizado no próprio banco (Tabela III.3.47).

TABELA III.3.47

INFORMAÇÃO SOBRE NÍVEL ELEVADO DE COLESTEROL SEGUNDO

ESCOLARIDADE

AMBOS OS SEXOS

AMBAS AS DEPENDÊNCIAS

\begin{tabular}{|c|c|c|c|c|}
\hline \multirow[b]{3}{*}{ ESCOLARIDADE } & \multicolumn{4}{|c|}{ COLESTEROL ELEVADO } \\
\hline & SIM & NÃO & & $\overline{\mathrm{AL}}$ \\
\hline & $\%$ & $\%$ & $\mathbf{n}$ & $\%$ \\
\hline < SUPERIOR* & 27,8 & 72,2 & 76 & 100,0 \\
\hline SUPERIOR INCOMPLETO & 20,5 & 79,5 & 230 & 100,0 \\
\hline SUPERIOR COMPLETO & 25,9 & 74,1 & 582 & 100,0 \\
\hline
\end{tabular}

$\mathrm{N}=\mathbf{8 8 8}$

Proporçes corrigidas por fator de expansão

* $2^{\circ}$ grau incompleto ou completo

\section{h- HISTÓRIA FAMILIAR}

Dentre as doenças do aparelho cardiovascular ou condições a elas associadas (diabetes e obesidade), a hipertensão arterial foi a mais citada em parentes consanguíneos, em ambas as dependências, ficando a obesidade como a de menor prevalência nesse mesmo grupo (Tabela III.3.48).

TABELA III.3.48

PROBLEMAS DE SAÚdE DIAGNOSTICADOS

EM PARENTES CONSANGUÍNEOS

AMBAS AS DEPENDÊNCIAS

\begin{tabular}{l|cc|cc}
\hline & \multicolumn{2}{|c|}{ DIREÇÃO GERAL } & \multicolumn{2}{c}{ CESEC } \\
CONDIÇÃO & $\%$ & $\mathrm{n}$ & $\%$ & $\mathrm{n}$ \\
\hline PRESSĀO ALTA & 54,9 & 293 & 59,1 & 382 \\
DIABETES & 41,2 & 220 & 43,0 & 278 \\
INFARTO AGUDO DO & 36,7 & 196 & 33,3 & 215 \\
MIOCÁRDIO & & & & \\
DERRAME, TROMBOSE, & 30,1 & 161 & 34,5 & 223 \\
EMBOLIA CEREBRAL & 23,2 & 124 & 26,2 & 169 \\
OBESIDADE & & $\mathrm{n}=534$ & & $\mathrm{n}=646$ \\
\hline TOTAL & & & & \\
\hline
\end{tabular}

Proporções corrigidas por fator de expansão 


\section{i- CONHECIMENTO DOS FATORES DE RISCO}

A informação acerca dos fatores de risco é essencial, embora não suficiente, para a mudança de hábitos e comportamentos. Em função de sua importância, uma pergunta foi incluída para avaliação dos conhecimentos dessa população. A pergunta listou itens reconhecidamente associados, e também outros ainda sujeitos a estudos (Tabelas III.3.49 III. 3.50)

Dentre os fatores listados, cerca de $95 \%$ da população de ambos os sexos assinalou corretamente que fumo, hipertensão, obesidade, dieta, colesterol alto e vida sedentária aumentam o risco de doenças do coração. A diferença mais importante entre homens e mulheres ocorreu na "história familiar" onde maior proporção de mulheres $-94,2 \%$ (IC 95\%: 92,4-96,0) do que de homens -83,4\% (IC 95\%: 81,0-85,8)- respondeu que "aumenta o risco". $\mathrm{O}$ diabetes foi o único fator de risco já estabelecido que elevada proporção de homens e mulheres parece desconhecer, já que cerca de 50\% não soube informar sobre sua associação com as doenças do coração.

Dentre os outros fatores, "Preocupação ou ansiedade" aumenta o risco para cerca de $100 \%$ da população, "Muito trabalho" aumenta o risco para dois terços dos homens e $72,6 \%$ das mulheres, e "Tomar café" para cerca de 50\% das mulheres e $35 \%$ dos homens. 
TABELA III.3.49

RESPOSTAS SOBRE FATORES DE RISCO QUE AUMENTAM

A CHANCE DE DOENÇAS DO CORAÇÃO

AMBAS AS DEPENDÊNCIAS

HOMENS

\begin{tabular}{l|ccc|cc}
\hline & \multicolumn{4}{|c}{ RESPOSTAS } \\
\cline { 2 - 7 } FATOR & AUMENTA & $\begin{array}{c}\text { NÃO } \\
\text { AUMENTA } \\
\%\end{array}$ & $\begin{array}{c}\text { NÃO SEI } \\
\text { DIZER } \\
\%\end{array}$ & \multicolumn{2}{c}{ TOTAL* } \\
\hline FUMAR CIGARROS & 94,7 & 1,9 & 2,6 & 685 & 100,0 \\
PREOCUPAÇÃO OU & 96,8 & 1,5 & 1,7 & 687 & 100,0 \\
ANSIEDADE & 97,4 & 0,7 & 1,9 & 685 & 100,0 \\
HIPERTENSÃO & 43,6 & 11,0 & 45,4 & 676 & 100,0 \\
DIABETES & 97,1 & 0,8 & 2,1 & 686 & 100,0 \\
ESTAR MUITO & 66,3 & 21,4 & 12,3 & 684 & 100,0 \\
ACIMA DO PESO & 35,3 & 27,8 & 36,9 & 671 & 100,0 \\
MUITO TRABALHO & 90,8 & 1,9 & 7,4 & 686 & 100,0 \\
TOMAR CAFÉ & & & & & \\
DIETA COM MUITA & 83,4 & 6,0 & 10,6 & 685 & 100,0 \\
GORDURA ANIMAL & & & & & \\
HISTÓRIA FAMILIAR & 96,3 & 1,0 & 2,7 & 688 & 100,0 \\
DE DOENÇAS DO & 89,9 & 3,3 & 6,8 & 688 & 100,0 \\
CORAÇÃO & & & & &
\end{tabular}

* Do total de 689 homens de ambos os tipos de dependência, os números assinalados responderam a cada um dos ítens.

Proporçôes corrigidas por fator de expansão 
TABELA III.3.50

RESPOSTAS SOBRE FATORES DE RISCO QUE AUMENTAM

A CHANCE DE DOENÇAS DO CORAÇÃO

AMBAS AS DEPENDÊNCIAS

MULHERES

\begin{tabular}{|c|c|c|c|c|c|}
\hline \multirow[b]{3}{*}{ FATOR } & \multicolumn{3}{|c|}{ RESPOSTAS } & \multirow{2}{*}{\multicolumn{2}{|c|}{ TOTAL }} \\
\hline & AUMENTA & $\begin{array}{c}\text { NÁO } \\
\text { AUMENTA }\end{array}$ & $\begin{array}{l}\text { NĀO SEI } \\
\text { DIZER }\end{array}$ & & \\
\hline & $\%$ & $\%$ & $\%$ & $\mathrm{n}$ & $\%$ \\
\hline FUMAR CIGARROS & 92,2 & 3,2 & 4,5 & 490 & 100,0 \\
\hline $\begin{array}{l}\text { PREOCUPAÇÃO OU } \\
\text { ANSIEDADE }\end{array}$ & 97,4 & 1,8 & 0,8 & 492 & 100,0 \\
\hline HIPERTENSÃO & 98,0 & 0,5 & 1,5 & 494 & 100,0 \\
\hline DIABETES & 35,3 & 15,9 & 48,7 & 482 & 100,0 \\
\hline $\begin{array}{l}\text { ESTAR MUITO ACIMA } \\
\text { DO PESO }\end{array}$ & 97,4 & 0,9 & 1,7 & 493 & 100,0 \\
\hline MUITO TRABALHO & 72,6 & 19,0 & 8,4 & 490 & 100,0 \\
\hline TOMAR CAFÉ & 47,5 & 25,3 & 27,3 & 479 & 100,0 \\
\hline $\begin{array}{l}\text { DIETA COM MUTTA } \\
\text { GORDURA ANIMAL }\end{array}$ & 94,0 & 0,6 & 5,4 & 493 & 100,0 \\
\hline $\begin{array}{l}\text { HISTÓRIA FAMILIAR } \\
\text { DE DOENÇAS DO } \\
\text { CORAÇÃO }\end{array}$ & 94,2 & 1,3 & 4,5 & 494 & 100,0 \\
\hline COLESTEROL ALTO & 96,9 & 0,3 & 2,8 & 494 & 100,0 \\
\hline VIDA SEDENTÁRIA & 91,6 & 2,5 & 5,9 & 494 & 100,0 \\
\hline
\end{tabular}

* Do total de 494 mulheres de ambos os tipos de dependência, os números assinaladosresponderam a cada um dos ítens.

Proporçóes estimadas com base na expansão de totais. 


\section{4- COMPARAÇÃO ENTRE A MEDIDA DIRETA E AS INFORMAÇÕES FORNECIDAS SOBRE PRESSÄO ARTERIAL, PESO E ESTATURA}

Os resultados relativos às medidas diretas de pressão arterial, peso e estatura se referem a 322 funcionários, distribuídos nas dependências de acordo com a Tabela III.4.1.

TABELA III.4.1

DISTRIBUIÇÃO DOS FUNCIONÁRIOS EXAMINADOS DE ACORDO COM A DEPENDÊNCIA

\begin{tabular}{lcccc}
\hline & \multicolumn{2}{c}{ MEDIDA } & RESPONDENTES & LOTAÇĀO \\
DEPENDÊNCIA & $\mathbf{n}$ & $\%$ & $\mathbf{n}$ & $\mathbf{N}$ \\
\hline CENTRO $^{*}$ & 88 & 22,0 & 137 & 607 \\
CESEC CENTRO & 69 & 17,3 & 102 & 556 \\
DIREÇÃO GERAL & 113 & 28,3 & 536 & 1174 \\
ILHA GOVERNADOR* & 52 & 13,0 & 65 & 76 \\
\hline TOTAL & 322 & 100,0 & 840 & 2413 \\
\hline
\end{tabular}

* Agências

\section{a- ÍNDICE DE MASSA CORPORAL}

A medida da estatura foi realizada no conjunto dos funcionários examinados, enquanto o peso de um deles é ignorado. Assim, os resultados apresentados se referem a 321 individuos.

As diferenças médias entre peso medido e peso informado apresentaram pequena magnitude, revelando grande concordância entre as duas fontes de informação (Tabela 4.5.2). Assim mesmo, os funcionários tenderam a informar valores subestimados já que essas diferenças médias foram positivas em ambos os sexos e em todas as dependências.

As diferenças médias entre estatura medida e estatura informada foram ainda menores do que no caso do peso. Considerando-se esse valor médio, os homens superestimaram o valor informado apenas no Cesec Centro, e as mulheres, na Direção Geral (Tabela III.4.2). 
TABELA III.4.2

DIFERENÇAS MÉDIAS ENTRE PESO MEDIDO E PESO INFORMADO

E ENTRE ESTATURA MEDIDA E ESTATURA INFORMADA

POR SEXO

POR DEPENDÊNCIA

\begin{tabular}{l|cc|cc}
\hline \multirow{2}{*}{ DEPENDÊNCIA } & \multicolumn{3}{c}{ DIFERENÇAS MÉDIAS* } \\
\cline { 2 - 5 } & \multicolumn{3}{|c}{ HOMENS } & \multicolumn{2}{c}{ MULHERES } \\
\hline PESO* & ESTATURA** & PESO* $^{*}$ & ESTATURA** \\
\hline CESEC CENTRO & 1,093 & 0,002 & 1,016 & 0,003 \\
DIREÇÃO GERAL & 1,275 & $-0,005$ & 0,737 & 0,001 \\
ILHA GOVERNADOR & 0,689 & 0,001 & 0,819 & $-0,001$ \\
\hline
\end{tabular}

* Peso Medido - Peso Informado/ Total de informaçoes (kg)

** Estatura Medida - Estatura Informada/Total de informaçoes (cm)

Comparando-se as médias dos Índices de Massa Corporal estimados através da medida direta de peso e estatura (IMC medido)e da informação dos funcionários (IMC informado), em cada dependência, é possivel observar que são praticamente idênticas, na maioria dos casos (Tabelas III.4.3 e III.4.4), confirmando a alta concordância entre as duas fontes de informação.

TABELA III.4.3

MÉdIAS DO IMC ESTIMADO ATRAVÉS DA MEDIDA DIRETA E DA INFORMAÇÃO DOS FUNCIONÁRIOS

POR DEPENDÊNCIA

HOMENS

\begin{tabular}{l|ccc|ccc}
\hline & \multicolumn{3}{|c|}{ MEDIDA } & \multicolumn{3}{c}{ INFORMAÇÃO } \\
DEPENDÊNCIA & MÉDIA & EP* & n & MÉDIA & EP* & n \\
\hline CENTRO & 25,48 & 0,96 & 45 & 25,77 & 0,99 & 41 \\
CESEC CENTRO & 25,95 & 1,43 & 30 & 25,81 & 1,45 & 27 \\
DIREÇÃO GERAL & 25,69 & 0,92 & 69 & 25,84 & 0,92 & 65 \\
ILHA GOVERNADOR & 25,17 & 1,90 & 20 & 25,41 & 2,27 & 15 \\
\hline
\end{tabular}

* EP= Erro Padrão da Média 
TABELA III.4.4

MÉdIAS DO IMC ESTIMADO ATRAVÉS DA MEDIDA DIRETA E DA INFORMAÇÃO DOS FUNCIONÁRIOS

POR DEPENDÊNCIA

MULHERES

\begin{tabular}{l|ccc|ccc}
\hline & \multicolumn{3}{|c|}{ MEDIDA } & \multicolumn{3}{c}{ INFORMAÇÁO } \\
DEPENDÊNCIA & MÉDIA & EP* & $\mathrm{n}$ & MÉDIA & EP* & $\mathrm{n}$ \\
\hline CENTRO & 23,22 & 0,89 & 42 & 23,74 & 0,95 & 37 \\
CESEC CENTRO & 23,80 & 1,76 & 39 & 24,40 & 2,11 & 33 \\
DIREÇÃO GERAL & 22,52 & 0,84 & 44 & 22,78 & 0,86 & 42 \\
ILHA GOVERNADOR & 23,59 & 1,26 & 32 & 24,07 & 1,47 & 27 \\
\hline
\end{tabular}

* EP= Erro Padrão da Média

Assim como foi observado em relação às médias, os valores individuais do IMC medido e do IMC informado apresentaram grande concordância, em cada uma das dependências e em ambos os sexos (Gráfico III.4.1).

GRÁFICOS III.4.1

COMPARAÇÃO ENTRE IMC MEDIDO E IMC INFORMADO POR SEXO - POR DEPENDÊNCIA

\section{AGÊNCIA CENTRO}

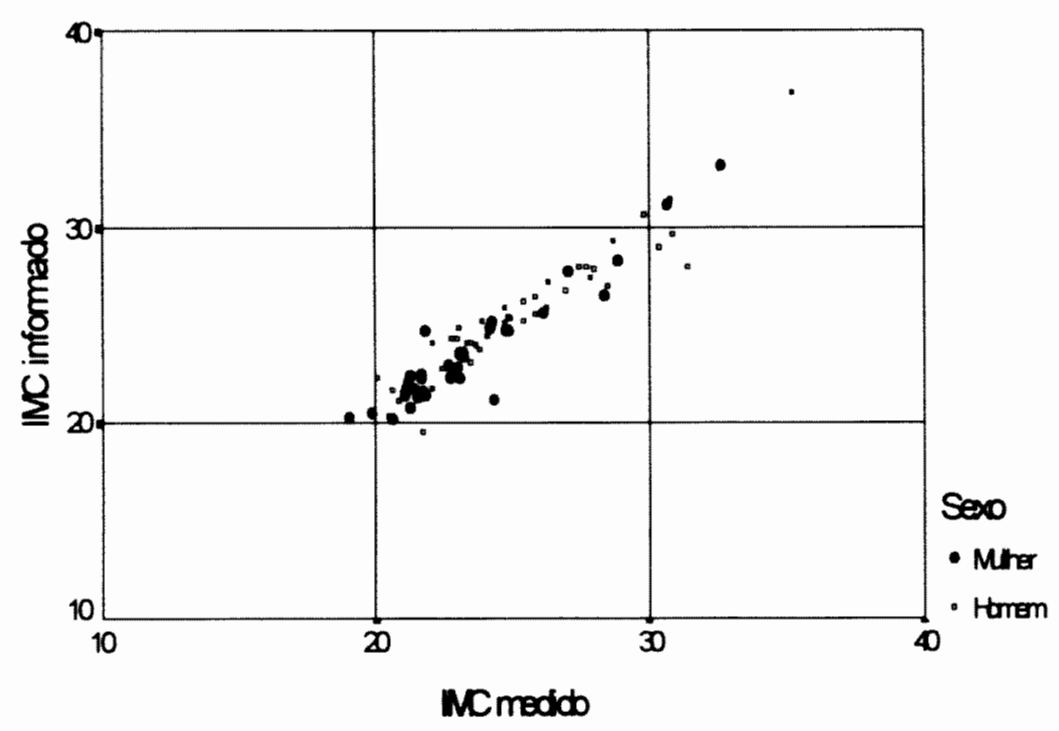


CESEC CENTRO

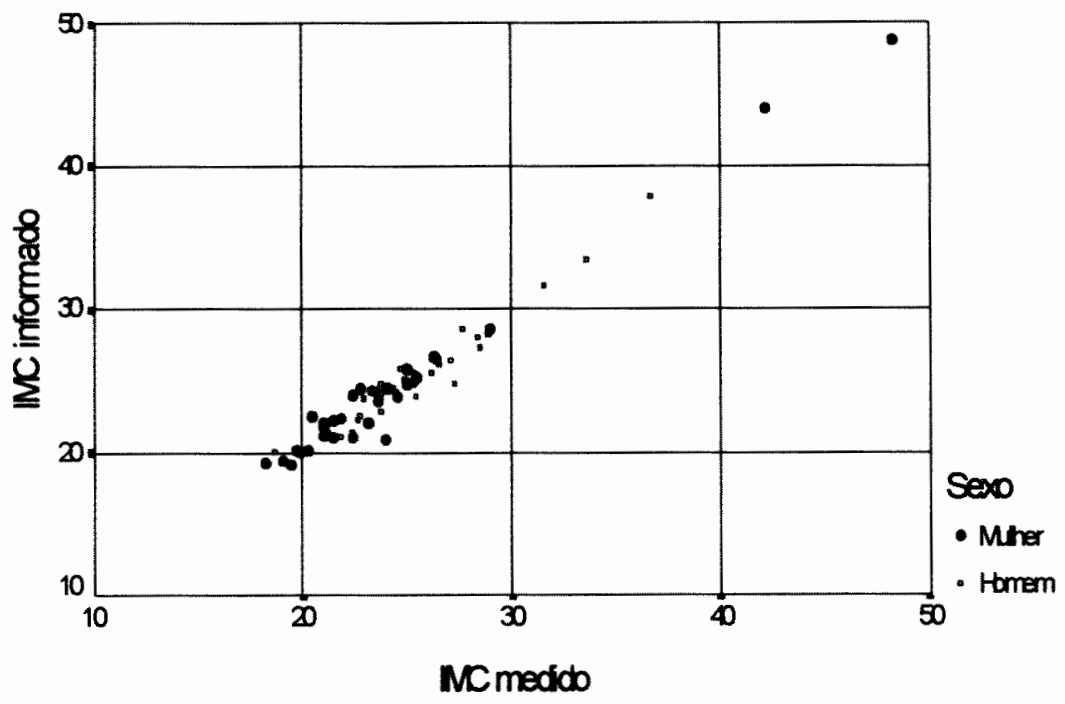

DIREÇÃO GERAL

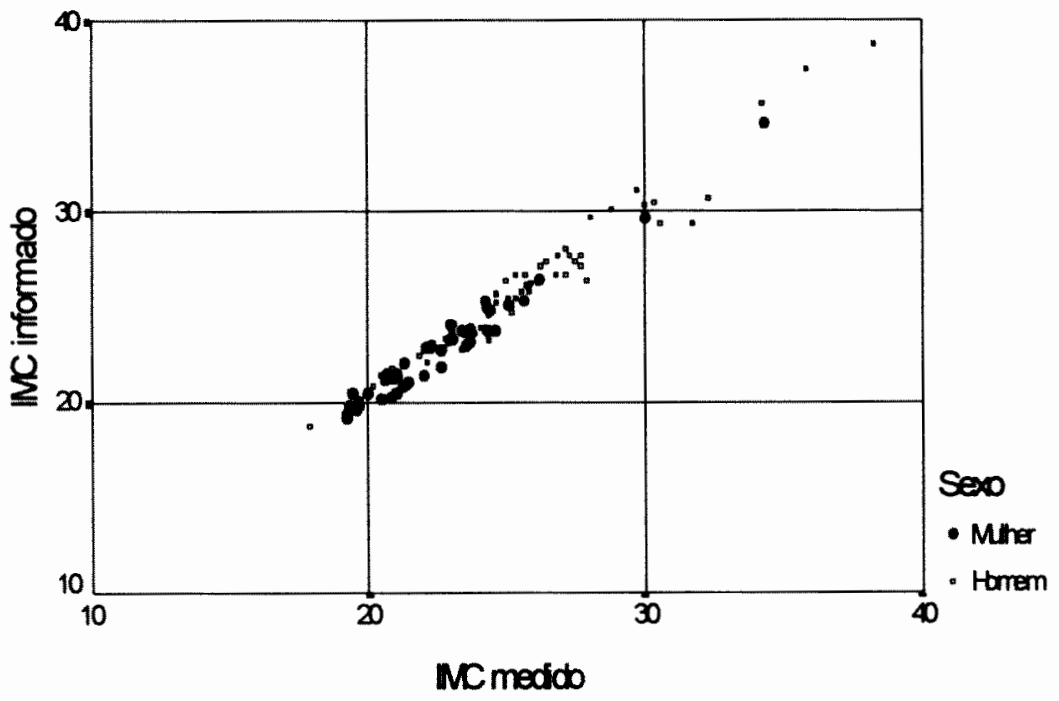




\section{AGÊNCIA ILHA DO GOVERNADOR}

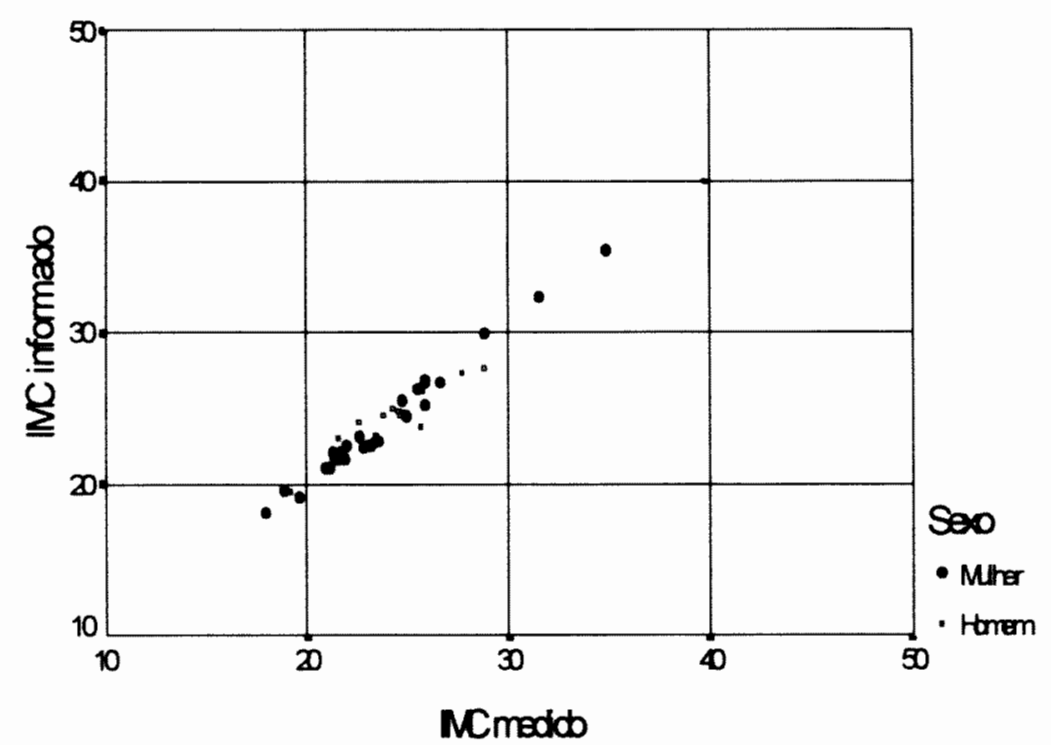

Os coeficientes de correlação entre IMC medido e IMC informado foram próximos à unidade em ambos os sexos e em todas as dependências, o que permite confirmar os resultados apresentados anteriormente. Assim, é possível concluir que as informações de peso e estatura fornecidas pelos funcionários de ambos os sexos das dependências estudadas, são válidas (Tabela III.4.5)

TABELA III.4.5

COEFICIENTES DE CORRELAÇÃO ENTRE IMC MEDIDO

E IMC INFORMADO

POR SEXO

POR DEPENDÊNCIA

\begin{tabular}{l|cc|cc}
\hline & HOMENS & \multicolumn{2}{|c}{ MULHERES } \\
DEPENDÊNCIA & CORRELAÇÃO* & $\mathbf{n}$ & CORRELAÇÃO* & n \\
\hline CENTRO & 0,95 & 41 & 0,95 & 36 \\
CESEC CENTRO & 0,97 & 27 & 0,99 & 33 \\
DIREÇÃO GERAL & 0,98 & 65 & 0,98 & 42 \\
ILHA GOVERNADOR & 0,98 & 15 & 0,99 & 27 \\
\hline
\end{tabular}

Coeficientes estimados para 286 funcionários já que não havia informação sobre peso e/ou estatura no questionário de 35 dentre os 321 examinados.

$* \mathrm{p}=0,000$

Ao compararmos as categorias do IMC de acordo com o questionário ou com a medida de peso e estatura (padrão ouro), estimamos a sensibilidade e especificidade da informação do funcionário. A sensibilidade variou entre $76,2 \%$ no Cesec Centro e 
96,0\% na Agência Centro, enquanto a especificidade foi próxima a 100,0\% em todas as dependências (Tabelas III.4.6). Os Valores Preditivos Positivo e Negativo foram bastante elevados, situando-se acima de $\mathbf{8 8 , 1 \%}$. Dessa maneira, a grande maioria dos casos seria classificada corretamente a partir da informação contida no questionário.

TABELAS III.4.6

COMPARAÇÃO ENTRE A CLASSIFICAÇÃO DO IMC SEGUNDO MEDIDA E INFORMAÇÕES DO QUESTIONÁRIO POR DEPENDÊNCIA

\section{AGÊNCIA CENTRO}

\begin{tabular}{|c|c|c|c|c|c|c|c|c|}
\hline \multirow[b]{3}{*}{ MEDIDA } & \multicolumn{8}{|c|}{ QUESTIONÁRIO } \\
\hline & \multicolumn{3}{|c|}{$\begin{array}{c}\text { NORMAL e } \\
\text { BALXO PESO }\end{array}$} & \multicolumn{3}{|c|}{$\begin{array}{l}\text { SOBREPESO e } \\
\text { OBESIDADE }\end{array}$} & \multicolumn{2}{|c|}{ TOTAL } \\
\hline & $\mathbf{n}$ & $\% *$ & $\% * *$ & $\mathbf{n}$ & $\% *$ & $\% * *$ & $\mathbf{n}$ & $\%$ \\
\hline $\begin{array}{l}\text { NORMAL e } \\
\text { BAIXO PESO }\end{array}$ & 51 & 98,1 & 98,1 & 1 & 1,9 & 4,0 & 52 & 100,0 \\
\hline $\begin{array}{l}\text { SOBREPESO e } \\
\text { OBESIDADE }\end{array}$ & 1 & 4,0 & 4,0 & $\begin{array}{l}2 \\
4\end{array}$ & 96,0 & 96,0 & 25 & 100,0 \\
\hline TOTAL & 52 & $\overline{67,5}$ & 100,0 & 25 & 32,5 & 100,0 & 77 & 100,0 \\
\hline
\end{tabular}

Kappa $=0,94 \mathrm{p}<0,001$

* Percentual na linha

* Percentual na coluna

\section{CESEC CENTRO}

\begin{tabular}{|c|c|c|c|c|c|c|c|c|}
\hline \multirow[b]{3}{*}{ MEDIDA } & \multicolumn{8}{|c|}{ QUESTIONÁRIO } \\
\hline & \multicolumn{3}{|c|}{$\begin{array}{c}\text { NORMAL } \mathrm{e} \\
\text { BAIXO PESO }\end{array}$} & \multicolumn{3}{|c|}{$\begin{array}{l}\text { SOBREPESO e } \\
\text { OBESIDADE }\end{array}$} & \multicolumn{2}{|c|}{ TOTAL } \\
\hline & $\mathrm{n}$ & $\% *$ & $\% * *$ & $\mathrm{n}$ & $\% *$ & $\% * *$ & $\mathrm{n}$ & $\%$ \\
\hline $\begin{array}{l}\text { NORMAL } \\
\text { BAIXO PESO }\end{array}$ & 37 & 94,9 & 88,1 & 2 & 5,1 & 11,1 & 39 & 100,0 \\
\hline $\begin{array}{l}\text { SOBREPESO e } \\
\text { OBESIDADE }\end{array}$ & 5 & 23,8 & 11,9 & 16 & 76,2 & 88,9 & 21 & 100,0 \\
\hline TOTAL & 42 & $\overline{70,0}$ & 100,0 & 18 & 30,0 & 100,0 & 60 & 100,0 \\
\hline
\end{tabular}

Kappa $=0,73$ p $<0,001$

* Percentual na linha

** Percentual na coluna 


\section{DIREÇÃO GERAL}

\begin{tabular}{|c|c|c|c|c|c|c|c|c|}
\hline \multirow[b]{3}{*}{ MEDIDA } & \multicolumn{8}{|c|}{ QUESTIONÁRIO } \\
\hline & \multicolumn{3}{|c|}{$\begin{array}{c}\text { NORMAL e } \\
\text { BAIXO PESO }\end{array}$} & \multicolumn{3}{|c|}{$\begin{array}{l}\text { SOBREPESO e } \\
\text { OBESIDADE }\end{array}$} & \multicolumn{2}{|c|}{ TOTAL } \\
\hline & $\mathrm{n}$ & $\% *$ & $\% * *$ & $\mathrm{n}$ & $\% *$ & $\% * *$ & $\mathrm{n}$ & $\%$ \\
\hline $\begin{array}{l}\text { NORMAL e } \\
\text { BAIXO PESO }\end{array}$ & 67 & 97,1 & 93,1 & 2 & 2,9 & 5,7 & 69 & 100,0 \\
\hline $\begin{array}{l}\text { SOBREPESO e } \\
\text { OBESIDADE }\end{array}$ & 5 & 13,2 & 6,9 & 33 & 86,8 & 94,3 & 38 & 100,0 \\
\hline TOTAL & 72 & 67,3 & 100,0 & 35 & $\overline{32,7}$ & 100,0 & 107 & 100,0 \\
\hline
\end{tabular}

Kappa $=0,85$ p $<0,001$

* Percentual na linha

** Percentual na coluna

\section{ILHA DO GOVERNADOR}

\begin{tabular}{|c|c|c|c|c|c|c|c|c|}
\hline \multirow[b]{3}{*}{ MEDIDA } & \multicolumn{8}{|c|}{ QUESTIONÁRIO } \\
\hline & \multicolumn{3}{|c|}{$\begin{array}{c}\text { NORMAL e } \\
\text { BAIXO PESO }\end{array}$} & \multicolumn{3}{|c|}{$\begin{array}{l}\text { SOBREPESO e } \\
\text { OBESIDADE }\end{array}$} & \multicolumn{2}{|c|}{ TOTAL } \\
\hline & $\mathbf{n}$ & $\% *$ & $\% * *$ & $\mathbf{n}$ & $\% *$ & $\% * *$ & $\mathbf{n}$ & $\%$ \\
\hline $\begin{array}{l}\text { NORMAL } \\
\text { BAIXO PESO }\end{array}$ & 28 & 96,6 & 93,3 & 1 & 3,4 & 8,3 & 29 & 100,0 \\
\hline $\begin{array}{l}\text { SOBREPESO e } \\
\text { OBESIDADE }\end{array}$ & 2 & 15,4 & 6,7 & 11 & 84,6 & 91,7 & 13 & 100,0 \\
\hline TOTAL & 30 & $\overline{71,4}$ & 100,0 & 12 & 28,6 & 100,0 & 42 & 100,0 \\
\hline
\end{tabular}

Kappa $=0,83 \mathrm{p}<0,001$

* Percentual na linha

** Percentual na coluna

\section{b- PRESSÃO ARTERIAL}

Duas medidas de pressão arterial foram realizadas em 319 funcionários. Os níveis médios de pressão sistólica foram maiores entre os homens em todas as dependências, embora com diferenças estatisticamente significantes $(p<0,01)$ somente no Cesec Centro e Direção Geral (Tabela III.4.7). Os níveis médios de pressão diastólica também foram significativamente maiores entre os homens $(p<0,01)$, exceto na Agência Centro (Tabela III.4.8). Os níveis médios de pressão sistólica e diastólica aumentaram com a idade entre homens e mulheres (Gráficos III.4.2 e III.4.3). 
TABELA III.4.7

MÉDIAS* DE PRESSÃO SISTÓLICA MEDIDA

POR SEXO

POR DEPENDÊNCIA

\begin{tabular}{l|lcc|ccc}
\hline & \multicolumn{3}{|c|}{ HOMENS } & \multicolumn{3}{c}{ MULHERES } \\
DEPENDÊNCIA & MÉDIA & EP & n & MÉDIA & EP & n \\
\hline CENTRO** & 127,47 & 2,22 & 45 & 121,91 & 3,05 & 43 \\
CESEC CENTRO & 127,72 & 3,18 & 29 & 117,14 & 3,26 & 37 \\
DIREÇÃO GERAL & 131,30 & 1,80 & 69 & 118,27 & 2,54 & 44 \\
ILHA GOVERNADOR** & 128,10 & 4,59 & 20 & 118,25 & 3,10 & 32 \\
\hline
\end{tabular}

* em mm Hg

** Agências

TABELA III.4.8

MÉDIAS* DE PRESSÃO DIASTÓLICA MEDIDA

POR SEXO

POR DEPENDÊNCIA

\begin{tabular}{l|ccc|ccc}
\hline & \multicolumn{3}{|c|}{ HOMENS } & \multicolumn{3}{c}{ MULHERES } \\
\hline DEPENDÊNCIA & MÉDIA & EP & n & MEDIA & EP & n \\
\hline CENTRO** & 84,44 & 1,87 & 45 & 79,77 & 2,23 & 43 \\
CESEC CENTRO & 86,69 & 2,24 & 29 & 78,43 & 1,88 & 37 \\
DIREÇÃO GERAL & 87,39 & 1,36 & 69 & 79,66 & 1,71 & 44 \\
ILHA GOVERNADOR** & 90,50 & 3,70 & 20 & 76,50 & 1,52 & 32 \\
\hline
\end{tabular}

* em mm Hg

** Agências 
GRÁFICO III.4.2

DISTRIBUIÇÃO dOS NÍVEIS MÉDIOS DE PRESSÃo SISTÓLICA E

DIASTÓLICA MEDIDOS

TODAS AS DEPENDÊNCIAS

HOMENS

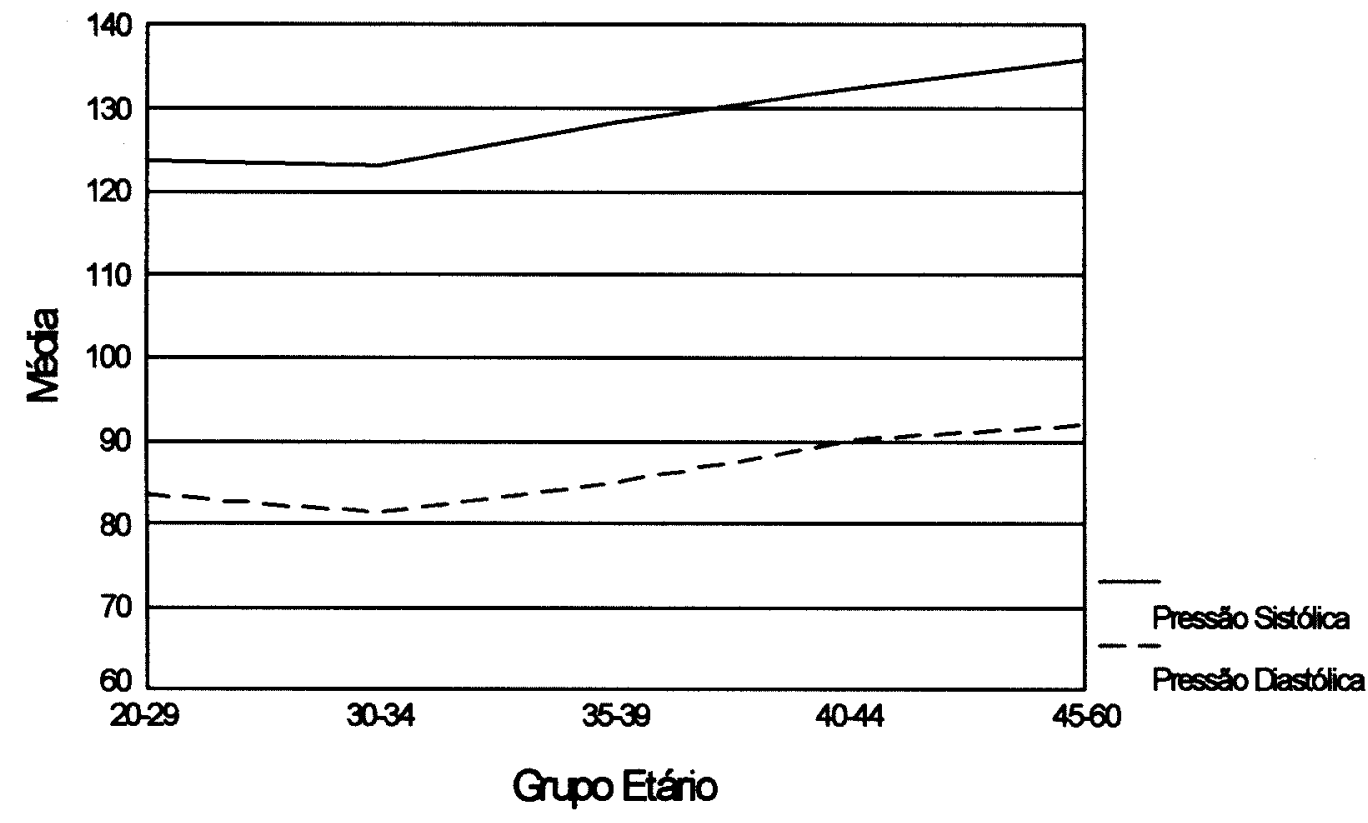

\section{GRÁFICO III.4.3}

DISTRIBUIÇÃO DOS NÍVEIS MÉdIOS DE PRESSÃO SISTÓLICA E

DIASTÓLICA MEDIDOS

TODAS AS DEPENDÊNCIAS

MULHERES

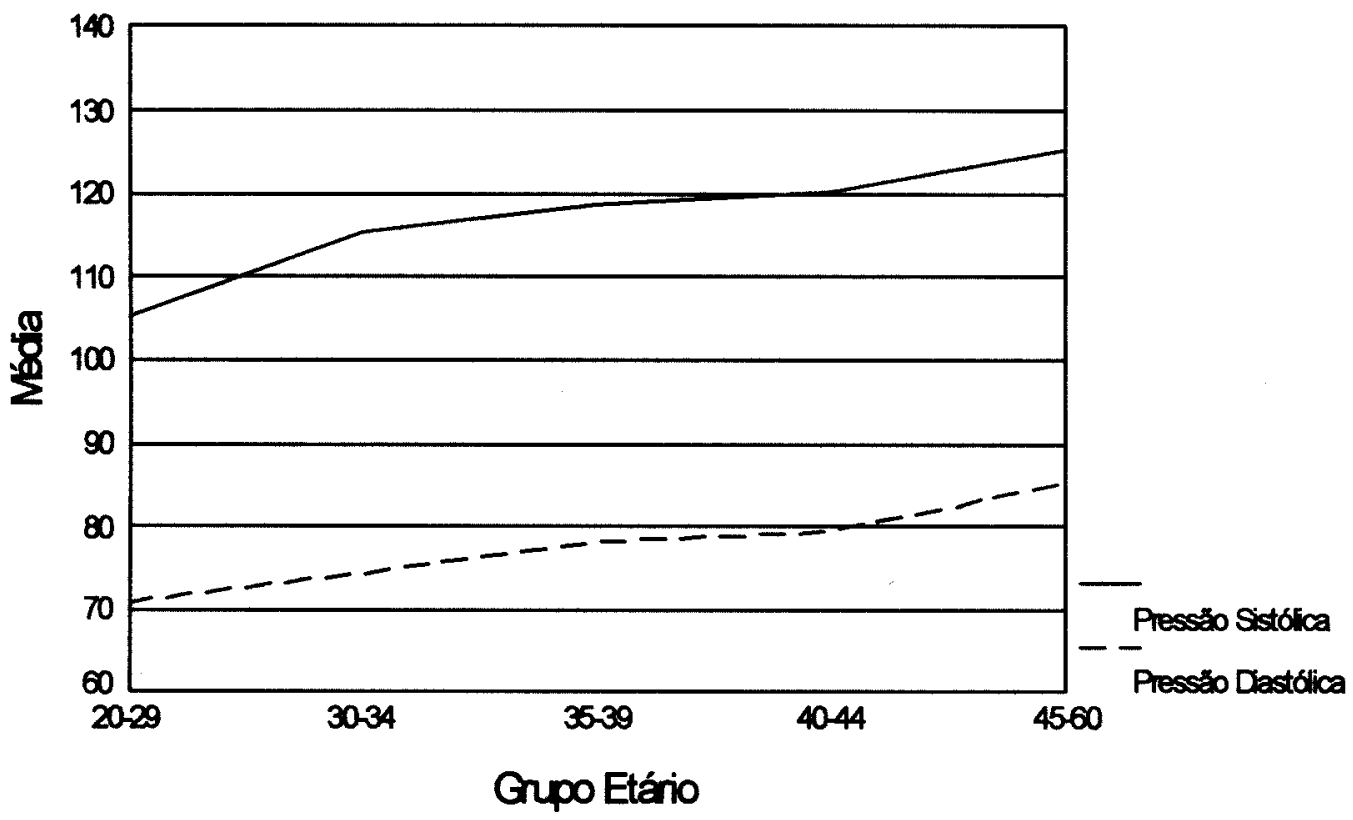


A fim de classificar os funcionários cujos níveis pressóricos foram medidos, utilizou-se a definição de hipertensão arterial recomendada pela Organização Mundial de Saúde (1978) para estudos de população. Segundo esse critério, são considerados hipertensos todos os indivíduos cujas pressões sistólica e diastólica sejam iguais ou superiores a 160 ou $95 \mathrm{mmHg}$, respectivamente, durante a segunda medida de pressão feita em repouso relativo. Além disso, são também considerados hipertensos todos os indivíduos que se declarem em tratamento específico, independente dos resultados obtidos durante a segunda medida de pressão arterial.

A proporção de funcionários com níveis pressóricos iguais ou superiores a 160/95 mmHg variou entre 17,3\% (Agência Ilha do Governador) e 20,4\% (Direção Geral), enquanto a prevalência de níveis intermediários (entre 140/90 mmHg e 159/94 mmHg) variou entre 5,8\% (Ilha do Governador) e 15,9\% (Centro) (Tabela III.4.9).

TABELA III.4.9

DISTRIBUIÇÃO dOS NÍVEIS DE PRESSÃO ARTERIAL MEDIDA POR DEPENDÊNCIA

\begin{tabular}{l|cc|cc|cc|c}
\hline DEPENDÊNCIA & $<140 / 90 \mathrm{mmHg}$ & \multicolumn{2}{|c|}{$\begin{array}{c}\text { Entre } \\
140 / 90\end{array}$} & $\begin{array}{c}\geq 160 / 95 \\
\mathrm{mmHg}\end{array}$ & TOTAL \\
\hline & $\mathrm{n}$ & $\%$ & $\mathrm{n}$ & $\%$ & $\mathrm{n}$ & $\%$ & $\mathrm{n}$ \\
CENTRO** & 58 & 65,9 & 14 & 15,9 & 16 & 18,2 & 88 \\
CESEC CENTRO & 47 & 71,2 & 7 & 10,6 & 12 & 18,2 & 66 \\
DIREÇÃO GERAL & 74 & 65,5 & 16 & 14,2 & 23 & 20,4 & 113 \\
ILHA GOVERNADOR** & 40 & 76,9 & 3 & 5,8 & 9 & 17,3 & 52 \\
\hline
\end{tabular}

De acordo com o critério de classificação adotado, a utilização de medicamentos específicos para controle de hipertensão arterial deve ser levada em conta também, além dos niveis pressóricos medidos. Assim, além dos funcionários com níveis iguais ou superiores a 160/95 mmHg, foram também classificados como hipertensos "segundo a medida" aqueles sob medicação. As prevalências estimadas através da medida direta e declaração de uso de medicamento no momento do exame, em cada dependência, são apresentadas nas Tabelas 4.5.10. De acordo com essa fonte de informação (MEDIDA OU USO DE MEDICAMENTO), 19 funcionários (22,6\%) foram classificados como hipertensos na agência Centro, $12(18,8 \%)$ no Cesec Centro, 26 (23,9\%) na Direção Geral e $11(22,9 \%)$ na agência Ilha do Governador. Essas estimativas foram 
comparadas àquelas obtidas a partir do questionário (Tabelas III.4.10). De acordo com as respostas às perguntas $n^{\circ} .68,97$ e 70 , os critérios adotados para classificação de hipertensão foram:

1. Informado por profissional de saúde, pelo menos uma vez, de que tinha pressão alta ou hipertensão arterial (pergunta $n^{\circ} 68$ ) ou

2. Declarou ser portador de hipertensão arterial (pergunta $n^{\circ} 97$ ) ou

3. Declarou, no questionário, estar em tratamento para controle de hipertensão arterial (pergunta ${ }^{\circ} 70$ )

$\mathrm{Na}$ Agência Centro, dentre os 19 funcionários classificados como hipertensos segundo a medida, $12(63,2 \%)$ foram classificados como hipertensos segundo o questionário (sensibilidade), enquanto a especificidade foi de $95,4 \%$, já que 62 dentre os 65 funcionários classificados como não hipertensos segundo a medida o foram também pelo questionário. O valor preditivo negativo (VPN) foi de $89,9 \%$ já que dentre os 69 funcionários classificados como não hipertensos segundo o questionário, 62 foram confirmados pela medida, ficando o valor preditivo positivo (VPP) em $80,0 \%$. Entre as outras dependências, o valor mais baixo de sensibilidade e VPP ocorreram no Cesec Centro, enquanto os valores estimados de especifidade e VPN foram elevados em todas elas. A concordância avaliada através do coeficiente Kappa variou entre 0,49 no Cesec Centro e 0,65 na Agência Ilha do Governador. De acordo com esses resultados, a concordância entre a classificação obtida a partir da medida e do questionário pode ser considerada moderada em algumas dependências (Cesec Centro e Direção Geral) e boa em outras (Agência Centro e Agência Ilha do Governador). 
TABELAS III.4.10

COMPARAÇÃO ENTRE A CLASSIFICAÇÃO DE HIPERTENSÃO ARTERIAL SEGUNDO MEDIDA E INFORMAÇÕES DO QUESTIONÁRIO

POR DEPENDÊNCIA

\section{AGÊNCIA CENTRO}

\begin{tabular}{|c|c|c|c|c|c|c|c|c|}
\hline \multirow{3}{*}{$\begin{array}{l}\text { MEDIDA ou } \\
\text { MEDICAMENTO }\end{array}$} & \multicolumn{8}{|c|}{ QUESTIONÁRIO } \\
\hline & \multicolumn{3}{|c|}{$\begin{array}{c}\text { NÃO } \\
\text { HIPERTENSO }\end{array}$} & \multicolumn{3}{|c|}{ HIPERTENSO } & \multicolumn{2}{|c|}{ TOTAL } \\
\hline & $\mathbf{n}$ & $\% *$ & $\% * *$ & $\mathrm{n}$ & $\%$ & $\% * *$ & $\mathrm{n}$ & $\%$ \\
\hline NÁO HIPERTENSO & 62 & $\overline{95,4}$ & 89,9 & 3 & 4,6 & 20,0 & 65 & 100,0 \\
\hline HIPERTENSO & 7 & 36,8 & 10,1 & 12 & 63,2 & 80,0 & 19 & 100,0 \\
\hline TOTAL & 69 & 82,6 & 100,0 & 15 & 17,9 & 100,0 & 84 & 100,0 \\
\hline
\end{tabular}

$\mathrm{KAPPA}=0,63 \mathrm{p}<0,001$

* Percentual na linha

** Percentual na coluna

CESEC CENTRO

\begin{tabular}{|c|c|c|c|c|c|c|c|c|}
\hline \multirow{3}{*}{$\begin{array}{l}\text { MEDIDA ou } \\
\text { MEDICAMENTO }\end{array}$} & \multicolumn{8}{|c|}{ QUESTIONÁRIO } \\
\hline & \multicolumn{3}{|c|}{$\begin{array}{c}\text { NÁO } \\
\text { HIPERTENSO }\end{array}$} & \multicolumn{3}{|c|}{ HIPERTENSO } & \multicolumn{2}{|c|}{ TOTAL } \\
\hline & $\mathrm{n}$ & $\% *$ & $\% * *$ & $\mathrm{n}$ & $\%^{*}$ & $\% * *$ & $\mathrm{n}$ & $\%$ \\
\hline NĀO HIPERTENSO & 47 & $\overline{90,4}$ & 90,4 & 5 & 9,6 & 41,7 & 52 & 100,0 \\
\hline HIPERTENSO & 5 & 41,7 & 9,6 & 7 & 58,3 & 58,3 & 12 & 100,0 \\
\hline TOTAL & 52 & $\overline{81,3}$ & $\overline{100,0}$ & 12 & $\overline{18,8}$ & 100,0 & 64 & $\overline{100,0}$ \\
\hline
\end{tabular}

$\mathrm{KAPPA}=0,49 \mathrm{p}<0,001$

* Percentual na linha

** Percentual na coluna

\section{DIREÇÃO GERAL}

\begin{tabular}{|c|c|c|c|c|c|c|c|c|}
\hline \multirow{3}{*}{$\begin{array}{l}\text { MEDIDA ou } \\
\text { MEDICAMENTO }\end{array}$} & \multicolumn{8}{|c|}{ QUESTIONÁRIO } \\
\hline & \multicolumn{3}{|c|}{$\begin{array}{c}\text { NÃO } \\
\text { HIPERTENSO }\end{array}$} & \multicolumn{3}{|c|}{ HIPERTENSO } & \multicolumn{2}{|c|}{ TOTAL } \\
\hline & $\mathrm{n}$ & $\% *$ & $\% * *$ & $\mathbf{n}$ & $\% *$ & $\% * *$ & $\mathrm{n}$ & $\%$ \\
\hline NÁO HIPERTENSO & 76 & 91,6 & 88,4 & 7 & 8,4 & 30,4 & 83 & 100,0 \\
\hline HIPERTENSO & 10 & 38,5 & 11,6 & 16 & 61,5 & 69,6 & 26 & 100,0 \\
\hline TOTAL & 86 & 78,9 & $\overline{100,0}$ & 23 & 61,5 & 100,0 & 109 & 100,0 \\
\hline
\end{tabular}

$\mathrm{KAPPA}=0,55 \mathrm{p}<0,001$

* Percentual na linha

** Percentual na coluna 


\section{ILHA DO GOVERNADOR}

\begin{tabular}{|c|c|c|c|c|c|c|c|c|}
\hline \multirow{3}{*}{$\begin{array}{l}\text { MEDIDA ou } \\
\text { MEDICAMENTO }\end{array}$} & \multicolumn{8}{|c|}{ QUESTIONÁRIO } \\
\hline & \multicolumn{3}{|c|}{$\begin{array}{c}\text { NÃO } \\
\text { HIPERTENSO }\end{array}$} & \multicolumn{3}{|c|}{ HIPERTENSO } & \multicolumn{2}{|c|}{ TOTAL } \\
\hline & $\mathrm{n}$ & $\% *$ & $\% * *$ & $\mathrm{n}$ & $\% *$ & $\% * *$ & $\mathrm{n}$ & $\%$ \\
\hline NÃO HIPERTENSO & 34 & 91,9 & 91,9 & 3 & 8,1 & 27,3 & 37 & 100,0 \\
\hline HIPERTENSO & 3 & 27,3 & 8,1 & 8 & 72,7 & 72,7 & 11 & 100,0 \\
\hline TOTAL & 37 & 77,1 & 100,0 & 11 & 22,9 & 100,0 & 48 & 100,0 \\
\hline
\end{tabular}

KAPPA $=0,65 p<0,001$

* Percentual na linha

** Percentual na coluna 


\section{5- OCORRÊNCIA SIMULTÂNEA DE FATORES DE RISCO E EFEITOS}

Nesta seção, buscamos identificar a ocorrência simultânea dos quatro fatores de risco investigados -fumo, consumo de álcool, dieta e atividade física- isto é, se ocorrem de forma independente na população ou se existem subgrupos que apresentam padrão saudável de comportamento, com nenhum ou poucos fatores de risco, ou a associação de diversos hábitos imprudentes (aglomeração ou "clusterização" dos fatores de risco). Além disso, buscamos também identificar características demográficas dos diferentes subgrupos, classificados de acordo com aqueles fatores de risco, bem como investigar a ocorrência simultânea de hipertensão, sobrepeso/obesidade e informação sobre hipercolesterolemia, aqui chamados de "efeitos". Como nas seções anteriores, os intervalos de confiança das prevalências estimadas são apresentados entre parênteses.

A análise do cruzamento dos quatro fatores de risco, dois a dois, revela coexistência entre comportamentos extremos, na maioria dos casos. É possível observar, por exemplo, que entre os funcionários que declararam consumir álcool diariamente, em comparação aos que consomem ocasionalmente ou nunca, encontramos a maior prevalência de grandes fumantes, em ambos os sexos (Tabela III.5.1). Entre os homens, 24,0\% (IC 95\%: 20,3-27,7) dos que consomem álcool com grande frequência são grandes fumantes em comparação a 10,5\% (IC 95\%: 2,2-18,8) dos que nunca consomem álcool. Entre as mulheres, essas proporções são ainda mais extremas: $22,8 \%$ (IC 95\%: 16,6-29,0) e 5,3\% (IC 95\%: 0,1-10,5), respectivamente.

É possível observar também que existe tendência ao aumento da proporção de funcionários que não fumam a medida que o consumo de álcool se torna menos frequente, sugerindo de maneira consistente a associação positiva entre as duas variáveis, isto é, quanto mais frequente o consumo de álcool, maior o consumo de cigarros. 
TABELA III.5.1

HÁBITO DE FUMAR E CONSUMO DE ÁLCOOL

POR SEXO

AMBAS AS DEPENDÊNCIAS

\begin{tabular}{|c|c|c|c|c|c|}
\hline \multirow[b]{2}{*}{ ÁLCOOL } & \multicolumn{4}{|c|}{ FUMO } & \multirow[b]{2}{*}{$\begin{array}{c}\text { TOTAL } \\
n\end{array}$} \\
\hline & $\begin{array}{c}\text { GRANDE } \\
\%\end{array}$ & $\begin{array}{c}\text { LEVE } \\
\%\end{array}$ & $\begin{array}{c}\text { EX- } \\
\text { FUMANTE } \\
\%\end{array}$ & $\begin{array}{c}\text { NUNCA } \\
\text { FUMOU } \\
\%\end{array}$ & \\
\hline \multicolumn{6}{|l|}{ HOMENS } \\
\hline $\begin{array}{l}\text { DIÁRIO ou } \\
\text { SEMANAL }\end{array}$ & 24,0 & 13,3 & 20,1 & 42,6 & 384 \\
\hline OCASIONAL & 11,7 & 13,6 & 22,6 & 52,1 & 251 \\
\hline NUNCA & 10,5 & 8,0 & 15,4 & 66,0 & 40 \\
\hline \multicolumn{6}{|l|}{ MULHERES } \\
\hline $\begin{array}{l}\text { DIARIO ou } \\
\text { SEMANAL }\end{array}$ & 22,8 & 19,1 & 25,6 & 32,5 & 130 \\
\hline OCASIONAL & 10,2 & 13,0 & 21,9 & 54,9 & 293 \\
\hline NUNCA & 5,3 & 6,7 & 15,4 & 72,6 & 53 \\
\hline
\end{tabular}

Proporções corrigidas por fator de expansão

Grande fumante $=20$ cigarros ou mais por dia

Associação entre a intensidade do hábito de fumar e o tipo de dieta também foi encontrada. Entre os funcionários mais jovens, de ambos os sexos, a proporção de grandes fumantes aumenta conforme a dieta se torna menos saudável -do primeiro para o quinto quintil-, embora somente entre as mulheres tenha sido encontrada diferença significativa entre as proporções no quintil mais saudável e no menos saudável: $4,0 \%$ (IC 95\%: 0,3-7,7) e 24,1\% (IC 95\%: 11,9-36,3) - Tabela III.5.2. A tendência das proporções de não fumantes aponta na mesma direção, já que são menores entre aqueles que apresentam dieta menos saudável. Também nesse caso essa tendência é mais nítida entre as mulheres, onde a proporção de não fumantes é significativamente menor no quintil de dieta menos saudável -30,8\% (IC 95\%: 17,6-44,0)-comparada ao quintil de dieta mais saudável -56,0\% (IC 95\%: 46,6-65,4)-. 


\section{TABELA III.5.2 \\ HÁBITO DE FUMAR E QUINTIS DE DIETA* \\ POR SEXO \\ AMBAS AS DEPENDÊNCIAS \\ IDADE MENOR OU IGUAL A 40 ANOS}

\begin{tabular}{|c|c|c|c|c|c|}
\hline \multirow[b]{2}{*}{ DIETA } & \multicolumn{5}{|c|}{ FUMO } \\
\hline & $\begin{array}{c}\text { GRANDE } \\
\%\end{array}$ & $\begin{array}{c}\text { LEVE } \\
\% \\
\end{array}$ & $\begin{array}{c}\text { EX- } \\
\text { FUMANTE } \\
\%\end{array}$ & $\begin{array}{c}\text { NUNCA } \\
\text { FUMOU } \\
\%\end{array}$ & $\begin{array}{c}\text { TOTAL } \\
n\end{array}$ \\
\hline \multicolumn{6}{|l|}{ HOMENS } \\
\hline$\overline{\text { DIETA } 1}$ & $\overline{11,5}$ & $\overline{15,6}$ & 13,8 & 59,1 & 68 \\
\hline DIETA 2 & 13,2 & 10,3 & 11,0 & 65,5 & 73 \\
\hline DIETA 3 & 19,2 & 18,8 & 15,0 & 47,1 & 59 \\
\hline DIETA 4 & 17,5 & 9,6 & 12,6 & 60,4 & 93 \\
\hline DIETA 5 & 17,6 & 14,1 & 16,6 & 51,7 & 107 \\
\hline \multicolumn{6}{|c|}{ MULHERES } \\
\hline$\overline{\text { DIETA } 1}$ & 4,0 & $\overline{14,2}$ & 25,8 & 56,0 & 78 \\
\hline DIETA 2 & 8,7 & 11,8 & 17,9 & 61,6 & 66 \\
\hline DIETA 3 & 15,9 & 15,9 & 21,4 & 46,8 & 37 \\
\hline DIETA 4 & 18,1 & 10,6 & 17,6 & 53,7 & 63 \\
\hline DIETA 5 & 24,1 & 17,3 & 27,8 & 30,8 & 35 \\
\hline
\end{tabular}

\footnotetext{
Proporções corrigidas por fator de expansão

* Quintis de dieta baseados em Escore ; Dieta 1 - mais saudável

Grande fumante $=20$ cigarros ou mais por dia
}

Entre os funcionários com mais de 40 anos, é possível observar associação entre fumo e dieta menos saudável entre os homens, cujas proporções de grandes fumantes aumentaram e de não fumantes diminuíram, conforme a dieta se tornou menos saudável (Tabela III.5.3). Entre as mulheres, a prevalência de grandes fumantes aumentou entre o primeiro e o quarto quintis, cabendo considerar o pequeno número de funcionárias incluídas no quintil de dieta menos saudável -apenas dezesseis- o que possibilita grande flutuação dos resultados. Não se observou, nesse caso, a diminuição da prevalência de não fumantes de acordo com a piora da dieta.

É possível afirmar portanto que dieta pouco saudável e fumo estão associados, embora essa associação não apresente a mesma intensidade nos diferentes sub-grupos da população. 
TABELA III.5.3

HÁBITO DE FUMAR E QUINTIS DE DIETA*

POR SEXO

AMBAS AS DEPENDÊNCIAS

MAIORES DE 40 ANOS DE IDADE

\begin{tabular}{|c|c|c|c|c|c|}
\hline \multirow[b]{2}{*}{ DIETA } & \multicolumn{4}{|c|}{ FUMO } & \multirow[b]{2}{*}{$\begin{array}{c}\text { TOTAL } \\
n\end{array}$} \\
\hline & $\begin{array}{c}\text { GRANDE } \\
\%\end{array}$ & $\begin{array}{c}\text { LEVE } \\
\% \\
\%\end{array}$ & $\begin{array}{c}\text { EX- } \\
\text { FUMANTE } \\
\%\end{array}$ & $\begin{array}{c}\text { NUNCA } \\
\text { FUMOU } \\
\%\end{array}$ & \\
\hline \multicolumn{6}{|c|}{ HOMENS } \\
\hline DIETA 1 & 14,8 & 13,6 & 34,2 & 37,4 & 70 \\
\hline DIETA 2 & 16,3 & 10,3 & 43,8 & 29,6 & 57 \\
\hline DIETA 3 & 13,4 & 7,9 & 39,0 & 39,6 & 44 \\
\hline DIETA 4 & 30,1 & 7,3 & 20,7 & 42,0 & 51 \\
\hline DIETA 5 & 38,9 & 23,6 & 19,7 & 17,8 & 52 \\
\hline \multicolumn{6}{|c|}{ MULHERES } \\
\hline DIETA 1 & 9,0 & 12,2 & 34,4 & 44,3 & 58 \\
\hline DIETA 2 & 9,1 & 19,7 & 26,3 & 44,9 & 56 \\
\hline DIETA 3 & 20,3 & 7,3 & 7,3 & 65,0 & 32 \\
\hline DIETA 4 & 24,2 & 13,6 & 15,2 & 47,0 & 36 \\
\hline DIETA 5 & 7,2 & 20,3 & 13,0 & 59,4 & 16 \\
\hline
\end{tabular}

Proporções corrigidas por fator de expansão

* Quintis de dieta baseados em Escore ; Dieta 1 - mais saudável

Grande fumante $=20$ cigarros ou mais por dia

A proporção de grandes fumantes também é maior entre os funcionários mais jovens que não praticam atividade física, de ambos os sexos (Tabela III.5.4). Entre os homens, $21,5 \%$ (IC 95\%: 16,7-26,3) dos que não praticam são grandes fumantes comparado a 8,6\% (IC 95\%: 2,0-15,2) daqueles que praticam com maior frequência. Entre as mulheres que praticam com grande frequência, nenhuma é grande fumante, comparado a $17,7 \%$ (IC 95\%: 12,7-22,7) dentre as que não praticam (Tabela III.5.4). Reforçando o sentido daquela associação, a proporção de homens não fumantes é maior entre os que praticam frequentemente $-64,7 \%$ (IC 95\%: 53,5-75,9)-, comparado aos que não praticam $-49,1 \%(43,3-54,9)$ - o que ocorre também entre as mulheres, embora sem diferença significativa entre as proporções. 


\section{TABELA III.5.4 \\ HÁBITO DE FUMAR E ATIVIDADE FÍSICA SEMANAL \\ POR SEXO \\ AMBAS AS DEPENDÊNCIAS \\ IDADE MENOR OU IGUAL A 40 ANOS}

\begin{tabular}{|c|c|c|c|c|c|}
\hline \multirow[b]{2}{*}{$\begin{array}{l}\text { ATIVIDADE } \\
\text { FÍSICA }\end{array}$} & \multicolumn{5}{|c|}{ FUMO } \\
\hline & $\begin{array}{c}\text { GRANDE } \\
\%\end{array}$ & $\begin{array}{c}\text { LEVE } \\
\%\end{array}$ & $\begin{array}{c}\text { EX- } \\
\text { FUMANTE } \\
\%\end{array}$ & $\begin{array}{c}\text { NUNCA } \\
\text { FUMOU } \\
\%\end{array}$ & $\begin{array}{c}\text { TOTAL } \\
n\end{array}$ \\
\hline \multicolumn{6}{|l|}{ HOMENS } \\
\hline FREQUENTE & 8,6 & 19,9 & 6,8 & 64,7 & 53 \\
\hline MODERADA & 15,0 & 4,6 & 15,0 & 65,4 & 40 \\
\hline $\begin{array}{l}\text { POUCO } \\
\text { FREQUENTE }\end{array}$ & 8,1 & 9,4 & 16,5 & 65,9 & 95 \\
\hline NÃO PRATICA & 21,5 & 15,1 & 14,3 & 49,1 & 211 \\
\hline \multicolumn{6}{|l|}{ MULHERES } \\
\hline FREQUENTE & 0,0 & 10,7 & 21,4 & 67,9 & 23 \\
\hline MODERADA & 7,6 & 19,5 & 28,8 & 44,1 & 33 \\
\hline $\begin{array}{l}\text { POUCO } \\
\text { FREQUENTE }\end{array}$ & 5,9 & 20,3 & 23,0 & 50,8 & 57 \\
\hline NÃO PRATICA & 17,7 & 10,5 & 19,6 & 52,3 & 164 \\
\hline
\end{tabular}

Proporções corrigidas por fator de expansão

Frequente $=7$ vezes; Moderada $=5$ ou 6 vezes; Pouco frequente $=2$ a 4 vezes

Grande fumante $=20$ cigarros ou mais por dia

Entre homens e mulheres mais velhos, a prevalência de grandes fumantes também foi significativamente maior entre aqueles que não praticam atividades físicas, comparados aos que praticam com grande frequência: $28,6 \%$ (IC $95 \%: 22,6-34,6$ ) e 12,9\% (IC 95\%: 1,8-24,0) no sexo masculino, 18,9\% (IC 95\%: 12,9-24,9) e $8,1 \%$ (IC 95\%: 0-19,5) respectivamente, no sexo feminino (Tabela III.5.5). Ao contrário da tendência observada entre os mais jovens, as prevalências de não fumantes foram menores entre os que praticam com frequência em ambos os sexos, comparados aos que não praticam, embora sem diferença significativa: $27,7 \%$ (IC $95 \%$ : 12,9-42,5) e 32,9\% (IC 95\%: 26,7-39,1) entre os homens, e entre as mulheres, 43,5\% (IC 95\%: 22,8-64,2) e $47,2 \%$ (IC $95 \%: 39,6-54,8$ ), respectivamente. 


\section{TABELA III.5.5 \\ HÁBITO DE FUMAR E ATIVIDADE FÍSICASEMANAL \\ POR SEXO \\ AMBAS AS DEPENDÊNCIAS \\ MAIORES DE 40 ANOS DE IDADE}

\begin{tabular}{|c|c|c|c|c|c|}
\hline \multirow[b]{2}{*}{$\begin{array}{l}\text { ATIVIDADE } \\
\text { FISICA } \\
\end{array}$} & \multicolumn{5}{|c|}{ FUMO } \\
\hline & $\begin{array}{c}\text { GRANDE } \\
\%\end{array}$ & $\begin{array}{c}\text { LEVE } \\
\%\end{array}$ & $\begin{array}{c}\text { EX- } \\
\text { FUMANTE } \\
\%\end{array}$ & $\begin{array}{c}\text { NUNCA } \\
\text { FUMOU } \\
\%\end{array}$ & $\begin{array}{c}\text { TOTAL } \\
n\end{array}$ \\
\hline \multicolumn{6}{|l|}{ HOMENS } \\
\hline FREQUENTE & 12,9 & 14,9 & 44,6 & 27,7 & 27 \\
\hline MODERADA & 13,3 & 12,2 & 39,8 & 34,7 & 30 \\
\hline $\begin{array}{l}\text { POUCO } \\
\text { FREQUENTE }\end{array}$ & 8,3 & 18,9 & 34,9 & 37,9 & 52 \\
\hline NÃO PRATICA & 28,6 & 10,5 & 28,0 & 32,9 & 163 \\
\hline \multicolumn{6}{|l|}{ MULHERES } \\
\hline FREQUENTE & 8,1 & 22,6 & 25,8 & 43,5 & 17 \\
\hline MODERADA & 2,3 & 31,0 & 24,1 & 42,5 & 21 \\
\hline $\begin{array}{l}\text { POUCO } \\
\text { FREQUENTE }\end{array}$ & 6,3 & 4,9 & 23,6 & 65,3 & 38 \\
\hline NÃO PRATICA & 18,9 & 12,4 & 21,6 & 47,2 & 120 \\
\hline
\end{tabular}

Proporç̃es corrigidas por fator de expansão

Frequente $=7$ vezes; Moderada $=5$ ou 6 vezes; Pouco frequente $=2$ a 4 vezes

Grande fumante $=20$ cigarros ou mais por dia

A parcela de funcionários que pratica atividades físicas com grande frequência é maior entre aqueles que apresentam a dieta mais saudável em ambos os sexos e estratos etários (Tabelas III.5.6 e III.5.7). Entre os homens mais jovens, 22,3\% (IC 95\%: 13,6$31,0)$ dos que se encontram no quintil mais saudável de dieta, praticam atividades fisicas com grande frequência, comparados a 12,3\% (IC 95\%: 7,0-17,6) do quintil menos saudável. A mesma tendência foi observada para atividade física moderada. Entre as mulheres mais jovens, $19,4 \%$ (IC 95\%: 12,0-26,8), das que se encontram no quintil mais saudável praticam frequentemente, enquanto nenhuma das incluídas no último quintil o faz.

A proporção de funcionários que não pratica atividades fisicas em cada um dos quintis de dieta sugere o mesmo padrão, já que é maior entre aqueles que apresentam a dieta menos saudável: $61,4 \%$ (IC $95 \%$ : 53,5-69,3) contra 36,7\% (IC 95\%: 46,7-26,7) 
entre os homens, e 68,9\% (IC 95\%: 55,7-82,1) contra 45,4\% (IC 95\%: 36,1-54,7) entre as mulheres.

\section{TABELA III.5.6 \\ ATIVIDADE FÍSICA SEMANAL E QUINTIS DE DIETA* \\ POR SEXO \\ AMBAS AS DEPENDÊNCIAS \\ IDADE MENOR OU IGUAL A 40 ANOS}

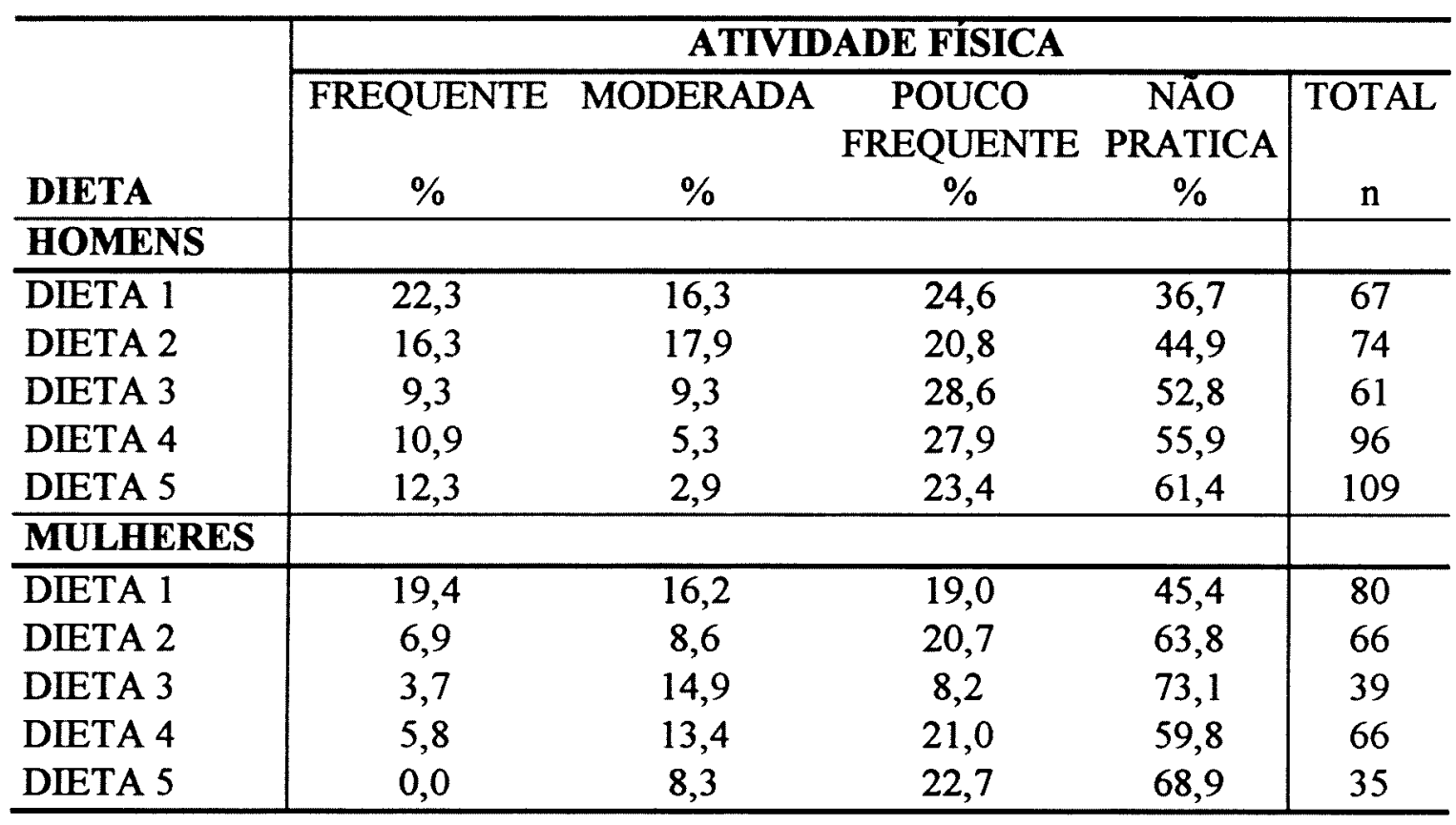

Proporções corrigidas por fator de expansão

* Quintis de dieta baseados em Escore ; Dieta 1 - mais saudável

Frequente $=7$ vezes; Moderada $=5$ ou 6 vezes; Pouco frequente $=2$ a 4 vezes

Entre os funcionários mais velhos, o mesmo comportamento foi observado, chamando a atenção a grande proporção de homens e mulheres que não praticam atividades físicas no quintil de dieta menos saudável -79,5\% (IC 95\%: 69,9-89,1) e 73,6\% (IC 95\%: 55,2-92,0)- respectivamente, comparadas às mesmas proporções no primeiro quintil (Tabela III.5.7) 
TABELA III.5.7

ATIVIDADE FÍSICA SEMANAL E QUINTIS DE DIETA

POR SEXO

AMBAS AS DEPENDÊNCIAS

MAIORES DE 40 ANOS DE IDADE

\begin{tabular}{|c|c|c|c|c|c|}
\hline \multirow[b]{2}{*}{ DIETA } & \multicolumn{5}{|c|}{ ATIVIDADE FISICA } \\
\hline & $\begin{array}{c}\text { FREQUENTE } \\
\%\end{array}$ & $\begin{array}{c}\text { MODERADA } \\
\%\end{array}$ & $\begin{array}{c}\text { POUCO } \\
\text { FREQUENT } \\
\%\end{array}$ & $\begin{array}{c}\text { NÃO } \\
\text { PRATICA } \\
\%\end{array}$ & $\begin{array}{c}\text { TOTAL } \\
\text { n }\end{array}$ \\
\hline \multicolumn{6}{|c|}{ HOMENS } \\
\hline$\overline{\text { DIETA } 1}$ & $\overline{16,2}$ & 14,3 & 20,0 & 49,4 & 72 \\
\hline DIETA 2 & 13,5 & 10,6 & 9,6 & 66,3 & 58 \\
\hline DIETA 3 & 4,7 & 12,9 & 17,1 & 65,3 & 45 \\
\hline DIETA 4 & 7,8 & 6,7 & 23,3 & 62,2 & 51 \\
\hline DIETA 5 & 4,0 & 5,5 & 11,0 & 79,5 & 51 \\
\hline \multicolumn{6}{|c|}{ MULHERES } \\
\hline$\overline{\text { DIETA } 1}$ & $\overline{9,8}$ & 20,4 & 21,3 & 48,5 & 62 \\
\hline DIETA 2 & 11,6 & 9,1 & 28,8 & 50,5 & 56 \\
\hline DIETA 3 & 5,8 & 7,4 & 9,1 & 77,7 & 31 \\
\hline DIETA 4 & 3,6 & 6,6 & 13,1 & 76,6 & 38 \\
\hline DIETA 5 & 6,9 & 6,9 & 12,5 & 73,6 & 17 \\
\hline
\end{tabular}

Proporções corrigidas por fator de expansão

* Quintis de dieta baseados em Escore ; Dieta 1 - mais saudável

Frequente $=7$ vezes; Moderada $=5$ ou 6 vezes; Pouco frequente $=2$ a 4 vezes

A distribuição do consumo de álcool entre as diversas categorias de dieta apresentou tendência consistente somente entre homens com mais de 40 anos de idade (Anexo 6). Foi possível observar ainda em três dentre os quatro estratos, que quanto pior a dieta menor a proporção de funcionários que não consomem álcool. Assim, os resultados são apenas sugestivos de que o consumo de álcool é maior entre aqueles que apresentam dieta menos saudável. A ausência de tendência consistente fói observada também em relação ao consumo de álcool nas diferentes categorias de atividade física, (Anexo 7).

Uma vez efetuada a observação dos fatores de risco dois a dois, interessa identificar padrões de ocorrência simultânea dos quatro, com seus diversos níveis de intensidade. Os resultados da análise de correspondência serão apresentados com essa finalidade. 


\section{a- FATORES DE RISCO}

As categorias de cada um dos quatro fatores de risco - fumo, dieta, atividade física e consumo de álcool- determinaram 16 eixos cujos valores próprios são apresentados na Tabela III.5.8 e Gráfico III.5.1. Conforme exposto na Metodologia, o valor próprio é uma medida da importância do eixo na explicação da variância global. Nesse caso, o valor próprio do primeiro eixo $-0,1323$ - foi bem superior ao dos outros fatores, o que também pode ser observado por sua maior percentagem de explicação da variância global -15,561\%-. Já que do segundo eixo em diante, a percentagem de explicação diminui, tornando-se homogênea e sem maior significado, apenas os dois primeiros serão analisados.

TABELA III.5.8

VALORES PRÓPRIOS E PERCENTAGEM DE EXPLICAÇÃO

DA VARIÂNCIA DE CADA EIXO

FATORES DE RISCO

\begin{tabular}{c|ccc}
\hline EIXO & $\begin{array}{c}\text { VALOR } \\
\text { PRÓPRIO }\end{array}$ & $\begin{array}{c}\text { PERCENTAGEM } \\
\text { DE } \\
\text { EXPLICAÇÃO }\end{array}$ & $\begin{array}{c}\text { PERCENTAGEM } \\
\text { ACUMULADA }\end{array}$ \\
\hline 1 & 0,1323 & 15,561 & 15,561 \\
2 & 0,0817 & 9,612 & 25,173 \\
3 & 0,0793 & 9,325 & 34,498 \\
4 & 0,0727 & $\mathbf{8 , 5 4 9}$ & 43,047 \\
5 & 0,0704 & $\mathbf{8 , 2 8 1}$ & 51,328 \\
6 & 0,0665 & 7,816 & 59,144 \\
7 & 0,0620 & 7,289 & 66,433 \\
8 & 0,0596 & 7,013 & 73,446 \\
9 & 0,0573 & 6,733 & 80,179 \\
10 & 0,0529 & 6,224 & 86,403 \\
11 & 0,0494 & 5,804 & 92,207 \\
12 & 0,0392 & 4,605 & 96,812 \\
13 & 0,0271 & 3,185 & 99,997 \\
14 & 0,0000 & 0,003 & 100,00 \\
15 & 0,0000 & 0,000 & \\
16 & 0,0000 & 0,000 & \\
\hline
\end{tabular}



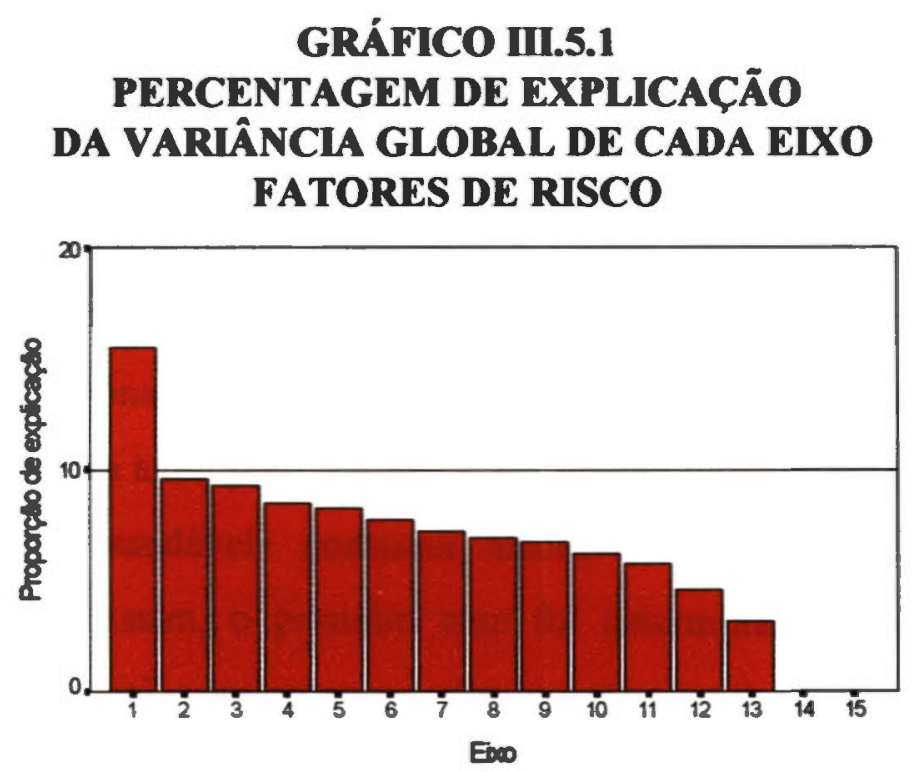

A contribuição absoluta de cada categoria das variáveis (ou elementos) pode ser interpretada como a parte da variância do eixo explicada pela respectiva categoria (Tabela III.5.9). Quanto maior a contribuiçĩo absoluta, maior a importância do elemento no eixo. Nesse caso, "Grande Fumante" por um lado e "Dieta 1" por outro, foram responsáveis pela maior parte da variância do primeiro eixo.

A categoria "Grande Fumante" foi também a que apresentou a maior correlaçio com o primeiro eixo - 0,73- enquanto "Atividade Física muito Frequente" apresentou a menor correlação $-0,34$.

TABELA III.5.9

CONTRIBUIÇÃO ABSOLUTA E CORRTLAÇÃO DOS PRINCIPAIS ELEMINTOS COM O PRIMIIRO EIXO FATORES DE RISCO

\begin{tabular}{l|ccc}
\hline CATEGORIAS & $\mathbf{3}$ & $\begin{array}{c}\text { CONTRIBUIÇÃO } \\
\text { ABSOLUTA }\end{array}$ & CORRELAÇÃo \\
\hline GRANDE FUMANTE & 190 & $23,4(+)$ & 0,73 \\
DIETA 5 & 214 & $11,9(+)$ & 0,54 \\
ÁLCOOL DIÁRIO & 121 & $8,4(+)$ & 0,44 \\
ATIVIDADE FÍSICA NENHUMA & 677 & $5,9(+)$ & 0,52 \\
DIETA 1 & 283 & $11,7(-)$ & 0,53 \\
ATIVIDADE FISICA MODERADA & 129 & $7,2(-)$ & 0,40 \\
NÃO FUMA & 564 & $5,3(-)$ & 0,46 \\
ÁLCOOL OCASIONAL & 559 & $5,3(-)$ & 0,45 \\
ATIVIDADE FÍSICA MUITO & 122 & $5,1(-)$ & 0,34 \\
FREQUENTE & & & - \\
\hline TOTAL & \multicolumn{4}{c}{} \\
\hline
\end{tabular}

Obs: Apesar das contribuiçð̃es absolutas estarem sob a forma de percentual, apresentamos o sinal da coordenada de cada item. Esses sinais devem ser entendidos como oposiçlo de um grupo $\rightarrow$ de sinal positivo- a outro - os de sinal negativo. 
De acordo com esses resultados, o primeiro eixo apresenta um gradiente entre comportamentos mais radicais -nos extremos do eixo horizontal - e comportamentos intermediários. Dessa forma, de um lado do eixo encontram-se os funcionários incluídos no primeiro quintil de dieta (d1) $\multimap$ mais saudável-, e que declararam atividade física de lazer muito frequente ou moderada (gf ou gm), não fumar (nf), e consumir álcool ocasionalmente (ao) (Gráfico III.5.2). Essas categorias estão em oposição a ou se referem a um perfil oposto a: ser grande fumante (fg), quinto quintil de dieta (d5) $\multimap$ menos saudável- consumir álcool diariamente (ad) e não praticar atividade física (gn). Assim, o primeiro eixo foi determinado principalmente pelos comportamentos "radicais" e opostos: aqueles que são grandes fumantes por exemplo, têm maior probabilidade de consumir álcool diariamente, ter dieta pouco saudável e não praticar atividade física, enquanto o inverso ocorre com os não fumantes.

Cabe notar que nesses "comportamentos radicais" não se incluem muitos indivíduos $-163(13,7 \%)$ não apresentam nenhum dos fatores e $68(5,6 \%)$ apresentam todos (fumam, consomem álcool diariamente ou semanalmente, quintis 4 ou 5 de dieta, não praticam atividade física)- mas esses dois grupos são os que exibem padrão mais típico ou "coerente" de comportamento, em função de terem todos ou nenhum fator de risco, e essa característica faz com que sejam os principais elementos do primeiro eixo. No primeiro grupo, os mesmos indivíduos fumam muito, têm dieta pouco saudável, consomem álcool diariamente e são sedentários. No segundo, estão incluídos aqueles que têm dieta saudável, praticam atividade física de lazer, não fumam e consomem álcool apenas ocasionalmente. Entre os dois grupos encontra-se a maioria da população que apresenta um, dois ou três fatores de risco, com graus de intensidade diversos, sem apresentar no entanto padrão "coerente" de comportamento. Os resultados reforçam a idéia esboçada na análise dos fatores de risco dois a dois, segundo a qual existe um padrão de aglomeração dos hábitos mais saudáveis por um lado, e dos menos prudentes por outro.

Os dois grupos diferenciados, com os quatro ou nenhum dos fatores de risco, são apresentados na Tabela III.5.10, segundo características demográficas. A grande maioria do grupo com todos os fatores é do sexo masculino, oito em cada dez, comparado a cerca de $50 \%$ no grupo sem fatores de risco. A distribuição etária não 
apresentou diferenças importantes, enquanto o grupo com quatro fatores apresentou menor nível de escolaridade. Nesse grupo, 4\% (IC 95\%: 0-8,0) têm segundo grau incompleto e 43,4\% (IC 95\%: 33,2-53,6) têm superior completo, comparado a 0,8\% (IC 95\%: 0-1,8) e 63,2\% (IC 95\%: 56,8-69,6) respectivamente, do grupo sem fatores de risco.

TABELA III.5.10

CARACTERÍSITCAS DEMOGRÁFICAS DOS FUNCIONÁRIOS QUE APRESENTARAM TODOS OS FATORES DE RISCO E DOS QUE NÃO APRESENTARAM NENHUM FATOR DE RISCO AMBAS AS DEPENDÊNCIAS

\begin{tabular}{l|c|c}
\hline \multirow{2}{*}{ SEXO } & \multicolumn{2}{|c}{ FATORES } \\
\cline { 2 - 3 } & $\begin{array}{c}\text { TODOS } \\
\%^{*}\end{array}$ & $\begin{array}{c}\text { NENHUM } \\
\%^{*}\end{array}$ \\
\hline HOMENS & 79,8 & 49,5 \\
MULHERES & 20,2 & 50,5 \\
\hline TOTAL (n) & 68 & 163 \\
\hline WADE & TODOS & $\begin{array}{c}\text { NENHUM } \\
\%\end{array}$ \\
\hline S40 ANOS & 60,2 & 56,8 \\
>40 ANOS & 39,8 & 43,2 \\
\hline TOTAL (n) & 68 & 163 \\
\hline ESCOLARIDADE & TODOS & $\begin{array}{c}\text { NENHUM } \\
\%\end{array}$ \\
\hline $2^{\circ}$ GRAU & 4,0 & 0,8 \\
INCOMPLETO & & 11,3 \\
$2^{\circ}$ GRAU & 8,0 & 24,7 \\
COMPLETO & & 63,2 \\
SUPERIOR & 44,6 & 163 \\
INCOMPLETO & & \\
SUPERIOR & 43,4 & \\
COMPLETO & & \\
\hline TOTAL (n) & 68 & \\
\hline
\end{tabular}

* Proporções calculadas em relação ao total de cada coluna Proporções corrigidas por fator de expansão Fatores de Risco: Fumante grande ou leve; Álcool diário ou semanal; Quarto ou quinto quintis de dieta;Não pratica atividade física de lazer

No segundo eixo (Gráfico III.5.2), identificamos outro tipo de padrão, que pode ser considerado "misto" -combinação entre hábitos de risco e comportamentos 
saudáveis- Tabela III.5.11. Nesse sentido, estão juntos o quarto quintil de dieta (d4)pouco saudável-, não consumir álcool (an), não fumar (fn) e atividade física pouco frequente (leve) (gl), em oposição a atividade física de frequência moderada (gm), ser ex-fumante (ef) e fumar pouco (fl). Cabe notar no entanto, os baixos valores da correlação dos elementos com o segundo eixo (Tabela III.5.11), indicando a ausência de padrões tão típicos como aqueles apresentados no primeiro eixo.

TABELA III.5.11

CONTRIBUIÇÃO ABSOLUTA E CORRELAÇÃo DOS PRINCIPAIS ELEMENTOS COM O SEGUNDO EIXO FATORES DE RISCO

\begin{tabular}{|c|c|c|c|}
\hline \multirow[b]{2}{*}{ CATEGORIAS } & \multicolumn{3}{|c|}{ CONTRIBUIÇÃO } \\
\hline & $\mathbf{n}$ & ABSOLUTA \% & CORRELAÇÃO \\
\hline $\begin{array}{l}\text { ATIVIDADE FISICA } \\
\text { MODERADA }\end{array}$ & 129 & $11,9(+)$ & 0,41 \\
\hline EX-FUMANTE & 246 & $8,5(+)$ & 0,37 \\
\hline FUMO LEVE & 152 & $7,9(+)$ & 0,34 \\
\hline DIETA 4 & 251 & $18,9(-)$ & 0,55 \\
\hline ÁLCOOL NÃO BEBE & 96 & $17,0(-)$ & 0,48 \\
\hline NUNCA FUMOU & 564 & $12,1(-)$ & 0,54 \\
\hline ATIVIDADE FÍSICA LEVE & 247 & $9,6(-)$ & 0,39 \\
\hline TOTAL & & 85,9 & - \\
\hline
\end{tabular}

Obs: Apesar das contribuições absolutas estarem sob a forma de percentual, apresentamos o sinal da coordenada de cada ítem. Esses sinais devem ser entendidos como oposição de um grupo -os de sinal positivo- a outro - os de sinal negativo.

De acordo com esses resultados, conseguimos identificar dois sub-grupos bem diferenciados na população, já que apresentam todos os fatores de risco com grande intensidade ou nenhum deles. Cada um desses grupos apresenta exatamente o mesmo perfil no que diz respeito aos comportamentos estudados, enquanto o restante dos funcionários têm comportamento "misto", com um ou alguns dos fatores de risco, nem sempre no maior grau, ao mesmo tempo que declararam hábitos saudáveis em relação a outros fatores. Do ponto de vista do estilo de vida, o grupo que apresenta todos os fatores de risco é aquele que corre o maior risco de desenvolver doenças cardiovasculares. Suas principais características sócio-demográficas -homens com grau mais baixo de escolaridade- podem definir grupo de alto risco, que merece abordagem e acompanhamento especiais. 


\section{GRÁFICO III.5.2 \\ FATORES DE RISCO \\ PRIMEIRO E SEGUNDO EIXOS}

\section{EIXO 2}

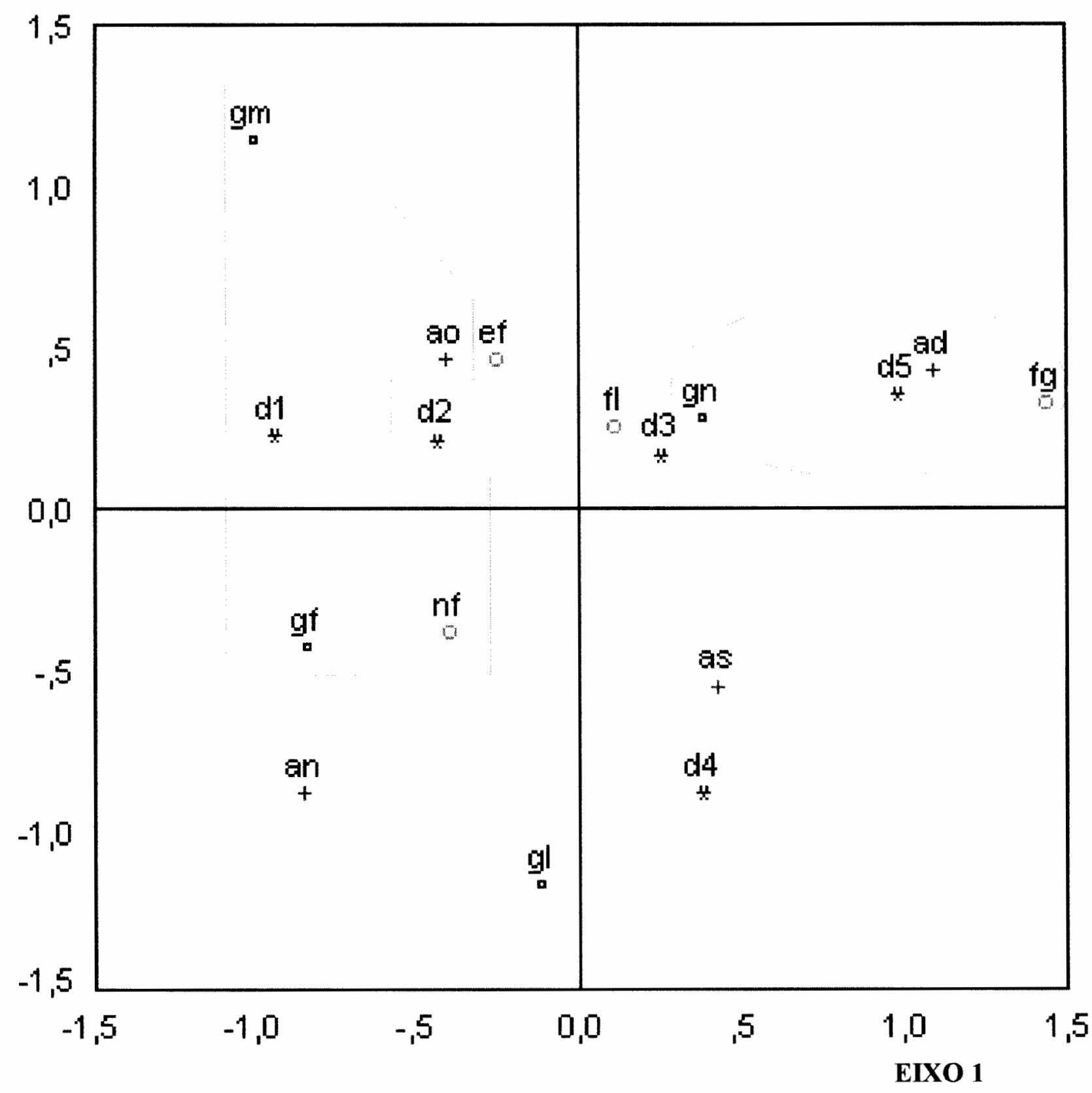

$\mathrm{d} 1=$ dieta quintil $1 \quad \mathrm{gf}=$ ginástica

$\mathrm{d} 2=$ dieta quintil 2 frequente

$\mathrm{d} 3=$ dieta quintil $3 \quad \mathrm{gm}=$ ginástica

$\mathrm{d} 4=$ dieta quintil 4

d5=dieta quintil 5 moderada

$\mathrm{gl}=$ ginástica leve gn=ginástica não faz ad=álcool diário fg=grande fumante as=álcool semanal $\mathrm{fl}$ =fumante leve $\quad \mathrm{ao}=$ =álcool ocasional ef=ex-fumante an=álcool nunca nf=não fuma 
Quando sexo e idade são também analisados, além dos quatro fatores de risco, os três primeiros eixos são os de maior importância, já que a partir do quarto eixo, os valores próprios e percentagens de explicação da variância tornam-se homogênenos (Tabela III.5.12 e Gráfico III.5.3). Assim, os três serão analisados.

TABELA III.5.12

VALORES PRÓPRIOS E PERCENTAGEM DE EXPLICAÇÃO DA VARIÂNCIA DE CADA EIXO

FATORES DE RISCO, IDADE E SEXO

\begin{tabular}{|c|c|c|c|}
\hline EIXO & $\begin{array}{c}\text { VALOR } \\
\text { PRÓPRIO }\end{array}$ & $\begin{array}{c}\text { PERCENTAGEM } \\
\text { DE } \\
\text { EXPLICAÇÃO }\end{array}$ & $\begin{array}{l}\text { PERCENTAGEM } \\
\text { ACUMULADA }\end{array}$ \\
\hline 1 & 0,0759 & 14,145 & 14,145 \\
\hline 2 & 0,0537 & 10,015 & 24,160 \\
\hline 3 & 0,0411 & 7,667 & 31,827 \\
\hline 4 & 0,0357 & 6,651 & 38,478 \\
\hline 5 & 0,0331 & 6,175 & 44,653 \\
\hline 6 & 0,0322 & 6,007 & 50,660 \\
\hline 7 & 0,0304 & 5,662 & 56,322 \\
\hline 8 & 0,0290 & 5,406 & 61,728 \\
\hline 9 & 0,0287 & 5,345 & 67,073 \\
\hline 10 & 0,0277 & 5,159 & 72,232 \\
\hline 11 & 0,0260 & 4,855 & 77,087 \\
\hline 12 & 0,0253 & 4,719 & 81,806 \\
\hline 13 & 0,0242 & 4,516 & 86,322 \\
\hline 14 & 0,0216 & 4,031 & 90,353 \\
\hline 15 & 0,0184 & 3,422 & 93,775 \\
\hline 16 & 0,0125 & 2,329 & 96,104 \\
\hline 17 & 0,0108 & 2,019 & 98,123 \\
\hline 18 & 0,01 & 1,872 & 99,995 \\
\hline 19 & 0 & 0,002 & 100,0 \\
\hline 20 & 0 & 0 & - \\
\hline 21 & 0 & 0 & - \\
\hline 22 & 0 & 0 & - \\
\hline 23 & 0 & 0 & - \\
\hline
\end{tabular}




\section{GRÁFICO III.5.3 \\ PERCENTAGEM DE EXPLICAÇÃO \\ DA VARIÂNCIA GLOBAL DE CADA EIXO \\ FATORES DE RISCO IDADE E SEXO}

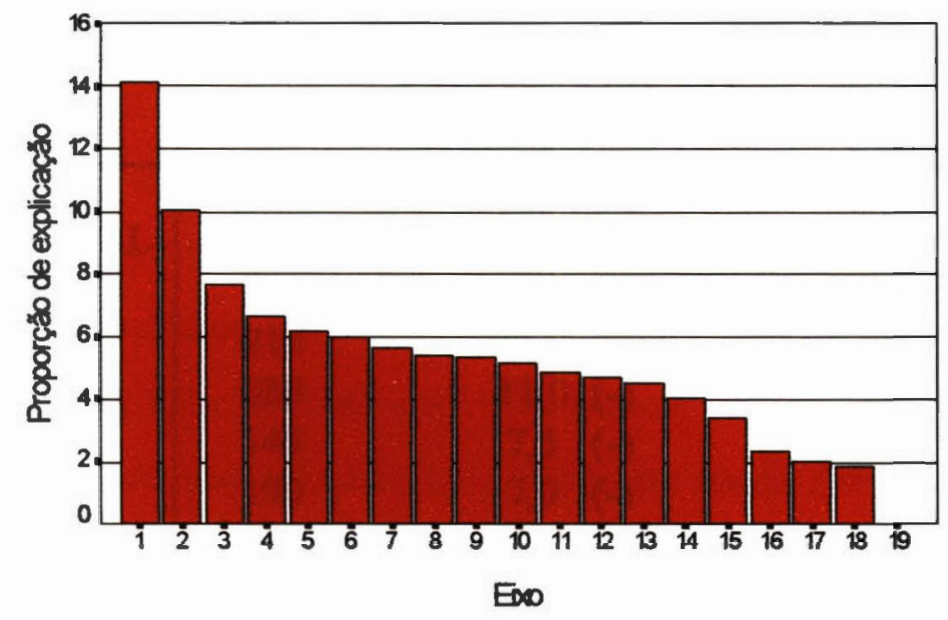

Ao incluirmos sexo e idade à análise, encontramos os mesmos padrões de ocorrência entre os fatores de risco descritos anteriormente, mantendo-se a associação entre comportamentos saudáveis por um lado, e hábitos pouco prudentes por outro. Assim, há consistência entre os resultados encontrados em relação à associação entre os faotres de risco.

As categorias "Homem" e "Mulher" são as que apresentaram as maiores correlações com o primeiro eixo, bem como estão entre as maiores contribuições absolutas (Tabela III.5.13). Ser homem ou mulher determina portanto padrões típicos e opostos de comportamento, como pode ser observado também através da distribuição da ocorrência simultânea dos fatores de risco (Tabela III.5.14): um em cada quatro homens apresenta três ou quatro fatores, enquanto apenas $16 \%$ das mulheres encontram-se nessas categorias. Da mesma forma, mais da metade das mulheres não apresenta nenhum ou apenas um fator de risco, ao contrário do que ocorre no sexo masculino. 
TABELA III.5.13

CONTRIBUIÇÃo ABSOLUTA E CORRELAÇÃo dOS PRINCIPAIS

ELEMENTOS COM O PRIMEIRO EIXO

FATORES DE RISCO, IDADE E SEXO

\begin{tabular}{l|ccc}
\hline CATEGORIAS & n & $\begin{array}{c}\text { CONTRIBUIÇÃO } \\
\text { ABSOLUTA \% }\end{array}$ & CORRELAÇÃO \\
\hline MULHER & 494 & $15,4(+)$ & 0,773 \\
ÁLCOOL OCASIONAL & 559 & $8,0(+)$ & 0,607 \\
DIETA 1 & 283 & $7,6(+)$ & 0,483 \\
DIETA 5 & 214 & $11,7(-)$ & 0,593 \\
HOMEM & 689 & $11,0(-)$ & 0,774 \\
20 ANOS & 143 & $7,5(-)$ & 0,448 \\
FUMO PESADO & 190 & $7,0(-)$ & 0,452 \\
ÁLCOOL SEMANAL & 405 & $7,4(-)$ & 0,529 \\
ÁLCOOL DIÁRIO & 121 & $7,1(-)$ & 0,447 \\
\hline TOTAL & & 82,7 & - \\
\hline
\end{tabular}

Obs: Apesar das contribuições absolutas estarem sob a forma de percentual, apresentamos o sinal da coordenada de cada ítem. Esses sinais devem ser entendidos como oposiçâo de um grupo -os de sinal positivo- a outro -os de sinal negativo

TABELA III.5.14

DISTRIBUIÇĀO DA OCORRÊNCIA CONJUNTA DOS FATORES DE RISCO

SEGUNDO SEXO

AMBAS AS DEPENDÊNCIAS

\begin{tabular}{l|ccccc|c}
\hline & \multicolumn{6}{|c}{ NÜMERO DE FATORES } \\
\cline { 2 - 7 } SEXO & NENHUM & UM & DOIS & TRÊS & QUATRO & TOTAL \\
\hline HOMENS & $\%$ & $\%$ & $\%$ & $\%$ & $\%$ & n \\
MULHERES & 11,6 & 26,0 & 33,3 & 21,4 & 7,7 & 670 \\
\hline TOTAL & 18,0 & 37,0 & 29,1 & 12,9 & 3,0 & 472 \\
\hline
\end{tabular}

Proporçðes corrigidas por fator de expansão

Fatores de Risco: Fumante grande ou leve; Álcool diário ou semanal; Quarto ou quinto quintis de dieta; Não pratica atividade fisica de lazer

A representação gráfica da oposição entre os comportamentos feminino e masculino encontra-se no Gráfico III.5.4. Em seu eixo horizontal estão por um lado, as mulheres (mu), consumo de álcool ocasional (ao) e dieta 1 (d1) -0 quintil mais saudável- em oposição a dieta 5 (d5)- o quintil menos saudável-, homens (ho), 20 anos (20), ser grande fumante (fg) e consumir álcool diariamente (ad) ou semanalmente 
(as). Verificamos portanto que comportamentos pouco saudáveis, especialmente em relação à dieta, são também determinados pela idade além do sexo, de acordo com o que foi apresentado na seção relativa ao "Consumo Alimentar".

De acordo com a análise das contribuições absolutas e correlações das categorias com o segundo eixo (Tabela III.5.15), os elementos mais importantes foram "20 anos" (20) e "Não fumar" (fn) por um lado, e ser "Grande Fumante" (fg), por outro. No caso desse eixo, esses comportamentos extremos estão vinculados à idade: os mais jovens não fumam e os funcionários entre 40 e 44 anos fumam muito. Além de não fumar, os mais jovens praticam atividades fisicas com pouca ou muita frequência, enquanto os mais velhos consomem álcool diariamente e são ex-fumantes (Gráfico III.5.4). Assim, uma parcela importante dos funcionários entre 20 e 29 anos apresenta comportamentos saudáveis, em contraste com outra parcela que apresentou, no primeiro eixo, associação com dieta pouco saudável, consumo de álcool e fumo.

\section{TABELA III.5.15}

CONTRIBUIÇÃO ABSOLUTA E CORRELAÇÃO DOS PRINCIPAIS ELEMENTOS COM O SEGUNDO EXXO

FATORES DE RISCO, IDADE E SEXO

\begin{tabular}{l|ccc}
\hline \multicolumn{1}{c|}{ VARIÁVEL } & n & $\begin{array}{c}\text { CONTRIBUIÇÃO } \\
\text { ABSOLUTA \% }\end{array}$ & CORRELAÇÃO \\
\hline 20 ANOS & 143 & $20,8(+)$ & 0,63 \\
NÃO FUMA & 564 & $15,9(+)$ & 0,74 \\
ATIVIDADE FÍSICA LEVE & 247 & $5,0(+)$ & 0,34 \\
ATIVIDADE FÍSICA & 122 & $5,0(+)$ & 0,32 \\
FREQUENTE & 190 & $17,3(-)$ & 0,60 \\
GRANDE FUMANTE & 357 & $7,1(-)$ & 0,43 \\
40 ANOS & 121 & $6,6(-)$ & 0,36 \\
ÁLCOOL DIÁRIO & 246 & $9,6(-)$ & 0,38 \\
EX-FUMANTE & & 87,3 & - \\
\hline TOTAL & & &
\end{tabular}

Obs: Apesar das contribuições absolutas estarem sob a forma de percentual, apresentamos o sinal da coordenada de cada ítem. Esses sinais devem ser entendidos como oposição de um grupo -os de sinal positivo- a outro - os de sinal negativo. 


\section{GRÁFICO III.5.4}

FATORES DE RISCO, IDADE E SEXO

PRIMEIRO E SEGUNDO EIXOS

\section{EIXO 2}

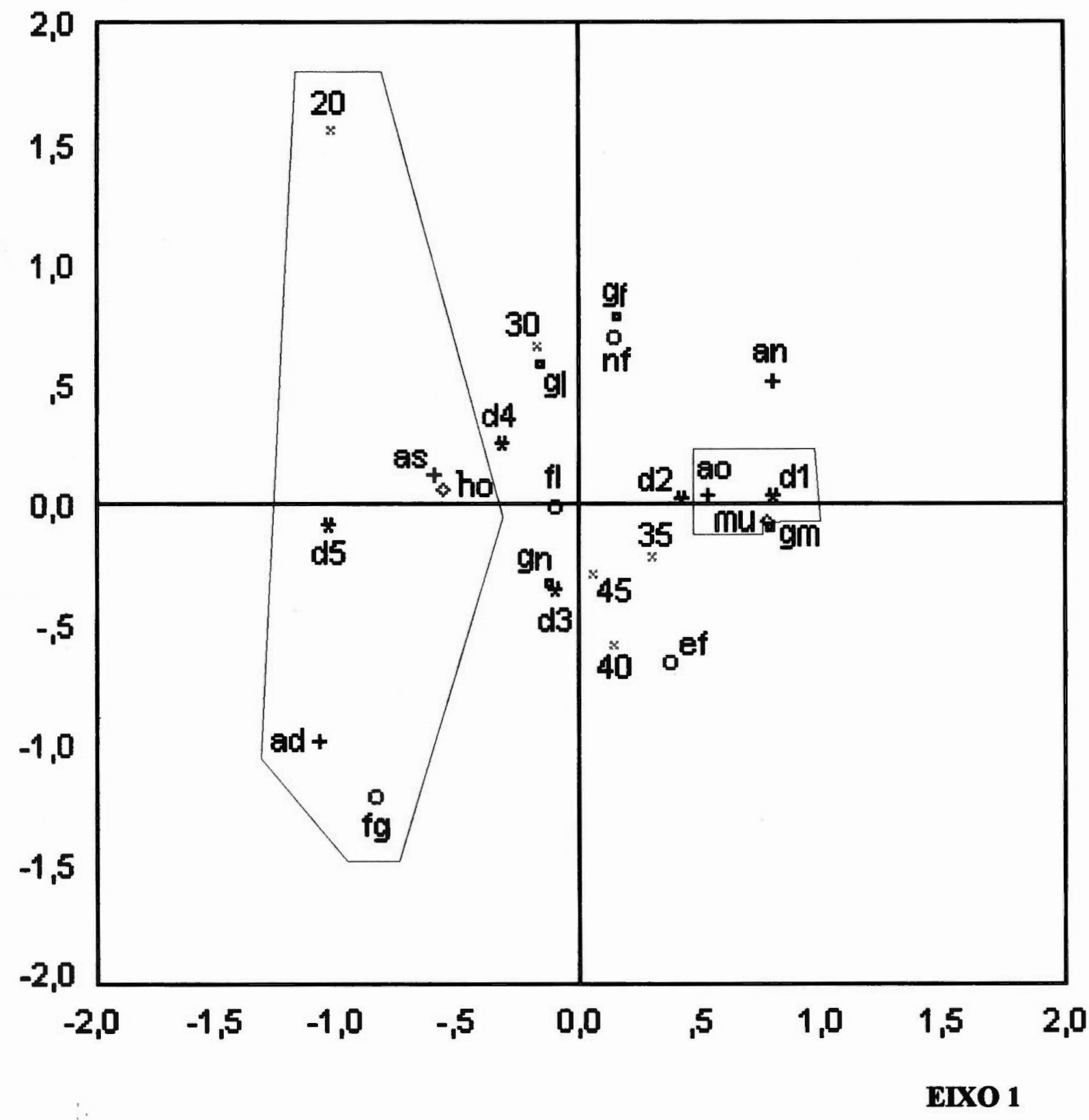

d1=dieta quintil 1 d2=dieta quintil 2 d3=dieta quintil 3 d4=dieta quintil 4 d5=dieta quintil 5 ho=homem mu=mulher gf-ginástica

frequente

$\mathbf{g m}=$ ginástica moderada

gl=ginástica leve gn=ginástica não faz

$20=20$ a 29 anos
$30=30$ a 34 anos $35=35$ a 39 anos $40=40$ a 44 anos $45=45$ anos $e$ mais $\mathrm{fg}=$ grande fumante $\mathrm{fl}=$ fumante leve ef=ex-fumante nf=não fuma $\mathrm{ad}=$ álcool diário as=álcool semanal $\mathrm{aO}^{\mathrm{O}}=$ álcool ocasional an=álcool nunca 
Embora as correlações das categorias com o terceiro eixo sejam mais fracas do que com os eixos anteriores, é possível ainda detectar padrões típicos de comportamento (Tabela III.5.16). Foi possível identificar outros sub-grupos nessa população, caracterizados pela idade ou pelo sexo. Hábitos saudáveis -primeiro quintil de dieta (d1), atividade fisica frequente (gf) e ser ex-fumante (ef)- estão associados ao grupo de 45 anos ou mais (45), enquanto as mulheres (mu) estão relacionadas a não praticar atividades físicas (gn) e ao quarto quintil de dieta (d4), que é pouco saudável (Gráfico III.5.5). Os dados sugerem portanto que uma parcela de funcionários mais velhos apresenta dieta mais saudável do que os mais jovens e praticam atividades físicas frequentemente, enquanto uma parcela de mulheres aparece agora associada ao sedentarismo e dieta pouco saudável, em contraste com outra parcela que está associada à dieta saudável (primeiro eixo). Cabe notar no entanto, que a correlação da categoria "mulher" com o primeiro eixo é bem maior do que com o terceiro $-0,77$ contra $0,36-0$ que sugere que o padrão mais típico é o descrito no primeiro eixo.

\section{TABELA III.5.16 \\ CONTRIBUIÇÃO ABSOLUTA E CORRELAÇÃO DOS PRINCIPAIS ELEMENTOS COM O TERCEIRO EIXO \\ FATORES DE RISCO, IDADE E SEXO}

\begin{tabular}{l|ccc}
\hline CATEGORIAS & n & $\begin{array}{c}\text { CONTRIBUICÁO } \\
\text { ABSOLUTA \% }\end{array}$ & CORRELAÇÃO \\
\hline DIETA 1 & 283 & $12,1(+)$ & 0,45 \\
ATIVIDADE FÍSICA & 122 & $11,0(+)$ & 0,42 \\
FREQUENTE & 246 & $9,6(+)$ & 0,42 \\
EX-FUMANTE & 128 & $8,9(+)$ & 0,38 \\
45 ANOS & 129 & $5,0(+)$ & 0,28 \\
ATIVIDADE FÍSICA & & & \\
MODERADA & 677 & $11,2(-)$ & 0,60 \\
ATIVIDADE FÍSICA & 251 & $6,6(-)$ & 0,34 \\
NÃO PRATICA & 494 & $6,3(-)$ & 0,36 \\
DIETA 4 & & 70,7 & - \\
MULHER & &
\end{tabular}

Obs: Apesar das contribuições absolutas estarem sob a forma de percentual, apresentamos o sinal da coordenada de cada ítem. Esses sinais devem ser entendidos como oposição de um grupo -os de sinal positivo- a outro -os de sinal negativo. 
A incorporação das variáveis sexo e idade à análise da distribuição dos fatores de risco parece reforçar o padrão misto de comportamento, comentado anteriormente. As mulheres não estão relacionadas somente a comportamentos prudentes, já que além de apresentarem dieta saudável e consumo de álcool pouco frequente, existe um grupo de funcionárias sedentárias. Os homens por outro lado, apresentam padrão mais uniforme em relação ao grande consumo de fumo e álcool. A incorporação da variável idade a essa análise sugere diferentes comportamentos entre grupos etários que, à primeira vista, poderiam parecer homogêneos. Os funcionários mais jovens apresentam por um lado comportamentos de risco, especialmente relacionado à dieta, mas também praticam atividades físicas e não fumam com alta frequência. O grupo entre 40 e 44 anos, aparece associado ao hábito de fumar muito e ao consumo diário de álcool, enquanto a partir dos $\mathbf{4 5}$ anos, estão relacionados à dieta saudável, prática de atividades fisicas e ser ex-fumante. 
GRÁFICO III.5.5

FATORES DE RISCO, IDADE E SEXO

PRIMEIRO E TERCEIRO EIXOS

\section{EIXO 3}

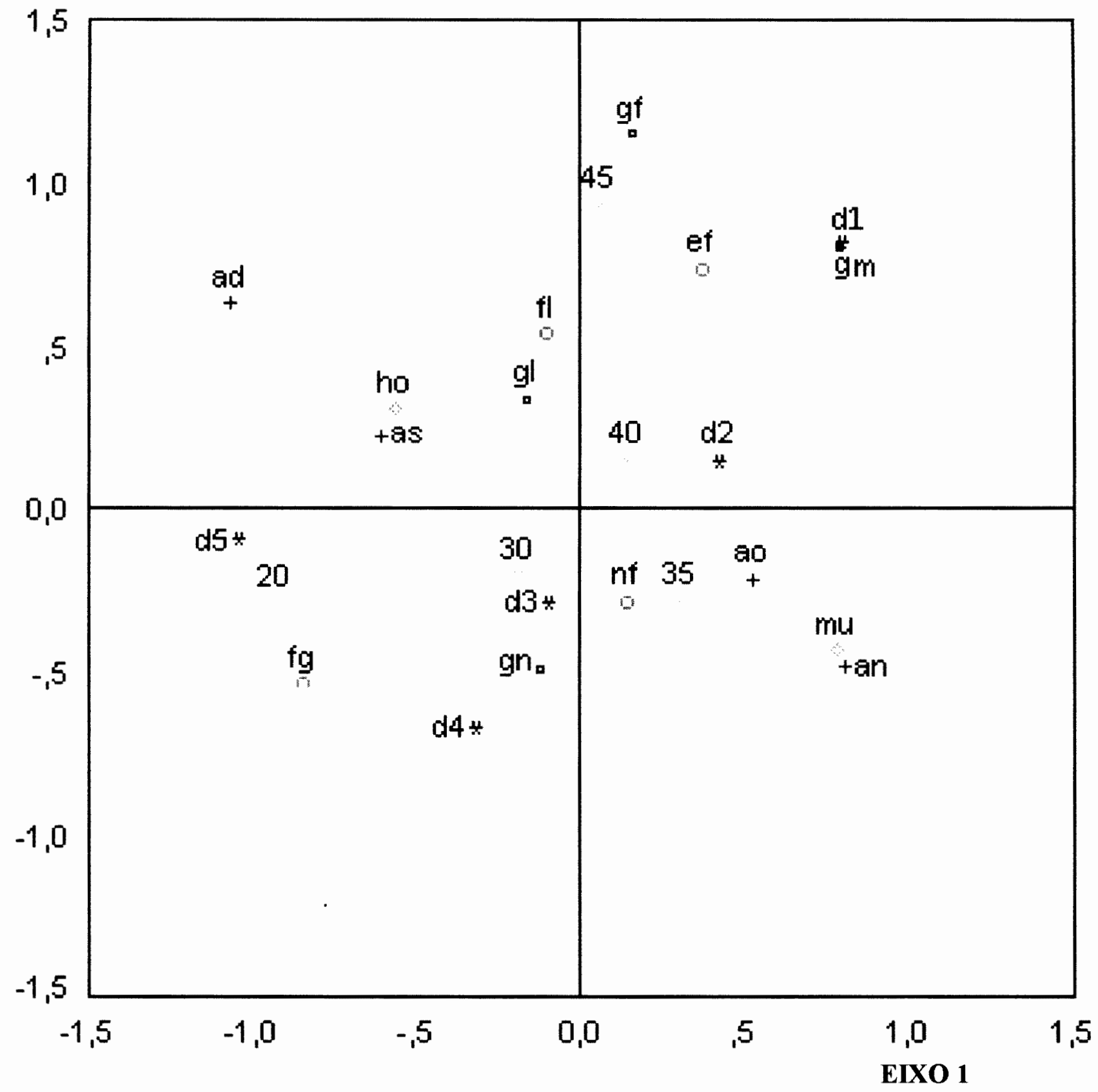

$\mathrm{d} 1=$ dieta quintil $1 \quad \mathrm{gf}=$ ginástica

$\mathrm{d} 2=$ dieta quintil 2

$\mathrm{d} 3=$ dieta quintil 3

$\mathrm{d} 4=$ dieta quintil 4

d5=dieta quintil 5

ho=homem

mu $=$ mulher frequente

$\mathrm{gm}=$ ginástica

moderada

$\mathrm{gl}=$ ginástica leve

gn=ginástica não

faz

$20=20$ a 29 anos
$30=30$ a 34 anos

$35=35$ a 39 anos

$40=40$ a 44 anos

$45=45$ anos $\mathrm{e}$

mais

fg=grande

fumante

$\mathrm{fl}=$ fumante leve ef=ex-fumante

$\mathrm{nf}=$ não fuma

$\mathrm{ad}=$ álcool diário

as=álcool

semanal

ao=álcool

ocasional

an=álcool nunca 


\section{C-ANALISE DA OCORRÊNCIA DE HIPERTENSÄO,CATEGORIAS DO ÍNDICE DE MASSA CORPORAL E COLESTEROLEMIA, DE ACORDO COM SEXO E IDADE}

As maiores magnitudes dos valores próprios e percentagem de explicação da variância são observadas nos dois primeiros eixos, sendo essa última medida muito homogênea do terceiro eixo em diante (Tabela III.5.17 e Gráfico III.5.6). Em função disso, a análise se restringirá ao primeiro e segundo eixos.

TABELA III.5.17

VALORES PRÓPRIOS E PERCENTAGEM DE EXPLICAÇÃO

DA VARIÂNCIA DE CADA EIXO

EFEITOS , IDADE E SEXO

\begin{tabular}{c|ccc}
\hline \multirow{2}{*}{ EIXO } & $\begin{array}{c}\text { VALOR } \\
\text { PRÓPRIO }\end{array}$ & $\begin{array}{c}\text { PERCENTAGEM } \\
\text { DE } \\
\text { EXPLICAÇÃO }\end{array}$ & $\begin{array}{c}\text { PERCENTAGEM } \\
\text { ACUMULADA }\end{array}$ \\
\hline 1 & 0,1153 & 23,9 & 23,9 \\
2 & 0,0693 & 14,3 & 38,2 \\
3 & 0,0531 & 11,0 & 49,2 \\
4 & 0,0469 & 9,7 & 58,9 \\
5 & 0,0459 & 9,5 & 68,4 \\
6 & 0,0413 & 8,5 & 76,9 \\
7 & 0,0393 & 8,1 & 85,0 \\
8 & 0,0312 & 6,4 & 91,4 \\
9 & 0,0236 & 4,9 & 96,3 \\
10 & 0,0162 & 3,3 & 99,6 \\
11 & 0,0011 & 0,24 & 99,8 \\
12 & 0,0001 & 0,02 & 99,82 \\
13 & 0 & 0,00 & \\
14 & 0 & 0 & \\
\hline
\end{tabular}




\section{GRÁFICO III.5.6 \\ PERCENTAGEM DE EXPLICAÇÃO \\ DA VARIÂNCLA GLOBAL DE CADA EIXO \\ EFEITOS IDADE E SEXO}

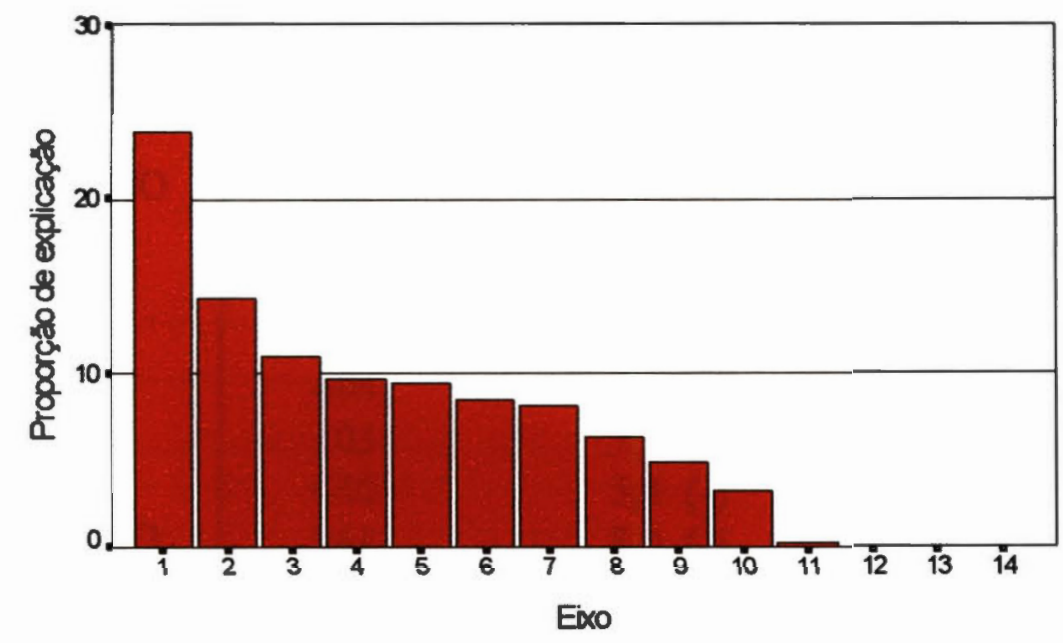

Os elementos de maior correlação com o primeiro eixo foram ausência ou presença de hipertensão, homem e mulher, indicando padrões típicos dos efeitos em relação ao sexo (Tabela III.5.18). De maneira semelhante ao que ocorreu em relação aos fatores de risco, as mulheres (mu) estão pricipalmente associadas às condições positivas: baixo peso (pb), peso normal (pn) e ausência de hipertensão (hn), condições também associadas ao grupo de 35 a 39 anos de idade (35). Do outro lado estão os homens (ho), presença de hipertensão (hs), sobrepeso (ps), colesterol alto (ca), obesidade (po) e 45 anos (45) (Tabela III.5.18 e Gráfico III.5.7). De acordo com o esperado, os efeitos negativos também estão associados à idade -45 anos- além da associação com o sexo masculino. 


\section{TABELA III.5.18 \\ CONTRIBUIÇÃo ABSOLUTA E CORRELAÇÃO DOS PRINCIPAIS \\ ELEMENTOS COM O PRIMEIRO EIXO \\ EFEITOS, IDADE E SEXO}

\begin{tabular}{l|ccc}
\hline CATEGORIAS & n & $\begin{array}{c}\text { CONTRIBUIÇÃO } \\
\text { ABSOLUTA \% }\end{array}$ & CORRELAÇÃO \\
\hline HIPERTENSÃO SIM & 218 & $19,0(+)$ & 0,74 \\
SOBREPESO & 318 & $12,4(+)$ & 0,64 \\
COLESTEROL ALTO & 219 & $10,6(+)$ & 0,59 \\
HOMEM & 689 & $8,3(+)$ & 0,65 \\
OBESIDADE & 62 & $6,3(+)$ & 0,42 \\
45 ANOS & 128 & $5,2(+)$ & 0,40 \\
MULHER & 494 & $12,7(-)$ & 0,70 \\
BAIXO PESO & 103 & $7,5(-)$ & 0,44 \\
PESO NORMAL & 640 & $5,4(-)$ & 0,54 \\
HIPERTENSÃO NÃO & 941 & $5,0(-)$ & 0,74 \\
35 ANOS & 387 & $4,6(-)$ & 0,40 \\
\hline TOTAL & & 97,0 & - \\
\hline
\end{tabular}

Obs: Apesar das contribuiçðes absolutas estarem sob a forma de percentual, apresentamos o sinal da coordenada de cada ítem. Esses sinais devem ser entendidos como oposiçăo de um grupo -os de sinal positivo- a outro -os de sinal negativo

O segundo eixo foi determinado fortemente pela oposição entre os sexos e os grupos etários, sem no entanto apresentar associações com os efeitos. De um lado, estão as mulheres (mu) e o grupo entre 40 e 44 anos (40), em oposição aos mais jovens -20 a 29 anos (20) e 30 a 34 anos (30)- e os homens (ho) (Tabela III.5.19). Cabe notar que a contribuição absoluta do grupo de 20 a 29 anos foi a mais importante, indicando que esse grupo etário se destaca em relação aos outros, já que hipertensão e hipercolesterolemia não são frequentes nessa faixa. 


\section{TABELA III.5.19 \\ CONTRIBUIÇÃO ABSOLUTA E CORRELAÇÃO DOS PRINCIPAIS \\ ELEMENTOS COM O SEGUNDO EIXO \\ EFEITOS, IDADE E SEXO}

\begin{tabular}{l|ccc}
\hline CATEGORIAS & n & $\begin{array}{c}\text { CONTRIBUIÇÃO } \\
\text { ABSOLUTA \% }\end{array}$ & CORRELAÇÃO \\
\hline MULHER & 494 & $13,1(+)$ & 0,55 \\
40 ANOS & 357 & $6,2(+)$ & 0,38 \\
20 ANOS & 143 & $46,2(-)$ & 0,81 \\
HOMEM & 689 & $12,3(-)$ & 0,61 \\
30 ANOS & 168 & $6,3(-)$ & 0,32 \\
\hline TOTAL & & $\mathbf{8 4 , 1}$ & - \\
\hline
\end{tabular}

Obs: Apesar das contribuições absolutas estarem sob a forma de percentual, apresentamos o sinalda coordenada de cada ítem. Esses sinais devem ser entendidos como oposição de um grupo -os de sinal positivo- a outro -os de sinal negativo.

Assim, sexo e idade são determinantes na ocorrência de sobrepeso e obesidade, hipertensão e hipercolesterolemia, estando principalmente os homens e os grupos mais velhos associados a esses efeitos. 
PRIMEIRO E SEGUNDO EIXOS

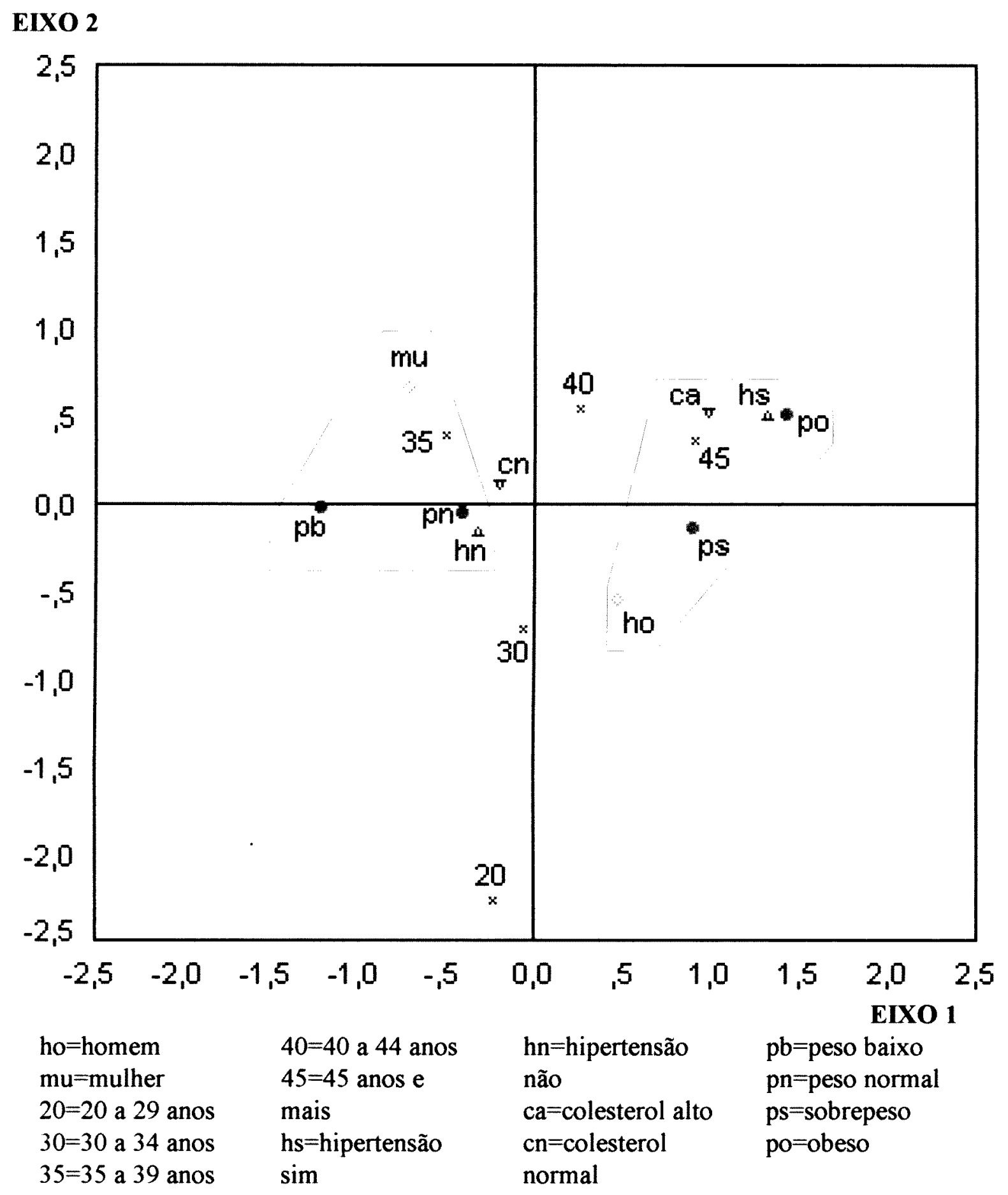




\section{d- OCORRÊNCIA SIMULTÂNEA DOS FATORES DE RISCO, HIPERTENSÄO, SOBREPESO/OBESIDADE E HIPERCOLESTEROLEMIA}

Na tabela III.5.20 e Gráfico III.5.8 são apresentados os valores próprios e as proporções de explicação da variância de cada um dos eixos. Já que aquelas percentagens tornam-se homogêneas a partir do terceiro eixo, apenas os dois primeiros serão analisados

TABELA III.5.20

VALORES PRÓPRIOS E PERCENTAGEM DE EXPLICAÇÃo DA VARIÂNCIA DE CADA EIXO

FATORES DE RISCO E EFEITOS

\begin{tabular}{c|ccc}
\hline \multirow{2}{*}{ EIXO } & $\begin{array}{c}\text { VALOR } \\
\text { PRÓPRIO }\end{array}$ & $\begin{array}{c}\text { PERCENTAGEM } \\
\text { DE } \\
\text { EXPLICAÇÃO }\end{array}$ & $\begin{array}{c}\text { PERENTAGEM } \\
\text { ACUMULADA }\end{array}$ \\
\hline 1 & 0,0530 & 12,5 & 12,5 \\
2 & 0,0421 & 9,9 & 22,4 \\
3 & 0,0320 & 7,5 & 29,9 \\
4 & 0,0314 & 7,4 & 37,3 \\
5 & 0,0279 & 6,6 & 43,9 \\
6 & 0,0264 & 6,2 & 50,1 \\
7 & 0,0243 & 5,7 & 55,8 \\
8 & 0,0229 & 5,4 & 61,2 \\
9 & 0,0224 & 5,3 & 66,5 \\
10 & 0,0211 & 5,0 & 71,5 \\
11 & 0,0195 & 4,6 & 76,1 \\
12 & 0,0189 & 4,5 & 80,6 \\
13 & 0,0179 & 4,2 & 84,8 \\
14 & 0,0161 & 3,8 & 88,6 \\
15 & 0,0141 & 3,3 & 91,9 \\
16 & 0,0132 & 3,1 & 95,0 \\
17 & 0,0105 & 2,5 & 97,5 \\
18 & 0,0093 & 2,2 & 99,7 \\
19 & 0,0009 & 0,2 & 99,9 \\
20 & 0 & 0,01 & 99,91 \\
\hline
\end{tabular}




\section{GRÁFICO III.5.8 \\ PERCENTAGEM DE EXPLICAÇÃO \\ DA VARIÂNCIA GLOBAL DE CADA EIXO \\ EFEITOS IDADE E SEXO}

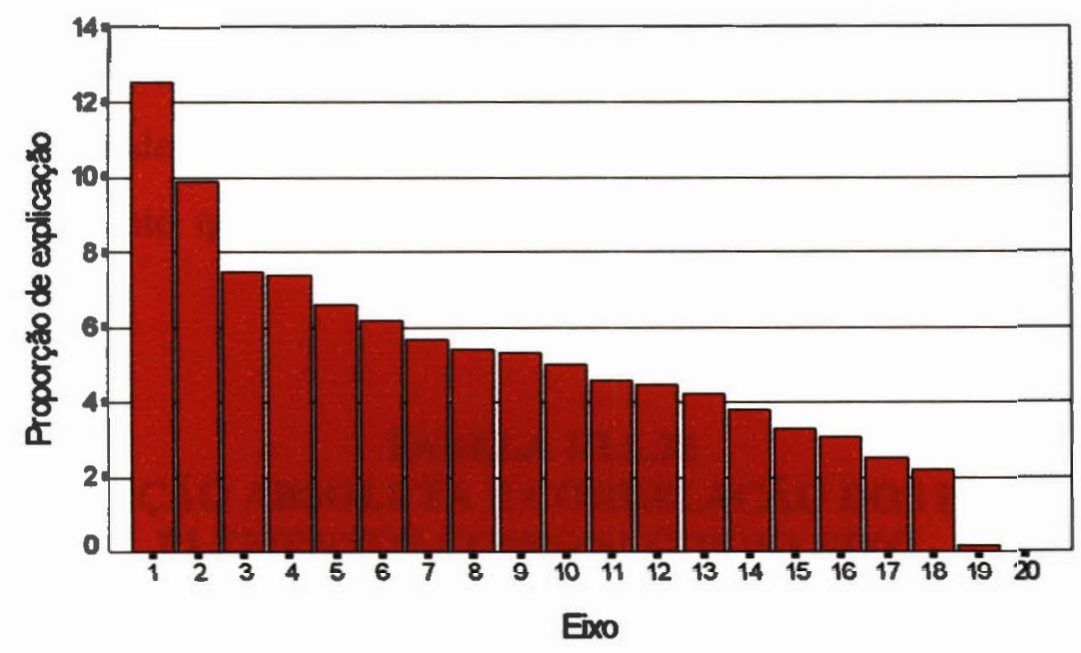

A presença de hipertensão não parece determinar mudanças de hábitos em uma parcela dos funcionários já que no primeiro eixo encontramos comportamentos de risco, hipertensão e sobrepeso associados, em oposição a comportamentos saudáveis. De um lado estão grande fumante (fg), consumo diário de álcool (ad) e o quintil de dieta menos saudável $\left(5^{\circ}\right)$ (d5), acompanhados de hipertensão (hs), colesterol alto (ca) e sobrepeso (ps). Do lado oposto estão localizadas as categorias não fumar (fn), baixo peso (pb) e consumo ocasional de álcool (ao) (Tabela III.5.21 e Gráfico III.5.9).

TABELA III.5.21

CONTRIBUIÇÃo ABSOLUTA E CORRELAÇÃo DOS PRINCIPAIS ELEMENTOS COM O PRIMEIRO EIXO FATORES DE RISCO E EFEITOS

\begin{tabular}{l|ccc}
\hline CATEGORIAS & n & $\begin{array}{c}\text { CONTRIBUIÇÃO } \\
\text { ABSOLUTA \% }\end{array}$ & CORRELAÇÃo \\
\hline GRANDE FUMANTE & 190 & $15,5(+)$ & 0,63 \\
HIPERTENSÃO & 218 & $13,2(+)$ & 0,59 \\
ÁLCOOL DIÁRIO & 121 & $9,6(+)$ & 0,49 \\
COLESTEROL ALTO & 219 & $6,7(+)$ & 0,45 \\
DIETA 5 & 214 & $6,5(+)$ & 0,42 \\
SOBREPESO & 318 & $6,0(+)$ & 0,44 \\
NÃO FUMAR & 564 & $6,3(-)$ & 0,52 \\
BAIXO PESO & 103 & $5,9(-)$ & 0,38 \\
ÁLCOOL OCASIONAL & 559 & $5,1(-)$ & 0,46 \\
\hline TOTAL & & 74,8 & - \\
\hline
\end{tabular}

Obs: Apesar das contribuições absolutas estarem sob a forma de percentual, apresentamos o sinal da coordenada de cada ítem. Esses sinais devem ser entendidos como oposição de um grupo -os de sinal positivo- a outro -os de sinal negativo. 
No segundo eixo por outro lado, aparecem os funcionários hipertensos e informados sobre hipercolesterolemia que podem ter alterado comportamentos em função da doença. Nesse eixo, hipertensão (hs), informação sobre níveis altos de colesterol (ca) e sobrepeso (ps) estão associados ao quintil mais saudável de dieta (d1), atividade fisica moderada (gm) e ser ex-fumante (ef), em oposição a ser grande fumante (fg) e quinto quintil de dieta (d5) (o menos saudável) - Tabela III.5.22 e Gráfico III.5.9.

TABELA III.5.22

CONTRIBUIÇÃO ABSOLUTA E CORRELAÇÃO DOS PRINCIPAIS ELEMENTOS COM O SEGUNDO EIXO FATORES DE RISCO E EFEITOS

\begin{tabular}{l|ccc}
\hline \multicolumn{1}{c|}{ VARIÁ VEL } & $\mathbf{n}$ & $\begin{array}{c}\text { CONTRIBUIÇÁO } \\
\text { ABSOLUTA \% }\end{array}$ & CORRELAÇÁO \\
\hline DIETA 1 & 283 & $14,6(+)$ & 0,57 \\
HIPERTENSÃO & 218 & $12,9(+)$ & 0,52 \\
COLESTEROL ALTO & 219 & $8,1(+)$ & 0,44 \\
ATIVIDADE & 129 & $6,4(+)$ & 0,36 \\
MODERADA & & & \\
EX-FUMANTE & 246 & $5,6(+)$ & 0,37 \\
SOBREPESO & 318 & $5,1(+)$ & 0,36 \\
GRANDE FUMANTE & 190 & $6,9(-)$ & 0,38 \\
DIETA 5 & 214 & $5,8(-)$ & 0,35 \\
\hline TOTAL & & 65,4 & - \\
\hline
\end{tabular}

Obs: Apesar das contribuiçð̃es absolutas estarem sob a forma de percentual, apresentamos o sinal da coordenada de cada ítem. Esses sinais devem ser entendidos como oposição de um grupo -os de sinal positivo- a outro -os de sinal negativo.

Ao analisarmos fatores de risco e efeitos, confirmou-se a aglomeração de hábitos saudáveis por um lado, e os menos saudáveis por outro. Além disso, podemos observar ainda no Gráfico III.5.9 que os quatro fatores de risco descrevem curvas que apresentam a mesma direção, das respectivas categorias de baixo risco (quadrante superior esquerdo) para as categorias de alto risco (quadrante inferior direito). Assim, a probabilidade de um funcionário que por exemplo, consome álcool semanalmente não praticar atividade física ou ter dieta pouco saudável é maior do que a probabilidade de praticar atividade frequentemente ou ter dieta saudável. A direção das curvas descritas pelas categorias do Índice de Massa Corporal e hipertensão também caminham na 
mesma direção, indicando que os não hipertensos têm maior probabilidade de apresentar IMC normal do que sobrepeso e obesidade. Ao contrário, a probabilidade de um hipertenso ter peso normal é menor do que a probabilidade de apresentar sobrepeso ou obesidade. 


\section{GRÁFICO III.5.9 \\ FATORES DE RISCO E EFEITOS \\ PRIMEIRO E SEGUNDO EIXOS}

\section{EIXO 2}

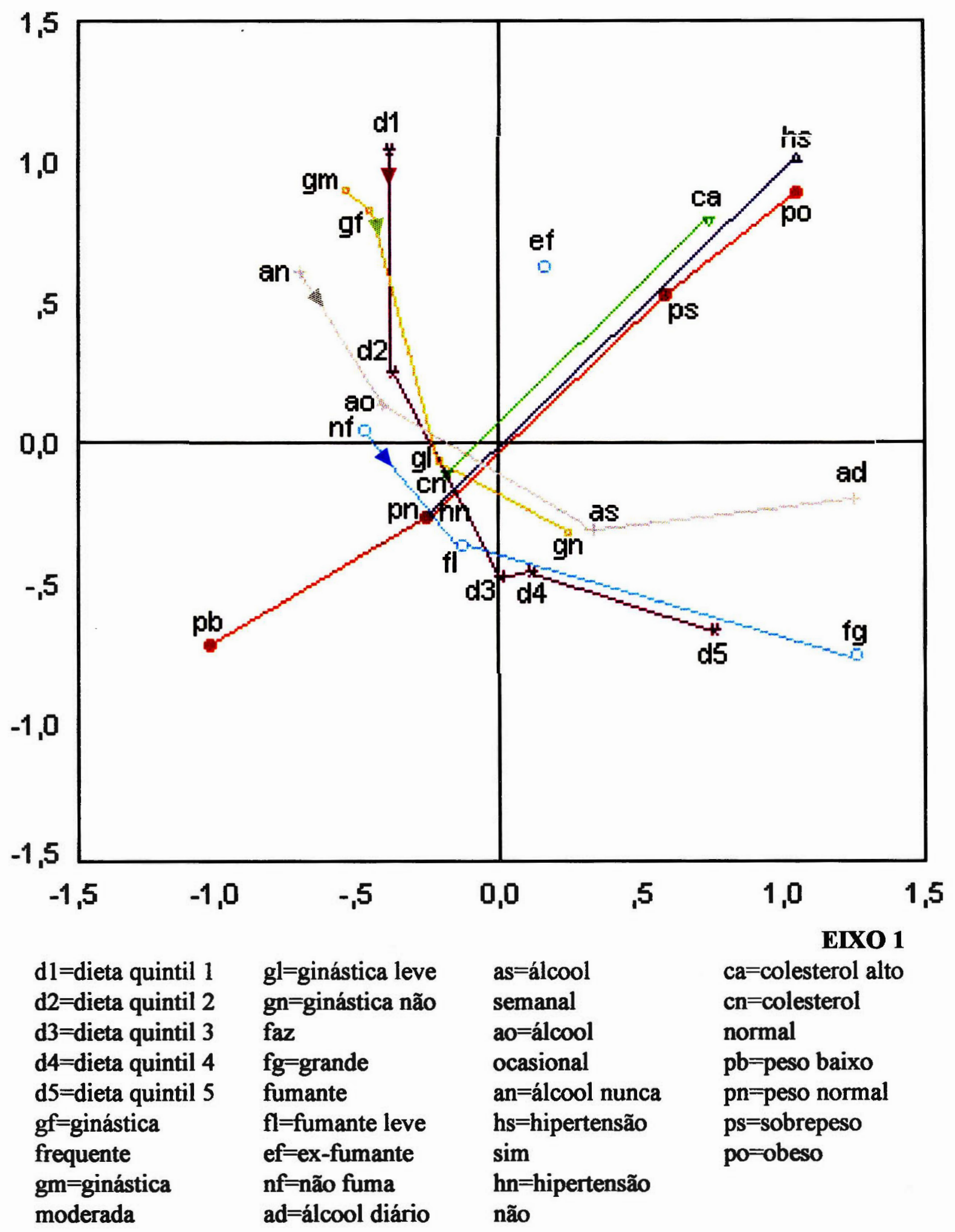


Observando-se a prevalência de cada fator de risco entre hipertensos e não hipertensos, os resultados do primeiro eixo são confirmados já que o diagnóstico da doença não parece determinar a diminuição da quantidade de cigarros ou do álcool consumidos, nem melhorar a dieta ou incentivar a prática de atividades fisicas (Tabela III.5.23). Além disso, mesmo considerando que os hipertensos são mais velhos do que os não hipertensos, a prevalência de sobrepeso e obesidade entre os hipertensos é alarmante, 43,3\% (IC 95\%: 37,5 49,1 ) e 17,6\% (IC 95\%: 13,1-22,1), respectivamente. (Tabela III.5.24).

TABELA III.5.23

DISTRIBUIÇÃO DOS FATORES DE RISCO ENTRE HIPERTENSOS E NÃO HIPERTENSOS AMBOS OS SEXOS - AMBAS AS DEPENDÊNCIAS

\begin{tabular}{|c|c|c|c|c|c|}
\hline FUMO & GRANDE & LEVE & EX-FUMANTE & \multicolumn{2}{|c|}{ NUNCA FUMOU } \\
\hline $\begin{array}{l}\text { HIPERTENSO } \\
n=213(100,0 \%)\end{array}$ & 21,1 & 11,8 & 26,3 & \multicolumn{2}{|c|}{40,8} \\
\hline $\begin{array}{l}\text { NAO } \\
\text { HIPERTENSO } \\
\mathrm{n}=916(100,0 \%)\end{array}$ & 15,3 & 13,5 & 0,2 & \multicolumn{2}{|c|}{51,0} \\
\hline ÁLCOOL & DIÁRIO & SEMANAL & OCASIONAL & \multicolumn{2}{|c|}{ NUNCA BEBE } \\
\hline $\begin{array}{l}\text { HIPERTENSO } \\
\mathrm{n}=218(100,0 \%) \\
\text { NÃO }\end{array}$ & 13,4 & 35,4 & 40,9 & \multicolumn{2}{|c|}{10,3} \\
\hline $\begin{array}{l}\text { HIPERTENSO } \\
\mathrm{n}=939(100,0 \%)\end{array}$ & 9,4 & 34,0 & 48,6 & \multicolumn{2}{|c|}{8,1} \\
\hline $\begin{array}{l}\text { ATIVIDADE } \\
\text { FISICA } \\
\end{array}$ & FREQUENTE & MODERADA & $\begin{array}{c}\text { POUCO } \\
\text { FREQUENTE }\end{array}$ & \multicolumn{2}{|c|}{ NÃO PRATICA } \\
\hline $\begin{array}{l}\text { HIPERTENSO } \\
\mathrm{n}=216(100,0 \%) \\
\text { NÄO }\end{array}$ & 8,8 & 11,6 & 19,4 & \multicolumn{2}{|c|}{60,1} \\
\hline $\begin{array}{l}\text { HIPERTENSO } \\
\mathrm{n}=935(100,0 \%)\end{array}$ & 11,4 & 10,6 & 20,9 & \multicolumn{2}{|c|}{57,0} \\
\hline DIETA & 1 & 2 & 3 & 4 & 5 \\
\hline $\begin{array}{l}\text { HIPERTENSO } \\
\mathrm{n}=218(100,0 \%) \\
\text { NÄO }\end{array}$ & 27,8 & 18,2 & 11,4 & 23,0 & 19,6 \\
\hline $\begin{array}{l}\text { HIPERTENSO } \\
\mathrm{n}=941(100,0 \%)\end{array}$ & 22,7 & 22,4 & 16,2 & 20,1 & 18,6 \\
\hline
\end{tabular}


TABELA III.5.24

DISTRIBUIÇÃO DO IMC E INFORMAÇÃO SOBRE HIPERCOLESTEROLEMIA ENTRE HIPERTENSOS E NÃO HIPERTENSOS

AMBOS OS SEXOS

AMBAS AS DEPENDÊNCIAS

\begin{tabular}{|c|c|c|c|c|}
\hline IMC & BAIXO PESO & NORMAL & SOBREPESO & OBESIDADE \\
\hline $\begin{array}{l}\text { HIPERTENSO } \\
n=206(100,0 \%)\end{array}$ & 2,6 & 36,6 & 43,3 & 17,6 \\
\hline $\begin{array}{l}\text { NÃO } \\
\text { HIPERTENSO } \\
n=895(100,0 \%)\end{array}$ & 10,6 & 61,0 & 25,2 & 3,3 \\
\hline COLESTEROL & $\overline{\text { ALTO }}$ & NORMAL & & \\
\hline $\begin{array}{l}\text { HIPERTENSO } \\
n=191(100,0 \%)\end{array}$ & 39,9 & 60,1 & & \\
\hline $\begin{array}{l}\text { NÃO } \\
\text { HIPERTENSO } \\
n=681(100,0 \%)\end{array}$ & 20,3 & 79,7 & & \\
\hline
\end{tabular}

Proporções corrigidas por fator de expansão

Totais (n) variam de acordo com o número de respostas a cada pergunta

Os resultados sugerem coexistência de hipertensão, hipercolesterolemia e sobrepeso e hábitos pouco saudáveis em relação aos principais fatores de risco para as doenças cardiovasculares - fumo, álcool e dieta - embora uma parcela dos hipertensos apresente dieta saudável e pratique atividades físicas. Merece destaque no entanto, que as altas prevalências desses fatores bem como de sobrepeso e obesidade revelam a ausência de estratégias de mudança de estilo de vida para os hipertensos. 
CAPÍtulo IV Discussão 


\section{1- QUALIDADE DAS INFORMAÇÕES}

\section{VALIDADE DE CONTEÚDO E VALIDADE DE CRITÉRIO}

A validade de conteúdo do instrumento utlizado pode ser avaliada através da comparação entre os resultados dessa investigação e de outros estudos (ADAY, 1990). No entanto, antes de apresentar essa comparação, consideramos importante discutir alguns dos procedimentos adotados que, a nosso ver, contribuíram para a pequena proporção de recusas em participar, bem como para despertar, nos funcionários, o desejo de colaborar através de informações fidedignas, com implicações diretas na validade desse estudo. Tal colaboração foi expressa em inúmeras oportunidades, por funcionários de diferentes dependências, com observações do tipo: "Nunca me senti tão cuidado, com tantos aspectos sobre a minha saúde!" "Essa pesquisa é o resgate do elemento humano nessa instituição!"

Em primeiro lugar, o preenchimento do questionário foi precedido pelo envio de cartazes a todas as dependências sorteadas, que informavam sobre a pesquisa, mensagens via BB-Mail, o correio eletrônico utilizado diariamente pelos funcionários, bem como o agendamento de data adequada com o gerente, de forma a evitar que a aplicação coincidisse com dias de intenso movimento na dependência. Assim, caracterizou-se o que de acordo com Aday (1990) é chamado de "warm contact" ou seja, os respondentes tomam conhecimento da pesquisa e seus objetivos com antecedência.

Além da divulgação do estudo antes de sua implementação, o "Termo de Consentimento para Participação em Pesquisa" (Anexo 1) surtiu grande efeito em termos do respeito à participação voluntária, já que era entregue antes do questionário, fazendo com que o funcionário escolhesse responder ou não. Além disso, consideramos também importante o fato de serem funcionários do banco os que entregavam tanto o termo de consentimento quanto o questionário (os aplicadores), possibilitando assim o uso do jargão e situações próprias do banco para conquistar a participação do 
funcionário sorteado. Por outro lado, a inclusão das instituições assessoras foi fundamental no sentido de infundir confiança no sigilo das informações fornecidas, o que não seria possivel se a pesquisa fosse realizada exclusivamente por funcionários do banco. Dessa forma, foi possível transmitir aos respondentes dois aspectos complementares: a pesquisa não era "mais uma coisa do banco", nem "coisa de fora" cujos resultados poderiam não reverter em seu beneficio.

$O$ instrumento de coleta de dados utilizado, questionário preenchido pelos próprios funcionários, apresenta vantagens e desvantagens, de acordo com a literatura (BOURQUE \& FIELDER, 1995; ADAY, 1990). Entre as primeiras estão o menor custo comparado à entrevistas domiciliares ou por telefone; seleção e treinamento mais simples dos aplicadores, já que o questionário foi preenchido pelo funcionário; no caso desta pesquisa, menor duração do periodo de coleta de dados, já que o questionário foi aplicado simultâneamente a grupos de funcionários; maior probabilidade de obter informação completa e fidedigna a respeito de tópicos sensiveis como consumo de álcool e transmissão de aids, entre outros.

Entre as desvantagens potenciais, são citadas a possibilidade de listagem incompleta da população de estudo, baixa taxa de resposta quando enviado pelo correio e necessidade de população com bom nível de escolaridade, boa compreensão da linguagem utilizada e boa acuidade visual (BOURQUE \& FIELDER, 1995). No caso dessa investigação, a listagem utilizada para o sorteio da amostra era aquela utilizada para a folha de pagamento, sendo assim, atualizada. O questionário auto-preenchido mostrou-se a forma mais adequada para coletar os dados, tendo em vista o grau de escolaridade dos funcionários e questões relativas ao custo e tempo disponivel para aplicação. Nesse ponto, cabe um comentário a respeito da exclusão dos funcionários de apoio (contínuos), que não fizeram parte da população-alvo. Tal exclusão foi motivada principalmente pela impossibilidade de esses funcionários responderem ao questionário sem a ajuda de um entrevistador (conforme foi verificado no estudo piloto), já que seu ingresso no banco não exigia nenhum grau de escolaridade, nem ocorria através de concurso público. Desta forma, considerou-se que o pequeno número de funcionários de apoio (1500 em todo o pais) não justificaria a mudança de estratégia de aplicação da 
pesquisa, do questionário auto-preenchido para entrevista, e nem a adoção de estratégia diferente para este grupo, o que dificultaria a comparação entre os resultados

Concluímos o trabalho de campo, assessores e bancários que compuseram o Grupo de Trabalho CASSI-Pesquisas Epidemiológicas, com forte impressão de que os respondentes aceitaram participar do estudo por compreender o alcance de seus resultados em termos da possível reformulação dos serviços prestados pela CASSI.

Além dos aspectos relativos à aplicação do questionário, outra característica sugere também a qualidade das informações coletadas. Trata-se da consistência dos resultados estimados para a Direção Geral e os Cesec's, que ocorreu de maneira generalizada, o que sugere a ausência de diferenças importantes entre aqueles tipos de dependência, em termos do perfil de risco cardiovascular. A mesma consistência foi encontrada em outros blocos do questionário, relativos à morbidade (GRUPO TÉCNICO CASSI-PESQUISAS EPIDEMIOLÓGICAS, 1996).

Apresentamos a seguir, um resumo das prevalências estimadas, que serão comparadas aos resultados de outros estudos (Tabelas IV.1.1e IV.1.2). 
TABELA IV.1.1

PREVALENCIAS (\%) E INTERVALOS DE CONFIANÇA (95\%)

TODOS OS FATORES DE RISCO

POR SEXO

DIREÇÃO GERAL

\begin{tabular}{|c|c|c|c|c|c|c|}
\hline \multirow[b]{3}{*}{ CATEGORIA } & \multicolumn{2}{|c|}{ HOMENS } & \multicolumn{2}{|c|}{ MULHERES } & \multicolumn{2}{|c|}{ TOTAL } \\
\hline & PREVAI & ECIA & PREV & NCIA & $\overline{\text { PREVA }}$ & NCIA \\
\hline & $(\%)$ & I.C. ${ }^{*}$ & $(\%)$ & I.C. ${ }^{*}$ & $(\%)$ & I.C.* \\
\hline FUMANTES & 32,6 & $( \pm 4,3)$ & 28,0 & $( \pm 4,6)$ & 30,9 & $( \pm 3,2)$ \\
\hline EX - FUMANTES & 21,0 & $( \pm 3,2)$ & 21,5 & $( \pm 4,1)$ & 21,2 & $( \pm 2,6)$ \\
\hline NUNCA FUMARAM & 46,3 & $( \pm 4,0)$ & 50,5 & $( \pm 5,1)$ & 47,9 & $( \pm 3,1)$ \\
\hline ÁLCOOL DIÁRIO & 17,0 & $( \pm 3,2)$ & 3,4 & $( \pm 1,8)$ & 11,8 & $( \pm 2,0)$ \\
\hline ÁLCOOL NÃO CONSOME & 5,2 & $( \pm 1,8)$ & 7,4 & $( \pm 2,6)$ & 6,0 & $( \pm 1,5)$ \\
\hline $\begin{array}{l}\text { NÃO PRATICA ATIVIDADE } \\
\text { FÍSICA DE LAZER }\end{array}$ & 54,4 & $( \pm 4,6)$ & 59,5 & $( \pm 5,0)$ & 56,3 & $( \pm 3,4)$ \\
\hline DIETA $1^{\circ}$ QUINTIL** & 21,2 & $( \pm 3,3)$ & 27,3 & $( \pm 4,5)$ & 23,6 & $( \pm 2,7)$ \\
\hline DIETA $5^{\circ}$ - QUINTIL** & 23,9 & $( \pm 3,4)$ & 7,3 & $( \pm 2,6)$ & 17,6 & $( \pm 2,4)$ \\
\hline HIPERTENSOS & 21,1 & $( \pm 3,2)$ & 9,9 & $( \pm 3,0)$ & 16,8 & $( \pm 2,3)$ \\
\hline SOBREPESO & 39,5 & $( \pm 4,5)$ & 12,6 & $( \pm 3,8)$ & 29,2 & $( \pm 3,1)$ \\
\hline OBESIDADE & 6,6 & $( \pm 2,5)$ & 1,0 & $( \pm 2,1)$ & 4,4 & $( \pm 1,7)$ \\
\hline $\begin{array}{l}\text { NÍVEL ALTO DE } \\
\text { COLESTEROLEMIA }\end{array}$ & 28,9 & $( \pm 3,6)$ & 21,3 & $( \pm 4,1)$ & 25,9 & $( \pm 2,7)$ \\
\hline
\end{tabular}


TABELA IV.1.2

PREVALÊNCIAS E INTERVALOS DE CONFIANÇA (95\%)

TODOS OS FATORES DE RISCO

POR SEXO

CESEC

\begin{tabular}{|c|c|c|c|c|c|c|}
\hline \multirow[b]{3}{*}{ CATEGORIA } & \multicolumn{2}{|c|}{ HOMENS } & \multicolumn{2}{|c|}{ MULHERES } & \multicolumn{2}{|c|}{ TOTAL } \\
\hline & $\overline{\text { PREVA }}$ & NCIA & PREV & NCIA & PREVA & NCIA \\
\hline & $(\%)$ & I.C. ${ }^{*}$ & $(\%)$ & I.C. ${ }^{*}$ & $(\%)$ & I.C. ${ }^{*}$ \\
\hline FUMANTES & 32,8 & $( \pm 4,4)$ & 28,8 & $( \pm 4,6)$ & 31,0 & $( \pm 3,2)$ \\
\hline EX - FUMANTES & 20,2 & $( \pm 3,8)$ & 21,5 & $( \pm 4,2)$ & 20,8 & $( \pm 2,8)$ \\
\hline NUNCA FUMARAM & 47,1 & $( \pm 4,7)$ & 49,7 & $( \pm 5,1)$ & 48,2 & $( \pm 3,4)$ \\
\hline ÁLCOOL DIÁRIO & 13,7 & $( \pm 3,0)$ & 3,1 & $( \pm 1,8)$ & 9,0 & $( \pm 2,0)$ \\
\hline ÁLCOOL NÃO CONSOME & 6,7 & $( \pm 2,3)$ & 13,8 & $( \pm 3,5)$ & 9,9 & $( \pm 2,1)$ \\
\hline $\begin{array}{l}\text { NÃO PRATICA ATIVIDADE } \\
\text { FÍSICA DE LAZER }\end{array}$ & 56,4 & $( \pm 4,0)$ & 59,9 & $( \pm 5,0)$ & 58,0 & $( \pm 3,1)$ \\
\hline DIETA $1^{\circ}$ QUINTIL ** & 19,6 & $( \pm 3,7)$ & 30,1 & $( \pm 4,7)$ & 24,3 & $( \pm 3,0)$ \\
\hline DIETA $5^{\circ}$ QUINTIL ** & 23,2 & $( \pm 4,0)$ & 12,8 & $( \pm 3,4)$ & 18,5 & $( \pm 2,7)$ \\
\hline HIPERTENSOS & 24,3 & $( \pm 3,4)$ & 15,8 & $( \pm 3,7)$ & 20,5 & $( \pm 2,5)$ \\
\hline SOBREPESO & 36,4 & $( \pm 3,9)$ & 16,7 & $( \pm 3,4)$ & 27,8 & $( \pm 2,8)$ \\
\hline OBESIDADE & 7,9 & $( \pm 2,0)$ & 4,5 & $( \pm 1,0)$ & 6,4 & $( \pm 1,3)$ \\
\hline $\begin{array}{l}\text { NIVEL ALTO DE } \\
\text { COLESTEROLEMIA }\end{array}$ & 28,7 & $( \pm 4,2)$ & 18,5 & $( \pm 4,0)$ & 23,7 & $( \pm 2,9)$ \\
\hline
\end{tabular}

* 1,96.Erro-Padrão

** Quintis baseados em escore (vide Metodologia) 


\section{a- HÁBITO DE FUMAR}

As prevalências estimadas de tabagismo -30,9\% na Direção Geral e 31,0\% nos Cesec's- estão de acordo com pesquisas nacionais realizadas no final da década de 80 , embora na maioria das vezes, a definição de "fumante" e a idade da população de estudo (coortes mais velhas fumam mais) não sejam os mesmos. $\mathrm{O}$ critério e a pergunta empregados nessa investigação tiveram sua confiabilidade estimada em $100 \%$ por Brownson (1994), ao avaliarem as respostas obtidas no "Behavioral Risk Factor Surveillance System", em 1993.

Na Pesquisa Nacional de Saúde e Nutrição (PNSN), realizada pelo Instituto Brasileiro de Geografia e Estatística (IBGE) em 1988, a prevalência estimada para o país foi de 32,6\% (MINISTÉRIO DA SAÚDE, 1992). Em Porto Alegre, estudo seccional realizado em 1991 entre maiores de 18 anos, estimou a prevalência de tabagismo em 34,9\% (MOREIRA, 1995). No Município de Cotia, São Paulo, foi estimada em 40,4\% entre os maiores de 20 anos, com dados coletados entre 1990 e 1991 (MARTINS, 1995). No final da década de 80, a prevalência de tabagismo foi estimada em $40 \%$ em quatro áreas docente-assistenciais de Porto Alegre (DUNCAN, 1993), 37,9\% para o Município de São Paulo (REGO, 1990) e 32,8\% em Araraquara, São Paulo (LOLIO, 1993).

A menor prevalência estimada entre os funcionários dos Cesec's e Direção Geral em relação a alguns desses estudos pode ser atribuída, além da diferença de grupos etários e definições de tabagismo empregadas, ao grupo social estudado. Assim, o tabagismo tem sido fortemente associado à menor escolaridade, o que também foi verificado nessa investigação, e classes sociais de menor poder aquisitivo (BLAXTER, 1990), justificando maiores prevalências em pesquisas na população geral, onde diferentes estratos sociais estão representados. Os funcionários do Banco do Brasil têm características bastante peculiares se comparados ao conjunto da população brasileira, já que têm emprego e cerca de $90 \%$ apresenta curso superior completo ou incompleto (GRIEP, 1996)

A estimativa pontual da prevalência de fumantes do sexo masculino $-32,6 \%$ - foi inferior às estimativas das pesquisas nacionais citadas, que se situaram entre $39,9 \%$ 
(MINISTÉRIO DA SAÚDE, 1992) e 52\% (DUNCAN, 1993). A prevalência entre as mulheres $-28,0 \%$ - foi semelhante aos outros estudos. De fato, nossas estimativas por sexo estão bastante próximas às prevalências estimadas para a população norteamericana e canadense, o que é compatível com o nível sócio-econômico dos bancários. Nos Estados Unidos, estimou-se a prevalência de 32\% para homens e $27 \%$ para mulheres, em 1987 (NOVOTNY, 1990), enquanto no Canadá, em 31\% e 28\%, respectivamente (EPSTEIN, 1989). Como no caso dessa investigação, prevalências semelhantes em ambos os sexos também foram estimadas para o Reino Unido $-36 \%$ entre homens e $32 \%$ entre mulheres- (BLAXTER, 1990) e Austrália -24\% e $21 \%$, respectivamente (NATIONAL HEALTH FOUNDATION OF AUSTRALIA- NHFA, 1990). Por outro lado, na maioria dos estudos nacionais citados, a prevalência entre os homens foi nitidamente superior, variando entre $40 \%$ e $100 \%$ a mais do que entre as mulheres (LOLIO, 1993; DUNCAN, 1993; MOREIRA, 1995; REGO, 1990). Somente no estudo de Martins (1995), estratificado por classes sociais, o mesmo resultado foi observado: na classe de maior nível sócio-econômico do Município de Cotia, região metropolitana de São Paulo, 45,3\% dos homens e 47,2\% das mulheres são fumantes.

Nossos resultados parecem confirmar os de Blaxter (1990) para a população inglesa, segundo os quais existe pequena diferença entre a prevalência de homens e mulheres fumantes nas classes sociais mais ricas, enquanto nas mais pobres, os homens fumam mais. Tal situação pode ser consequência do maior abandono do hábito de fumar entre homens de maior nível sócio-econômico, ocasionando prevalências de magnitude semelhante em ambos os sexos. No nosso caso, a prevalência de tabagismo foi similar na maioria dos grupos etários, e em termos do número de cigarros consumidos, já há estratos em que as mulheres fumam tanto quanto os homens (mulheres entre 20 e 39 anos dos Cesec's). Esses dados sugerem portanto que, embora o hábito de fumar ainda predomine entre os homens, as mulheres das dependências estudadas estão mais próximas ao padrão masculino do que as mulheres da população geral

A prevalência de fumantes e quantidade de cigarros consumidos aumentaram com a idade, o que está de acordo com outros estudos (DUNCAN, 1993; ACHUTTI, 1994). Apesar disso, não é possível afirmar que os mais jovens estão fumando menos 
atualmente, já que devido ao delineamento transversal do estudo, não podemos diferenciar entre os efeitos de coorte e idade. Cabe notar ainda a pequena parcela de homens que nunca fumaram entre aqueles com 40 anos ou mais, já que nesse grupo, cerca de dois terços já esteve ou ainda está exposta aos efeitos do cigarro

Apesar do pequeno contingente de funcionários que não chegaram a ingressar na universidade, o consumo diário de vinte cigarros ou mais esteve inversamente associado ao grau de escolaridade. Diferentes distribuições etárias entre os distintos graus de escolaridade (aqueles que concluiram curso superior são mais velhos do que os demais) não parecem explicar a tendência verificada. Uma vez que as prevalências de fumantes e também de grandes fumantes aumentaram com a idade, se a composição etária explicasse a distribuição da quantidade de cigarros consumidos segundo escolaridade, a maior prevalência de grandes fumantes deveria ser estimada entre os que concluíram curso superior (que são mais velhos), e não entre aqueles que não chegaram a ingressar na universidade (como foi encontrado). Assim, o maior consumo de cigarros parece estar, de fato, associado ao menor grau de escolaridade, tendência verificada também em outros estudos nacionais e estrangeiros (LOLIO, 1993; MOREIRA, 1995; BLAXTER, 1990).

\section{b-CONSUMO DE ÁLCOOL}

O consumo de álcool é uma variável reconhecidamente dificil de ser medida. A comparação entre diferentes estudos esbarra em objetivos diversos: tipo, quantidade, frequência, duração ou classificação de alcoolismo. No caso dessa investigação, optamos por medir a frequência já que visávamos avaliar padrões de comportamento. Além disso, como se tratava de uma empresa, a inclusão de questões que tivessem como objetivo a classificação de alcoolismo poderiam prejudicar o preenchimento do questionário.

Os resultados foram consistentes entre os dois tipos de dependência e também com outros estudos nacionais e internacionais, em relação ao nítido predomínio do consumo de álcool entre homens (ALMEIDA, 1993; DUNCAN, 1993; MARTINS, 1995; REGO, 1990; BLAXTER, 1990; NHFA, 1990). Apesar da possibilidade de 
declaração subestimada da frequência de consumo, os resultados apontaram pequena parcela de funcionários que nunca consomem álcool (porque pararam ou nunca consumiram) $-5,2 \%$ dos homens na Direção Geral e 6,7\% nos Cesec's; 7,4\% e 13,8\% das mulheres, respectivamente-, comparada a $12 \%$ da população da Inglaterra e Escócia (BLAXTER, 1990), e 12,6\% dos homens e $24,7 \%$ das mulheres australianos (NHFA, 1990).

De acordo com outros estudos, o hábito de beber predomina entre 20 e 50 anos (ALMEIDA, 1993; ACHUTTI, 1994). Como a população dessa investigação concentrase nessa faixa etária, não houve predomínio de nenhum dos grupos específicos, embora os mais jovens, de ambos os sexos, e também as mulheres mais velhas, tenham apresentado menor prevalência de consumo diário.

É possível supor que a frequência de consumo declarada seja próxima da verdadeira, em função da atitude cada vez mais complacente, da sociedade brasileira, com o consumo de álcool. Assim, exceto nos casos de consumo excessivo, como a frequência diária, esse é um hábito socialmente aceito, e sua declaração pode ter deixado de ser tão problemática quanto em épocas anteriores.

\section{C-ATIVIDADE FÍSICA NO LAZER}

A prevalência de sedentarismo estimada entre os homens $-54,4 \%$ na Direção Geral e 56,4\% nos Cesec's- aproxima-se daquela encontrada por Rego (1990) no Município de São Paulo -57,3\%-, e é menor do que aquela estimada por Duncan (1993) em Porto Alegre -69,0\%-. Entre as mulheres, as prevalências de sedentarismo estimadas nas mesmas investigações $-80,2 \%$ e $82,0 \%$, respectivamente- foram bem maiores do que entre as bancárias: 59,5\% na Direção Geral e 59,9\% nos Cesec's.

As diferenças encontradas podem ser atribuídas, além dos diferentes grupos etários incluídos em cada estudo, às diversas definições de sedentarismo empregadas. Assim, essas definições variaram entre "realizar somente atividade fisica sem esforço físico no tempo de lazer" (REGO, 1990) até “ menos de quatro horas semanais de atividade de pequeno esforço físico" (DUNCAN, 1993). No caso dessa investigação, 
utilizamos o critério de "pelo menos duas vezes por semana, durante vinte minutos cada vez" (Behavioral Risk Factor Questionnaire - 1991) já que visávamos captar o maior número possivel de funcionários que praticam atividade física de lazer com regularidade, assumindo que esse grupo pode apresentar perfil diferente daqueles que declararam não praticar nenhum tipo de exercício. A partir dessa definição mais abrangente, detalhamos tipo, duração e frequência da atividade física. A avaliação dessa última característica revelou resultado interessante, relacionado à grande frequência com que os funcionários se exercitam. Assim, cerca da metade dos não sedentários pratica atividade fisica pelo menos cinco vezes por semana, caracterizando hábito diário para boa parcela desse sub-grupo da população.

A proporção de sedentários aumentou com a idade nos Cesec's, tendência também apontada em outros estudos (ACHUTTI, 1994; NHFA, 1990; BLAXTER, 1990), e que não foi observada na Direção Geral. Essa diferença entre os dois tipos de dependência pode ter resultado dos funcionários mais velhos, da Direção Geral, não terem declarado corretamente seus hábitos sedentários. Por outro lado, pode sugerir que na Direção Geral, maior importância é atribuída à aparência física, uma possível exigência do tipo de função exercida.

A prevalência de sedentarismo estimada entre os bancários situou-se em nível intermediário entre outras estimativas nacionais e as proporções observadas em outros países. Dessa forma, boa parcela dos bancários estudados, especialmente as mulheres, pratica atividade física de lazer regularmente, quando comparados a outros grupos brasileiros. Por outro lado, quando comparados a outros países como Inglaterra e Escócia, por exemplo, a proporção de bancários sedentários é importante. Naquelas populações, entre trabalhadores manuais com idade entre 18 e 40 anos, a prevalência de sedentarismo foi de $42 \%$ para os homens e $51 \%$ para as mulheres (Blaxter, 1990)

\section{d-CONSUMO ALIMENTAR}

Importantes mudanças no padrão alimentar da população urbana brasileira ocorreram nas três últimas décadas: substituição de gordura animal por óleos $\mathrm{e}$ margarinas; redução no consumo de cereais e tubérculos; substituição de carboidratos 
por lipídios e de proteinas vegetais por proteinas animais. Se as três últimas modificações foram acompanhadas pelo aumento da obesidade, "o virtual abandono de gordura de porco e toucinho" e ainda o aumento no consumo relativo de ácidos graxos polinsaturados podem trazer consequências benéficas em relação à prevalência de diversas doenças crônicas (MONDINI, 1994).

Estudos sobre consumo alimentar são escassos no Brasil. Isso porque, entre outros motivos, é difícil "medir" a dieta individual, ao contrário da medida de outros fatores de risco. Nessa investigação, optamos por incluir questões de freqüência de grupos de alimentos, indicado para questionário auto-preenchido, aplicado em população com boa escolaridade e alto nível de cooperação (WILLETT, 1994). Outro estudo nacional utilizou questionário de frequeência alimentar, aplicando-o em população de idosos (NAJAS, 1994). A validade e confiabilidade desse instrumento têm sido avaliadas, sendo suas principais fontes de erro a restrição imposta pela lista de alimentos, erros de memória e interpretação das questões (GOLDBOHM, 1994; JACOBSEN, 1990). De fato, não existe uma metodologia considerada como "padrão ouro" para o estudo do consumo alimentar.

O questionário de frequência de grupos de alimentos foi a única estratégia disponível para a coleta de dados sobre a dieta dos funcionários, considerando-se que não se tratava de pesquisa específica sobre esse tema. Após a análise de dados, concluímos que foi uma decisão acertada incluir a questão a respeito de um dos principais fatores de risco para inúmeras doenças crônicas, embora resultados mais detalhados sobre consumo alimentar não possam ser obtidos.

De maneira geral, os funcionários apresentaram bons hábitos alimentares já que a freqüência de consumo da maioria dos grupos de alimentos de risco é baixa, o hábito de acrescentar sal aos alimentos já preparados não é muito freqüente -cerca de $20 \%$ - se comparado a $40 \%$ da população australiana (NHFA, 1990), e a maior parte consome comida caseira em sua principal refeição diária. As exceções a esse bom padrão são representadas pelo consumo de frituras, especialmente entre os homens -um em cada quatro consome quatro ou mais vezes por semana-, refrigerantes, açúcar e manteiga. Chama atenção também a proporção de funcionários que "costumam" utilizar gordura 
animal (banha de porco ou manteiga) para fritura -cerca de $20 \%$ - considerando-se a escolaridade da população de estudo e também o amplo acesso à informação sobre os riscos para a saúde desses produtos. Assim, de acordo com a tendência apontada por Mondini (1990) para a região Sudeste do pais, de "virtual abandono de banha de porco" e "ampla substituição de manteiga por margarina", esperava-se encontrar menor proporção de consumo desses tipos de gordura.

As informações relativas aos doze grupos de alimentos foram resumidas em escore que apresentou boa confiabilidade (coeficiente alpha de Cronbach $=0,73$ ). Seus resultados são compativeis com a literatura em relação ao maior consumo de ítens de risco por homens, especialmente os mais jovens (BLAXTER, 1990; FARCHI, 1993). Além disso, os funcionários incluídos no primeiro quintil do escore -0 mais saudávelapresentaram também menor prevalência de fumantes de mais de 20 cigarros por dia, de consumidores diários de álcool e de sedentarismo, enquanto o inverso ocorreu com aqueles incluídos no último quintil. Esses resultados ajudam a validar o escore elaborado, além dos critérios de qualidade apresentados, já que todos os estudos disponíveis apontam a "clusterização" de hábitos pouco saudáveis por um lado, e saudáveis por outro (RAITAKARI, 1995; JOUSILAHTI, 1994; RAITAKARI, 1994; BERTOLAMI, 1993).

É interessante notar que a dieta foi o único fator de risco em que os funcionários mais jovens -especialmente os homens- apresentaram comportamento menos saudável do que os mais velhos. Embora considerando o caráter transversal do estudo, cabe especular que o aparecimento de doenças que impõem restriç̋̃es alimentares pode justificar parte desses resultados, que por outro lado, apontam grupo-alvo específico para programas de controle e prevenção das doenças crônicas.

\section{e- ÍNDICE DE MASSA CORPORAL}

Obesidade é um excesso de gordura corporal associado com riscos elevados para a saúde (National Institutes of Health Consensus Development Conference Statement, 1985; WHO, 1995). Sua avaliação pode ser realizada através de inúmeras técnicas como a medida da densidade corporal ou do potássio total, que são utilizadas 
em pesquisas especificas sobre o tema (GARROW, 1983; BRAY, 1985). Na maioria dos estudos clínicos e epidemiológicos, no entanto, a prevalência de obesidade tem sido estimada pelo Índice de Massa Corporal (IMC), calculado através da divisão do peso em quilogramas pela estatura em metros elevada ao quadrado.

Apesar da facilidade com que pode ser calculado, o IMC é uma medida apenas aproximada da gordura, já que a composição corporal varia entre pessoas de mesmo peso e altura (National Institutes of Health Consensus Development Conference Statement, 1985). Assim, as limitações do IMC referem-se à ausência de medida da distribuição da gordura corporal (implicada no risco de doença coronariana) e à ausência de distinção entre massa magra, massa gorda e edema, o que torna possível a classificação errônea de indivíduos magros como obesos (HORTOBAGYI, 1994). Mesmo assim, assume-se que valores acima de determinado ponto de corte significam obesidade, por sua alta correlação com medidas diretas de gordura corporal como a massa de gordura corporal e o percentual de gordura corporal, e por sua independência em relação à estatura (HORTOBAGYI, 1994; National Institutes of Health Consensus Development Conference Statement, 1985). De acordo com Anjos (1992), "o IMC parece válido como indicador do estado mutricional em grupos de individuos", e vem sendo amplamente utilizado com essa finalidade.

A definição do ponto de corte acima do qual os indivíduos são classificados como obesos é menos óbvia e evoluiu de conceitos gerais de "peso ideal" para o de "peso saudável", definido como valores que não ocasionem danos à saúde. Assim, a Organização Mundial de Saúde (OMS) propôs expressar diferentes níveis do IMC em termos de graus de sobrepeso ao invés de graus de obesidade (WHO, 1995), já que entre outros motivos, a importância do excesso de gordura, em termos de saúde pública, não está nos indivíduos obviamente obesos, mas na grande parcela da população que apresenta sobrepeso (GARROW, 1983). Como resume Kushner (1993), a definição de sobrepeso varia segundo diferentes fontes: o National Center for Health Statistics recomenda o IMC entre $20,7 \mathrm{~kg} / \mathrm{m}^{2}$ e $27,8 \mathrm{~kg} / \mathrm{m}^{2}$ para homens e entre $19,1 \mathrm{~kg} / \mathrm{m}^{2}$ e $27,3 \mathrm{~kg} / \mathrm{m}^{2}$ para mulheres, classificando como sobrepeso os índices acima desses limites; a OMS recomenda o intervalo entre $20 \mathrm{~kg} / \mathrm{m}^{2}$ e $25 \mathrm{~kg} / \mathrm{m}^{2}$ para ambos os sexos, já que esse vem sendo apontado como o de menor mortalidade geral 
e também como de baixo risco para doença coronariana (HORTOBAGYI, 1994). Meisler (1996) apontou recentemente valores especificos $-22,6 \mathrm{~kg} / \mathrm{m}^{2}$ para homens e $21,1 \mathrm{~kg} / \mathrm{m}^{2}$ para mulheres- como aqueles que otimizam o perfil de risco cardiovascular. Outras classificações levam ainda em consideração a idade da população, embora valores do IMC progressivamente mais altos de acordo com o aumento da idade, já não sejam mais recomendados (DWYER, 1996).

Na tentativa de achar a classificação do IMC mais adequada a essa investigação, tentamos basear os pontos de corte na própria população de estudo, identificando os percentis 85 e 95 da população entre 20 e 29 anos, acima dos quais sobrepeso e obesidade estariam definidos (BRAY, 1985). No entanto, o pequeno número de funcionários de cada sexo nessa faixa etária impediu a utilização desse critério. Embora a classificação atual da OMS tenha ampliado o intervalo de normalidade do IMC (a partir de $18,5 \mathrm{~kg} / \mathrm{m}^{2}$ ) e tenha subdividido diferentes graus de sobrepeso (WHO, 1995), utilizamos classificação anterior (GRAY, 1989; MINISTÉRIO DA SAÚDE, 1991), já que poucos funcionários apresentam IMC acima de $40 \mathrm{~kg} / \mathrm{m}^{2}$ (grau III na nova classificação), e também para facilitar a comparação com outros estudos.

Os resultados obtidos nesta investigação, através da comparação do peso e estatura informados com os valores medidos de forma direta, merecem alguns comentários (que se aplicam também à comparação entre proporção de hipertensos estimada através do questionário e da medida direta). Embora tenhamos calculado a amostra de funcionários cujos peso e estatura (e hipertensão arterial) deveriam ser medidos, com base na diferença entre duas proporções (proporção de obesos estimada através da informação do questionário e a mesma proporção estimada através da medida direta), resultando um total de 322 funcionários (Anexo 8), e tenhamos examinado um número ainda maior -455 funcionários- tivemos que excluir 133 examinados dos resultados finais. Isto porque não procedemos a novo sorteio das dependências onde as medidas diretas foram realizadas, especifico para esse procedimento, mas escolhemos as dependências de forma intencional, medindo em cada uma delas, um sub-grupo dentre os funcionários previamente sorteados para o preenchimento do questionário. Todos os procedimentos que deveriam ser realizados para possibilitar a soma dos resultados das medidas nas diferentes dependências (estimativa de fatores de expansão e de intervalos 
de confiança dos estimadores), adequados à amostragem probabilística, perderam então o sentido. Optamos, assim, por apresentar os resultados relativos apenas às dependências onde mais de 50 funcionários foram examinados, consideradas isoladamente, excluindo a Agência Campos (39 funcionários examinados); Agência Mendes (11 funcionários examinados); Agência Miguel Pereira (12 funcionários examinados); Agência Sapucaia (5 funcionários examinados) e Agência Volta Redonda (26 funcionários examinados), pela grande flutuação dos resultados baseados em números pequenos. Rigorosamente portanto, os resultados da comparação entre medidas e informação se referem apenas às dependências onde os funcionários foram examinados, já que representam uma amostra aleatória simples dos funcionários aí lotados, e não ao conjunto de dependências do banco. Apesar disso, a consistência dos resultados, especialmente aqueles referentes ao Índice de Massa Corporal, possibilitou a discussão que passamos a desenvolver.

A comparação entre informação sobre peso e estatura e as respectivas medidas, sugerem que os dados fornecidos pelos funcionários são válidos. Isso porque em todas as dependências e em ambos os sexos, a correlação entre medida e informação mostrouse consistentemente elevada, variando entre 0,95 e 0,99. De fato, esse resultado era esperado em função do alto nível de escolaridade da população e também da periodicidade anual do exame de saúde, onde peso e altura são medidos, garantindo dessa forma que pelo menos nessa oportunidade, os funcionários tomem conhecimento de seus valores. Outros estudos também evidenciaram a validade da informação do peso tanto no Brasil como em outros países (SCHMIDT, 1993; PALTA, 1982; BOWLIN, 1993). Em estudo realizado em quatro áreas docente-assistenciais de Porto Alegre, a correlação entre peso informado e peso medido em 659 adultos foi estimada em 0,97 (SCHMIDT, 1993). Em outro caso, estudo de validação dos dados coletados por telefone, para o "Behavioral Risk Factor Survey" (BRFS), em Nova York, a correlação entre informação e medida direta de peso e estatura foi de 0,93 para homens e 0,95 para mulheres (BOWLIN, 1993).

Quanto à sensibilidade da informação comparada à medida, estimamos valores também bastante elevados, variando entre $76,2 \%$ no Cesec Centro e $96 \%$ na Agência Centro. Esses resultados indicam que pequena parcela dos funcionários com sobrepeso 
funcionário. Os valores de especificidade foram ainda mais elevados, sendo o menor igual a $94,9 \%$, indicando que quase todos os funcionários que apresentam IMC normal ou baixo peso seriam classificados corretamente apenas com a informação. Valores preditivos positivo e negativo elevados -acima de $88 \%$ - foram também estimados em todas as dependências. No estudo de Porto Alegre, resultados semelhantes foram encontrados, estimando-se valores elevados de sensibilidade e especifidade $-89 \%$ e 97\% respectivamente- em relação à categoria de sobrepeso e obesidade (SCHMIDT, 1993). Na validação do BRFS, a sensibilidade da informação foi estimada em $77 \%$ para os homens e $72 \%$ para as mulheres (BOWLIN, 1993).

As pequenas diferenças entre peso medido e informado estimadas nessa investigação revelaram tendência a informar valores subestimados em ambos os sexos, comportamento descrito anteriormente apenas entre mulheres (Schmidt, 1993). De maneira geral, também se observou comportamento semelhante em ambos os sexos em relação à informação da estatura, cujas diferenças foram ainda mais triviais. Pode-se concluir, portanto, da mesma forma que na maioria dos estudos disponíveis, que a informação de peso e estatura constituem bons indicadores das medidas reais.

O padrão de distribuição de sobrepeso e obesidade de acordo com a idade, é compatível com aquele descrito para o conjunto da população brasileira e também em outros países: a prevalência aumenta com a idade (MINISTÉRIO DA SAÚDE, 1991; GRAY, 1989). Em relação à ocorrência de sobrepeso por sexo, o padrão encontrado no banco é semelhante ao de países desenvolvidos onde a prevalência é maior entre os homens (NHFA, 1991; GRAY, 1989) (Tabela IV.1.3). A prevalência entre os bancários é compatível também com outros grupos populacionais comparáveis do ponto de vista sócio-econômico, como é o caso da população brasileira com renda superior a 2,2 salários-mínimo percapita (SICHIERI, 1994; MINISTÉRIO DA SAÚDE, 1991) e de funcionários da Universidade Federal do Rio de Janeiro (NOGUEIRA, 1990). A prevalência de obesidade masculina nos dois tipos de dependência também foi semelhante a grupos populacionais comparáveis, cabendo notar que situam-se entre as proporções mais elevadas (Tabela IV.1.3). Além dos estudos citados, estimativas relativas à população da Ilha do Governador, bairro do Rio de Janeiro, também se aproximam das nossas: $33 \%$ de sobrepeso e 13\% de obesidade, considerando-se ambos 
os sexos (BLOCH, 1994). Outros estudos nacionais utilizaram pontos de corte diferentes, impossibilitando a comparação (REGO, 1990; DUNCAN, 1993).

TABELA IV.1.3

COMPARAÇÃO ENTRE PREVALÊNCIAS

DE SOBREPESO E OBESIDADE POR SEXO

\begin{tabular}{l|c|cc|cc}
\hline \multirow{2}{*}{ ESTUDO } & IDADE & \multicolumn{2}{|c|}{ HOMENS } & \multicolumn{2}{c}{ MULHERES } \\
\cline { 2 - 6 } & & $\begin{array}{c}\text { SOBRE- } \\
\text { PESO } \\
(\%)\end{array}$ & $\begin{array}{c}\text { OBESIDADE } \\
\text { SOBRE- } \\
\text { PESO } \\
(\%)\end{array}$ & OBESIDADE \\
\hline DIREÇÃO GERAL & $22-56$ & 39,5 & $(\%)$ & 12,6 & 1,0 \\
CESEC & $22-53$ & 36,4 & 7,9 & 16,7 & 4,5 \\
PNSN & $>18$ & $36,2^{*}$ & $8,2^{*}$ & $28,9^{*}$ & $12,4^{*}$ \\
& & 22,5 & 4,8 & 26,4 & 11,7 \\
ARARAQUARA & $18-74$ & 26,9 & 10,2 & 27,7 & 14,7 \\
UFRJ & $35-64$ & 36,0 & 7,0 & $\ldots$ & $\ldots$ \\
AUSTRÁLIA & $20-69$ & 38,6 & 9,3 & 22,4 & 11,1 \\
INGLATERRA & $16-65$ & 34,0 & 6,0 & 24,0 & 8,0 \\
CANADÁ & $>20$ & 40,0 & 9,0 & 28,0 & 12,0 \\
ESTADOS UNIDOS & $20-74$ & 31,0 & 12,0 & 24,0 & 12,0 \\
\hline
\end{tabular}

PNSN - Pesquisa Nacional de Saúde e Nutrição (Ministério da Saúde, 1991)

*População com renda percapita > do que 2,2 salários mínimos

Araraquara - Lolio, 1991

UFRJ - Universidade Federal do Rio de Janeiro - Nogueira, 1990

Austrália - NHFA, 1991

Inglaterra, Canadá e Estados Unidos - Gray, 1989

Em contraste com os homens, as prevalências de sobrepeso e obesidade femininas, especialmente na Direção Geral, foram bem menores do que aquelas estimadas para grupos populacionais comparáveis (Tabela IV.1.3). Esses resultados merecem alguns comentários. Consideramos a possibilidade de ter ocorrido diferença entre o comportamento das mulheres submetidas à medida de peso e das mulheres cujo peso não foi conferido. $O$ primeiro grupo poderia ter informado corretamente por saber que teria seu peso medido, enquanto o segundo grupo poderia ter subestimado seus valores. A tendência a informar valores menores do peso já foi descrita, especialmente em relação às mulheres mais jovens e às obesas (PALTA, 1982). Para esclarecer essa possibilidade, comparamos o IMC médio do grupo cujas medidas foram realizadas com 
o IMC médio do grupo não examinado, em cada dependência e em ambos os sexos (Tabela IV.1.4). De acordo com esses resultados, as médias do IMC em ambos os grupos foram semelhantes em todas as dependências e em ambos os sexos. Assim, a subestimação do valor do peso por parte das mulheres não examinadas não parece ser uma explicação plausível para a baixa prevalência encontrada. Resta supor, portanto, que as estimativas correspondam à realidade, o que faz sentido, conhecendo-se as exigências em relação à aparência física das mulheres, especialmente na Direção Geral, onde estão diversos cargos de decisão da empresa. Cabe lembrar ainda que as bancárias são mais jovens do que as mulheres incluídas nas populações comparadas na Tabela IV.1.1, o que pode contribuir para aumentar a prevalência de sobrepeso e obesidade naquelas populações. De acordo com dados da PNSN, essa prevalência aumenta com a idade de forma muito mais acelerada nas mulheres do que nos homens, considerando-se a população brasileira com renda per capita maior ou igual a dois salários mínimos (MINISTÉRIO DA SAÚDE, 1991).

\section{TABELA IV.1.4 \\ COMPARAÇÃO ENTRE IMC MÉDIO DO GRUPO SUBMETIDO À MEDIDA DE PESO E ESTATURA E DO GRUPO NÃO MEDIDO POR SEXO E POR DEPENDÊNCIA}

\begin{tabular}{l|cc|cc}
\hline DEPENDÉNCIA & \multicolumn{2}{|c|}{ HOMEM } & \multicolumn{2}{c}{ MULHER } \\
\hline & MEDIDO & NÃO MEDIDO & MEDIDO & NÃO MEDIDO \\
DIREÇÃO GERAL & $25,3(3,7)$ & $24,9(3,4)$ & $22,2(2,8)$ & $22,3(2,8)$ \\
AGÊNCIA CENTRO & $25,2(3,2)$ & $25,0(4,2)$ & $23,2(2,9)$ & $23,6(4,0)$ \\
CESEC CENTRO & $25,2(3,8)$ & $24,6(3,1)$ & $23,8(6,0)$ & $22,5(2,4\}$ \\
ILHA GOVERNADOR & $24,8(4,4)$ & $27,0(3,3)$ & $23,5(3,8)$ & $23,6(2,1)$ \\
\hline
\end{tabular}

Desvio Padrão entre parênteses

Todas as diferenças entre médias apresentaram $p>0,10$ comparando-se "medidos"e

"não medidos"através do teste $\mathrm{t}$ de student.

$\mathrm{IMC} \mathrm{em} \mathrm{kg/ \textrm {m } ^ { 2 }}$

\section{$f$-COLESTEROL}

Os resultados encontrados em relação à pergunta utilizada para estimar a prevalência de hipercolesterolemia -"Algum médico ou outro porfissional de saúde já the disse que seus níveis de colesterol no sangue estavam elevados?" - foram 
consistentes em ambos os tipos de dependências. Entre os homens, 28,9\% na Direção Geral e $28,7 \%$ nos Cesec's responderam afirmativamente, enquanto entre as mulheres, $21,3 \%$ e $18,5 \%$ respetivamente, o fizeram. Também os resultados encontrados quando se utilizou a análise de correspondência foram coerentes, já que o grupo que declarou já ter sido informado sobre níveis altos de colesterol estava associado a faixas etárias mais velhas, à obesidade e à hipertensão, o que tem sido frequentemente descrito na literatura (JOFFRES, 1992; MEISLER, 1996).

Estudos nacionais de prevalência de hipercolesterolemia são escassos. Entre os disponiveis, alguns se restringiram à população masculina (NOGUEIRA, 1990), ou divulgaram prevalências de hipercolesterolemia associada às frações do colesterol total (MARTINS, 1996) ou não utilizaram amostra probabilística (NICOLAU, 1992; DIOGUARDI, 1994), o que limita a comparação de resultados. Entre as investigações cujas prevalências podem ser comparadas, Nogueira (1990) estimou que $26 \%$ dos funcionários do sexo masculino da Universidade Federal do Rio de Janeiro (UFRJ) apresentavam niveis maiores do que $240 \mathrm{mg} / \mathrm{dl}$, e $53 \%$ acima de $200 \mathrm{mg} / \mathrm{dl}$. Em indústria metalúrgica de São Bernardo do Campo, onde 1586 funcionários foram avaliados (presumivelmente $o$ total de funcionários da empresa, excluindo-se diabéticos e hipertensos), a prevalência foi estimada em $38 \%$ para os homens e $26,7 \%$ para as mulheres, considerando-se niveis superiores a $200 \mathrm{mg} / \mathrm{dl}$. Quando o ponto de corte passa a $240 \mathrm{mg} / \mathrm{dl}$, as prevalências foram estimadas em $14,8 \%$ e $7,9 \%$ respectivamente (BERTOLAMI, 1993). Entre servidores do Hospital de Clínicas da Universidade de São Paulo, sem história familiar de doença coronariana, a prevalência de hipercolesterolemia (acima de $200 \mathrm{mg} / \mathrm{dl}$ ) foi estimada em $35 \%$ para homens e $36 \%$ para mulheres, e de $11,3 \%$ e $8,5 \%$ respectivamente, acima de 240 mg/dl (GIANNINI, 1992).

Na população norte-americana, a prevalência de hipercolesterolemia (acima de $240 \mathrm{mg} / \mathrm{dl}$ ) foi estimada em $25 \%$ para os homens e $28 \%$ para as mulheres (SEMPOS, 1989), enquanto na Austrália, com o mesmo ponto de corte, a prevalência populacional foi de $16 \%$ e $14 \%$, respectivamente (NHFA, 1991). 
Nossas estimativas são compatíveis com algumas daquelas relatadas em estudos nacionais e também com as prevalências da população norte-americana, embora não possamos comparar prevalências de acordo com os dois pontos de corte $200 \mathrm{mg} / \mathrm{dl}$ e $240 \mathrm{mg} / \mathrm{dl}-\mathrm{já}$ que não nos baseamos na medida direta do colesterol. No entanto, a grande parcela de funcionários com menos de 40 anos, especialmente homens, que declarou nunca ter medido seu nível de colesterol sanguíneo, o grande número de respostas ausentes (295) e também a possibilidade de utilização de diferentes critérios de definição de "colesterol alto" por parte dos médicos (alguns classificam como alto a partir de $200 \mathrm{mg} / \mathrm{dl}$, outros somente acima de $240 \mathrm{mg} / \mathrm{dl}$ ) limitam o alcance dos resultados encontrados. Além disso, a ausência de validação da informação através da medida direta torna impossível a avaliação da validade de critério dos dados. Essa validação não foi realizada em função de limitações operacionais envolvidas na coleta de sangue no ambiente de trabalho.

Apesar de algumas indicações de que nossas estimativas podem não estar muito longe da realidade, cabe supor que dentre os funcionários que realmente apresentavam hipercolesterolemia, uma parcela respondeu que não foi informado, causando subestimação da prevalência e erros de classificação. Nesse sentido, os resultados apresentados por Bowlin (1993) ao comparar a informação obtida por telefone, através da mesma pergunta utilizada em nosso estudo, com a medida direta, obteve baixos resultados de sensibilidade $-41 \%$ para homens e $47 \%$ para mulheresNaquela investigação portanto, cerca da metade dos portadores de hipercolesterolemia não tinha conhecimento de sua condição. Ao validar a informação sobre hipercolesterolemia entre os 15739 participantes do Atherosclerosis Risk in Communities Study (ARIC), sensibilidade semelhante foi estimada já que apenas $42 \%$ daqueles que apresentaram níveis elevados de colesterol ao exame, informaram corretamente (NIETO, 1995). Também no Estado de São Paulo, apenas 30\% dos médicos que responderam questionário acerca de fatores de risco e apresentaram hipercolesterolemia à medida direta, conheciam sua condição (DIOGUARDI 1994). Embora os resultados desse último estudo não tenham se baseado em amostra probabilística, chama a atenção que também entre médicos, a informação a respeito dos níveis de colesterol sanguineo tenha apresentado baixa sensibilidade. 
Em relação ao grupo de funcionários que realmente não apresenta níveis elevados de colesterolemia, podemos supor que boa parcela respondeu corretamente à pergunta. Isso porque abaixo de $200 \mathrm{mg} / \mathrm{dl}$, todos os médicos costumam classificar como "nivel normal", não ocorrendo variação de critério como nos niveis limitrofes. De acordo com o estudo de Bowlin (1993), citado anteriormente, a especifidade da pergunta utilizada também em nosso estudo foi alta $-75 \%$ para homens e $88 \%$ para mulheres-, o mesmo ocorrendo em relação ao valor preditivo positivo, $65 \%$ e $85 \%$ para homens e mulheres, respectivamente. Uma vez que nosso questionário foi aplicado pessoalmente e não por telefone como o de Bowlin, o que melhora a validade de critério do instrumento (PALTA, 1982; FORTMAN, 1984) a especificidade e o valor preditivo positivo de nosso estudo podem ser ainda mais elevados.

\section{g- HIPERTENSÄO ARTERIAL}

As estimativas de prevalência de hipertensão arterial apresentam grande variação em função de diferentes critérios de classificação e instrumentos de medida utilizados (KLEIN, 1992; DUNCAN, 1993; LOLIO, 1991; REGO, 1990) (Tabela IV.1.5). As prevalências estimadas nessa investigação $-21,1 \%$ entre os homens e $9,9 \%$ entre as mulheres na Direção Geral, e nos Cesec's, 24,3\% e 15,8\%, respectivamente- são próximas daquelas estimadas por diversas outras pesquisas nacionais, embora tenham sido baseadas nas respostas ao questionário e não na medida direta dos níveis tensionais. Dentre aquelas prevalências, chama atenção que apenas 9,9\% das mulheres da Direção Geral tenham sido classificadas como hipertensas, em comparação a 15,8\% nos Cesec's. No entanto, a prevalência excepcionalmente baixa de obesidade bem como a distribuição etária (são mais jovens do que as funcionárias dos Cesec's) podem justificar esse resultado. 
TABELA IV.1.5

COMPARAÇÃO ENTRE PREVALÊNCIAS

DE HIPERTENSÃO ARTERIAL

POR SEXO

\begin{tabular}{l|c|c|c|c}
\hline ESTUDO & IDADE & HOMENS & MULHERES & TOTAL \\
\hline DIREÇÃO GERAL & $22-56$ & 21,1 & 9,9 & 16,8 \\
CESEC & $22-53$ & 24,3 & 15,8 & 20,5 \\
ILHA DO GOVERNADOR & $>20$ & 22,6 & 26,8 & 24,9 \\
PORTO ALEGRE (4 Áreas) & $15-64$ & 15,0 & 15,0 & 15,0 \\
ARARAQUARA & $18-74$ & 30,5 & 21,7 & 25,5 \\
SÃO PAULO (Município) & $15-59$ & 15,8 & 7,8 & 11,6 \\
AUSTRÁLIA & $20-69$ & 18,0 & 14,0 & $\ldots$ \\
CANADÁ & $18-74$ & 23,0 & 18,0 & 20,0 \\
\hline
\end{tabular}

Ilha do Governador- Klein, 1992

Porto Alegre - Ducan, 1993

Araraquara - Lolio, 1991

São Paulo - Rego, 1990

Austrália - NHFA, 1991

Canadá - Joffres, 1992

A confiabilidade da pergunta utilizada nessa investigação -"Algum médico ou outro profissional de saúde já lhe informou que você era hipertenso ou tinha pressão alta?"- foi estimada em 0,82 (coeficiente kappa), através de estudo tipo teste-reteste, com duas entrevistas telefônicas, no "Missouri Behavioral Risk Factor Survey" (BOWSON, 1994).

Avaliações da validade de critério da mesma pergunta apresentam diferentes resultados. De acordo com a literatura disponível, estimativas de sensibilidade da pergunta em relação à medida direta parecem variar segundo a idade da população estudada (os mais velhos costumam conhecer melhor seus níveis tensionais), critérios de classificação adotados, e também do tipo de coleta de dados (entrevistas telefônicas parecem acarretar mais erros de classificação do que questionários enviados pelo correio ou entrevistas pessoais) (BOWLIN, 1993). Entre os 15739 participantes de 45 a 64 anos de idade, do Atherosclerosis Risk in Communities Study (ARIC) nos Estados Unidos, apenas 16\% daqueles classificados como hipertensos pela medida, não conheciam sua condição (sensibilidade=84\%) (NIETO, 1995) Nessa comparação, entrevistas pessoais, no domicílio, foram utilizadas para a coleta 
de informações e o ponto de corte adotado foi de $140 / 90 \mathrm{mmHg}$. Ao utilizarem metodologia semelhante em relação a nove províncias canadenses, com população entre 18 e 74 anos de idade, Joffres e colaboradores (1992) também estimaram boa sensibilidade $-74 \%$-, restando portanto $26 \%$ dos hipertensos que não conheciam essa condição. A sensibilidade da pergunta foi menor em três distritos de Nova York, onde a classificação de hipertensão através de entrevista telefônica foi comparada à medida direta da pressão arterial. Apenas $40 \%$ dos homens e $46 \%$ das mulheres hipertensas segundo a medida (acima de 140/90 $\mathrm{mmHg}$ ), responderam de forma coerente à pergunta (BOWLIN, 1993). Em Porto Alegre, 57,7\% da população classificada como hipertensa (acima de 160/95 mmHg) conhecia sua condição (FUCHS, 1995).

No caso dessa investigação, a concordância entre as duas fontes de informação, avaliada através do coeficiente kappa, variou entre 0,49 e 0,65, valores considerados entre moderados a bons (FLEISS, 1981). A classificação baseada no questionário parece identificar corretamente os normotensos, já que a especificidade e o valor preditivo negativo foram elevados (acima de 90\%). Esse resultado é compatível com outro estudo, que também estimou especificidade da informação fornecida pelo participante em torno de 90\% (BOWLIN, 1993). Os valores preditivos positivos que variaram entre 58,3\% (Cesec Centro), 69,6\% (Direção Geral), 72,7\% (Agência Ilha do Governador) e 80,0\% (Agência Centro), indicam que boa parcela dos hipertensos classificados através do questionário, foram confirmados pela medida, com exceção do Cesec Centro. Assim, a fragilidade do questionário encontra-se na proporção de falsos-negativos, medida através da sensibilidade, que variou entre $58,3 \%$ (Cesec Centro) e 72,7\% (Agência Ilha do Governador). Essa fragilidade não comprometeu, provavelmente, os resultados encontrados, se assumirmos que foram estimadas prevalências mínimas (em função dos falsos-negativos), e que os erros de classificação de hipertensão não afetaram de maneira diferenciada as categorias dos outros fatores de risco. Assim, ao considerarmos a distribuição de fumantes e não fumantes, sedentários e não sedentários, e também dos outros fatores, entre hipertensos e não hipertensos, assumimos que o impacto dos erros de classificação foi o mesmo em cada uma das categorias dos outros fatores, já que não conseguimos identificar motivos para que cada uma fosse afetada de forma diferenciada (mais erros 
de classificação de hipertensão entre fumantes do que entre não fumantes, por exemplo)

O critério de classificação de hipertensão de acordo com a medida (acima de 160/95 $\mathrm{mmHg}$ ou uso de medicamento) além de ser recomendado para pesquisa (OMS, 1978), nos pareceu mais adequado por diminuir o número de falsos positivos, já que elevações transitórias da pressão arterial, entre 140/90 mmHg e 160/95 mmHg, são frequentes. Por outro lado, os valores de sensibilidade seriam ainda mais baixos se o ponto de corte de 140/90 mmHg tivesse sido adotado: 40,6\% (Agência Centro); 47,4\% (Cesec Centro); 57,9\% (Direção Geral); 61,5\% (Agência Ilha do Governador).

Em relação aos critérios adotados para classificação a partir do questionário, aceitamos uma das duas dimensões avaliadas: diagnóstico médico (pergunta $n^{\circ} 68$ ) e auto-classificação de hipertensão (pergunta $n^{\circ} 97$ ), além da condição de tratamento específico. A inclusão da pergunta $n^{\circ} 97$, onde o funcionário deveria assinalar suas doenças do aparelho circulatório, permitiu classificar sete funcionários como hipertensos, o que não ocorreria se somente a pergunta $n^{\circ} 68$ fosse levada em consideração. Esses sete funcionários responderam que nunca foram informados na pergunta $n^{\circ} 68$, mas declararam que têm ou tiveram hipertensão na pergunta $n^{\circ} 97$. Decidimos pois classificá-los como hipertensos já que em estudo como esse, que foi também um "screening" da população de risco, a sensibilidade da informação do questionário constituiu nossa principal preocupação. Assim, nosso objetivo foi o de diminuir o número de falsos-negativos, através da incorporação da pergunta ${ }^{\circ} 97$, admitindo que todos os funcionários que "se declararam" hipertensos deveriam ser classificados como tal, e encaminhados para diagnóstico clínico posterior. Só nesse momento então, os possiveis falsos positivos seriam identificados e classificados corretamente. De fato, com a inclusão da pergunta $n^{\circ} 97$, conseguimos melhorar a sensibilidade da informação contida no questionário, sem alterar a especificidade, cujos valores permaneceram elevados.

A discordância entre as duas fontes de informação pode ser atribuída a diversos motivos. Em primeiro lugar, a ausência de diagnóstico médico de hipertensão arterial pode ocorrer mesmo nessa população com amplo acesso a 
serviços de saúde, já que não existe padronização de conduta dos médicos credenciados pela CASSI no sentido de priorizarem sua deteç̧ão, o que seria justificado pela magnitude da doença e gravidade de suas consequências na faixa etária da população de estudo. Além disso, os critérios utilizados pelos diversos médicos podem variar, e nos casos em que os níveis tensionais não são muito altos (a maioria), a doença pode ser diagnosticada por alguns e negada por outros, deixando o indivíduo em dúvida sobre sua condição. Diferenças entre os critérios utilizados para diagnóstico clínico e de pesquisa podem ter causado também parte da discordância: o diagnóstico clínico correto deve ser baseado em diversas medidas dos níveis tensionais, em dias diferentes, enquanto na pesquisa, duas medidas são tomadas no mesmo dia. A rigor, estudos de validação do tipo que realizamos podem estar comparando coisas distintas, que têm objetivos diferentes: classificação de um grupo populacional para estimativa de prevalência e diagnóstico individual de hipertensão arterial.

A classificação de grupos populacionais em hipertensos e não hipertensos não é uma tarefa fácil. A medida direta dos níveis pressóricos, para a qual o treinamento padronizado é essencial, tem sido utilizada como "padrão ouro" em estudos de prevalência no Brasil e em outros países, embora não esteja livre de erros. Os critérios de classificação adotados com base no questionário apresentam alta especifidade, o que significa baixa proporção de falsos positivos, bom poder preditivo negativo (dentre aqueles classificados como não hipertensos pelo questionário, boa proporção foi confirmada pela medida), valor preditivo positivo entre moderado e bom (dentre aqueles classificados como hipertensos pelo questionário, boa proporção foi confirmada pela medida), mas valores baixos de sensibilidade. Assim, as prevalências de hipertensão baseadas no questionário são prevalências mínimas, enquanto a chance de cometer erro inverso, classificando não hipertensos como hipertensos, é bem menor.

A proporção de funcionários que declararam estar sob tratamento específico para controle de hipertensão arterial merece comentário adicional. Apenas 58,5\% na Direção Geral e 53,4\% nos Cesec's, dentre aqueles informados mais de uma vez de que eram portadores dessa condição estavam em tratamento, o que significa que cerca 
de $40 \%$ interrompeu o tratamento ou nunca se tratou. Além disso, $45,3 \%$ dos funcionários que interromperam o tratamento o fizeram "porque ficaram curados" (motivo apontado com a maior frequência). Já que se trata de populacão com alto nível de escolaridade e amplo acesso a serviços de saúde, esses resultados são surpreendentes. Indicam a inadequação da assistência à hipertensão arterial, e também que informação e poder aquisitivo para compra de medicamentos não são suficientes para garantir a adesão ao tratamento da hipertensão. A ausência de sintomas em muitos dos casos moderados, bem como a diminuição da crença na autoridade médica, entre outros motivos, devem ser cogitados como justificativas para que os funcionários não tenham aceitado o "rótulo" de doentes, prescindindo do tratamento.

\section{2- OCORRÊNCIA SIMULTÂNEA DOS FATORES DE RISCO: O ESTILO DE VIDA}

Estilo de vida pode ser definido como um fenômeno sócio-cultural proveniente da interação entre padrões de comportamento e situações de vida (DEAN, 1995). As doenças não seriam, de acordo com o conceito do autor, o resultado direto de determinado estilo de vida, mas da interação entre comportamentos e condições biológicas, psicológicas e sociais, que em última análise, determinariam tanto o estado de saúde quanto a longevidade (DEAN, 1995).

O conceito de estilo de vida engloba alguns aspectos importantes para a compreensão da forma com que hábitos e comportamentos se distribuem entre os individuos, bem como para o planejamento de estratégias populacionais de controle de doenças. Estilo de vida refere-se a comportamentos que estão, a princípio, abertos à escolha individual, mas inclui também a idéia de partilha de hábitos semelhantes entre grupos expostos às mesmas circunstâncias. Além disso, comportamentos são de alguma forma relacionados uns com os outros, de maneira que ao nos referirmos a determinado estilo de vida, reduzimos diversos hábitos a um número menor de diferentes estilos (UITENBROEK, 1996). 
Os resultados desta investigação confirmam a relação entre tipos de comportamento, já que a ocorrência simultânea de fumo e consumo de álcool, fumo e dieta pouco saudável, fumo e sedentarismo, sedentarismo e dieta pouco saudável foram identificados. Inúmero outros estudos também concluiram que hábitos imprudentes ocorrem juntos (em "cluster"), desde a infância e adolescência até a vida adulta (RAITAKARI, 1995; FOLSOM, 1985; RAITAKARI, 1994; JOUSILAHTI, 1994).

Ao estudar três coortes de adultos jovens, Raitakari et al (1995) encontraram associação entre os mesmos hábitos relatados por nós, e ainda entre sedentarismo e frequência de consumo excessivo de álcool, que não apresentou padrão nítido entre os bancários. Algumas dessas associações foram particularmente estudadas. A ocorrência simultânea do hábito de fumar e dieta rica em gordura saturada aumentou em duas províncias da Finlândia entre 1972 e 1987, apesar do declínio acentuado das prevalências isoladas de cada um desses fatores. Assim, enquanto mudanças positivas ocorreram na proporção de fumantes e no consumo alimentar da população em geral, maior número de indivíduos que fumavam muito ou apresentavam dieta muito rica em gordura passaram a exibir ambos os fatores de risco, o que trouxe implicações óbvias para estratégias de controle das doenças cardiovasculares (JOUSILAHTI, 1994). Maior probabilidade de identificar grandes consumidores de gordura, colesterol e sal entre fumantes também foi relatada entre pacientes de 10 hospitais, recrutados em cinco cidades americanas. Naquele estudo, o fumo estava positivamente associado com o consumo de carne e negativamente com o de cereais, entre os homens. Fumantes de ambos os sexos consumiam menos vegetais e frutas, e maior quantidade de álcool e café do que aqueles que nunca fumaram (MORABIA \& WINTER, 1990).

Adolescentes foram acompanhados durante seis anos em diversas cidades finlandesas com o objetivo de comparar a prevalência de fatores de risco entre o grupo sedentário e o grupo que praticava atividades físicas regularmente (RAITAKARI, 1994). A prática de atividades fisicas esteve associada a menor prevalência de fumantes em ambos os sexos, já que adolescentes ativos raramente começaram a fumar. Além disso, entre os meninos, a prática de exercícios esteve associada também ao menor consumo de gordura saturada e melhor relação ácidos graxos polinsaturados/saturados. Associação entre sedentarismo e outros fatores de risco foi encontrada também entre 
adultos de 25 a 74 anos, residentes em Minnesota (FOLSOM, 1985). De acordo com esses autores, parte do efeito benéfico da atividade física regular nas taxas de mortalidade por doenças cardiovasculares pode ser atribuído a mudanças positivas em outros fatores de risco, tais como fumo e dieta, além do efeito sobre o perfil lipídico, insulinemia e adiposidade. O sedentarismo, ao contrário, reforçaria tendências a adotar hábitos e comportamentos pouco saudáveis.

Ao analisarmos todos os fatores de risco simultâneamente através da análise de correspondência, pudemos identificar dois grupos distintos e opostos de funcionários, caracterizados pela "coerência" de comportamento: ou apresentaram todos os fatores de risco, em seus maiores níveis, ou não apresentaram nenhum deles. Entre os bancários, hábitos pouco saudáveis -consumir álcool diariamente, ser grande fumante, consumir dieta rica em gordura saturada, colesterol, sal e açúcar, e ser sedentário- "andam juntos" isto é, o funcionário que apresenta uma dessa condições, tem maior probabilidade de exibir também qualquer uma das outras. $O$ mesmo ocorre com o grupo "saudável”, que apresenta um "cluster" de hábitos positivos para a saúde. Confirma-se dessa forma a observação de outros autores, segundo a qual, prevalências elevadas de um determinado fator de risco devem ser buscadas entre grupos com alto nível de outro fator (JOUSILAHTI, 1994).

Além daqueles fatores de risco, a hipertensão, sobrepeso/obesidade e hipercolesterolemia também ocorreram simultâneamente. $O$ funcionário obeso ou com sobrepeso tem maior probabilidade de ser hipertenso e ter hipercolesterolemia do que um funcionário com peso normal ou baixo peso. Essa ocorrência simultânea encontra respaldo na literatura nacional e estrangeira (FUCHS, 1995; KLEIN, 1992; RAITAKARI, 1995; JOUSILAHTI, 1994), e adquire maior importância na medida que hipertensão arterial e perfil lipídico aterogênico (nível alto de colesterol total, triglicerídeos e LDL-colesterol; nível baixo de HDL-colesterol) têm efeito sinérgico, e não apenas aditivo, no risco de doenças cardiovasculares.

A associação entre obesidade e hipertensão arterial foi observada em virtualmente todas as sociedades, grupos etários e étnicos, e em ambos os sexos. Assim, o Índice de Massa Corporal tornou-se, juntamente com a idade, o melhor 
preditor dos níveis de pressão arterial. A associação entre hipertensão arterial e hipercolesterolemia tem como fatores de risco comuns a obesidade e a dieta rica em colesterol (RAITAKARI, 1995; STAMLER, 1992). Além disso, parecem compartilhar alterações metabólicas semelhantes já que por exemplo, o ganho de peso na infância e adolescência é preditor do aumento dos níveis tensionais e também de colesterol total (McCARRON \& REUSSER, 1996).

Outros fatores de risco como sedentarismo, fumo e consumo de álcool também têm relação com a ocorrência de hipertensão e do perfil lipídico aterogênico. Além do efeito direto, como no caso do álcool sobre os níveis tensionais, esses fatores conformam uma "síndrome comportamental" (ISTVAN, 1992) onde o estilo de vida favorece a obesidade, e determina a relação entre todos os fatores. Assim, por exemplo, alguns estudos têm associado obesidade e grande consumo diário de cigarros (um a dois maços), embora considere-se que fumantes pesam menos do que não fumantes (ISTVAN, 1992). Comparando-se jovens sedentários com os que praticavam atividade física regular, observou-se que estes apresentaram menores níveis de triglicerideos e insulina, assim como melhor relação HDL/colesterol total (RAITAKARI, 1994). Já entre adultos, Raitakari e colaboradores (1995) relataram que o "cluster" de fatores "biológicos" -hipertensão e perfil lipídico aterogênico - estava significativamente associado ao "cluster" de fatores de risco comportamentais -fumo, álcool, dieta e sedentarismoespecialmente entre homens, sugerindo que uma parcela daqueles que apresentam estilo de vida pouco saudável desenvolvem alterações metabólicas e consequentemente acabam por exibir múltiplos riscos. Associação entre perfil lipídico aterogênico com o hábito de fumar mais de 10 cigarros por dia, menor atividade física no trabalho, maior consumo de álcool, sobrepeso e obesidade foi relatada também por Bertolami e colaboradores (1993), ao investigarem 1586 metalúrgicos em São Bernardo do Campo (São Paulo).

Entre os bancários, a convergência entre fatores de risco comportamentais e efeitos biológicos -hipertensão, hipercolesterolemia e sobrepeso/obesidade- esteve fortemente representado entre os homens. Esse grupo apresentou hábitos menos saudáveis e também maior prevalência de efeitos, especialmente a partir dos 45 
anos. Dentre os efeitos a prevalência de sobrepeso/obesidade chama particularmente a atenção uma vez que cerca de $50 \%$ dos homens apresentou IMC acima do normal já a partir dos 30 anos na Direção Geral, e dos 35 anos nos Cesec's. A prevalência feminina, por outro lado, não chegou a $20 \%$, considerando-se os mesmos grupos etários.

Uma vez que a coexistência dos diversos fatores de risco é reconhecida, constituindo estilos de vida típicos, cabe identificar determinantes sócioeconômicos, demográficos e comportamentais que contribuam para essa "clusterização". Esses determinantes não atuam somente nos grupos que apresentam todos ou nenhum dos fatores de risco mas também na maior parte da população, que exibe comportamento misto, caracterizado por adotarem alguns dos comportamentos de risco, nem sempre no maior grau de intensidade.

Diferenças entre gêneros aparecem em todos os estudos disponíveis, que apontam comportamentos mais saudáveis entre as mulheres. Assim, na maioria das investigações, os homens apresentam maior prevalência do hábito de fumar, de consumo de álcool e de dieta pouco saudável (BLAXTER, 1990; NHFA, 1990; MARTINS, 1996; DUNCAN, 1993; LOLIO, 1993; MOREIRA, 1995; LIS \& COUTINHO, 1993). Além disso, conforme observamos em outro bloco dessa investigação, os homens vão a médicos, fazem exames e procuram diversos tipos de tratamento, desde clínica geral, psicoterapia até os ditos alternativos, em proporçōes nitidamente inferiores às mulheres (GRUPO TÉCNICO CASSI-PESQUISAS EPIDEMIOLÓGICAS, 1996). Quanto aos diferenciais de doença entre homens e mulheres, Macintyre (1996) chama atenção para a revisão necessária do padrão em que se acreditava, no qual o excesso de doença era geralmente atribuído às mulheres. Profundas modificações na participação de homens e mulheres na educação, emprego, lazer e vida doméstica teriam contribuido, nas últimas décadas, para que os homens apresentem maior frequência de enfermidades graves, que podem encurtar a vida, enquanto as mulheres apresentam mais condições ligadas a sintomas psicológicos e condições menos sérias (MACINTYRE, 1996). As teorias a respeito dos diferenciais de condições de saúde entre homens e mulheres ainda estão 
longe de esgotar a questão, sendo no entanto condição essencial para o entendimento da distribuição de saúde e doença na população.

A possibilidade da maternidade $\mathrm{e}$ todas as questões femininas a ela relacionadas, como a menstruação, com sua periodicidade fixa, podem contribuir para que a mulher seja sistematicamente "lembrada de seu corpo". Toda mulher, desde menina, aprende a observar se seu corpo está "funcionando bem", pelo menos uma vez por mês. No entanto, estaríamos simplificando demasiadamente a questão se reduzíssemos apenas à físiologia, as raizes das distintas condutas diante do ato de cuidar-se. Tais diferenças têm sido relacionadas também aos papéis determinados, pela sociedade, a homens e mulheres, concedendo a essas o papel de cuidar de si e da família, enquanto ao homem não é permitido "fraquejar". Adoecer é sinônimo de derrota, uma vez que a doença prejudica e até impede o trabalho, valor maior que assegura inserção social, respeitabilidade, além da sobrevivência e consumo (GRUPO CASSI-PESQUISAS EPIDEMIOLÓGICAS, 1996). A construção da identidade masculina reforça aspectos relacionados à racionalidade, por oposição a sentimentos e emoções, identificados como reações femininas: "ser homem significa ser capaz de esquecer que se tem um coração e um corpo" (grifo nosso) (CORNEAU, 1995; SEIDLER, 1987).

Considerar a influência da idade na distribuição dos fatores de risco não é tarefa simples já que ela representa diferentes dimensões. Grupos mais velhos são diferentes dos mais jovens por dois conjuntos de motivos: por efeito do envelhecimento (efeito idade) e por efeito de coorte, que significa que cada geração atravessa diferentes periodos históricos. Assim, diferenças entre grupos etários refletem tanto fatores biológicos como histórias culturais e individuais. A ocorrência simultânea de fatores de risco parece aumentar com a idade, pelo menos até os 50 anos de idade (DUNCAN, 1993; MOREIRA, 1996), enquanto cada fator, considerado isoladamente, apresenta comportamento específico.

A influência da escolaridade também tem sido apontada de forma consistente, na distribuição dos fatores de risco entre os diversos grupos da população. Aqueles com maior escolaridade fumam menos, praticam atividade fisica 
com maior frequência e apresentam dieta mais saudável (UITENBROEK, 1996; RAITAKARI, 1995; LOLIO, 1993; BLAXTER, 1990). Quanto ao consumo de álcool, os resultados diferem, já que em alguns estudos a prevalência é maior entre os de maior escolaridade (UITENBROEK, 1996; LIZ \& COUTINHO, 1993) enquanto em outros, o contrário é relatado (MARTINS, 1995). Maior escolaridade tem sido considerada também como fator protetor contra o "cluster" de fatores de risco (RAITAKARI, 1995). Em relação à situação de ocupação, os desempregados têm sido apontados como um grupo onde o "cluster"de fatores de risco é mais frequente (UITENBROEK, 1996).

Além das explicações que enfocam diferenças de gênero e sócio-econômicas, o nível de auto-cuidado e atenção com as questões relativas à saúde também tem sido associados a diferentes estilos de vida, e à predição de mortalidade por todas as causas (RAITAKARI, 1995). De acordo com esse enfoque, grupos que se importam mais com sua saúde no presente e no futuro, se comportariam de maneira mais prudente. As diferentes explicações se completam ao invés de se excluirem, já que por exemplo, as mulheres e os grupos de maior escolaridade exibiriam hábitos mais saudáveis não só por questões sociais mas também por serem mais atentos a questões relacionadas com a saúde.

Nesta investigação, os homens apareceram nitidamente associados a comportamentos de risco em relação à dieta, fumo e consumo de álcool, enquanto a prevalência de sedentarismo foi semelhante em ambos os sexos. Quanto à idade, as tendências variaram. Enquanto o hábito de fumar, especialmente mais de 20 cigarros por dia, aumentou com a idade, a tendência do consumo de álcool não foi tão nítida. A prática de atividades físicas por outro lado, diminuiu com a idade em uma das dependências, enquanto os funcionários mais jovens, especialmente os homens, apresentaram a dieta menos saudável. Essas variações tornaram-se mais nítidas através da análise de correspondência, onde uma parcela dos funcionários mais jovens, entre 20 e 29 anos, aparece associada a comportamentos saudáveis e outra parcela a hábitos de risco dos diferentes fatores. 
Os resultados de outros estudos em relação à escolaridade foram confirmados nessa investigação, embora se trate de grupo muito homogêneo, com poucos funcionários sem curso superior. Também entre os bancários, a ocorrência simultânea de fatores de risco está associada a menor escolaridade, assim como o hábito de fumar mais de 20 cigarros por dia.

\section{3- MUDANÇAS DE COMPORTAMENTO: UMA QUESTÃO CONTEMPORANEA}

Parece não haver mais dúvida de que os niveis de pressão arterial e o hábito de fumar são preditores da mortalidade por todas as causas (KORNITZER \& GOLDBERG). Além desses dois fatores, também o colesterol sérico, que na maioria das vezes está elevado em função da dieta, prediz a mortalidade por doença coronariana. Álcool e obesidade, por outro lado, estão associados à ocorrência de doenças cerebrovasculares, através da elevação dos níveis tensionais. De acordo com esse quadro de determinação, Rose (1992) afirma que "a ocorrência da maioria das doenças está relacionada com o que as pessoas comem e bebem, com suas atividades diárias, e a seu ambiente físico e social". Assim, sua prevenção ou pelo menos seu aparecimento mais tardio, poderia ser realizada através da redução dos fatores que seriam passíveis de modificação

Mann e colaboradores (1993) apontam três requisitos básicos para o sucesso na prevenção da aids que, como veremos mais adiante, apresenta importantes traços em comum com as doenças cardiovasculares. Em primeiro lugar, informação e educação, seguidos de serviços sociais e de saúde, e por fim, um ambiente social adequado. Se comparados ao conjunto da população brasileira, os bancários apresentam nível elevado de escolaridade, dispõem de trabalho e moradia (a maioria reside em imóvel próprio quitado ou não), bem como diversos serviços sociais como empréstimo para compra da casa própria, auxílio para compra de medicamentos, enfermagem domiciliar, próteses e transporte de emergência em unidades de terapia intensiva. Quanto aos serviços de saúde, os desafios contemporâneos estão colocados Se, por uma lado, dispõem de ampla oferta de profissionais e instituições 
credenciadas, e portanto subsidiados pela Caixa de Assistência, essa pulverização dificulta a implantação de programas especificos, se a assistência tivesse a lógica de priorizar problemas coletivos de saúde. A hipertensão arterial, por exemplo, deveria ser objeto de atenção em todas as oportunidades de contacto com os serviços, constituindo uma verdadeira "busca ativa" de casos para tratamento e controle. Ao invés disso, identificamos boa parcela de funcionários que nunca tomaram conhecimento de seus níveis tensionais elevados e, o que é mais surpreendente, apenas $50 \%$ daqueles informados, declararam estar em tratamento. Esses resultados sugerem que mesmo nesse grupo altamente diferenciado do restante da população, a racionalidade dos gastos com saúde é a mesma: assistência pura e simples, sem preocupação com estratégias coletivas de controle, comprovadamente eficazes.

De acordo com os três requisitos básicos citados por Mann (1993), os bancários parecem apresentar bons antecedentes para a implantação de programas multifatoriais de redução dos fatores de risco (multifatoriais em oposição a estratégias isoladas anti-fumo ou de controle de peso, por exemplo). Apesar dessas boas condições, é preciso considerar outros tópicos que vem sendo discutidos, não só em relação às doenças cardiovasculares, mas também a propósito da aids, e de outros acontecimentos recentes como a encefalopatia espongiforme bovina (EEB). Trata-se dos aspectos ligados à compreensão dos determinantes do comportamento humano. Diversos estudos têm demonstrado que educação, informação e acesso a bens e serviços não são suficientes para causar e manter mudanças de hábitos e atitudes relacionadas à saúde (ROSE, 1992; MARMOT, 1996). Nesta investigação por exemplo, cerca de $100 \%$ dos bancários associou os principais fatores de risco a maior chance de doenças do coração. No entanto, profundas alterações de comportamento, com graves consequências econômicas, ocorrem em situações inesperadas, como nos dez casos da doença de Creutzfeldt-Jakob, "possivelmente" relacionados à EEB. O número reduzido de casos assim como a ausência de "certeza científica" de associação entre as duas doenças não justificariam, à primeira vista, a drástica redução de consumo da carne de vaca. Tal mudança de comportamento não havia ocorrido após mais de uma década de comunicações sobre a associação entre consumo de gordura e 
doenças responsáveis por boa parte da mortalidade britânica, como o câncer de mama e as enfermidades cardiovasculares (MARMOT, 1996).

É consensual a influência de determinantes coletivos do comportamento da população como preço de produtos, disponibilidade, propaganda, e a atitude da sociedade em relação a determinada conduta. Existe, portanto, uma inter-relação profunda entre atitudes individuais e coletivas, que se manifesta também através dos números. Baseando-se nos resultados de 52 grupos populacionais, relativos a 32 países, Rose (1992a) estimou alto coeficiente de correlação entre o comportamento de cada população e seus "desviantes". Assim, dada a média de pressão arterial de determinado grupo populacional, é possível prever a prevalência de hipertensão arterial naquele grupo. De forma semelhante, a prevalência de obesidade é função do peso médio populacional, o número de consumidores excessivos de álcool é previsto de forma precisa através do consumo médio de álcool, e o mesmo foi observado em relação ao consumo de sal. Não é possível, portanto, separar sociedade e "desviantes", já que "um pertence ao outro, goste a sociedade ou não" (ROSE, 1992a). Esses resultados não são tão óbvios quanto podem parecer à primeira vista já que contradizem o senso comum, que atribui a responsabilidade do "desvio" somente ao indivíduo, sem que nenhuma parcela seja compartilhada com o grupo social. Seja o "desvio" representado pelo consumo excessivo de álcool, pela obesidade, ou mesmo pela hipertensão, o status individual também depende dos conceitos de normalidade $\mathrm{e}$ comportamentos socialmente desejáveis existentes naquele grupo social. As implicações dessa idéia nas estratégias que visam mudanças de comportamento populacional são imediatas, porque revelam a inter-relação entre os indivíduos. De fato, sub-grupos populacionais que compartilham situações de vida semelhantes constituem verdadeiras "redes sociais", que conforme explicitadas por Castiel (1996a), exibem relações que influenciam idéias, normas e condutas.

No entanto, a dimensão social do problema não parece esgotar a questão, faltando compreender o caráter não racional das escolhas de comportamento, especialmente quando se trata do prazer, seja ele ligado ao hábito de fumar, beber, comer ou à vida sexual (CASTIEL, 1996a; MARMOT, 1996). Estilos de vida resultam da "mescla complexa de elementos ditos biopsicosociais (ou relativos a 
corpolmentelsociedade)" (CASTIEL, 1996a) onde resultados de trabalhos científicos apontam efeitos a longo prazo, quando não se tem nenhuma garantia de ainda estar vivo, demandando modos de pensar elaborados e complexos. É evidente que determinados comportamentos são perigosos, seja para o próprio indivíduo, ou para aqueles que o cercam, demandando intervenções apropriadas. No entanto, se não levarmos em consideração também essa dimensão, é possível que nos tornemos reguladores do que deve ou não ser feito para que se leve uma "vida saudável" verdadeiros vigilantes do prazer alheio-, culpando aqueles que não a escolhem, e ainda com grande chance de nos frustrarmos na tarefa de promover a saúde da população (FRANKENBERG, 1994). Esse modo de perceber escolhas individuais de hábitos e comportamentos, com o olhar voltado para determinantes que fazem parte do mundo objetivo, mas também aqueles subjetivos, do mundo dos símbolos, é ainda mais adequado em uma sociedade em que somos ensinados a fugir da idéia da morte, que torna-se longínqua, e só ocorre com o outro. Uma sociedade onde alertas sobre risco convivem com estímulos para o consumo de tabaco, álcool e comida industrializada, criando um ambiente onde duplas mensagens têm que ser processadas, na maior parte do tempo. Desse ponto de vista, pretender lidar com mudanças de comportamento de grupos populacionais torna obrigatória a compreensão e integração do conjunto de aspectos que constituem a experiência humana, onde os indivíduos se movem, aparentemente, sem muita coerência, e que nem sempre cabem ou tomam a forma do raciocínio científico.

\section{4- PARA ALÉM DE UM DIAGNÓSTICO: DE COMO TRANSFORMAR NOSSO CONHECIMENTO EM AÇÃO}

Ao considerarmos a ocorrência de doenças em indivíduos específicos, ou a distribuição das enfermidades no conjunto da população, duas abordagens são necessárias. Diferenças de risco entre indivíduos são principalmente determinadas por susceptibilidades genéticas distintas. Embora seja possível, por exemplo, diminuir os níveis de colesterol de um portador de hipercolesterolemia (geneticamente determinada), através de mudanças alimentares, seus valores permanecerão, provavelmente, entre os mais elevados do grupo populacional a que pertence (ROSE, 
1992b). Por outro lado, diferenças de risco (taxa de incidência) entre grupos populacionais são modeladas segundo condições do ambiente social, por hábitos e comportamentos prevalentes: estudos com migrantes que passam a apresentar taxas de incidência semelhantes às taxas do país de adoção são casos exemplares.

A distinção entre risco individual e populacional se faz necessária já que no caso da susceptibilidade individual, os meios para alterá-la não estão disponíveis (mesmo que inúmeros cientistas venham explorando essa possibilidade). Hábitos e comportamentos, por outro lado, são passíveis de modificação, e embora todas essas condições sejam denominadas fatores de risco, possibilidades completamente diferentes são apresentadas, do ponto de vista das ações de saúde pública.

Os dois níveis de abordagem do risco de ocorrência de doenças -individual e populacional- têm sua contrapartida nas estratégias de prevenção. A abordagem individual busca identificar e alterar o estilo de vida daqueles que apresentam tanto maior susceptibilidade genética quanto hábitos de risco. A estratégia populacional constitui uma tentativa de lidar com as causas de doenças de massa, e por isso mesmo devem visar atingir o conjunto da população.

Ambas as abordagens não se excluem mas são complementares, já que a classificação da população em "doentes" e "não doentes" é o resultado de pontos de corte arbitrários numa escala que é contínua (ROSE, 1992b). De fato, nas populações do Ocidente, praticamente todos os indivíduos são portadores de algum grau de hipertensão arterial e doença coronariana, sendo a diferença de carater quantitativo e não qualitativo (doentes $x$ não doentes) (ROSE, 1992 b). Não foi possível, por exemplo, identificar um limiar crítico dos principais fatores de risco, abaixo do qual o risco de doença "não existe". O que foi possível demonstrar é que quanto mais baixos os níveis de pressão arterial, colesterol, quantidade de cigarros consumidos (ROSE, 1986) e também de peso corporal (MEISLER, 1996) menor o risco de doenças cardiovasculares, a longo prazo. Os resultados do estudo de Whitehall, com funcionários públicos ingleses, ilustra esta afirmação (REID, 1976). Naquela investigação, um escore de risco foi calculado para cada participante, baseado nos níveis de colesterol, pressão arterial e hábito de fumar. Se, por um lado, o grupo 
incluído no decil de risco superior apresentou mortalidade dez vezes maior por doença coronariana, e trinta vezes maior por doenças cerebrovasculares do que os individuos que apresentaram os menores escores, a doença coronariana foi ainda a principal causa de morte no grupo incluído no decil de risco inferior. Assim, se foi possivel separar os indivíduos de alto risco, o mesmo não ocorreu em relação aos de baixo risco.

Estratégias baseadas na identificação e intervenção em grupos de alto risco necessitam da avaliação de custo-beneficio, que varia de acordo com o fator específico. No caso do colesterol, resultados baseados no estudo de Framingham demonstraram que a maior parte dos casos de doença coronariana devidos ao excesso de risco associado a esse fator, não ocorreram entre portadores de hipercolesterolemia, mas entre a grande maioria de indivíduos que apresentam níveis situados ao redor ou pouco acima da média (WHO, 1982). Por outro lado, os riscos de doenças cardiovasculares associados à elevação dos niveis de pressão arterial estão mais concentrados no final da distribuição do que no caso do colesterol. Também no estudo de Framingham demonstrou-se que cerca de $50 \%$ do excesso de casos de doenças cerebrovasculares associados à hipertensão arterial ocorreram entre $16 \%$ da população que apresentava maiores níveis de pressão diastólica (>100 mmHg) (Royal College of Physicians, 1989; apud ROSE, 1992 b). Isso significa que, de maneira geral, pode-se esperar melhores resultados de um screening para identificação de hipertensos do que de portadores de hipercolesterolemia.

A melhor predição de risco é, no entanto, obtida através de "screening" multifatorial, já que tanto a doença coronariana quanto as cerebrovasculares são determinadas por múltiplos fatores. No estudo de Whitehall, $42 \%$ da mortalidade por doença coronariana, acompanhada ao longo de 15 anos, ocorreu no quintil superior do escore de risco multifatorial (pressão sistólica, colesterol e fumo) (REID, 1976). Naquele caso, o "screening" desses três fatores de risco demandaria intervenção em $20 \%$ da população (quintil de maior risco), o que poderia melhorar as condições de $42 \%$ dos candidatos a doença coronariana.

Apesar das justificativas lógicas e científicas, os beneficios da estratégia de alto risco são limitados por questões de efetividade, viabilidade e custo. Não existem recursos para sua implementação na população geral e sua viabilidade, a longo prazo, não é conhecida. No entanto, no ambiente de trabalho, parece bastante factivel a 
implementação de um screening que priorize hipertensão arterial, niveis de colesterol sanguíneo e hábito de fumar. De fato, não é possivel justificar que apesar do conhecimento científico já acumulado, empresas gastem enormes quantidades de recursos exclusivamente com atividades assistenciais. Trata-se de planejar um "screening" dirigido aos principais fatores de risco, voltado para subsidiar a implementação de um programa de promoção de saúde cardiovascular, levando em consideração as condições listadas por Rose (1992 b):

1- O "screening" só deve ser realizado se houver recursos para acompanhamento e tratamento do grupo de alto risco, já que classificar como "doentes", indivíduos que se consideravam saudáveis, exige a disponibilidade desses recursos.

2- O "screening" deve ser aplicado a sub-grupos da população para elevar seu custoefetividade. Embora ao considerarmos a população geral, esse princípio se justifique, consideramos que toda a população deve ser examinada no ambiente de trabalho onde a seleção prévia em termos de faixa etária e outras condições já ocorreram.

3- "Screening" para doença multifatorial deve ser multifatorial. Já que o risco associado a cada fator isolado depende da coexistência dos outros fatores, isto é, depende também das outras características do indivíduo, ... “devemos buscar a identificação do risco e não do fator de risco".

4- 0 quarto princípio é consequência do terceiro: a prevenção de uma doença multifatorial deve ser também multifatorial, já que os fatores de risco interagem. Assim, ajudar um hipertenso a parar de fumar pode ser tão importante quanto tratar a hipertensão propriamente dita.

Uma vez feito o diagnóstico, apresenta-se o maior desafio que é a implantação de estratégias de controle, detecção precoce e prevenção. As duas abordagens devem ser utilizadas: ações relativas ao grupo de alto risco -funcionários hipertensos ou com niveis altos de colesterol ou que fumam-e também relativas ao conjunto da população. Embora as doenças cardiovasculares constituam o foco desse estudo, estratégias de promoção da saúde no ambiente de trabalho podem abranger, ao mesmo tempo, outras enfermidades cuja prevenção também está relacionada a hábitos e comportamentos, como por exemplo, a aids. A forma de abordar esse conjunto de doenças, 
aparentemente heterogêneo, é um desafio que uma vez superado, pode favorecer a implantação de ações de saúde no ambiente de trabalho.

Em relação ao grupo de alto risco, os médicos da empresa, muitas vezes responsáveis apenas pelo exame de saúde periódico e pela concessão de licenças devem ser envolvidos e treinados. Esse treinamento consistiria na discussão da importância da hipertensão em termos de incidência e mortalidade, em nosso país, (foi também a enfermidade mais citada, pelos bancários, entre parentes consanguíneos), o que a torna prioritária para programas de promoção da saúde no ambiente de trabalho, tendo em vista a faixa etária de grupos econômicamente ativos. Além disso, seriam discutidos critérios padronizados de classificação do grupo de risco, e também da conduta a ser adotada em cada caso, na dependência dos níveis de pressão arterial, de colesterol , e outras características individuais (medidas que visem melhoria do estilo de vida através do controle de peso, atividade física e dieta específica, e ainda a necessidade da utilização de medicamentos). Consideramos importante o envolvimento dos médicos da empresa pela facilidade do acesso aos funcionários, pelo conhecimento da dinâmica interna daquele grupo e também pela possibilidade de participarem de outras atividades de controle e prevenção, envolvidas no programa elaborado. No entanto, o envolvimento desses profissionais depende de seu desejo de participar. Muitas divisões médicas de empresas têm sido pouco aproveitadas em função da ênfase nos serviços conveniados, e assim, o aumento do volume de trabalho desses profissionais pode ser um impedimento à sua participação. $\mathrm{Na}$ ausência do desejo de participar, a relação médico-paciente não ocorre, e a adesão do funcionário a qualquer programa estaria fortemente ameaçada.

Além dos médicos da empresa, os companheiros de trabalho e a família também devem ser envolvidos, utilizando-se a idéia de rede social de apoio. Os indivíduos se comportam de acordo com seu grupo social, e poucos se afastam muito das normas de comportamento adotadas pelo conjunto a que estão vinculados (ROSE, 1992b). Trata-se então de não excluir o hipertenso do grupo, não estigmatizá-lo, não "vigiá-lo", mas informar a companheiros e à família, que todos nós apresentamos algum grau de hipertensão e hipercolesterolemia, em função dos hábitos prevalentes em nossa sociedade, e que portanto, mudanças de hábitos e comportamentos trazem benefícios 
não só para o hipertenso, mas também para o conjunto do grupo, através da melhoria da qualidade de vida.

Múltiplas abordagens devem ser adotadas para o conjunto de funcionários, buscando-se não restingí-las a velhas fórmulas de "campanhas anti-fumo" ou de "educação em saúde" (como uma catequização). Inúmeras empresas têm investido recursos em treinamentos de "Qualidade Total", cuja dinâmica inclui a discussão de tópicos como qualidade de trabalho e qualidade de vida, o que favorece a vinculação entre essas questões e condições de saúde. O que se deseja, em última análise é "mudar a percepção do que é normal e socialmente desejável' (ROSE, 1992b), como única forma de garantir não só mudanças de comportamento, mas o que é mais difícil, sua manutenção. Uma vez que reconhecemos a importância do grupo social no estilo de vida adotado por cada um, não podemos nos eximir de abordar os hábitos do grupo, restringindo-nos apenas a "convencer" indivíduos de alto risco a mudar. Se o grupo a que pertencem tem o costume de "sair para beber" diariamente, após o trabalho, como única forma de socialização, tentativas de mudança de estilo de vida precisam incluir a discussão desse hábito do grupo. Como se trata de uma questão delicada, exige abordagem cuidadosa, que não pode assumir ares moralistas, de vigilância ou regulação das horas de lazer. No entanto, não podemos fazer de conta que essas questões não dizem respeito a todos os profissionais de saúde, antes de mais nada como cidadãos, mas também como especialistas. As doenças de maior prevalência e/ou que mais preocupam a sociedade nos apresentam o desafio de discutir os limites entre escolhas individuais e determinações coletivas do comportamento humano, já que como tentamos demonstrar, poucos indivíduos se afastam muito das normas de conduta de seu grupo social. Assumindo a premissa de que a escolha (quando é possivel fazê-la) de estilos de vida "não resultam apenas de disposições intencionais, racionais $e$ voluntárias", nossa abordagem não pode ser a de culpar, mas informar "para refletir" e não "para fazer cumprir", "sob o risco de serem implantadas ações insensiveis, limitadas, e provavelmente de efetividade restrita" (CASTIEL, 1996b).

Em relação aos procedimentos médicos adotados para o conjunto de funcionários, todos os profissionais de saúde, sejam aqueles da divisão médica da empresa ou os credenciados por Caixas de Assistência devem ser conscientizados de 
que dentre todas as enfermidades crônicas que acometem grupos populacionais econômicamente ativos, a hipertensão arterial é a mais frequente, a que apresenta consequências mais graves, e cujo diagnóstico precoce e tratamento não demandam tecnologia sofisticada. Assim, dependem muito mais da aplicação do raciocínio clínico, critérios de classificação atualizados e da vinculação afetiva com o paciente, que terá que ser acompanhado pelo resto de sua vida. Assim, a medida dos níveis tensionais em todos os contactos do funcionário com o servico de saúde, seja qual for o motivo da consulta, precisa tornar-se (ou voltar a ser) parte obrigatória do atendimento dos funcionários de qualquer empresa. $\mathrm{O}$ envolvimento de médicos e serviços credenciados, tanto nas atividades voltadas para grupos de alto risco como para o conjunto da população, é essencial, em função do grande volume de atendimentos que prestam. Assim, é razoável pensar em incluí-los em programas de promoção da saúde no ambiente de tratalho através do envio de correspondência e da solicitação de informações sobre quantidade de diagnósticos de hipertensão arterial, tratamento utilizado, enfim, pensar sobre o intercâmbio entre a empresa e prestadores de serviços médicos, que contribua para a implantação de programas de saúde que considerem aquele conjunto de indivíduos como um grupo específico, cuja abordagem deve ser também coletiva e não somente individual.

Mudanças de comportamento dependem também da oferta de alternativas. Nesse caso, o envolvimento dos setores de decisão da empresa é fundamental, através do tipo de alimentação oferecida, do incentivo a atividades físicas e da discussão da implantação de áreas onde o fumo seja proibido. Atividades ditas alternativas como exercícios para relaxamento e meditação, têm sido adotadas por algumas empresas, e efeitos positivos vêm sendo apontados em relação aos hipertensos (MARMOT, 1993). No caso do Banco do Brasil, encontramos a opção de "dieta de baixa caloria" e ampla oferta de saladas e legumes no prédio que concentra o maior número de funcionários do Rio de Janeiro (Agência e Cesec Centro), mas em outras dependências, havia apenas cantinas com oferta de lanches rápidos. Além disso, o fumo é permitido em todas as dependências onde o questionário foi preenchido, desde agências abertas ao público, até os Cesec's onde a circulação de ar é ainda menor. 
Embora reconhecendo a dificuldade de implementar mudanças de comportamento, é possível perceber ambiente mais favorável a estilos de vida saudáveis, em função da maior divulgação do conhecimento científico, cujos efeitos se fazem sentir em campanhas anti-fumo, propagandas de alimentos com baixos níveis de colesterol e disponibilidade de alimentos sem açúcar, embora ainda convivendo com campanhas milionárias que incentivam o hábito de fumar e de consumir bebidas alcoólicas. Sabemos ainda muito pouco a respeito do que determina mudanças de comportamento na população, e assim, é preciso desenvolver uma "tecnologia" nacional em relação a formas de lidar com o comportamento de grupos sociais, reconhecendo a experiência acumulada em outros países, mas levando em conta também as peculiaridades existentes em cada população e seus sub-grupos. Aliás, como profissionais de saúde pública, não podemos abrir mão desse espaço, sob pena de assistirmos grupos privados especializados em "melhorar a auto-estima" se ocuparem da saúde coletiva. Compreender o comportamento humano é essencial para lidarmos com as doenças cardiovasculares, aids ou neoplasias, entre outras enfermidades. Pesquisar sua etiologia, compreender sua determinação e modo de transmissão não são nossas únicas tarefas. Transformar nossas idéias em programas de saúde que melhorem a qualidade de vida e diminuam a chance de adoecer constituem também nosso compromisso. 


\section{5- CONCLUSÕES}

1- A estratégia de condução da pesquisa - propaganda, agendamento da data de aplicação, equipe de aplicadores composta por funcionários do Banco e envolvimento das instituições assessoras- garantiram a participação de quase todos os funcionários: $89,5 \%$ dos sorteados na Direção Geral e $96,4 \%$ nos Cesec's.

2- Homens e mulheres apresentaram diferenças em relação às variáveis sóciodemográficas. Os funcionários do sexo masculino dos Cesec's eram mais jovens (idade média $=36,9$ anos) do que as mulheres dessas dependências (idade média $=39,1$ anos), e também em relação aos funcionários da Direção Geral (homens: idade média $=38,7$ anos e mulheres: idade média $=38,9$ anos). As mulheres apresentaram maior nível de escolaridade em ambas as dependências: $78,5 \%$ na Direção Geral e 66,8\% dos Cesec's tinham curso superior completo, comparadas a $64,7 \%$ e $47,2 \%$ dos homens, respectivamente. A maior parte dos funcionários de ambos os sexos estava casada (ou em união consensual), mas a proporção de mulheres separadas ou viúvas foi cerca de duas vezes maior do que a mesma proporção de homens. Não houve diferença entre as médias salariais de homens e mulheres, enquanto a renda per capita foi maior entre as mulheres.

3- Diferenças importantes no perfil de risco cardiovascular não foram observadas entre os dois tipos de dependências -Direção Geral e Cesec's-, ao contrário do que se verificou em relação ao sexo. Os homens constituíram grupo de maior risco, considerando-se hábitos e comportamentos, e também a prevalência de hipertensão arterial, sobrepeso/obesidade e hipercolesterolemia.

4- A prevalência do hábito de fumar foi semelhante em ambos os sexos, em ambos os tipos de dependências. Comparando-se nossos resultados a outros estudos nacionais, os bancários do sexo masculino apresentaram menor prevalência de tabagismo, enquanto as estimativas para o sexo feminino foram semelhantes a outras investigações. Assim, o perfil do hábito de fumar se aproximou ao de países desenvolvidos, onde a diferença entre as prevalências de homens e mulheres é pequena, ao contrário de populações pobres, onde maior proporção de homens é fumante. Quanto à quantidade de cigarros 
consumidos diariamente, os homens da Direção Geral apresentaram nítido predomínio sobre as mulheres dessa dependência, o que não se verificou nos Cesec's, onde a diferença entre os sexos foi menor.

5- A proporção de grandes fumantes aumentou com a idade, comparando-se o grupo entre 20 e 34 anos com as demais faixas etárias. Sugerindo a mesma tendência, a grande maioria dos mais jovens nunca fumaram, enquanto entre os mais velhos -especialmente homens- pequena proporção nunca foi exposta diretamente ao fumo. Ressalvando-se diferenças de idade e ainda o pequeno contingente de funcionários que não completou o segundo grau, a proporção de grandes fumantes aumentou a medida que o grau de escolaridade diminuiu.

6- A frequência de consumo de bebidas alcoólicas foi nitidamente maior entre os homens, já que mais da metade da população masculina bebe diáriamente ou semanalmente, enquanto menos de $30 \%$ das mulheres apresentam essa frequência. Não se observaram diferenças importantes entre os grupos etários, exceto o grupo mais jovem -entre 20 e 34 anos- cujo consumo diário foi menos frequente, em ambos os sexos.

7- Não houve diferença entre a prevalência de atividades físicas de lazer entre homens e mulheres, e a maior parcela de funcionários (acima de metade), de ambos os sexos, não as pratica. Mesmo assim, a parcela de bancárias que pratica atividades físicas é bem maior do que outros grupos femininos, enquanto os funcionários do sexo masculino apresentam prevalência semelhante a outros grupos populacionais do país. Observou-se tendência à diminuição da prevalência desse hábito com a idade, em um dos tipos de dependências -os Cesec's- o que não se verificou na Direção Geral. Entre aqueles que praticam atividades físicas a frequência semanal é alta, já que cerca da metade se exercita cinco ou mais vezes por semana.

8- Os bancários apresentaram bons hábitos alimentares, com baixa frequência de consumo de alimentos ricos em colesterol, gorduras saturadas ou sal, com exceção de frituras, refrigerantes não dietéticos, açúcar e manteiga. O consumo alimentar variou, de maneira importante, entre os sexos e também de acordo com a idade dos funcionários. 
Os homens apresentaram maior consumo de alimentos menos saudáveis, o que também ocorreu entre os funcionários mais jovens ( 20 a 29 anos de idade), de ambos os sexos.

9- Dentre os fatores de risco estudados, o Índice de Massa Corporal foi um dos que apresentou diferenças mais relevantes, ao compararmos homens e mulheres. Enquanto cerca da metade dos homens foi classificada como obeso ou com sobrepeso, essa prevalência foi menor do que $20 \%$ entre as bancárias. Assim, o padrão de distribuição de sobrepeso e obesidade encontrado entre os bancários foi semelhante ao de países desenvolvidos, onde a prevalência é maior no sexo masculino. A prevalência de sobrepeso e obesidade também aumentou de acordo com a idade, em ambos os sexos. Esses resultados não parecem ser explicados por subestimação ou superestimação sistemática de peso ou estatura, já que a comparação entre os valores de peso e estatura medidos e informados sugerem que as informações contidas no questionário são válidas.

10- Cerca de $30 \%$ dos homens e de $20 \%$ das mulheres que mediram alguma vez seu nível de colesterol sanguíneo, já foram informados de que esses estavam elevados. No entanto, o alcance desse resultado é limitado pela proporção de homens com menos de 40 anos de idade, que nunca dosaram o colesterol (cerca de $50 \%$ ), e também pela baixa sensibilidade da informação acerca da colesterolemia relatada em estudos recentes, quando comparada à medida direta. Assim, essa medida seria necessária para estimar a prevalência real de hipercolesterolemia, por evitar perda de informação daqueles que nunca mediram, por garantir critério padronizado de classificação de nível alto ou normal, e também para validar a informação do questionário.

11- A classificação de hipertensão arterial realizada através do questionário não é rigorosamente comparável à classificação obtida através da medida direta dos níveis tensionais, já que na primeira, questões relativas ao diagnóstico médico e à aceitação do indivíduo de seu status de hipertenso são determinantes, enquanto na segunda, critérios de pesquisa são utilizados. Mesmo assim, a medida direta foi utilizada como padrãoouro, e através dessa comparação foi possível concluir que a classificação baseada no questionário apresenta baixa proporção de falsos positivos (funcionários classificados errôneamente como hipertensos), mas alta proporção de falsos negativos (funcionários 
classificados errôneamente como não hipertensos). Por outro lado, os niveis dos valores preditivos negativo e positivo permitem concluir que boa parcela da classificação de hipertensão baseada no questionário foi confirmada através da medida, possibilitando a estimativa de prevalências mínimas e a avaliação da distribuição dos outros fatores de risco entre hipertensos e não hipertensos. Nesse sentido, podemos concluir que o diagnóstico de hipertensão não parece determinar a adoção de hábitos de vida mais saudáveis ou o controle do peso, sugerindo que o controle da hipertensão arterial não vem sendo realizado de maneira adequada, o que é confirmado pela proporção de funcionários que não estão sob tratamento: cerca de $50 \%$ dos homens e $40 \%$ das mulheres informados mais de uma vez de que têm hipertensão.

12- A população estudada reconhece os principais fatores de risco para doenças do coração apontados pela literatura -fumo, hipertensão, hipercolesterolemia-, embora mais da metade dos funcionários não associe o diabetes à ocorrência daquelas enfermidades.

13- Dentre as doenças apontadas entre parentes consanguíeos, a hipertensão arterial foi a mais frequente.

14- Existe padrão de aglomeração de hábitos e comportamentos mais saudáveis por um lado, e dos menos saudáveis por outro, caracterizando estilos de vida diversos. Funcionários classificados como grandes fumantes, por exemplo, têm maior probabilidade de consumirem álcool frequentemente e também dieta rica em colesterol, gorduras saturadas e sal, e serem sedentários. Não fumantes, por outro lado, estão associados a hábitos mais saudáveis. A maior parcela dos funcionários apresenta, no entanto, padrão misto de comportamento, com um ou alguns dos fatores de risco, nem sempre no maior grau de intensidade. Ser homem ou ser mulher determina padrões típicos de comportamento: os primeiros estão associados aos hábitos menos saudáveis, e os comportamentos mais saudáveis são mais frequentes entre as bancárias. Além do sexo, o nível de escolaridade também diferenciou grupos de risco: funcionários que apresentaram os quatro fatores -hábito de fumar, consumo diário ou semanal de álcool, sedentarismo e quarto ou quinto quintis de dieta - têm menor escolaridade do que o grupo que não apresenta nenhum dos fatores. Os funcionários mais jovens -entre $20 \mathrm{e}$ 
29 anos de idade- têm maior probabilidade de não fumar e praticar atividades físicas, mas também de consumir dieta rica em colesterol, gorduras saturadas e sal, enquanto aqueles de 40 a 44 anos estão associados a maior consumo de cigarro e álcool. Os efeitos "biológicos" também apresentaram padrão de aglomeração: hipertensão arterial, sobrepeso/obesidade e hipercolesterolemia ocorrem juntos, e também neste caso, associados aos funcionários do sexo masculino, além do grupo com mais de 45 anos de idade. 


\section{Referências Bibliográficas}

Abrams, D.B. \& Follick, M.J. Behavioral weight-loss intervention at the worksite: feasibility and maintenance. J. Cons. Clin. Psych. 1983;51:226-233

Achutti, A. \& Achutti,V.R. Fatores de risco para aterosclerose. Elementos para descrição da situação no Rio Grande do Sul. Arq. Bras. Cardiol. 1994; 63 (5): 427-431.

Albright, C.L. et al. Job strain and prevalence of hypertension in a biracial population of urban bus drivers. Am. J. Public Health 1992;82: 984-989.

Alderman, M.H. Academic medicine and the workplace. Am J Public Health. 1993;83:313314.

Alderman, M.H. Reduction of cardiovascular events by worksite hypertension treatment. Hypertension. 1983;5(suppl. 5):138-43.

Almeida, L.M. \& Coutinho, E.S.F. Prevalência de consumo de bebidas alcoólicas e de alcoolismo em uma região metropolitana do Brasil. Rev. Saúde Pública 1993, 27 (1): 23 29.

Anjos, L.A. Índice de massa corporal como indicador do estado nutricional de adultos: revisão da literatura. Rev. Saúde Públ. 1992;26 (6): 431-436.

Araújo, J.W.G. Hipertensão arterial em grupos sócio-ocupacionais de Volta Redonda, R.J. Rio de Janeiro, 1984. Tese de Mestrado - Escola Nacional de Saúde Pública/FIOCRUZ.

Baun, W.B. et al. A preliminary investigation of a corporate fitness program on absenteism and health care cost. J. Occup. Med. 1986;28:18-22.

Beaglehole, R. International trends in coronary heart disease mortality, morbidity, and risk factors. Epidemiol. Rev. 1990;12:1-15.

Berlin, J.A. \& Colditz, G.A. A meta-analysis of physical activity in the prevention of coronary heart disease. Am. J. Epidemiol. 1990;132(4):612-628.

Bertolami, M.C. et al. Perfil lipídico de funcionários de indústria metalúrgica e sua relação com outros fatores de risco. Arq. Bras. Cardiol 1993;60 (5): 293-298.

Bierman, E.L. Aterosclerose e outras formas de arteriosclerose in: Harrison, T.R. Medicina Interna. Rio de Janeiro, Guanabara Koogan, $10^{a}$ edição; 1988. pp. 1634-1645.

Blackburn,H. \& Luepker, R. Heart Diseases. in: Maxcy-Roseneau. Preventive Medicine and Public Health. Meredith Publishing Company, 1986. pp.1159-1193.

Blair, S.N.et al. A public health intervention model for the work-site health promotion. J. Am. Med. Soc. 1986;55:921-926. 
Blaxter, M. Health and Lifestyles, London e New York, Routledge, 1990, pp. 113-146.

Bloch, K.V. et al. Hipertensão arterial e obesidade na Ilha do Governador. Arq. Bras. Cardiol. 1994; 62 (1): 17-22.

Bourque L.B. \& Frelder E.P. How to conduct self-administered and mail surveys. California, Sage , 1995. pp.1-22

Bowlin, S.J. et al. Validity of cardiovascular disease risk factors assessed by telephone survey: the behavioral risk factor survey. J. Clin. Epidemiol. 1993;46 (6): 561-571.

Bray, G.A. Obesity: definition, diagnosis and disadvantages. Med. J. Australia 1995; 142(suppl.):52-58.

Browne, D.W.et al. Reduced disability and health care costs in an industrial fitness program. J. Occup. Med. 1984;26:809-816.

Brownell, K.D. et al. Weight loss competitions at the worksite: impact on weight, morale and cost-effectiveness. Am. J. Public Health 1984;74:1283-1285.

Brownson, R.C. et al. Reliability of information on chronic disease risk factors collected in the Missouri Behavioral Risk Factor Surveillance System. Epidemiology 1994;5(5):545549

Carvalho,M.S. Avaliação da Prática de Vigilância Epidemiológica nos Serviços Públicos de Saúde do Brasil. Tese de Mestrado - Escola Nacional de Saúde Pública/FIOCRUZ, 1990.

Cassel, J. The contribution of the social environment to host resistance. The fourth Wade Hampton Frost lecture. Am. J. Epidemiol.1976;104(2):107-123.

Castiel, L.D. (a) Força e Vontade: aspectos teórico-metodológicos do risco em epidemiologia e prevenção de HIV/AIDS. Rev. Saúde Pública 1996;30(1):91-100.

Castiel, L.D. (b). Vivendo entre exposições e agravos: a teoria da relatividade do risco (mimeo). Aceito para publicação em Manguinhos: História, Ciências, Saúde ,1996

Chor, D.et al (a). Doenças Cardiovasculares: Panorama da Mortalidade no Brasil. in: Minayo, C. Os muitos "Brasis": Saúde e População na década de 80. São Paulo-Rio de Janeiro, Hucitec, 1995. pp.57-86.

Chor, D. et al (b). Doenças cardiovasculares: comentários sobre a mortalidade precoce no Brasil. Arq. Bras. Cardiologia 1995;64(1):15-19.

Coitinho, D.C. et al. Condições nutricionais da população brasileira: adultos e idosos. Pesquisa Nacional de Saúde e Nutrição, Ministério da Saúde, Brasília, 1991

Corneau, G. Paternidade e Masculinidade. in: Nolasco, S. org. A desconstrução do Masculino. Rio de Janeiro, Rocco, 1995. pp.43-52 
Dawber, T.R. The Framingham Study. The epidemiology of atherosclerotic disease Cambridge, Harvard University Press, 1980.

Dean, A.G. et al. Epi Info, Version 5: a word processing, database, and statistics program for epidemilogy on micro-computers. Centers for Disease Control, Atlanta, Georgia, USA, 1990.

Dean, K. et al. Research on lifestyles and health: searching for meaning. Soc. Sci. Med. 1995;41(6)):845-855.

Dioguardi, G.S. et al. Fatores de risco para doenças cardiovasculares em médicos. Dados preliminares do projeto VIDAM da Associação Paulista de Medicina. Arq. Bras. Cardiol. 1994; 62(6):383-388.

Dressler, W.et al. Blood pressure, ethinicity and psychosocial resources. Psychosom. Med. 1986;48:509-19.

Duncan B.B. et al. Fatores de risco para doenças não transmissíveis em área metropolitana da região Sul do Brasil. Prevalência e simultaneidade. Rev. Saúde Pública 1993;27(1): 4348.

Dyer A.R. et al: Alcohol, cardiovascular risk factors and mortality: the Chicago experience. Circulation 1981;64(3 pt 2): 20-27.

Dwyer, J. Policy and healthy weight. Am. J. Clin. Nutr. 1996;63(suppl.): 4155-4185.

Epstein, F.H. The relatioships of lifestyle to international trends in CHD. Int. J. Epidemiol. 1989;18(3)(suppl 1):5203-5209.

Escola Nacional de Saúde Pública/FIOCRUZ. Mortalidade nas capitais brasileiras, 19301980. Radis.Dados 7, Rio de Janeiro, 1984; ano I, 2:1-8.

Farchi, G. et al. Is diet an independent risk factor for mortality ? 20 year mortality in the Italian rural cohots of the seven countries Study. Eur. J. Clin. Nutr. 1994; 48: 19-29.

Farquhar, J. et al. Effects of communitywide education on cardiovascular disease risk factors. The Stanford five-city project. JAMA 1990;264(3):359-65.

Fielding, J.E. Effectiveness of employee health improvement programs. J. Occup. Med. 1982;24(11):907-16.

Fielding, J.E. Health promotion and disease prevention at the worksite. Ann. Rev. Public Health 1984;5:237-65.

Fielding, J.E. Smoking: health effects and control. in: Maxcy Roseneau. Public Health and Preventive Medicine. Aplleton \& Lange, EUA, 1986. pp.999-1038. 
Fleiss, J.L. Statistical Methods for Rates and Proportions. New York: John Wiley, 1981. pp.218-220.

Folsom, A.R. et al. Leisure time physical activity and its relationship to coronary risk factors in a population-based sample. Am. J. Epidemiol. 1985;121(4):570-579.

Fonseca, M.J.M. Hábitos alimentares entre funcionários de Banco Estatal do Rio de Janeiro. Tese de Mestrado - Escola Nacional de Saúde Pública - FIOCRUZ, 1996.

Fortman, S.P. et al. Indirect measures of cigarette use: expired-air cabon monoxide versus plasma thiocyanate. Prev. Med. 1984; 13:127-135.

Frankenberg, R.J. The impact of HIV/AIDS on concepts relating to risk and culture within the British community epidemiology: candidates or targets for prevention? Soc. Sci. Med. 1994;38:1325-1335.

Fuchs, F.D. et al. Prevalência de hipertensão arterial sistêmica e fatores associados na região urbana de Porto Alegre. Estudo de Base Populacional. Arq. Bras. Cardiol.1995,63(6):473-479.

Gardell, B. Scandinavian research on stress in working life. Int. J. Health Serv. 1982;12(1): $31-41$.

Garrow, J.S. Indices of adiposity. Nutrition Abstracts and Reviews - Reviews in Clinical Nutrition. New York, John Wiley and sons and Commonwealth Agricultural Bureaux. séries A, 1983; 53 (8): 697-708.

Gianninni, S.D. et al. Prevalência de dislipidemias primárias em indivíduos com e sem história familiar de coronariopatia, tendo como referência os valores do "National Cholesterol Education Program". Arq. Bras. Cardiol.1992,58(4):281-287.

Glasgow, R.E. \& Terborg J.R. Occupational health promotion programs to reduce cardiovascular risk. J.Cons. Clin. Psych. 1988;56(3):365-73.

Goldbohm, R.A. et al. Validation of a dietary questionnaire used in a large-scale prospective cohort study on diet and cancer. Eur. J. Clin. Nutr. 1994;48:253-265.

Goldman, L. \& Cook, E.F. The decline in ischemic heart disease mortality rates. An analysis of the comparative effects of medical interventions and changes in lifestyle. Ann. Int. Med. 1984;101:825-36.

Gray, D.S. Diagnosis and prevalence of obesity. Med. Clin. North America 1989;73(1):113.

Greenacre, M.J. Practical correspondence analysis. in: Looking at multivariate data. New York, J.Willey e Sons, 1981. (Series in probability and mathematical statistics). 
Greenacre, M.J. Theory and applications of correspondence analysis. London, Academic Press, 1984.pp. 14-80

Griep, R.H. Tabagismo entre trabalhadores de um Banco Estatal. Tese de Mestrado - Escola Nacional de Saúde Pública. FIOCRUZ, 1996.

Grupo Técnico CASSI-Pesquisas Epidemiológicas. Estudo de Mortalidade dos funcionários do Banco do Brasil. Relatório de Pesquisa, 1992 (mimeo).

Grupo Técnico CASSI-Pesquisas Epidemiológicas. Condições de Saúde dos Associados da CASSI. Relatório de Pesquisa, 1996.

Habicht, J.P. Estandardización de métodos epidemiológicos quantitativos sobre el terrén. Boletin de la Oficina Sanitaria Panamericana.1978;76:375-381.

Heinzelmann, F. \& Bagley, R.W. Response to physical activity programs and their effects on health behavior. Public Health Rep. 1970;85:905-91 1.

Hjerman, I. et al. Effect of diet and smoking intervention on the incidence of coronary heart disease. Report from the Oslo study group of a randomized trial in healthy men. Lancet 1981;2:1303-1310.

Holme, I. et al. Coronary risk factors and socio-economic status: The Oslo Study. Lancet 1976;2: 1396-1398.

Hortobagyi, T. et al. Sensitivity and specificity of the Quetelet index to assess obesity in men and women. Eur. J.Clin. Nutr. 1994;48:369-375.

Hypertension Detection and Follow-up Group: the effect of treatment on mortality in "mild" hypertension. N. Engl. J. Med. 1982;307:976-980.

Hypertension Detection and Follow-up Program Cooperative Study. Five-year findings of the hypertension detection and follow-up program. I. Reductions in mortality of persons with high blood pressure, including mild hypertension. JAMA 1979;242:2563-2577.

INTERSALT Cooperative Research group. INTERSALT: an international study of electrolyte excretion and blood pressure. Results for 24 hour urinary sodium and potassium excretion. Br. Med. J. 1988;297:319-328.

Istvan, J.A. et al. Cigarret smoking and body weight in Cancer Prevention Study I. Int. J. Epidemiol. 1992;21(5):849-853.

Jacobsen, B.K.\& Bonnaa K.H. The reproducibility of dietary data from a self-administered questionnaire. The Tronso study. Int. J. Epidemiol. 1990; 19:349-353.

Joffres, M.R.et al. Prevalence, control and awareness of high blood presure among canadian adults. Can. Med. Assoc. J. 1992;146:1997-2005. 
Joseph, J.G.et al. Elevation of systolic and diastolic blood pressure associated with migration The Tokelau Island Migrant Study. J. Chronic Dis. 1983;36:507-516.

Jousilahti, P. et al. Trends in cardiovascular disease risk factor clustering in eastern Finland : results of 15-year follow-up of the North Korelia Project. Prev. Med. 1994;23:6-14.

Kannel, W. et al Factor risk in the development of coronary heart disease: six-year follow-up experience: The Framingham study. Ann. Intern. Med. 1961;55:33.

Kannel, W.B. \& Sorlie, P. Some health benefits of physical activity: the Framingham Study. Arch. Intern. Med. 1979;139:857-862.

Kannel, W.B. et al. Effect of weight on cardiovascular disease. Am. J. Clin. Nutr. 1996;63(suppl):4195-4225.

Karasek, R.A.et al. Job decision latitude, job demands, and cardiovascular disease: a prospective study of Swedish men. Am. J. Pub. Health. 1981;71:694-705.

Karasek, R.A.et al. Job characteristics in relation to the prevalence of myocardial infarction in the US Health Examination Survey (HES) and the Health and Nutrition Examination Survey (HANES). Am. J. Public Health. 1988; 78:910-918.

Keys A (ed): Coronary heart disease in seven countries. Circulation. 1970; suppl I;(41):1211.

Klein, C.H. Hipertensão arterial nos estratos geo-econômicos do Rio Grande do Sul. Rio de Janeiro, 1984. Tese de Mestrado - Escola Nacional de Saúde Pública/FIOCRUZ.

Klein, C.H. et al. Inquérito epidemiológico sobre hipertensão arterial em Volta Redonda - RJ. Cad. de Saúde Públ. 1985;1:58-70.

Klein, C.H., et al. Hipertensão arterial na Ilha do Governador - RJ. Relatório de Pesquisa, 1992 (mimeo).

Klesges, R.C.et al. A worksite smoking modification competition: potential for public health impact. Am J Public Health 1983;76:198-200.

Kornitzer, M.et al. Belgian heart study prevention project: incidence and mortality results. Lancet, 1983; 1:1066-1070.

Konitzer, M. \& Goldberg, R. Introduction. Cardiology 1993;82:85-88.

Kushner, R.F. Body weight and mortality. Nutr. Rev. 1993; 51(5):127-136.

Laurenti, R. et al. Características da mortalidade por Doença Isquêmica do Coração em adultos de 15 a 74 anos no município de São Paulo. Arq. Bras. Cardiol. 1981;36:85-9

Lemeshow S. Adequacy of sample size in health studies. World Health Organization, 1990 
Lessa, I. Estudos brasileiros sobre a epidemiologia da hipertensão arterial: análise crítica dos estudos de prevalência. Informe Epidemiológico do SUS 1993, Mai/Jun:59-75.

Lolio, C.A. \& Laurenti, R.(a). Evolução da mortalidade por doença isquêmica do coração no Município de São Paulo, 1970 a 1981. Arq. Bras. Cardiol. 1986;46:153-156.

Lolio, C.A. \& Laurenti, R.(b). Tendências da mortalidade por doença cerebrovascular em adultos maiores de 20 anos de idade no Município de São Paulo (Brasil), 1950 a 1981. Rev.Saúde Pública 1986;20(5):343-346.

Lolio, Cecilia A. Prevalência de tabagismo em localidade urbana da região Sudeste do Brasil. Rev. Saúde Pública 1993;27(4):262-265.

Lolio, C.A. \& Latorre, M.R.D.O. Prevalência de obesidade em localidades do Estado de São Paulo, Brasil, 1987. Rev. Saúde Pública, 1991, 25 (1): 33-36.

Lolio, C.A. Prevalência da hipertensão arterial em Araraquara. Arq. Bras. Cardiol., 1990, 55 (3): 167-173.

Lotufo, P.A. \& Lolio,C.A. Tendência da Mortalidade por Doença Isquêmica do Coração no Estado de São Paulo: 1970 a 1989. Arq.Bras.Cardiol. 1993;61(3):149-153.

Lotufo, P.A. \& Lolio, C.A. Tendência da mortalidade por Doença Cerebrovascular no Estado de São Paulo: 1970 a 1989. Arq. Neuropsiquiatr. 1993;51(4):441-46.

Macintyre, S.et al. Gender differences in health : are things really as simple as they seem? Soc. Sci. Med. 1996,42(4):617-624.

Mann, J., Tarantola, D.J.M., Netter, T.W. orgs. A AIDS no Mundo. Rio de Janeiro, RelumeDumará, 1993.

Manual de Referência - dBase IV - Datalogica/Ashton Tate, 1988.

Marks, J.S. et al. The behavioral risk factor surveys: 1- State-specific prevalence estimates of behavioral risk factors.Am. J. Prev. Med. 1985; 1(6):1-8.

Marmot, M. et al. Employment grade and coronary heart disease in British civil servants. J. Epidemiol. Comm. Health. 1978;32:244-249.

Marmot, M.G. Psychosocial factors and blood pressure. Prev. Med 1985; 14: 451-465.

Marmot, M.G. Coronary heart disease: rise and fall of a modern epidemic. in Marmot, M. \& Elliott, P. Coronary Heart Disease Epidemiology: from aetiology to public health. Oxford Medical Publications, 1992. pp.3-19.

Marmot, M.G. Preventive medicine and the health of a nation. J. Epidemiol. Comm. Health, $1993 ; 47(1): 1-5$ 
Marmot, M.G. Editorial: From alcohol and breast cancer to beef and BSE - Improving our communication of risk. Am. J. Public Health 1996;86(7):921-923.

Martins, I.S. et al. Doenças cardiovasculares arteroscleróticas, dislipidemias, hipertensão, obesidade e diabetes melito em população da área metropolitana da região Sudeste do Brasil: II-Dislipidemias. Rev. Saúde Pública 1996;30(1):75-84.

Martins, I.S. et al. Smoking, consumption of alcohol and sedentary lifestyle in population grouping and their relationships with lipemic disorders. Rev. Saúde Pública 1995;29(1):38-45.

McCarron, D.A. \& Reusser, M.E. Body weight and blood pressure regulation. Am. J. Clin. Nutr. 1996; 63(suppl):4235-4255.

Meisler, J. G. \& St. Jeor, S. Foreword. Am. J. Clin. Nutr. 1996;63(suppl.):4095-4115.

Ministério da Saúde. Condições nutricionais da População Brasileira: adultos e idosos. Pesquisa Nacional sobre Saúde e Nutrição. Instituto Nacional de Alimentação e Nutrição, Brasília, 1991.

Ministério da Saúde. Estatísticas de Mortalidade, 1988. Brasília: Centro de Documentação, 1993.

Ministério da Saúde. Controle do Tabagismo: um desafio. Instituto Nacional do Câncer. Coordenação de Programas de Controle de Câncer, Rio de Janeiro, março, 1992.

Mondini, L. \& Monteiro, C.A. Mudanças no padrão de alimentação da população urbana brasileira (1962-1988). Rev. Saúde Pública 1994;28(6):433-439.

Morabia, A. \& Wynder, E.L. Dietary habits of smokers, people who never smoked, and exsmokers. Am.J.Clin.Nutr. 1990;52:933-937.

Moreira, L.B. et al. Prevalência de tabagismo e fatores associados em área metropolitana da região Sul do Brasil. Rev. Saúde Pública 1995; 29(1):46-51.

Morisky, D.E.et al. Five-year blood pressure control and mortality following health education for hypertensive patients. Am J Public Health. 1983;73:153-162.

Najas, M.S. et al. Padrão alimentar de idosos de diferentes estratos sócio-econômicos residentes em localidades urbanas da região sudeste, Brasil. Rev. Saúde Pública 1994;28:187-191.

National Health Foundation of Australia (N.H.F.A.). Risk factor prevalence study. Survey $n^{\circ} 3$, 1989, ed National Heart Foundation of Australia and Australian Institute of Health, 1990

National Institutes of Health Consensus Development Conference Statement. Health implications of obesity. Ann. Intern. Med. 1995; 103:147-151 
Nicolau, J.C. et al. Perfil do colesterol na cidade de São José do Rio Preto. Arq. Bras. Cardiol. 1992;59(6):433-440.

Nieto, F.J.et al. Population awareness and control of hypertension and hypercholesterolemia The Atherosclerosis Risk in Communities Study. Arch. Intern. Med 1995;155 677-684

Nogueira, A.R. et al. Colesterol e outros fatores de risco cardiovascular nos servidores da U.F.R.J. Prevalência $\mathrm{e}$ influência de variáveis sociais. Arq. Bras. Cardiol. 1990;55(4):227-232.

Novotny, T. et al. Trends in smoking by age and sex, United States, 1974-1987: The implications for disease impact. Prev. Med. 1990;19:552-561

Norusis, M.S. SPSS for windows: base system user's guide release 5.0. Chicago, 1992.

Omram, A.R. The epidemiological transition: a theory of the epidemiology of population change. Milbank Mem. Fund. quart. 1971;49:509-583.

Palta, M.et al. Comparision of self-reported and measured height and weight. Am. J. Epidemiol. 1982;115:223-230

Petitti, D.B. \& Wigerd, J. Use of oral contraceptives, cigarette smoking, and risk of subarachnoid haemorrhage. Lancet, 1978;2: 234-236.

Puska, P. et al. The community-based strategy to prevent coronary heart disease: conclusions from ten years of the North Karelia Project. Ann. Rev. Pub. Health. 1985;6:147-93.

Puska, P. et al. The North Karelia Project: fifteen years of community-based prevention of coronary heart disease. Ann. Intern. Med. 1989;21:169-73.

Raitakari, O.T. et al. Clustering of risk habtis in young adults. The cardiovascular risk in young finns study. Am. J. Epidemiol. 1995;142(1):36-44.

Raitakari, O.T. Effects of persistent physical activity and inactivity on coronary risk factors in children and young adults. The cardiovascular risk in young finns study. Am. J. Epidemiol. 1994;140(3): 195-205.

Rego R.A. et al. Fatores de risco para doenças crônicas não transmissiveis: inquérito domiciliar no município de São Paulo, S.P.(Brasil). Metodologia e resultados preliminares.Rev. Saúde Pública 1990;24(4):277-285.

Reid, D.D. et al. Smoking and other risk factors for coronary heart diasease in British civil servants. Lancet 1976, ii:979-984.

Rose, G. (a). The Strategy of Preventive Medicine. New York, Oxford University Press, 1992. pp. 64-135. 
Rose, G. (b). Strategies of prevention: the individual and the population. in Marmot, M. \& Elliott, P. orgs. Coronary Heart Disease Epidemiology - From Aetiology to Public Health. New York, Oxford University Press, 1992. pp. 311-324.

Rose, G. \& Shipley, M. Plasma cholesterol concentration and death from coronary heart disease: 10 year results of the Whitehall study. Br. Med. J. 1986;293:306-307.

Rowland, D. et al. Computer-Based Data Analysis. Using SPSS in the Social and Behavioral Sciences. Chicago, Nelson-Hall Inc., 1991, p.193-205.

Ruchlin, H.S.et al. A comparative economic analysis of work-related hypertension care programs. J. Occup. Med. 1984; 26:45-49.

Schmidt, M.I. et al. Validity of self-reported weight - a study of urban brazilian adults. Rev. Saúde Pública, 1993, 27 (4): 271-276.

Schnall, P.L.et al. The relationship between job strain, workplace diastolic blood pressure, and left ventricular mass index. JAMA 1990;263(14):1929-1935.

Seidler, V.J. Reason, desire and male sexuality. in Caplan, P. org The Cultural Construction of Sexuality. London and New York, Routledge, 1987. pp. 82-112.

Sempos, C. et al. The prevalence of high blood cholesterol levels among adults in the United States. JAMA. 1989;262:45-52.

Sichieri, R. et al. High temporal, geographic, and income variation in body mass index among adults in Brazil. Am. J. Public Health 1994;85(5):793-798.

Silva Filho, J.F. et al.. Organização do trabalho e saúde mental: estudo das relações entre a prevalência de doenças mentais e organização do trabalho bancário no Município do Rio de Janeiro. Relatório de Pesquisa, 1993 (mimeo).

Siscovick, D.S.et al. Physical activity and primary cardiac arrest. JAMA 1982; 248(23):3113-3117.

Stamler, J. Established major coronary risk factors. in: Marmot, M.C. \& Elliott, P. Coronary Heart Disease Epidemiology: From aetiology to public health. Oxford University Press, 1992, pp.35-66.

Sorlie, M.S.et al. Body build and mortality. JAMA 1980;243:1828-31.

Thom, T. J. International mortality from heart disease: rates and trends. Int. J. Epidemiol. 1989; 18(3)(Supp. 1):S20-S28.

Uemura, K. \& Pisa, Z. Recent trends in cardiovascular disease mortality in 27 industrialized countries. Wld. Hlth. Statist. Quart. 1985;38:42-49. 
Uintenbroek, D.G. et al. Health lifestyle behaviour and socio-demogrphic characteristics. A study of Varna, Glasgow and Edinbugh. Soc. Sci. Med. 1996;43 (3 ):367-377.

Willet, W.C. Future directions in the development of food-frequency questionnaries. Am. J. Clin. Nutr 1994;59(suppl): 1715-1745.

World Health Organization (WHO): Arterial Hypertension. WHO Technical Report Series 628, Geneve, 1978

World Health Organization (WHO): Prevention of coronary heart disease: report of a WHO Expert Commitee, WHO Thecnical Report Series 678, Geneva, 1982.

World Health Organization (WHO). Physical status: the use and interpretation of anthropometry. WHO Thecnical Report Series 854, Geneva , 1995.

Wood, P. D. \& Haskell, W.L. The effect of exercise on plasma high density lipoproteins. Lipids 1979; 14:417-427. 


\section{ANEXO I}

\section{GRUPO TÉCNICO CASSI PESQUISAS EPIDEMIOLÓGICAS}

\section{TERMO DE CONSENTIMENTO PARA PARTICIPAÇĀO EM PESQUISA CIENTÍFICA}

(De acordo com as normas da Resoluçảo $n^{\circ} 1$ do Conselho Nacional de Saúde, de 13 de junho de 1988, publicada no D.O.U. de 05 de janeiro de 1989 e adaptado do modelo da Universidade de Maryland U.S.A.)

INSTITUIÇŌES:
CAIXA DE ASSISTÉNCIA DOS FUNCIONÁRIOS DO BANCO DO BRASIL E

TITULO DO PROJETO: PESQUISA SOBRE MORBIDADE E USO DOS SERVIÇOS DE SAÚDE DOS ASSOCIADOS DA CASSI

PESQUISADORES: GRUPO TÉCNICO CASSI PESQUISAS EPIDEMIOLÓGICAS COM ASSESSORIA DA ESCOLA NACIONAL DE CIÉNCIAS ESTATISTICAS (IBGE) E DA ESCOLA NACIONAL DE SAÚDE PÚBLICA (FUNDAÇĀO OSWALDO CRUZ)

O (A) Sr. (Sra.) está sendo solicitado (a) a participar de uma investigação cientifica, patrocinada pela CAIXA DE ASSISTÉNCIA DOS FUNCIONÁRIOS DO BANCO DO BRASIL (CASSI) e pela CAIXA DE PREVIDÉNCIA DOS FUNCIONÄRIOS DO BANCO DO BRASIL (PREVI), com os principais objetivos de levantar dados sobre as condiçōes de saúde e doença dos associados da CASSI e seus familiares e conhecer como os serviços de saúde ao seu alcance são utilizados.

Este documento, aprovado pela Comissão de Ética da Fundação Oswaldo Cruz, em 10.05.93, objetiva informá-lo (a) sobre o estudo e os beneficios que dele poderão advir.

O (A) Sr. (Sra.) poderá recusar-se a participar da pesquisa, dela se afastar a qualquer tempo ou deixar de responder a qualquer pergunta, sem que este fato venha causar-Ihe qualquer constrangimento ou penalidade por parte das instituiçōes envolvidas.

Os pesquisadores se obrigam a nāo revelar, em hipótese alguma, a identificaçāo do participante, em qualquer publicaçāo, apresentaçāo ou evento resultante desse estudo, sendo todos os dados tratados de forma nāo individualizada, em séries estatisticas, visando resguardar o sigilo das informaçōes.

Os questionários respondidos ficarão sob a responsabilidade do GRUPO TÉCNICO CASSI PESQUISAS EPIDEMIOLÓGICAS, sediado à Rua Senador Dantas, 105, $27^{\circ}$ andar, sala 2701, Centro, Rio de Janeiro (RJ), CEP:20031-201, Telefones: (021) 272-6061/ 272-6029 / 272-7057, sob a coordenação da Dra. Eneida Favre, médica, CRM: 52-29663-6, matricula 2.925.692-5, a quem o (a) Sr. (Sra.) poderá dirigir-se a qualquer tempo para esclarecimentos e orientação.

\section{Como beneficios diretos da pesquisa, salientamos:}

- reorientação dos programas de atenção à saúde da CASSI, identificando doenças e problemas de saúde, bem como faixas etárias prioritárias para intervençāo:

- e a possibilidade de empreender estudos que acompanhem as familias participantes da pesquisa em seu processo de saúde e doença, ao longo dos anos, com o intuito de rever posturas e propor açōes que venham beneficiar os usuários da CASSI. 
Caso o (a) Sr. (Sra.) aceite participar deste estudo, sua única responsabilidade será a de preencher o questionário anexo, sendo que, antes de assinar este TERMO DE CONSENTIMENTO e identificar-se como participante, o (a) Sr. (Sra.) tem - direito de verificar o conteúdo do questionário e fazer qualquer pergunta ao aplicador presente, o qual, se julgar necessário, entrará em contato com a Coordenaçāo do GT, a fim de Ihe prestar as informaçōes cabiveis.

Declaro estar ciente do inteiro teor deste TERMO DE CONSENTIMENTO e de acordo em participar do estudo proposto, sabendo que dele poderei desistir a qualquer momento, sem sofrer qualquer tipo de constrangimento ou punição, e que receberei uma cópia deste TERMO, sendo que outra ficará registrada nos arquivos do GRUPO TÉCNICO CASSI PESQUISAS EPIDEMIOLÓGICAS.

$-\cdot \mathcal{L}$

Declaro estar ciente do inteiro teor deste TERMO DE CONSENTIMENTO e de acordo em participar do estudo proposto, sabendo que dele poderei desistir a qualquer momento, sem sofrer qualquer tipo de constrangimento ou punição, e que receberei uma cópia deste TERMO, sendo que outra ficará registrada nos arquivos do GRUPO TÉCNICO CASSI PESQUISAS EPIDEMIOLÓGICAS. 


\section{ANEXO II}

PESQUISA SOBRE MORBIDADE E USO DOS SERVIÇOS DE SAÚDE DA CASSI

\section{MAPA DE PRESSÃO ARTERIAL E PESO}

01. NOME DA DEPENDÉNCIA

02-PREFIXO DA DEPENDÉI

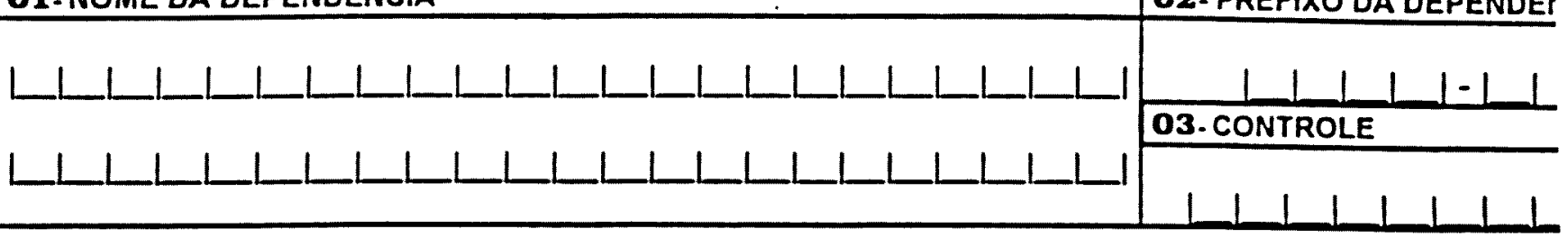

O4-DATA DE NASCIMENTO

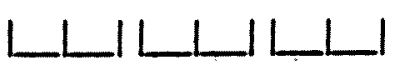

O5 - SEXO

[1] MASCULINO [2] FEMININO
O6 - DATA DA APLICAÇĀO

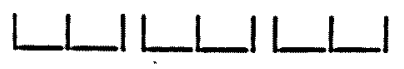

07 - USOU ALGUMA MEDICAÇĀO

NOS ÚLTIMOS 7 DIAS?

\section{8 - SE TOMOU, QUAL FOI A MEDICAÇĀO?}

\section{PRESSÁO ARTERIAL}

09 - DIAAMETROO DO BRAÇO

L $1 \mathrm{~cm}$

10 - PRIMEIRA MEDIIDA

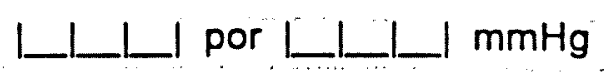

11 - SEGUNDA MEDIDA

LLLL por L ا $\mathrm{mmHg}$

\section{PESO}

12 - PESO ATUAL

LLLIL!

g

ESTATURA:

13 - DADOS COLHIDOS POR: 


\begin{abstract}
ANEXO III
GRUPO TÉCNICO CASSI PESQUISAS EPIDEM“OLÓGICAS

PESQUISA SOBRE MORBIDADE E USO DOS SERVIÇOS DE SAÚDE DA CASSI
\end{abstract}

TERMO DE SIGILO DO APLICADOR

Eu, abaixo-assinado,

matricula identidade na qualidade de aplicador da Pesquisa de Morbidade e Uso dos Serviços de Saúde dos Associados da CASSI. patrocinada pela CASSI e PREVI, comprometo-me por meio deste termo a respeitar os seguintes principios, conforme a CIC Administraçāo n 287, de 22.09.92, 5.3.8.1-2, que trata da segurança das informaçōes a terceiros:

1) Não fornecer, em nenhuma hipótese, cópia das informaçōes obtidas por meio da Pesquisa a elementos estranhos ao GT CASSI Pesquisas Epidemiológicas.

2) Nảo manusear em público os questionários preenchidos, exceto o estritamente necessário ao acondicionamento do material.

3) Não divulgar ou tecer comentários, por nenhum meio, de dados individuais relativos aos respondentes, no decorrer ou após o encerramento da pesquisa.

4) Cumprir as instruçōes contidas no Manual do Aplicador e as recebidas durante o treinamento.

Tenho clareza que a adesāo voluntária a estes principios éticos é indispensável ao bom andamento da Pesquisa.

Rio de Janeiro. de de 1994.

ass.

Endereço e telefone: 


\section{ANEXO IV}

LOTAÇÃO, AMOSTRA PLANEJADA E NÚMERO DE RESPONDENTES EM CADA DEPENDÊNCIA SORTEADA CESEC

\begin{tabular}{|c|c|c|c|c|c|c|c|c|c|c|c|c|}
\hline \multirow[t]{2}{*}{ CESEC } & \multicolumn{3}{|c|}{ LOTAÇÃO } & \multicolumn{3}{|c|}{ AMOSTRA } & \multicolumn{3}{|c|}{ RESPONDENTES } & \multirow[b]{2}{*}{ FALTOU } & \multirow[b]{2}{*}{ RECUSA } & \multirow[b]{2}{*}{$\begin{array}{l}\% \\
R E S P \\
\end{array}$} \\
\hline & $M A S C^{*}$ & $F E M^{*}$ & TOTAL & $M A S C$ & $F E M$ & TOTAL & $M A S C$ & FEM & TOTAL & & & \\
\hline ANDARAI & 360 & 284 & 644 & 66 & 66 & 132 & 63 & 65 & 128 & 0 & 4 & 97,0 \\
\hline CAMPOS & 139 & 59 & 198 & 27 & 15 & 42 & 26 & 15 & 41 & 0 & 1 & 97,6 \\
\hline CATETE & 106 & 90 & 196 & 25 & 25 & 50 & 25 & 25 & 50 & 0 & 0 & 100,0 \\
\hline COMPE & 329 & 151 & 480 & 63 & 30 & 93 & 54 & 30 & 84 & 4 & 5 & 90,3 \\
\hline LAPA & 122 & 79 & 201 & 28 & 14 & 42 & 28 & 14 & 42 & 0 & 0 & 100,0 \\
\hline MADUREIRA & 133 & 73 & 206 & 23 & 19 & 42 & 23 & 19 & 42 & 0 & 0 & 100,0 \\
\hline NITERÓI & 112 & 63 & 175 & 21 & 14 & 35 & 19 & 14 & 33 & 0 & 2 & 94,3 \\
\hline S. CRISTOVÃO & 174 & 109 & 283 & 32 & 24 & 56 & 32 & 24 & 56 & 0 & 0 & 100,0 \\
\hline SEDAN & 269 & 287 & 556 & 55 & 55 & 110 & 49 & 53 & 102 & 1 & 7 & 92,7 \\
\hline VILA ISABEL & 132 & 112 & 244 & 25 & 22 & 47 & 25 & 22 & 47 & 0 & 0 & 100,0 \\
\hline $\begin{array}{l}\text { VOLTA } \\
\text { REDONDA } \\
\end{array}$ & 72 & 28 & 100 & 14 & 8 & 22 & 14 & 8 & 22 & 0 & 0 & 100,0 \\
\hline TOTAL & 1948 & 1335 & 3283 & 379 & 292 & 671 & 358 & 289 & 647 & 5 & 19 & 96,4 \\
\hline
\end{tabular}




\section{ANEXO IV (CONTINUAÇÃO) \\ LOTAÇÃO, AMOSTRA PLANEJADA E NÚMERO DE RESPONDENTES EM CADA DEPENDÊNCIA SORTEADA DIREÇÃO GERAL}

\begin{tabular}{|c|c|c|c|c|c|c|c|c|c|c|c|c|}
\hline \multirow[t]{2}{*}{ ÓRGĀo } & \multicolumn{3}{|c|}{ LOTAÇÃO } & \multicolumn{3}{|c|}{ AMOSTRA } & \multicolumn{3}{|c|}{ RESPONDENTES } & \multirow[b]{2}{*}{ FALTOU } & \multirow[b]{2}{*}{ RECUSA } & \multirow[b]{2}{*}{$\% R E S I$} \\
\hline & $M A S C$ & $F E M$ & TOTAL & $M A S C$ & FEM & TOTAL & $M A S C$ & FEM & TOTAL & & & \\
\hline AJURE & 32 & 30 & 62 & 14 & 16 & 30 & 10 & 16 & 26 & 2 & 2 & 86,7 \\
\hline AUDIT & 15 & 2 & 17 & 6 & 1 & 7 & 4 & 1 & 5 & 0 & 2 & 71,4 \\
\hline BBDTVM & 75 & 49 & 124 & 39 & 10 & 59 & 39 & 18 & 57 & 0 & 2 & 96,6 \\
\hline CEDIP & 216 & 112 & 328 & 114 & 53 & 167 & 95 & 53 & 148 & 19 & 0 & 88,6 \\
\hline CEFOR & 2 & 3 & 5 & 2 & 3 & 5 & 2 & 2 & 4 & 0 & 1 & 80,0 \\
\hline СОСЕM & 21 & 33 & 54 & 9 & 17 & 26 & 9 & 17 & 26 & 0 & 0 & 100,0 \\
\hline DEATE & 51 & 35 & 86 & 27 & 22 & 49 & 26 & 22 & 48 & 0 & 1 & 98,0 \\
\hline DEPIM & 40 & 20 & 60 & 26 & 8 & 34 & 24 & 8 & 32 & 2 & 0 & 94,1 \\
\hline GECAM & 17 & 11 & 28 & 7 & 6 & 13 & 7 & 6 & 13 & 0 & 0 & 100,0 \\
\hline GENEB & 14 & 20 & 34 & 9 & 10 & 19 & 9 & 10 & 19 & 0 & 0 & 100,0 \\
\hline GEROF & 69 & 23 & 92 & 31 & 10 & 41 & 27 & 9 & 36 & 1 & 4 & 87,8 \\
\hline PREVI & 113 & 52 & 165 & 56 & 21 & 77 & 48 & 21 & 69 & 0 & 8 & 73,6 \\
\hline SUPER & 61 & 58 & 119 & 38 & 34 & 72 & 31 & 22 & 53 & 0 & 19 & 89,6 \\
\hline TOTAL & 726 & 448 & 1174 & 378 & 221 & 599 & 331 & 205 & 536 & 24 & 39 & 89,5 \\
\hline
\end{tabular}




\section{ANEXO V}

\section{MATRIZ DE CORRELAÇÃO DOS ITENS QUE COMPÕEM O ESCORE}

\begin{tabular}{|l|l|l|l|l|l|l|l|l|l|l|l|l}
\hline & $\begin{array}{l}\text { Carne } \\
\text { salgada }\end{array}$ & $\begin{array}{l}\text { Produto } \\
\text { industria- } \\
\text { lizado }\end{array}$ & Embutido & Fritura & Manteiga & $\begin{array}{l}\text { Carne } \\
\text { porco }\end{array}$ & $\begin{array}{l}\text { Carne } \\
\text { vaca }\end{array}$ & $\begin{array}{l}\text { Refrige- } \\
\text { rante }\end{array}$ & Balas & Açúcar & Ovos & Verdu \\
\hline $\begin{array}{l}\text { Carne } \\
\text { salgada }\end{array}$ & 1,000 & & & & & & & & & & & \\
\hline $\begin{array}{l}\text { Produto } \\
\text { industriali- } \\
\text { zado }\end{array}$ & 0,200 & 1,000 & & & & & & & & & & \\
\hline Embutido & 0,281 & 0,363 & 1,000 & & & & & & & & & \\
\hline Fritura & 0,224 & 0,243 & 0,344 & 1,000 & & & & & & & & \\
\hline Manteiga & 0,120 & 0,089 & 0,154 & 0,282 & 1,000 & & & & & & & \\
\hline $\begin{array}{l}\text { Carne de } \\
\text { porco }\end{array}$ & $\mathbf{0}, 398$ & 0,159 & 0,327 & 0,277 & 0,197 & 1,000 & & & & & & \\
\hline $\begin{array}{l}\text { Carne de } \\
\text { vaca }\end{array}$ & 0,289 & 0,169 & 0,357 & 0,384 & 0,244 & 0,348 & 1,000 & & & & & \\
\hline Refrigerante & 0,129 & 0,163 & 0,213 & 0,279 & 0,146 & 0,146 & 0,233 & 1,000 & & & & \\
\hline Balas & 0,066 & 0,221 & 0,179 & 0,260 & 0,141 & 0,091 & 0,126 & 0,329 & 1,000 & & & \\
\hline Açúcar & 0,071 & 0,065 & 0,138 & 0,251 & 0,219 & 0,086 & 0,172 & 0,222 & 0,223 & 1,000 & & \\
\hline Ovos & 0,203 & 0,200 & 0,211 & 0,290 & 0,161 & 0,184 & 0,170 & 0,123 & 0,222 & 0,178 & 1,000 & \\
\hline Verduras & 0,015 & 0,017 & 0,107 & 0,166 & 0,037 & 0,059 & 0,083 & 0,143 & $-0,032$ & $-0,008$ & 0,038 & 1,000 \\
\hline
\end{tabular}

\section{CORRELAÇÃO ENTRE O ESCORE ALIMENTAR E CADA ÍTEM UTILIZADO PARA SUA ELABORAÇÃO}

\begin{tabular}{|l|c|}
\hline \multicolumn{1}{|c|}{ Variável } & Escore alimentar \\
\hline Carne salgada & 0,442 \\
\hline Produto industrializado & 0,461 \\
\hline Embutido & 0,570 \\
\hline Fritura & 0,654 \\
\hline Manteiga & 0,523 \\
\hline Carne de porco & 0,485 \\
\hline Carne de vaca & 0,579 \\
\hline Refrigerante & 0,555 \\
\hline Balas & 0,492 \\
\hline Açúcar & 0,515 \\
\hline Ovos & 0,468 \\
\hline Verduras & 0,227 \\
\hline
\end{tabular}




\section{ANEXO VI \\ DISTRIBUIÇÃO DO CONSUMO DE ÁLCOOL E QUINTIS DE DIETA \\ POR SEXO - AMBAS AS DEPENDÊNCIAS \\ IDADE MENOR OU IGUAL A 40 ANOS}

\begin{tabular}{l|cccc|c}
\hline & \multicolumn{5}{|c}{ ALCOOL } \\
\cline { 2 - 6 } DIETA & $\begin{array}{c}\text { DIARIO } \\
\%\end{array}$ & $\begin{array}{c}\text { SEMANAL } \\
\%\end{array}$ & $\begin{array}{c}\text { OCASIONAL } \\
\%\end{array}$ & $\begin{array}{c}\text { NUNCA } \\
\%\end{array}$ & $\begin{array}{c}\text { TOTAL } \\
\mathrm{n}\end{array}$ \\
\hline HOMENS & 12,6 & 29,5 & 46,9 & 11,1 & 53 \\
DIETA 1 & 8,7 & 40,3 & 43,9 & 7,1 & 90 \\
DIETA 2 & 5,7 & 63,2 & 31,2 & 0,0 & 61 \\
DIETA 3 & 12,3 & 44,7 & 35,8 & 7,2 & 95 \\
DIETA 4 & 17,9 & 44,9 & 35,5 & 1,7 & 109 \\
DIETA 5 & & & & & \\
\hline MULHERES & 3,7 & 19,8 & 54,5 & 21,9 & 68 \\
DIETA 1 & 2,5 & 16,3 & 61,7 & 19,5 & 80 \\
DIETA 2 & 3,8 & 33,8 & 54,1 & 8,3 & 39 \\
DIETA 3 & 1,8 & 25,3 & 64,7 & 8,1 & 65 \\
DIETA 4 & 5,3 & 36,1 & 58,6 & 0,0 & 35 \\
DIETA 5 & \multicolumn{5}{|c}{}
\end{tabular}

Proporções corrigidas com base na expansão de totais

\section{DISTRIBUIÇÃO DO CONSUMO DE ÁLCOOL E QUINTIS DE DIETA POR SEXO - AMBAS AS DEPENDÊNCIAS MAIORES DE 40 ANOS DE IDADE}

\begin{tabular}{l|cccc|c}
\hline & \multicolumn{5}{|c}{ ALCOOL } \\
\cline { 2 - 7 } DIETA & $\begin{array}{c}\text { DIARIO } \\
\%\end{array}$ & $\begin{array}{c}\text { SEMANAL } \\
\%\end{array}$ & $\begin{array}{c}\text { OCASIONAL } \\
\%\end{array}$ & $\begin{array}{c}\text { NUNCA } \\
\%\end{array}$ & $\begin{array}{c}\text { TOTAL } \\
\text { N }\end{array}$ \\
\hline HOMENS & 11,5 & 31,3 & 42,4 & 14,7 & 60 \\
DIETA 1 & 15,2 & 44,0 & 40,9 & 0,0 & 70 \\
DIETA 2 & 25,9 & 27,6 & 36,5 & 10,0 & 45 \\
DIETA 3 & 21,6 & 34,5 & 29,9 & 13,9 & 51 \\
DIETA 4 & 22,3 & 40,3 & 33,6 & 3,8 & 53 \\
DIETA 5 & & & & & \\
\hline MULHERES & 2,6 & 22,4 & 66,7 & 8,3 & 51 \\
DIETA 1 & 2,9 & 21,2 & 68,6 & 7,3 & 68 \\
DIETA 2 & 4,0 & 18,5 & 58,9 & 18,5 & 32 \\
DIETA 3 & 3,6 & 36,5 & 53,3 & 6,6 & 38 \\
DIETA 4 & 6,9 & 6,9 & 66,7 & 19,4 & 17 \\
DIETA 5 & \multicolumn{5}{c}{}
\end{tabular}

Proporções corrigidas com base na expansão de totais 


\section{ANEXO VII \\ DISTRIBUIÇÃO DE ATIVIDADE FÍSICA E CONSUMO DE ÁLCOOL POR SEXO - AMBAS AS DEPENDÊNCIAS \\ IDADE MENOR OU IGUAL A 40 ANOS}

\begin{tabular}{|c|c|c|c|c|c|}
\hline \multirow[b]{2}{*}{$\begin{array}{l}\text { ATIVIDADE } \\
\text { FÍSICA }\end{array}$} & \multicolumn{4}{|c|}{$\bar{A} L C O O L$} & \multirow[b]{2}{*}{$\begin{array}{c}\text { TOTAL } \\
n\end{array}$} \\
\hline & $\begin{array}{c}\text { DIARIO } \\
\%\end{array}$ & $\begin{array}{c}\text { SEMANAI } \\
\%\end{array}$ & $\begin{array}{c}\text { OCASIONAI } \\
\%\end{array}$ & $\begin{array}{c}\text { NUNCA } \\
\%\end{array}$ & \\
\hline \multicolumn{6}{|l|}{ HOMENS } \\
\hline FREQUENTE & 15,1 & 44,9 & 32,9 & 7,1 & 54 \\
\hline MODERADA & 9,8 & 27,5 & 50,3 & 12,4 & 40 \\
\hline $\begin{array}{l}\text { POUCO } \\
\text { FREQUENTE }\end{array}$ & 10,9 & 55,6 & 31,9 & 1,7 & 98 \\
\hline NÃO PRATICA & 12,0 & 41,4 & 41,4 & 5,2 & 215 \\
\hline \multicolumn{6}{|l|}{ MULHERES } \\
\hline FREQUENTE & 0,0 & 36,0 & 56,2 & 7,9 & 24 \\
\hline MODERADA & 7,1 & 14,2 & 70,1 & 8,7 & 35 \\
\hline $\begin{array}{l}\text { POUCO } \\
\text { FREOUENTE }\end{array}$ & 2,1 & 27,4 & 58,4 & 12,1 & 58 \\
\hline NÃO PRATICA & 3,0 & 23,6 & 57,3 & 16,1 & 168 \\
\hline
\end{tabular}

Proporções corrigidas com base na expansão de totais

\section{DISTRIBUIÇÃO DE ATIVIDADE FÍSICA CONSUMO DE ÁlCOOL POR SEXO - AMBAS AS DEPENDÊNCIAS MAIORES DE 40 ANOS DE IDADE}

\begin{tabular}{|c|c|c|c|c|c|}
\hline \multirow[b]{2}{*}{$\begin{array}{l}\text { ATIVIDADE } \\
\text { FÍSICA }\end{array}$} & \multicolumn{4}{|c|}{ ÁLCOOL } & \multirow[b]{2}{*}{$\begin{array}{c}\text { TOTAL } \\
\mathrm{n}\end{array}$} \\
\hline & $\begin{array}{c}\text { DIÁRIO } \\
\%\end{array}$ & $\begin{array}{c}\text { SEMANAI } \\
\%\end{array}$ & $\begin{array}{c}\text { OCASIONAL } \\
\%\end{array}$ & $\begin{array}{c}\text { NUNCA } \\
\%\end{array}$ & \\
\hline \multicolumn{6}{|l|}{ HOMENS } \\
\hline FREQUENTE & 11,9 & 35,6 & 39,6 & 12,9 & 27 \\
\hline MODERADA & 12,4 & 23,8 & 48,6 & 15,2 & 32 \\
\hline $\begin{array}{l}\text { POUCO } \\
\text { FREOUENTE }\end{array}$ & 23,7 & 28,4 & 33,7 & 14,2 & 52 \\
\hline NÃO PRATICA & 18,9 & 40,2 & 36,2 & 4,7 & 166 \\
\hline \multicolumn{6}{|l|}{ MULHERES } \\
\hline FREQUENTE & 8,1 & 22,6 & 58,1 & 11,3 & 17 \\
\hline MODERADA & 5,6 & 30,3 & 64,0 & 0,0 & 22 \\
\hline $\begin{array}{l}\text { POUCO } \\
\text { FREOUENTE }\end{array}$ & 3,4 & 37,0 & 47,3 & 12,3 & 39 \\
\hline NÃO PRATICA & 2,4 & 16,6 & 69,7 & 11,4 & 126 \\
\hline
\end{tabular}

Proporções corrigidas com base na expansão de totais 


\section{ANEXO VIII}

\section{Fórmula utilizada para o cálculo do tamanho de amostra relativo à comparação entre informação sobre pressão arterial, peso e estatura e a medida direta dessas variáveis.}

O número de funcionários a serem examinados foi calculado com base na diferença entre duas proporções, a de hipertensos ou obesos estimadas através da informação do questionário, e a proporção de hipertensos ou obesos estimadas através da medida. Assim, para detectar uma diferença de pelo menos $10 \%$ entre essas proporções, com poder de $95 \%$ e nível de confiança de $95 \%$, seria necessário examinar 328 funcionários, número calculado através da seguinte fórmula (LEMESHOW, 1990):

$$
\mathrm{n}=\left[\left\{\mathrm{z}_{1}-\alpha / 2\{2 \mathrm{p}(1-\mathrm{p})\}^{1 / 2}+\mathrm{z}_{1}-\beta\left\{\mathrm{p}_{1}(1-\mathrm{p} 1)+\mathrm{p}_{2}\left(1-\mathrm{p}_{2}\right)\right\}^{1 / 2}\right\}\right]^{2} /\left(\mathrm{p}_{1}-\mathrm{p}_{2}\right)^{2}
$$

onde $\mathrm{z}_{1-\alpha / 2}=1,96$ (que corresponde a umintervalo de confiança de $95 \%$ ) $\mathrm{p}=0,15=$ prevalência média de hipertensão segundo as duas diferentes fontes: medida direta e informação do funcionário $(\mathrm{p} 1+\mathrm{p} 2 / 2)$

$z_{1-\beta / 2}=1,64$ (que corresponde a um poder do teste de $95 \%$ ) $\mathrm{p}_{1}=0,20=$ estimativa da prevalência de hipertensão segundo medida direta, de acordo com a literatura (KLEIN, 1985) $\mathrm{p}_{2}=0,10=$ estimativa da prevalência de hipertensão segundo informação dos funcionários no Estudo Piloto 
ANEXO IX

OS BLOCOS SEGUINTES, DE 09 A 27, LEVANTAM INFORMAÇŌES SOE SEU PESO E ALTURA, HÁBITOS ALIMENTARES, ATIVIDADES FÍSICAS HÁBITOS DE VIDA. ALGUNS DESTES COMPORTAMENTOS ESTÃO ASSOCIADOS AO RISCO DE ADOECER E, POR ISTO, FAZEM PARTE DESTA PESQUISA. 


\section{BLOCO 09}

\section{PARA TODOS OS FUNCIONÁRIOS RESPONDEREM.}

41- QUAL É SUA ALTURA EM CENTIMETROS?

1- MINHA ALTURA E L__L_ CM.

9 -[ ] NÃO SEI INFORMAR

42- QUAL É O SEU PESO ATUAL EM QUILOGRAMAS?

1- MEU PESO ATUAL É L___ KG.

9- [ ] NÄO SEI INFORMAR 


\section{BLOCO 10}

\section{PARA TODOS OS FUNCIONÁRIOS RESPONDEREM.}

43 - MARQUE A ALTERNATIVA QUE MELHOR DESCREVE SUA PRINCIPAL REFEIÇÃO NUM DIA ÚTIL, ATUALMENTE:

1- [ ] LANCHE RÁPIDO (SANDUICHE, PIZZA, SALGADINHOS, ETC.)

2- [ ] REFEIÇÃO EM CASA, COMIDA CASEIRA

3- [ ] REFEIÇÃO NO "BANDEJÃO" DO BANCO

4- [ ] REFEIÇÃO EM CANTINA, PENSÃO OU LANCHONETE

5- [ ] REFEIÇÃO EM RESTAURANTE

6- [ ] COMIDA CASEIRA EM MARMITA, NO TRABALHO

7-[ ] OUTRA

44 - QUE GORDURAS COSTUMAM SER USADAS NA SUA CASA PARA FRITAR ALIMENTOS? (PODE MARCAR MAIS DE UMA OPÇÃO.)

1- [ ] NÃO CONSUMO FRITURAS

2-[ ] ÓLEO DE SOJA

3- [ ] ÓLEO DE MILHO

4- [ ] ÓLEO DE GIRASSOL

5- [ ] BANHA DE PORCO

6- [ ] GORDURA DE COCO OU VEGETAL

7-[ ] MARGARINA

8- [ ] MANTEIGA

9- [ ] OUTRA GORDURA

9- [ ] NÃO SEI INFORMAR

45- VOCÊ COSTUMA ACRESCENTAR SAL AOS ALIMENTOS JÁ PREPARADOS, NO SEU PRATO?

1-[ ] SEMPRE

2-[ ] QUASE SEMPRE

3-[ ] RARAMENTE

4- [ ] NUNCA 


\section{BLOCO 11}

\section{PARA TODOS OS FUNCIONÁRIOS RESPONDEREM.}

\section{6 - COM QUE FREQÜÊNCIA, APROXIMADAMENTE, VOCÊ CONSOME OS ALIMENTOS LISTADOS ABAIXO?}

\begin{tabular}{|c|c|c|c|c|c|}
\hline ALIMENTO CONSUMIDO & $\begin{array}{l}\text { QUATRO OU } \\
\text { MAIS VEZES } \\
\text { POR } \\
\text { SEMANA }\end{array}$ & $\begin{array}{l}\text { DE UMAA } \\
\text { TRES VEZES } \\
\text { POR } \\
\text { SEMANA }\end{array}$ & $\begin{array}{l}\text { FREQÜEN- } \\
\text { CIA MENOR } \\
\text { QUE UMA } \\
\text { VEZ POR } \\
\text { SEMANA } \\
\end{array}$ & $\begin{array}{l}\text { NÃO } \\
\text { CONSUMO }\end{array}$ & $\begin{array}{l}\text { NÄO SEI } \\
\text { INFORMAR }\end{array}$ \\
\hline $\begin{array}{l}\text { 01- CARNES SALGADAS: BACALHAU / } \\
\text { CHARQUE / CARNE-SECA / CARNE-DE- } \\
\text { SOL / PAIO / TOUCINHO / COSTELA / ETC }\end{array}$ & $1-[]$ & $2-[]$ & $3-[]$ & 4- [ ] & $9-[]$ \\
\hline $\begin{array}{l}\text { 02- PRODUTOS INDUSTRIALIZADOS } \\
\text { ENVASADOS: ENLATADOS / CONSERVAS / } \\
\text { SUCOS ENGARRAFADOS / SUCOS } \\
\text { DESIDRATADOS / SOPAS DESIDRATADAS } \\
\text { / PRODUTOS EM VIDROS / ETC }\end{array}$ & $1-[]$ & $2-[]$ & $3-[]$ & $4-[]$ & $9-[]$ \\
\hline $\begin{array}{l}\text { 03- EMBUTIDOS: LINGÜIÇA / SALSICHA / } \\
\text { FIAMBRE / PRESUNTO / ETC }\end{array}$ & $1-[]$ & $2-[]$ & 3-[ ] & $4-[]$ & $9-[]$ \\
\hline 04- FRITURAS & $1-[]$ & $2-[]$ & $3-[]$ & 4- [ ] & $9-[]$ \\
\hline 05- MANTEIGA & $1-[]$ & $2-[1]$ & $3-[]$ & 4-[] & $9-[1]$ \\
\hline $\begin{array}{l}\text { 06- CARNE DE PORCO: PERNIL / CARRÉ I } \\
\text { COSTELETA / ETC OU CARNE DE } \\
\text { CARNEIRO OU CARNE DE CABRA }\end{array}$ & $1-[]$ & $2-[]$ & $3-[1]$ & 4-[ ] & $9-[]$ \\
\hline 07- CARNE DE VACA & $1-[]$ & $2-[]$ & $3-[]$ & 4-[ ] & $9-[]$ \\
\hline 08- REFRIGERANTES NÃO-DIETÉTICOS & $1-[]$ & $2-[]$ & $3-[]$ & 4-[ ] & $9-[]$ \\
\hline $\begin{array}{l}\text { 09- BALAS, DOCES, GELÉIAS, BOMBONS } \\
\text { OU CHOCOLATE }\end{array}$ & $1-[]$ & $2-[]$ & $3-[1]$ & $4-[]$ & $9-[]$ \\
\hline $\begin{array}{l}\text { 10- AÇÜCAR, MEL OU MELAÇO USADOS } \\
\text { COMO ADOÇANTES NO CAFÉ, CHÁ, } \\
\text { SUCOS, ETC }\end{array}$ & $1-[]$ & $2-[]$ & $3-[]$ & 4-[ ] & $9-[]$ \\
\hline $\begin{array}{l}\text { 11- OVOS:CRUS /COZIDOS /FRITOS/ } \\
\text { POCHE / ETC }\end{array}$ & $1-[]$ & $2-[]$ & $3-[]$ & 4-[] & $9-[]$ \\
\hline 12- VERDURAS, LEGUMES E FRUTAS & $1-[]$ & $2-[]$ & $3-[]$ & $4-[]$ & $9-[]$ \\
\hline
\end{tabular}




\section{BLOCO 12}

\section{PARA TODOS OS FUNCIONÁRIOS RESPONDEREM.}

47- ATUALMENTE, VOCÊ ESTÁ FAZENDO ALGUM TIPO DE DIETA? (PODE MARCAR MAIS DE UMA OPÇÃO.)

1- [ ] SIM, COM RESTRIÇÄO DE SAL

2-[ ] SIM, PARA EMAGRECER

3- [ ] SIM, COM RESTRIÇÃO DE AÇÜCAR

4- [ ] SIM, COM RESTRIÇÃO DE GORDURA

5- [ ] SIM, DE OUTRO TIPO

6- [ ] NÃO, MAS JÁ FIZ DIETA

7- [ ] NÃO, NUNCA FIZ DIETA

48 - NOS ÚlTIMOS 12 MESES, QUANTAS VEZES VOCÊ TENTOU PERDER PESO :

1-[ ] NENHUMA VEZ $\Rightarrow$ [ SIGA PARA O BLOCO 13]

2-[ ] UMA VEZ

3- [ ] MAIS DE UMA VEZ

4- [ ] ESTOU SEMPRE TENTANDO PERDER PESO

49 - NOS ÚLTIMOS 12 MESES, VOCÊ CONSEGUIU PERDER PESO NA ÚlTIMA TENTATIVA PARA EMAGRECER ?

1- [ ] SIM, PERDI PESO MAS ENGORDEI DE NOVO

2- [ ] SIM, PERDI PESO E CONSEGUI MANTER O PESO MAIS BAIXO QUE O ANTERIOR

3- [ ] AINDA ESTOU EM TRATAMENTO

4- [ ] NÃO, TENTEI PERDER PESO, MAS NÃO CONSEGUI 


\section{BLOCO 13}

\section{PARA TODOS OS FUNCIONÁRIOS RESPONDEREM.}

50- QUANDO FOI A ÚlTIMA VEZ QUE VOCÊ FEZ EXAME PARA DOSAR O COLESTEROL NO SANGUE?

1-[ [ ] HÁ MENOS DE UM ANO

2-[ ] ENTRE UM E DOIS ANOS

3-[ ] HÁ MAIS DE DOIS ANOS

4-[ ] NUNCA MEDI O COLESTEROL $\Rightarrow$ [ SIGA PARA O BLOCO 14]

9- [ ] NÃO SEI INFORMAR

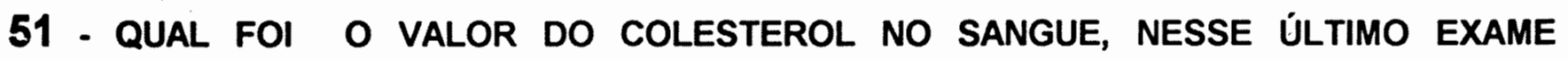
REALIZADO?

1-[ ] MENOR QUE $200 \mathrm{mg} / \mathrm{dl}$

2- [ ] ENTRE 200 E $239 \mathrm{mg} / \mathrm{dl}$

3- [ ] IGUAL OU MAIOR QUE $240 \mathrm{mg} / \mathrm{dl}$

9- [ ] NÃO SEI INFORMAR

52 - ALGUM MÉDICO OU OUTRO PROFISSIONAL DA ÁREA DA SAÚDE JÁ LHE DISSE QUE SEUS NIVEIS DE COLESTEROL NO SANGUE ESTAVAM ELEVADOS?

1-[ ] SIM

2-[ ] ] NÃO 


\section{BLOCO 14}

\section{PARA TODOS OS FUNCIONÁRIOS RESPONDEREM}

53 - VOCÊ É OU JÁ FOI FUMANTE, OU SEJA, JÁ FUMOU, AO LONGO DA VIDA, PELO MENOS 100 CIGARROS (CINCO CARTEIRAS DE CIGARROS) ?

1- [ ] NUNCA FUMEI $\Rightarrow$ [ SIGA PARA O BLOCO 17 ]

2-[ ] PAREI DE FUMAR

3- [ ] FUMO ATUALMENTE

4- [ ] FUMO EVENTUALMENTE (IRREGULARMENTE OU SOMENTE CIGARROS DE AMIGOS) 


\section{BLOCO 15}

\section{SÓ PARA AQUELES QUE SĀO OU JÁ FORAM FUMANTES.}

54 - COM QUE IDADE VOCÊ PASSOU A FUMAR COM REGULARIDADE?

1- COM LLI ANOS

2- [ ] NĀO SEI INFORMAR

55 - QUANTOS CIGARROS VOCÊ FUMA OU FUMAVA, EM MÉDIA, POR DIA?

1- CERCA DE L_L_LI CIGARROS POR DIA

2- [ ] FUMO OU FUMAVA IRREGULARMENTE

3- [ ] NÃO SEI INFORMAR

56 - O FUMO É PERMITIDO NA SUA SALA DE TRABALHO?

1-[ ] ] SIM

2- [ ] NÃO

57 - VOCÊ JÁ TENTOU PARAR DE FUMAR?

1- [ ] SIM, SOU EX-FUMANTE $\Rightarrow$ [ SIGA PARA O BLOCO 16]

2-[ ] SIM, MAS VOLTEI A FUMAR $\Rightarrow$ [ SIGA PARA O BLOCO 17]

3- [ ] NĀO, NUNCA TENTEI $\Rightarrow$ [ SIGA PARA O BLOCO 17] 


\section{BLOCO 16}

\section{SO PARA OS EX-FUMANTES RESPONDEREM.}

58- COM QUE IDADE VOCÊ PAROU DE FUMAR?

1- [ ] PAREI COM L_L ANOS

9- [ ] NÃO SEI INFORMAR

59- POR QUE VOCÊ PAROU DE FUMAR? (PODE MARCAR MAIS DE UMA OPÇÃO.)

1- [ ] POR CAUSA DE DOENÇA GRAVE

2- [ ] POR ORDEM MÉDICA

3- [ ] PORQUE O FUMO FAZ MAL A SAÚDE

4- [ ] POR PRESSŐES SOCIAIS / FAMILIARES

5- [ ] OUTRO MOTIVO 


\section{BLOCO 17}

\section{PARA TODOS OS FUNCIONÁRIOS RESPONDEREM.}

\section{ATENÇĀO!}

AS PERGUNTAS ABAIXO REFEREM-SE AO CONSUMO DE CERVEJA, CHOPP, VINHO, DESTILADOS, LICORES, BATIDAS OU QUALQUER OUTRO TIPO DE BEBIDA ALCOOLLICA CONSUMIDA EM REFEIÇÕES, OCASIÓES ESPECIAIS OU APENAS PARA RELAXAR.

60 - COM QUE FREQÜÊNCIA VOCÊ TOMA BEBIDAS ALCOÓLICAS?

1- [ ] DIARIAMENTE OU QUASE TODO DIA (QUATRO OU MAIS VEZES POR SEMANA)

2-[ ] PELO MENOS UMA VEZ POR SEMANA (ATÉ TRÊS VEZES POR SEMANA)

3- [ ] OCASIONALMENTE (PELO MENOS UMA VEZ POR MES)

4- [ ] RARAMENTE (MENOS DE UMA VEZ POR MÉS)

5- [ ] PAREI DE BEBER

6- [ ] NUNCA TOMEI BEBIDA ALCOÓLICA $\Rightarrow$ [ SIGA PARA O BLOCO 19]

61 - QUANDO FOI A ÚLTIMA VEZ EM QUE TOMOU BEBIDA ALCOÓLICA?

1- [ ] HOJE OU ONTEM

2-[ ] HÁ MENOS DE 7 DIAS

3- [ ] HÁ MAIS DE 7 DIAS $\Rightarrow$ [ SIGA PARA O BLOCO 19]

9-[ ] NÃO SEI INFORMAR $\Rightarrow$ [ SIGA PARA O BLOCO 19] 


\section{BLOCO 18}

SO PARA AQUELES QUE CONSUMIRAM QUALQUER TIPO DE BEBIDA ALCOÓLICA NOS ÚLTIMOS 7 DIAS RESPONDEREM.

62. DURANTE OS ÚLTIMOS 7 DIAS, NA ÚLTIMA OCASIAO EM QUE VOCE TOMOU BEBIDAS ALCOÓLICAS, O QUE VOCE BEBEU, E EM QUE QUANTIDADE?

\begin{tabular}{|c|c|c|c|c|c|c|c|}
\hline & & & & OSLI & Drs: & & \\
\hline EESIS & & NAO BEBI & COPOS & CALICES & DOSES & GARRAFAS & $\begin{array}{c}\text { NAO SEI } \\
\text { INFORMAR }\end{array}$ \\
\hline CERVEJA OU CHOPP & 1 & $1-[]$ & لــلـاـا 2 & لــاـLا - 3 & الـــاـا & 5- 5ـLا & $9-[1]$ \\
\hline VINHO & 2 & $1-[1]$ & الـLـا & 3-LL & 4-Lلـ & 5-LL & $9-[]$ \\
\hline $\begin{array}{l}\text { DESTILADOS (CACHAÇA, } \\
\text { CONHAQUE, UISQUE, } \\
\text { VODKA, RUM, GIM, BATIDAS, } \\
\text { DRINKS) }\end{array}$ & 3 & $1-[]$ & 2- & 3 - & 4-Lلـــ & 5-Lلـا & $9-[]$ \\
\hline $\begin{array}{l}\text { LICORES (VERMUTES, } \\
\text { CAMPARI ETC) }\end{array}$ & 4 & $1-[]$ & لـــاـا & 3- & لبـــــاـا 4 & ل 5 - 5ـــا & $9-[1]$ \\
\hline
\end{tabular}




\section{BLOCO 19}

\section{PARA TODOS OS FUNCIONÁRIOS RESPONDEREM.}

63- VOCÉ PRATICA, COM REGULARIDADE, ATIVIDADES FÍSICAS ESPECÍFICAS PARA MELHORAR SUA SAÚDE, CONDICIONAMENTO FÍSICO OU PARA FINS ESTÉTICOS?

\section{ATENÇÃO!}

\section{CONSIDERE ATIVIDADE FISICA REGULAR AQUELA PRATICADA PELO MENOS} DUAS (02) VEZES POR SEMANA, DURANTE VINTE (20) MINUTOS CADA VEZ.

1- [ ] SIM $\Rightarrow$ [ SIGA PARA O BLOCO 20 ]

2- [ ] NÃO

64- NO SEU CASO, O QUE IMPEDE A PRÁTICA DE ATIVIDADES FísICAS REGULARES? (PODE MARCAR MAIS DE UMA OPÇÃO.)

1- [ ] ROTINA DAS ATIVIDADES PESSOAIS

2- [ ] HORÁRIO DE TRABALHO

3- [ ] DIFICULDADE FINANCEIRA

4- [ ] FALTA DE OPÇÓES PERTO DE CASA OU DO TRABALHO

5- [ ] FALTA DE ÁNIMO PARA ATIVIDADES FÍSICAS

6- [ ] NÄO GOSTO DE PRATICAR ATIVIDADES FÍSICAS

7- [ ] IMPEDIMENTO FÍSICO OU DOENÇA

8- [ ] NĀO VEJO NECESSIDADE DE PRATICAR ATIVIDADES FÍSICAS

9- [ ] OUTRO FATOR

$\Rightarrow$ [ SIGA PARA O BLOCO 21 ] 


\section{BLOCO 20}

\section{SÓ PARA AQUELES QUE PRATICAM ATIVIDADES FÍSICAS, COM REGULARIDADE, RESPONDEREM.}

65- INDIQUE NA TABELA ABAIXO AS ATIVIDADES FÍSICAS QUE VOCÊ PRATICA REGULARMENTE, COMPLETANDO COM O NÚMERO DE VEZES PRATICADO POR SEMANA E O TEMPO MÉDIO EM MINUTOS GASTO EM CADA VEZ:

\section{ATENÇÃOI}

CONSIDERE ATIVIDADE FISICA REGULAR AQUELA PRATICADA PELO MENOS DUAS (02) VEZES POR SEMANA, DURANTE VINTE (20) MINUTOS CADA VEZ.

\begin{tabular}{|c|c|c|c|}
\hline ATIVIDADE FISICA & & $\begin{array}{c}\text { NÚMERO DE VEZES } \\
\text { POR SEMANA }\end{array}$ & $\begin{array}{l}\text { TEMPO MÉDIO GASTO } \\
\text { POR VEZ } \\
\text { EM MINUTOS }\end{array}$ \\
\hline CAMINHADAS & 1 & LL & LLL \\
\hline CORRIDA / BICICLETA / NATAÇĀO & 2 & டレ & LLL \\
\hline FUTEBOL & 3 & LL & டL」 \\
\hline VóLEI / BASQUETE & 4 & LL & டレム \\
\hline MUSCULAÇĀO & 5 & LL & LLLI \\
\hline GINÁSTICA AEROBICA & 6 & LLl & டLட। \\
\hline OUTRA (QUAL?) & 7 & LLI & டLLI \\
\hline OUTRA (QUAL?) & 8 & LLI & LLLI \\
\hline
\end{tabular}




\section{BLOCO 21}

\section{PARA TODOS OS FUNCIONÁRIOS RESPONDEREM.}

66 - QUAL É A SUA PRESSÃO ARTERIAL HABITUAL?

EXEMPLOS DE PRESSÕES ARTERIAIS: 09 POR 06; 12 POR 08; 14 POR 09; 17 POR 12

1- MINHA PRESSÃO ARTERIAL HABITUAL É LILI POR Lا_।

2- [ ] NÃO SEI INFORMAR QUAL É MINHA PRESSÃO ARTERIAL HABITUAL

3- [ ] MINHA PRESSÃO ARTERIAL_ NUINCA FOI MEDIDA $\Rightarrow$ [ SIGA PARA O BLOCO 23 ]

67 - QUANDO FOI A ÚLTIMA VEZ EM QUE A SUA PRESSÃO ARTERIAL FOI MEDIDA POR UM MÉDICO OU OUTRO PROFISSIONAL DA SAÚDE?

1-[ ] HÁ MENOS DE UM ANO

2-[ ] ENTRE 1 E 2 ANOS

3- [ ] HÁ MAIS DE 2 ANOS

9- [ ] NÃO SEI INFORMAR

68 - ALGUM MÉDICO OU OUTRO PROFISSIONAL DA SAÚDE JÁ LHE INFORMOU QUE VOCÊ ERA HIPERTENSO OU TINHA PRESSÃO ALTA?

1- [ ] SIM, APENAS UMA VEZ

2-[ ] SIM, MAIS DE UMA VEZ, EM DIAS DIFERENTES

3- [ ] SIM, APENAS DURANTE A GRAVIDEZ $\Rightarrow$ [ SIGA PARA O BLOCO 23]

4- [ ] NÃO, NUNCA TIVE PRESSÃO ALTA $\Rightarrow$ [ SIGA PARA O BLOCO 23] 


\section{BLOCO 22}

\section{SÓ PARA AQUELES QUE JÁ TIVERAM DIAGNÓSTICO DE HIPERTENSÃO OU PRESSÃO ALTA RESPONDEREM.}

\section{9 - HÁ QUANTO TEMPO VOCÊ SABE QUE TEM PRESSÃO ALTA?}

1- [ ] HÁ MENOS DE 2 ANOS

2- [ ] ENTRE 2 E 5 ANOS

3- [ ] HÁ MAIS DE 5 ANOS

9- [ ] NÄO SEI INFORMAR

70 - VOCÊ TRATOU OU TRATA A SUA PRESSÃO ALTA?

1- [ ] TRATEI NO PASSADO, MAS NÃO TRATO MAIS $\Rightarrow$ [ SIGA PARA A PERGUNTA 72 ]

2- [ ] ESTOU EM TRATAMENTO

3- [ ] NÃO, NUNCA TRATEI $\Rightarrow$ [ SIGA PARA O BLOCO 23]

71 - QUE MEDIDAS VOCÊ ESTÁ UTILIZANDO PARA TRATAMENTO DA PRESSÃO ALTA? (PODE MARCAR MAIS DE UMA OPÇÃO.)

\begin{tabular}{|l|c|c|c|}
\hline $\begin{array}{c}\text { MEDIDAS PARA BAIXAR } \\
\text { A PRESSÄO }\end{array}$ & $\begin{array}{c}\text { COM } \\
\text { ACOMPANHAMENTO } \\
\text { MÉDICO REGULAR } \\
\text { UMA OUMAIS VEZES AO } \\
\text { ANO) }\end{array}$ & $\begin{array}{c}\text { COM } \\
\text { ACOMPANHAMENTO } \\
\text { MÉDICO ESPORÁDICO } \\
\text { ONTERVALOS MAIORES } \\
\text { QUE UM ANO ENTRE AS } \\
\text { CONSULTAS) }\end{array}$ & $\begin{array}{c}\text { SEM } \\
\text { ACOMPANHAMENTO } \\
\text { MÉDICO }\end{array}$ \\
\hline $\begin{array}{l}\text { 1- DIETA COM RESTRIÇÁO DE } \\
\text { SAL }\end{array}$ & $1-[]$ & $2-[]$ & $3-[]$ \\
\hline 2- CONTROLE DE PESO & $1-[]$ & $2-[]$ & $3-[]$ \\
\hline 3- EXERCICIOS FISICOS & $1-[]$ & $2-[]$ & $3-[]$ \\
\hline 4- MEDICAMENTOS & $1-[]$ & $2-[]$ & $3-[]$ \\
\hline 5- OUTRAS MEDIDAS & $1-[]$ & $2-[]$ & $3-[]$ \\
\hline
\end{tabular}

72- NO CASO DE TER PARADO O TRATAMENTO QUE FAZIA PARA PRESSÃO ALTA, POR QUE PAROU? (PODE MARCAR MAIS DE UMA OPÇÃO.)

1- [ ] PORQUE FIQUEI CURADO

2-[ ] PORQUE NÃO OBTIVE BONS RESULTADOS COM O(S) TRATAMENTO(S)

3- [ ] PORQUE O(S) MEDICAMENTO(S) ME FAZIA(M) MAL

4-[ ] PORQUE OS MEDICAMENTOS ERAM MUITO CAROS

5-[ ] PORQUE O TRATAMENTO ERA MUITO DEMORADO

6-[ ] PORQUE NÃO SENTIA NADA

7-[ ] OUTRO MOT̃IVO 